\title{
MICROSTRUCTURE ANALYSES OF REINFORCEMENT MECHANISM OF CEMENT IN STABILIZING CHAMPLAIN SEA CLAY
}

\author{
by \\ Moulay Youssef Monsif, B.Eng. \\ Ryerson University, 2018 \\ Toronto, Canada
}

\begin{abstract}
A thesis
presented to Ryerson university in partial fulfillment of the

requirements for the degree of Master of Applied Science in the program of Civil Engineering
\end{abstract}

Toronto, Ontario, Canada, 2020

(C) Moulay Youssef Monsif, 2020 


\section{AUTHOR'S DECLARATION}

I hereby declare that I am the sole author of this thesis. This is a true copy of the thesis, including any required final revisions, as accepted by my examiners.

I authorize Ryerson University to lend this thesis to other institutions or individuals for the purpose of scholarly research

I further authorize Ryerson University to reproduce this Thesis by photocopying or by other means, in total or in part, at the request of other institutions or individuals for the purpose of scholarly research.

I understand that my thesis may be made electronically available to the public. 


\title{
MICROSTRUCTURE ANALYSES OF REINFORCEMENT MECHANISM OF CEMENT IN STABILIZING CHAMPLAIN SEA CLAY
}

\author{
Master of Applied Science, 2020 \\ Moulay Youssef Monsif \\ Civil Engineering \\ Ryerson University
}

\begin{abstract}
This research investigates the strength development and the formation of microstructures in Champlain Sea clay when treated with Portland cement and other cement-based binders and the effect of salinity level in the pore fluid on the strength and the mineralogical changes of cementtreated Champlain Sea clay. Champlain Sea clay, a sensitive marine clay commonly found in St. Lawrence Lowlands in eastern Canada, can lose up to $90 \%$ of its strength when disturbed. The unconfined compressive strength tests were used to measure the shear strength development of binder-treated samples. The results indicated that cement-treated clay samples gain the shear strength at a faster rate than other binders under short-term curing conditions up to 28 days. However, under the same cement dosage of $50 \mathrm{~kg} / \mathrm{m}^{3}$, the samples treated with cement with an additional $17 \mathrm{~kg} / \mathrm{m}^{3}$ slag and those treated by cement with an additional $50 \mathrm{~kg} / \mathrm{m}^{3} \mathrm{kiln}$ dust exceeded the performance of those treated with only cement under the 300-day curing condition. Qualitative microstructural and mineralogical characterisations of cement-treated clay samples are investigated using scanning electron microscopy and X-ray diffraction (XRD). The results confirmed the transformation of an open structure in natural clay to a flocculated and aggregated structure due to the development of cement hydration products. The XRD analysis confirmed the formation of hydration products are found to be more pronounced in clay samples with a lower salinity level.
\end{abstract}




\section{ACKNOWLEDGEMENTS}

I would like to express my deep gratitude to my supervisor Dr. Jinyuan Liu for giving me the opportunity to be part of his research team, providing me with unlimited support and unconditioned guidance, and having endless understanding. His commitment to excellence, together with his excellent knowledge, has been crucial for the accomplishment of this work. I have truly enjoyed being his student and friend and wish to have the opportunity to work with him again in the future.

I would like also to thank NSERC and Ryerson University for granting me two prestigious scholarships, Canada Graduate Scholarships-Master's Program (CGS-M), and Ryerson Graduate Scholarship (RGS).

Next, I would like to thank Mr. Naresh Gurpersaud from Keller North America and the members of my thesis committee, Dr. Songnian Li, Dr. Medhat Shehata, and Dr. Laifa Cao for their time and invaluable comments regarding the research.

Appreciation is also expressed to the Natural Sciences and Engineering Research council of Canada, NSERC, Keller North America, and Ontario Power Generation (OPG) for the financial support of this research and OPG for providing clay samples used in this research.

I would like to express sincere appreciation to the faculty and staff of the civil engineering department at Ryerson University. In particular, I am grateful to Dr. Qiang Li for his assistance during the SEM and XRD testing. I would like also to thank the geotechnical research team at Ryerson University for providing me a pleasant work environment and for their contribution to my work in numerous ways.

Finally, I would like to express my deepest appreciation to my family for their unlimited support and all their sacrifices throughout the course of my studies. 


\section{Table of Contents}

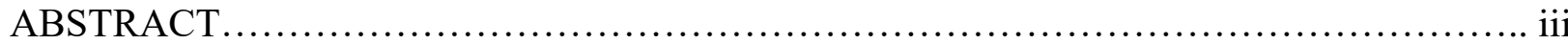

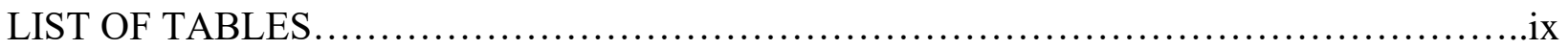

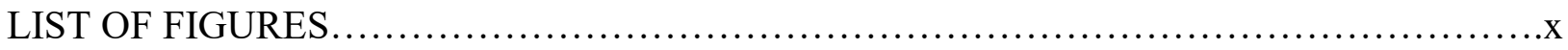

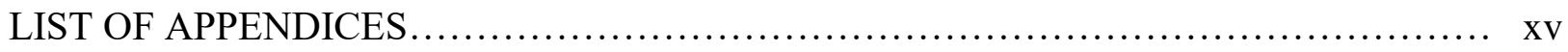

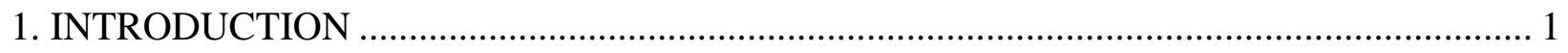

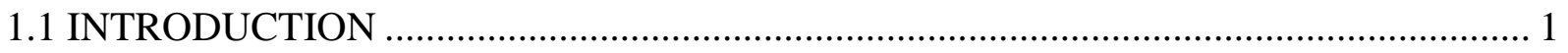

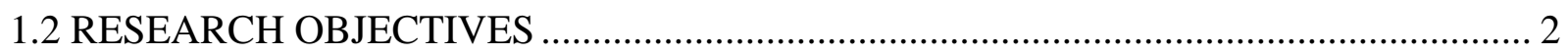

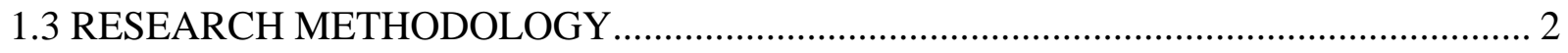

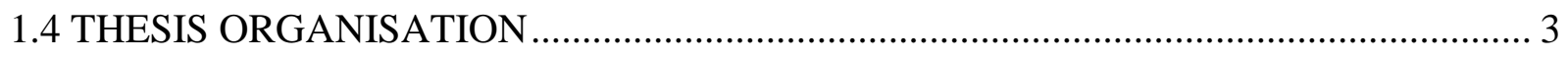

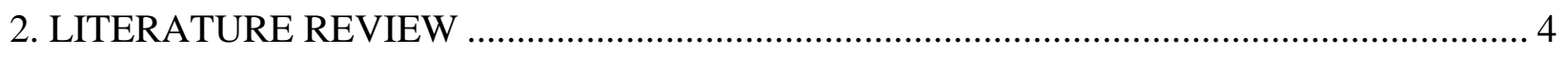

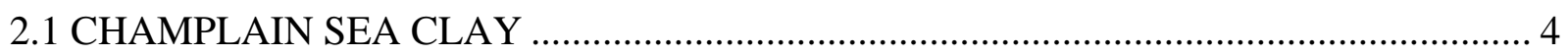

2.1.1 Geological and geotechnical background ..................................................................... 4

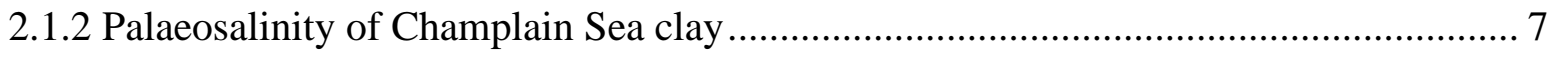

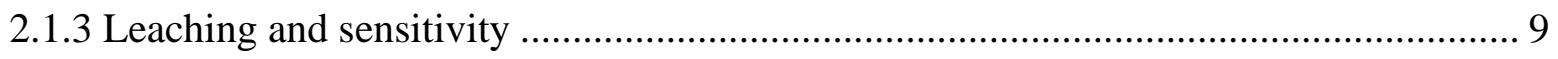

2.1.4 Microstructure of Champlain Sea clay …………….................................................. 12

2.2 DEEP SOIL MIXING IN CHAMPLAIN SEA CLAY ................................................. 15

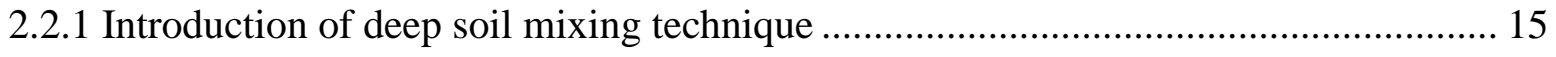

2.2.2 Factors affecting strength development in soil stabilization....................................... 16

2.2.3 Mechanisms of strength development in stabilized clay ............................................. 20

2.3 STRENGTH AND COMPRESSIBILITY OF TREATED CHAMPLAIN SEA CLAY ... 24

2.4 MICROSTRUCTURE OF CLAY AND SATBILIZED CLAY …………………........... 28

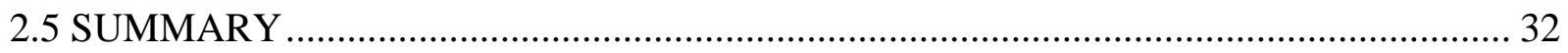




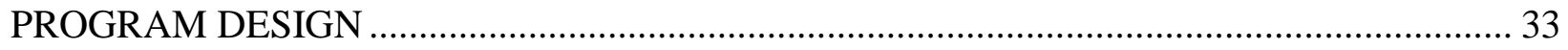

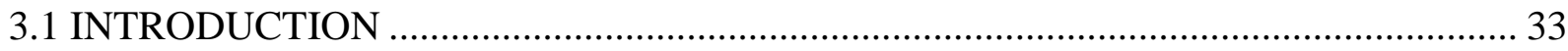

3.2 CLAY PHYSICAL AND MINERALOGICAL PROPERTIES .................................... 33

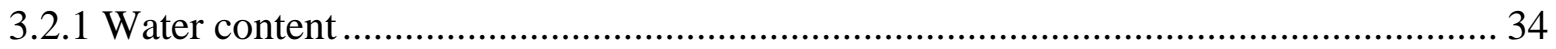

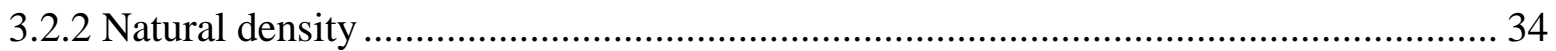

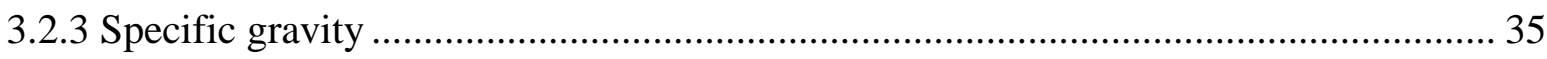

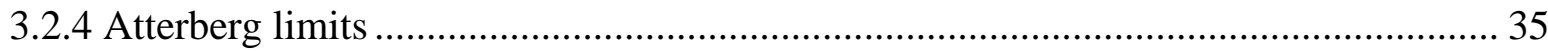

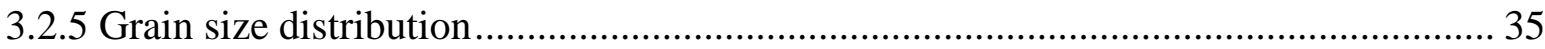

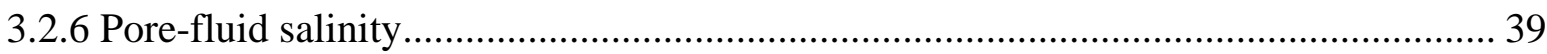

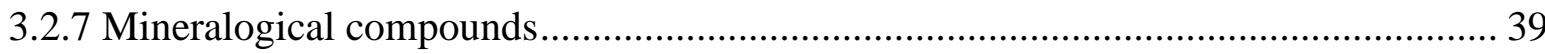

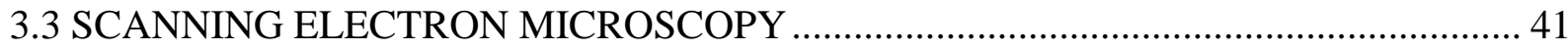

3.3.1 Fundamental principals of scanning electron microscopy ..................................... 41

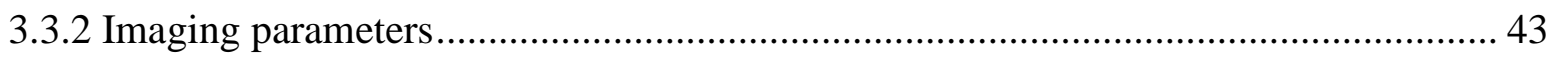

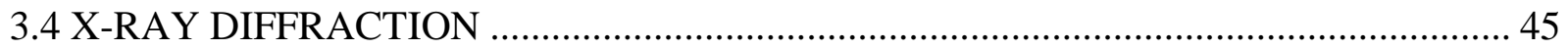

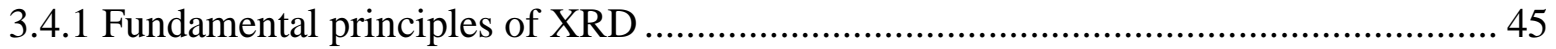

3.5 SAMPLES PREPARATION AND PROCEDURES ….............................................. 46

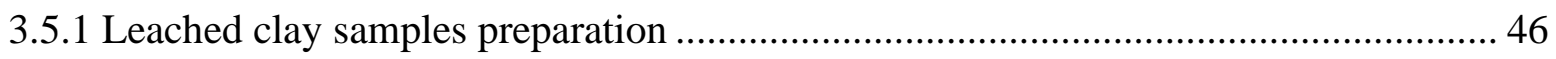

3.5.2 Unconfined compressive strength samples preparation ...................................... 49

3.5.3 Scanning electron microscopy specimen preparation ......................................... 52

3.5.4 X-rays diffraction specimen preparation .......................................................... 53

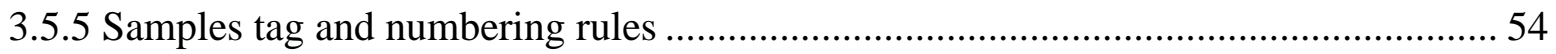

3.6 EXPERIMENTAL PARAMETERS ..................................................................... 54

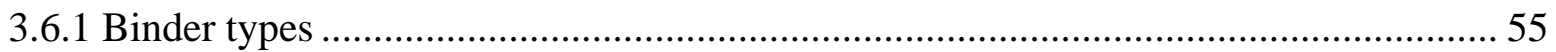




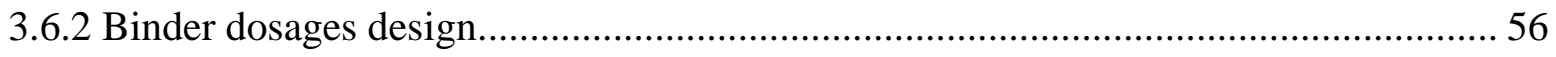

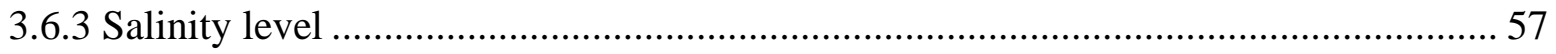

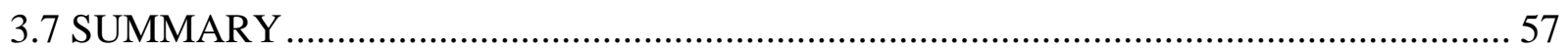

4. STRENGTH AND MICROSTRUCTURE ANALYSES OF STABILIZED CHAMLAIN SEA

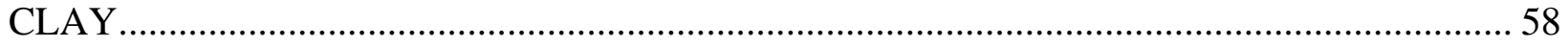

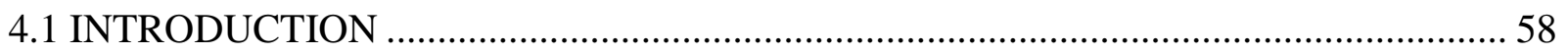

4.2 MICROSTRUCTURE AND STRENGTH OF CHAMPLAIN SEA CLAY AT DIFFERENT

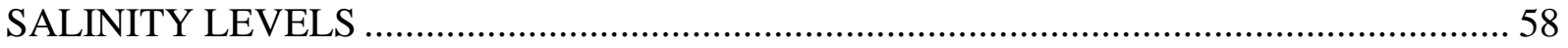

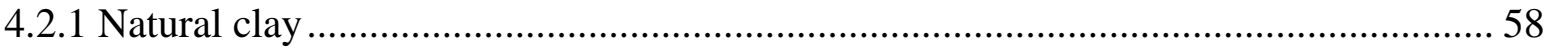

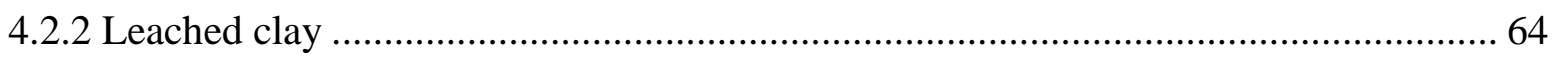

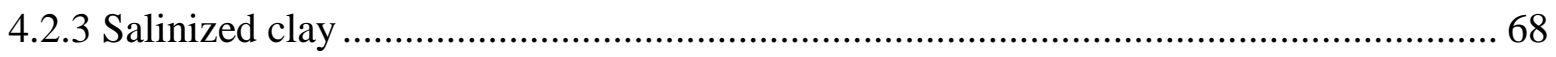

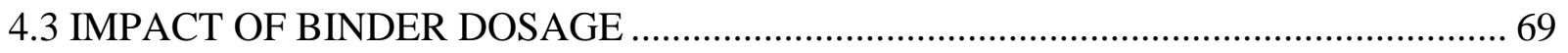

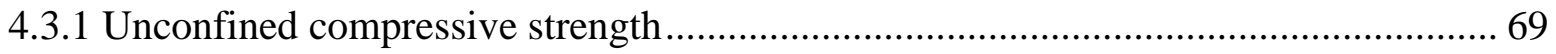

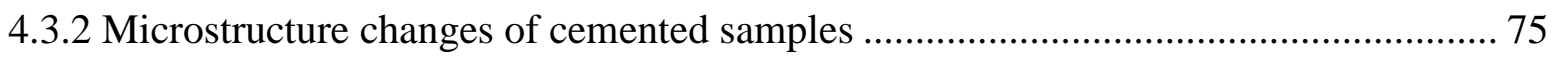

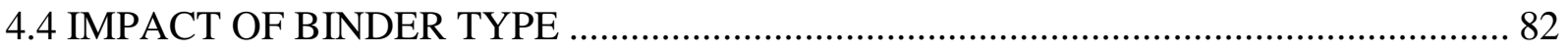

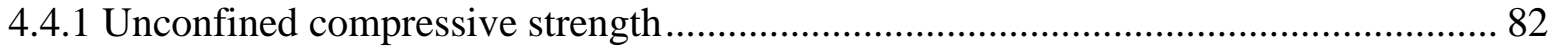

4.4.2 Microstructure changes of clay treated with different binders ...................................... 88

4.5 IMPACT OF SALINITY LEVEL IN THE PORE FLUID .............................................. 96

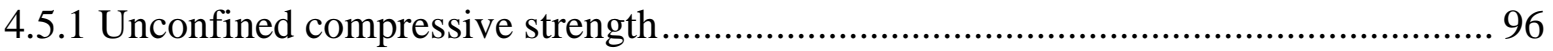

4.5.2 Microstructure changes of cement -treated clay at different salinity levels .............. 101

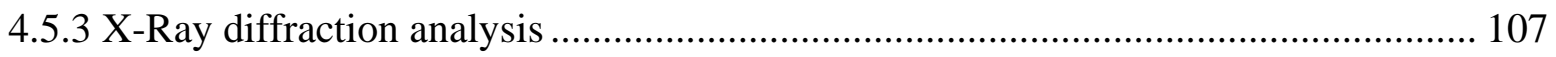

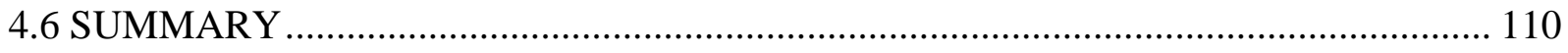

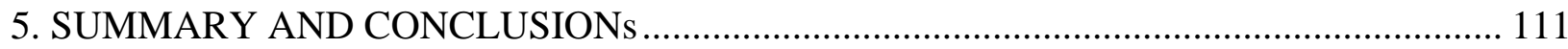

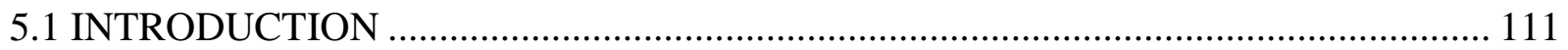

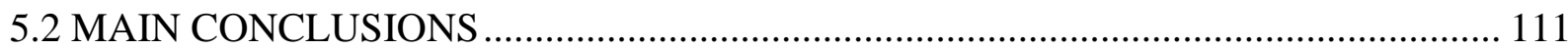




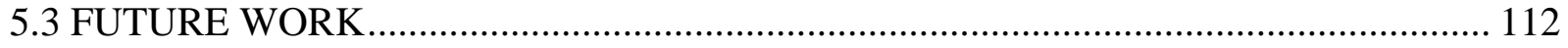

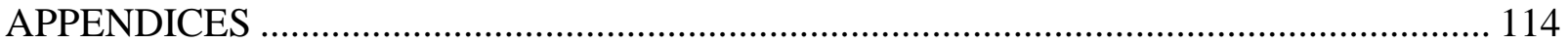

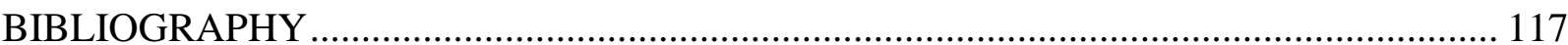




\section{LIST OF TABLES}

Table 2-1: Mineralogical analyses results from clay in eastern Canada (Locat et al., 1984) ......... 6

Table 2-2: Chemical analyses of clay in eastern Canada (Locat et al., 1984) ........................... 6

Table 2-3: Engineering properties of samples (Gillot, 1970) ............................................... 7

Table 2-4: Palaeosalinity data of Champlain Sea clay sample from Ottawa (Gillot, 1970) .......... 8

Table 2-5: Classification of sensitivity values (Norsk Geoteknisk Forening, 1974).................. 9

Table 2-6: Classification of sensitivity according to CFEM (CGS, 2006) .............................. 10

Table 2-7: Some geotechnical data on Norwegian and Canadian clays (Brenner et al., 1981).... 12

Table 2-8: Choice of binder based on different type soil conditions (EuroSoilStab, 2002)........ 17

Table 3-1: XRD analysis of Champlain Sea clay (Qualitas, 2016) ....................................... 41

Table 3-2: Typical composition of cement kiln dust (Haynes \& Kramer, 1982) ...................... 55

Table 3-3:Chemical composition (mass \%) and some physical properties of Portland cement (PC)

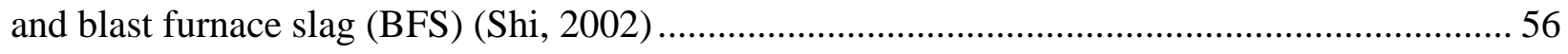

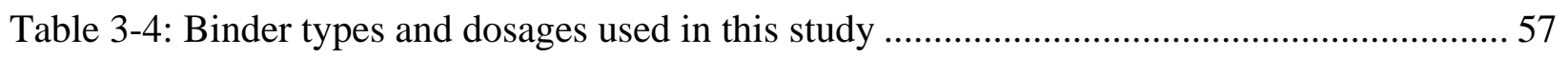

Table 4-1: Peak UCS values of cement treated Champlain Sea clay ..................................... 71

Table 4-2: Peak UCS values of treated Champlain Sea clay with different binders' types......... 84

Table 4-3: Peak UCS values of cement treated Champlain Sea clay at different salt level ........ 97 


\section{LIST OF FIGURES}

Figure 2-1: Extent of Champlain Sea clay deposition (Quinn et al., 2008) ................................ 5

Figure 2-2: Leaching on the sensitivity of Norwegian and Bangkok clays (Brenner et al., 1981)11

Figure 2-3: Photomicrographs of intact St. Marcel clay, on a vertical plane (b, X 7000; c, X 15000)

Figure 2-4 Photomicrograph of a remolded sample of St. Marcel clay (a, X3000; b, X7000) (Delage

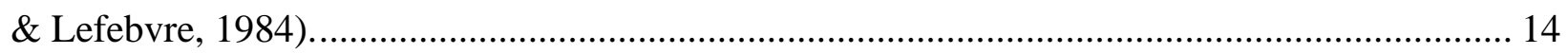

Figure 2-5: Deep soil mixing columns installation process (Hayward Baker, 2004) ................. 16

Figure 2-6: The effect of cement dosage on Kawasaki clay (Terashi et al., 1980) .................... 18

Figure 2-7: Binder dosage and shear strength relationship in peat soils (EuroSoilStab, 2002)... 19

Figure 2-8: Effect of curing time on lime-treated Japanese clay (Terashi et al., 1977).............. 19

Figure 2-9: Impact of salinity on strength development of treated clay (Horpibulsuk et al., 2012)

Figure 2-10: Schematic illustration of cation exchange (Brenner et al., 1981) ......................... 22

Figure 2-11: Schematic process of flocculation and agglomeration (Brenner et al., 1981) ........ 22

Figure 2-12: Process of cement hydration product in stabilizing clay particles (Brenner et al., 1981)

Figure 2-13: Pozzolanic reaction process (Brenner et al., 1981) ........................................... 24

Figure 2-14: Improvement ratio vs. slag/cement dosage of treated Kanata clay ....................... 25

Figure 2-15: Improvement ratio vs. slag/cement dosage of treated Kanata clay ....................... 25

Figure 2-16: Impact of cement dosage and mixing method of cement-treated samples ............ 26

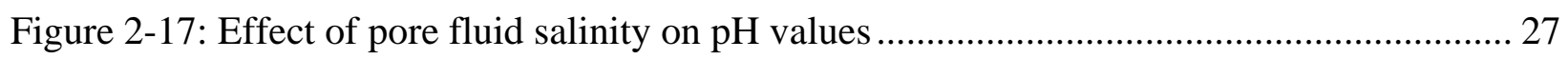

Figure 2-18 Effect of pore fluid salinity on undrained shear strength ................................. 27

Figure 2-19: SEM micrographs of the $10 \%$ cement samples compacted at different water contents

after 7 days of curing (Horpibulsuk et al., 2010) ................................................................. 29 
Figure 2-20: X-ray diffraction of kaolin clay stabilized by $12 \%$ cement (Du et al., 2014) ........ 30

Figure 2-21: Major hydration products of kaolin clay stabilized by cement (Du et al., 2014).... 30

Figure 2-22: SEM micrographs of Ottawa clay treated with Portland cement $3.1 \%$ (a,b) and 6.4\%

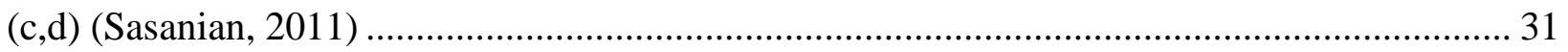

Figure 3-1: Laval clay samples collected from the dam site and used for this study ................. 34

Figure 3-2: The distribution of water content vs. depth in the foundation clay (Liu et al., 2017) 36

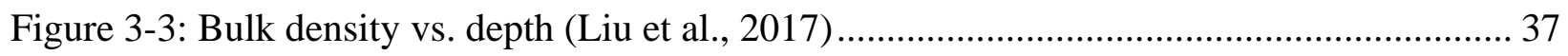

Figure 3-4: Plasticity chart of samples at different depths (Liu et al., 2017) .......................... 38

Figure 3-5: Grain size distribution curves of the clay samples (Liu et al., 2017)...................... 38

Figure 3-6: Salinity level in the pore fluid of foundation clay (Liu et al., 2017) ..................... 40

Figure 3-7: Schematics of a SEM machine (Akhtar et al., 2018) ......................................... 42

Figure 3-8: Scanning electron microscope machine used for this study ................................. 44

Figure 3-9: Schematic of an X-Ray diffractometer (U. S. Geological survey, 2020) ................ 45

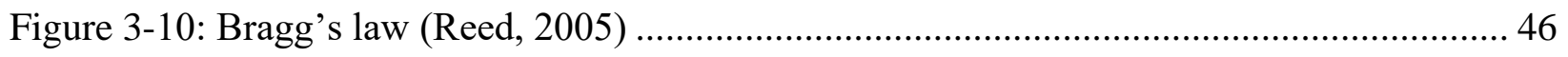

Figure 3-11: The leaching apparatus used in this study .................................................. 47

Figure 3-12: A leached clay sample being extruded from the leaching mold .......................... 48

Figure 3-13: Untreated sample preparation for UCS ...................................................... 49

Figure 3-14: A Kitchen Aid ultra power mixer and the electric milk shaker used in this study .. 50

Figure $3-15$ : Humboldt UCS testing machine ............................................................ 52

Figure 3-16: (a) Gold laboratory Vacuum thin film thermal evaporator, (b) two gold coated

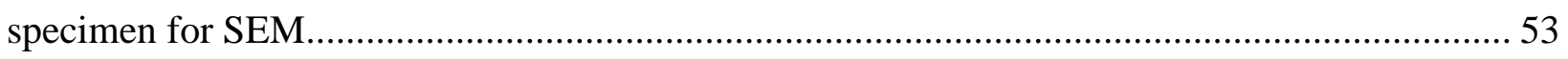

Figure 3-17: An XRD sample set-up in X'Pert X-ray diffraction machine .............................. 54

Figure 4-1: Stress-strain curve natural soil samples. ..................................................... 59

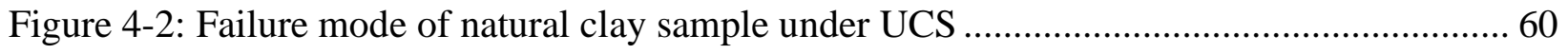


Figure 4-3: SEM micrographs of intact clay (a) magnified X 5000 (b) close-up on a silt particle

Figure 4-4:SEM photomicrograph of untreated Champlain Sea clay .................................... 62

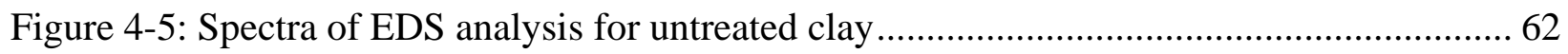

Figure 4-6: Localized elemental composition of untreated clay.......................................... 63

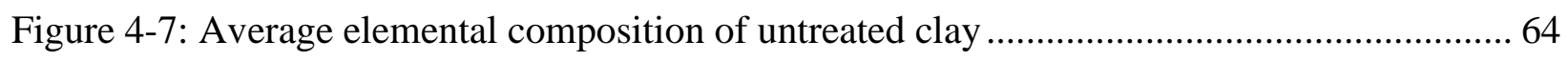

Figure 4-8: Stress-strain curve for clay leached to different salinity level ............................ 65

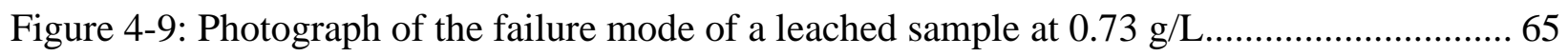

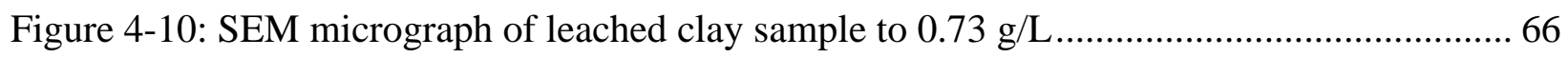

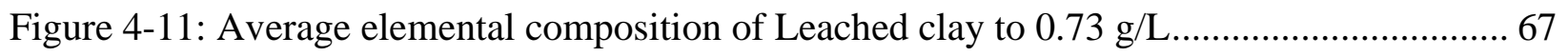

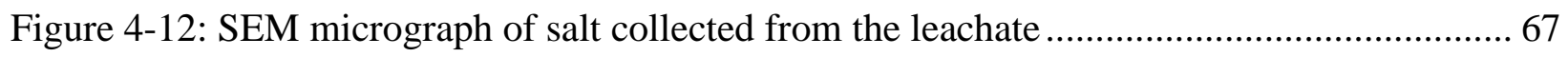

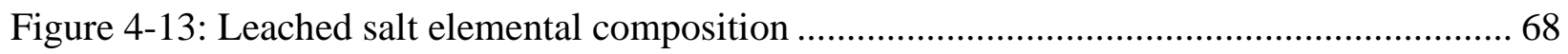

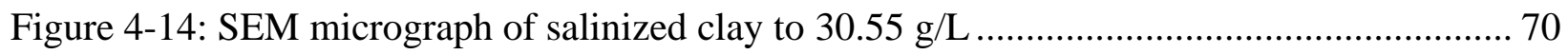

Figure 4-15: Average elemental composition of salinized clay to $30.55 \mathrm{~g} / \mathrm{L}$.......................... 70

Figure 4-16: Stress-strain curves of treated clay with $50 \mathrm{~kg} / \mathrm{m}^{3}$ cured for $7,14,28$, and 300 days

Figure 4-17: Stress-strain curves of treated clay with $100 \mathrm{~kg} / \mathrm{m}^{3}$ cured for 7, 14, 28 and, 300 days

Figure 4-18: Stress-strain curves of treated clay with $200 \mathrm{~kg} / \mathrm{m}^{3}$ cured for $7,14,28$, and 300 days

Figure 4-19: Stress-strain curves of treated clay with $50,100,200 \mathrm{~kg} / \mathrm{m}^{3}$ cured for 28 days ..... 74

Figure 4-20: UCS vs. curing time of samples treated with 50, 100, and $200 \mathrm{~kg} / \mathrm{m}^{3} \ldots \ldots \ldots \ldots \ldots \ldots .75$

Figure 4-21: SEM micrograph of untreated soil sample ................................................ 76

Figure 4-22: SEM micrograph of clay sample treated with $50 \mathrm{~kg} / \mathrm{m}^{3}$ cured for 7,14 , and 28 days 
Figure 4-23: SEMs of clay samples treated with $100 \mathrm{~kg} / \mathrm{m}^{3}$ cured for 7,14 , and 28 days......... 79

Figure 4-24: SEMs of clay samples treated with $200 \mathrm{~kg} / \mathrm{m}^{3}$ cured for 7,14 , and 28 days......... 81

Figure 4-25: Strain-strain curves for soil treated with $50 \mathrm{~kg} / \mathrm{m}^{3}$ of HSF.............................. 85

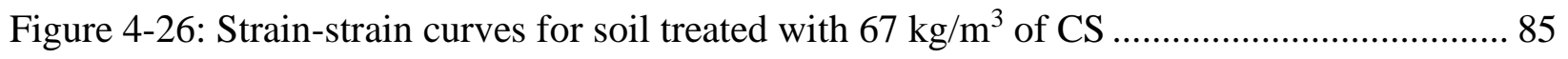

Figure 4-27: Strain-strain curves for soil treated with $67 \mathrm{~kg} / \mathrm{m}^{3}$ of CKD................................ 86

Figure 4-28: Strain-strain curves for soil treated with $100 \mathrm{~kg} / \mathrm{m}^{3}$ of CKD............................ 86

Figure 4-29: UCS vs. curing times of clay samples treated with different binders ................... 87

Figure 4-30: Effect of cement dosage and curing time on treated Champlain Sea clay .............. 87

Figure 4-31: Effect of slag/cement dosage and curing time on treated Champlain Sea clay ....... 88

Figure 4-32: SEM micrographs of clay samples treated with $50 \mathrm{~kg} / \mathrm{m}^{3}$ of $\mathrm{HSF}$.................... 90

Figure 4-33: SEM micrographs of clay samples treated with $67 \mathrm{~kg} / \mathrm{m}^{3}$ of CKD .................... 92

Figure 4-34: SEM micrographs of clay samples treated with $67 \mathrm{~kg} / \mathrm{m}^{3}$ of CS ....................... 94

Figure 4-35: SEM micrographs of clay samples treated with $100 \mathrm{~kg} / \mathrm{m}^{3}$ of CKD ................. 96

Figure 4-36: Stress-strain curves of cement-treated Champlain Sea clay samples ................... 98

Figure 4-37: UCS vs curing time of clay of cement-treated clay samples at different salinity levels

Figure 4-38: 28-days UCS of cement treated Champlain Sea clay vs. salt concentration.......... 100

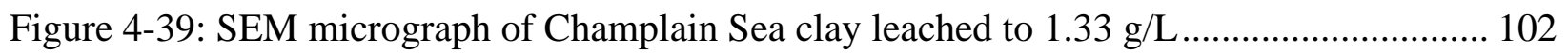

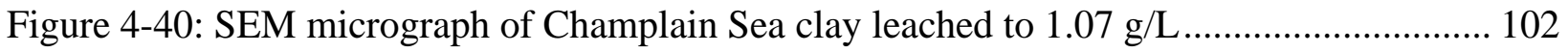

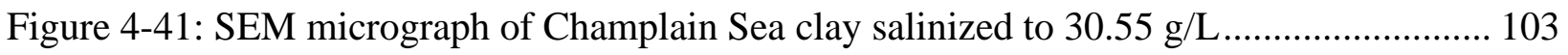

Figure 4-42: SEM micrograph of leached (1.33 g/L) Champlain Sea clay treated with $50 \mathrm{~kg} / \mathrm{m}^{3}$

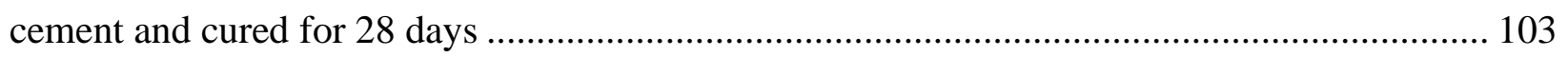

Figure 4-43: SEM micrograph of leached $(1.07 \mathrm{~g} / \mathrm{L})$ Champlain Sea clay treated with $50 \mathrm{~kg} / \mathrm{m}^{3}$ cement and cured for 28 days 104 
Figure 4-44: SEM micrograph of salinized ( $30.55 \mathrm{~g} / \mathrm{L}$ ) Champlain Sea clay treated with $50 \mathrm{~kg} / \mathrm{m}^{3}$ cement and cured for 28 days 104

Figure 4-45: Average elemental composition of natural Champlain Sea clay ( $15.53 \mathrm{~g} / \mathrm{L})$ treated with $50 \mathrm{~kg} / \mathrm{m}^{3}$ cement and cured for 28 days. 105

Figure 4-46: Average elemental composition of leached Champlain Sea clay ( $1.33 \mathrm{~g} / \mathrm{L})$ treated with $50 \mathrm{~kg} / \mathrm{m}^{3}$ cement and cured for 28 days 105

Figure 4-47: Average elemental composition of leached Champlain Sea clay ( $1.07 \mathrm{~g} / \mathrm{L})$ treated with $50 \mathrm{~kg} / \mathrm{m}^{3}$ cement and cured for 28 days.... 106

Figure 4-48: Average elemental composition of salinized Champlain Sea clay $(30.55 \mathrm{~g} / \mathrm{L})$ treated with $50 \mathrm{~kg} / \mathrm{m}^{3}$ cement and cured for 28 days............................................................... 106

Figure 4-49: X-ray diffraction spectrum of natural clay sample at salt level of $15.53 \mathrm{~g} / \mathrm{L} \ldots \ldots . .108$ Figure 4-50: X-ray diffraction spectrum of leached clay sample to $1.07 \mathrm{~g} / \mathrm{L}$ treated with $50 \mathrm{~kg} / \mathrm{m}^{3}$ cured for 28 days... 108

Figure 4-51: X-ray diffraction spectrum for leached clay sample to $1.33 \mathrm{~g} / \mathrm{L}$ treated with $50 \mathrm{~kg} / \mathrm{m}^{3}$ cured for 28 days. 109

Figure 4-52: X-ray diffraction spectrum for salinized clay sample to $30.55 \mathrm{~g} / \mathrm{L}$ treated with 50 $\mathrm{kg} / \mathrm{m}^{3}$ cured for 28 days 


\section{LIST OF APPENDICES}

Appendix A: Mix design according to FHWA (2013) ...................................

Appendix B: Intact Champlain Sea clay sample description (Qualitas, 2016) ................115 


\section{INTRODUCTION}

\subsection{INTRODUCTION}

Champlain Sea clay, of postglacial age, is a predominantly marine sediment that is found in the St. Lawrence lowland in eastern Canada. These marine sediments, which range up to nearly $60 \mathrm{~m}$ in thickness, are generally underlain by sedimentary rocks of the Saint Lawrence Platform and the Appalachian Orogen (Quinn et al., 2008). Many of the sediments like Champlain Sea clay are referred to by geotechnical engineers as "sensitive clays" and sometimes the term "quick clay" is used. When sensitive clays are disturbed their shear strength ca be reduced drastically. One of the research efforts to understand the behaviour of Champlain Sea clay focuses on the use of the microstructure information. Scanning electron microscopy (SEM) has been the most widely technique used to obtain information about the microstructure of Champlain Sea clay.

Artificial cementation method such as deep soil mixing (DSM) is an effective method to improve the engineering properties of soft clays such as Champlain Sea clay for several reasons: both strength and settlement can be improved simultaneously, the method is environmentally friendly, the small timescale of the installation and it is very cost effective compared to other methods. FHWA (2013) define DSM as an in-situ soil treatment in which native soils are mixed with cementitious material to enhance the engineering properties such as strength increase and reduction in permeability and compressibility. There are a number of parameters, such as binder type, curing time, cement/water content, temperature, soil mineralogy, and activity, that affect these reactions and hence control the strength and stiffness development in an artificially cemented clay (Bergado et al., 1996). However, there is a limitedstudies available to investigate the pore water salt concentration effect on the bonding and hydration products in artificially cemented Champlain Sea clay. Part of this research addresses the effect of salinity on cement-treated Champlain Sea clay at different salinity levels using X-rays diffraction (XRD) method. 


\subsection{RESEARCH OBJECTIVES}

The scope of this research is to establish a link between the strength development of treated Champlain Sea clay and its microstructural and mineralogical changes. The research conducted in this study has three main objectives:

1. The first objective is to investigate the effect of binder types on the strength development and the microstructure changes resulted from stabilization of Champlain Sea clay Different binders including silica fume, cement kiln dust, and cement/slag binders are used in this study.

2. The second objective is to establish the microstructure of natural Champlain Sea clay and compared with samples treated with cement at three different dosages of $50,100,200 \mathrm{~kg}$ per each cubic meter of mixed soil and establish the link between the strength development and the microstructure changes resulted from the artificial cementation..

3. The third one is to investigate the influence of pore fluid salinity level on the strength development of cement treated Champlain Sea clay and its microstructure.

\subsection{RESEARCH METHODOLOGY}

Initially, natural Champlain Sea clay samples were treated with cement in three dosages, 50, 100, and $200 \mathrm{~kg} /{ }^{3}$. A series of unconfined compressive strength (UCS) tests were conducted for different curing conditions at 7, 14, 28, and 300 days to measure the strength development of stabilized clay samples. From the same mix of the clay samples as UCS, samples were taken for scanning electron microscopy (SEM) analyses at 7,14, and 28 days of curing to establish the microstructures of cemented clay. The same set of UCS and SEM were also conducted for clay samples treated with different binders at different dosages. Cement/slag with cement-to-slag ratio of $3: 1,\left(50 \mathrm{~kg} / \mathrm{m}^{3}\right.$ of cement and $17 \mathrm{~kg} / \mathrm{m}^{3}$ of slag), cement kiln dust (CKD) with two cement-toCKD ratio, one of $3: 1\left(50 \mathrm{~kg} / \mathrm{m}^{3}\right.$ of cement and $17 \mathrm{~kg} / \mathrm{m}^{3}$ of CKD), and other of $1: 1\left(50 \mathrm{~kg} / \mathrm{m}^{3}\right.$ of cement and $50 \mathrm{~kg} / \mathrm{m}^{3}$ of CKD), and cement with $8 \%$ by weight of silica fume. In the second stage, the initial salinity level in the pore fluid Champlain Sea clay was leached from the original level of $15.53 \mathrm{~g} / \mathrm{L}$ to three different salinity levels of $1.33,1.07$, and $0.73 \mathrm{~g} / \mathrm{L}$ and increased by adding salt up to $30.55 \mathrm{~g} / \mathrm{L}$. The five salinity level clay samples were mixed with general use Portland 
cement of $50 \mathrm{~kg} / \mathrm{m}^{3}$ and cured for 7, 14, and 28 days before testing their UCS. X-ray diffraction (XRD) tests were conducted on clay samples at different salinity levels and cured for 28 days only.

\subsection{THESIS ORGANISATION}

This thesis is organized in five chapters that provide a complete picture about the research performed in this study. Detailed organization of the thesis can be summarized as follow:

Chapter 1 is an introductory chapter providing preliminary information about Champlain Sea clay and deep soil mixing method as a method as one of the potential ground improvement methods. It also outlines the objectives and the methodology of this research.

Chapter 2 presents a literature review of important research performed in the areas relevant to this study. In particular, this chapter aims to establish an overall idea of the current knowledge regarding the strength development in cement-treated Champlain Sea clay and its relationship to the microstructure changes.

Chapter 3 presents the experimental parameters and the index properties of the clay tested in this investigation. It also describes the equipment and procedures used to take SEM images and the fundamentals principals of XRD.

Chapter 4 presents the results of the effects of different parameters on the strength development and microstructure of treated Champlain Sea clay. Section 1 presents the results of strength and microstructure of natural clay samples and samples at different salinity levels. Section 2 presents the effect of cement dosage on the strength development and microstructure on the cement-treated clay. Section 3 summarizes the results of different binder types. The last section discusses the effect of pore water salinity on the strength development, microstructure and the hydration products.

Chapter 5 summarizes the main conclusions on the results of the research. Lastly, recommendations for future research are discussed in the end. 


\section{LITERATURE REVIEW}

\subsection{CHAMPLAIN SEA CLAY}

\subsubsection{Geological and geotechnical background}

The geology of the Champlain Sea region has been described by many geologists and scientists during last few decades (Gadd, 1963; Gillot, 1970; Quigley et al., 1983). During the Pleistocene Period, the earth's crust was depressed in eastern Canada by the continental ice sheet. Figure 2-1illustrates the approximate extent of Champlain Sea clay deposits, which includes the lowlands of eastern Ontario and southern Quebec. Following glacial melting, the area was inundated by marine water of the Champlain Sea about 8,000-12,000 years ago (Gillot, 1970). As streams, shoreline erosion, and ice ablation supplied the sediments, significant amount of Champlain Sea clay was deposited. These marine sediments, which range up to nearly $60 \mathrm{~m}$ in thickness, are generally underlain by sedimentary rocks of the Saint Lawrence Platform and the Appalachian Orogen (Quinn et al., 2008). Detailed field exploration showed that Champlain Sea is a late glacial rather than postglacial. Some of the uppermost layers of the Champlain Sea clay may have been re-deposited under fresh or/and brackish water conditions either from melting water from glacial sources or from the influx of fresh water from the Great Lakes Region (Gadd N. R., 1963). Strata with thin layers of silt and sand are found in some places.

Locat et al. (1984) investigated the quantitative mineralogy of Champlain Sea clay from eastern Canada. Samples from nine different sites were collected and analysed using XRD method. The mineralogy of the samples was evaluated according to an X-ray technique proposed by FoscalMella (1976). The analyses were repeated several times and the average values are shown in Table

Table 2-1. From his study, Locat et al. (1984) concluded that all samples have a fairly common mineralogy and the chemical analysis show that clay sample from eastern Canada are abundant with $\mathrm{SiO}_{2}$ and $\mathrm{Al}_{2} \mathrm{O}_{3}$ and much lower values with $\mathrm{CaO}, \mathrm{K}_{2} \mathrm{O}, \mathrm{FeO}, \mathrm{Na}_{2} \mathrm{O}, \mathrm{MgO}$, and $\mathrm{H}_{2} \mathrm{O}_{\mathrm{T}}$, as shown in Table 2-2. The resemblance in mineral composition among the nine sites is due to that Champlain Sea clay's minerals originate from the Canadian Shield which mainly are: quartz, feldspar, mica, smectite, amphibole, and other glacial amorphous material (Penner, 1965; Gillot, 1970; Quigley et al., 1983; Ontario Power Generation internal report, 2106). 


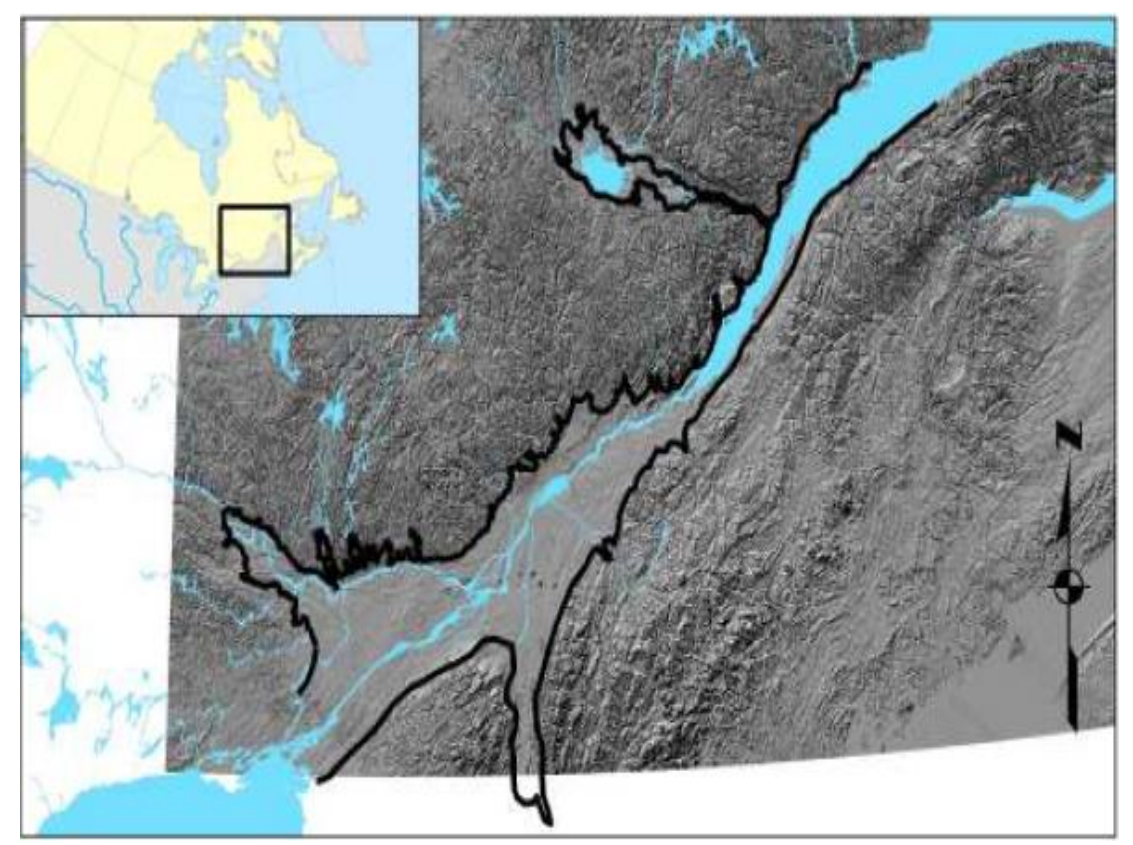

Figure 2-1: Extent of Champlain Sea clay deposition (Quinn et al., 2008) 
Table 2-1: Mineralogical analyses results from clay in eastern Canada (Locat et al., 1984)

\begin{tabular}{|c|c|c|c|c|c|c|c|c|c|c|}
\hline Ref. No. & Site & $N$ & $\begin{array}{l}P_{\mathrm{L}} \\
(\%)\end{array}$ & $\underset{(\%)}{Q_{Z}}$ & $\begin{array}{l}\text { Microcline } \\
(\%)\end{array}$ & $\begin{array}{l}\text { Hornblende } \\
(\%)\end{array}$ & $\begin{array}{l}\text { Dolomite } \\
(\%)\end{array}$ & $\begin{array}{c}\text { Calcite } \\
(\%)\end{array}$ & $\begin{array}{c}P \\
(\%)\end{array}$ & $\begin{array}{l}\text { Illite } \\
(\%)\end{array}$ \\
\hline $1 a$ & Grande-Baleine & 4 & $\begin{array}{c}41.3 \\
(39-46)\end{array}$ & $\begin{array}{c}15.3 \\
(14-16)\end{array}$ & $\begin{array}{c}13.5 \\
(13-14)\end{array}$ & $\begin{array}{c}12.7 \\
(11-15)\end{array}$ & $\begin{array}{c}1.0 \\
(0-2)\end{array}$ & $\begin{array}{c}0.3 \\
(0-0.5)\end{array}$ & 15.9 & 7.5 \\
\hline $1 b$ & Grande-Baleine & 5 & $\begin{array}{c}47.9 \\
(41-57)\end{array}$ & $\begin{array}{c}13.9 \\
(13-16)\end{array}$ & $\begin{array}{c}13.8 \\
(12-16)\end{array}$ & $\begin{array}{c}11.8 \\
(11-13)\end{array}$ & $\begin{array}{c}3.5 \\
(1-5)\end{array}$ & $\begin{array}{c}0.6 \\
(0.3-0.9)\end{array}$ & 8.5 & 7.2 \\
\hline $1 c$ & Grande-Baleine & 5 & $\begin{array}{c}40.4 \\
(37-48)\end{array}$ & $\begin{array}{c}16.8 \\
(13-20)\end{array}$ & $\begin{array}{c}14.5 \\
(13-16)\end{array}$ & $\begin{array}{l}11.0 \\
(9-14)\end{array}$ & $\begin{array}{c}1.9 \\
(1-3)\end{array}$ & $\begin{array}{c}0.4 \\
(0.2-0.6)\end{array}$ & 15.0 & 5.7 \\
\hline $2 a$ & Olga & 6 & $\begin{array}{c}29.1 \\
(22-34)\end{array}$ & $\begin{array}{c}11.4 \\
(10-13)\end{array}$ & $\begin{array}{c}9.6 \\
(8-11)\end{array}$ & $\begin{array}{c}9.4 \\
(7-10)\end{array}$ & $\begin{array}{c}3.7 \\
(0-5)\end{array}$ & $\begin{array}{c}2.3 \\
(1.5-2.7)\end{array}$ & 34.5 & 10.2 \\
\hline $2 c$ & Olga & 3 & $\begin{array}{c}33.1 \\
(31-36)\end{array}$ & $\begin{array}{c}13.0 \\
(11-15)\end{array}$ & $\begin{array}{l}10.8 \\
(8-13)\end{array}$ & $\begin{array}{c}8.6 \\
(7-9)\end{array}$ & $\begin{array}{c}2.5 \\
(2-3)\end{array}$ & $\begin{array}{c}0.7 \\
(0.5-0.9)\end{array}$ & 31.3 & 9.4 \\
\hline $3 a$ & St. Marcel & 3 & $\begin{array}{c}35.6 \\
(35-36)\end{array}$ & $\begin{array}{l}11.0 \\
(11)\end{array}$ & $\begin{array}{c}8.9 \\
(8-10)\end{array}$ & $\begin{array}{l}11.4 \\
(9-14)\end{array}$ & $\begin{array}{c}5.2 \\
(3-8)\end{array}$ & $\begin{array}{c}1.2 \\
(1.0-1.6)\end{array}$ & 26.7 & 9.2 \\
\hline $3 b$ & St. Marcel & 3 & $\begin{array}{l}33.7 \\
(34)\end{array}$ & $\begin{array}{c}13.9 \\
(13-14)\end{array}$ & $\begin{array}{c}9.8 \\
(8-11)\end{array}$ & $\begin{array}{l}11.1 \\
(9-12)\end{array}$ & $\begin{array}{c}5.0 \\
(5-6)\end{array}$ & $\begin{array}{c}1.6 \\
(1.5-1.7)\end{array}$ & 24.9 & 8.9 \\
\hline 4 & St. Léon & 15 & $\begin{array}{c}36.3 \\
(27-45)\end{array}$ & $\begin{array}{c}11.8 \\
(10-13)\end{array}$ & $\begin{array}{c}13.4 \\
(11-16)\end{array}$ & $\begin{array}{c}12.6 \\
(10-16)\end{array}$ & $\begin{array}{c}3.6 \\
(2-5)\end{array}$ & $\begin{array}{c}0.1 \\
(0-0.4)\end{array}$ & 32.2 & 11.1 \\
\hline 5 & St. Alban & 19 & $\begin{array}{c}25.1 \\
(22-33)\end{array}$ & $\begin{array}{c}20.5 \\
(17-24)\end{array}$ & $\begin{array}{c}9.5 \\
(8-13)\end{array}$ & $\begin{array}{c}9.5 \\
(5-14)\end{array}$ & $\begin{array}{c}1.5 \\
(0-5)\end{array}$ & $\begin{array}{c}0.7 \\
(0-1.2)\end{array}$ & 33.2 & 11.2 \\
\hline 6 & St. Barnabé & 3 & $\begin{array}{c}37.0 \\
(33-40)\end{array}$ & $\begin{array}{c}12.2 \\
(11-13)\end{array}$ & $\begin{array}{c}14.4 \\
(12-16)\end{array}$ & $\begin{array}{c}13.3 \\
(12-15)\end{array}$ & $\begin{array}{c}3.5 \\
(3-5)\end{array}$ & $\begin{array}{c}0.2 \\
(0.2-0.3)\end{array}$ & 19.4 & 6.9 \\
\hline 7 & Shawinigan & 5 & $\begin{array}{c}36.8 \\
(32-42)\end{array}$ & $\begin{array}{c}19.6 \\
(17-24)\end{array}$ & $\begin{array}{c}15.0 \\
(14-16)\end{array}$ & $\begin{array}{c}13.4 \\
(12-17)\end{array}$ & $\begin{array}{c}2.4 \\
(0-4)\end{array}$ & - & 12.8 & 9.4 \\
\hline 8 & Chicoutimi & 8 & $\begin{array}{c}41.1 \\
(35-44)\end{array}$ & $\begin{array}{c}19.8 \\
(17-23)\end{array}$ & $\begin{array}{c}13.2 \\
(12-16)\end{array}$ & $\begin{array}{c}9.7 \\
(7-13)\end{array}$ & $\begin{array}{c}1.5 \\
(0-3)\end{array}$ & $\begin{array}{c}0.7 \\
(0.4-1.0)\end{array}$ & 14.0 & 2.7 \\
\hline
\end{tabular}

Table 2-2: Chemical analyses of clay in eastern Canada (Locat et al., 1984)

\begin{tabular}{|c|c|c|c|c|c|c|c|c|}
\hline \multirow[b]{2}{*}{ Compound } & \multicolumn{6}{|c|}{ Site No. } & \multirow[b]{2}{*}{$\begin{array}{c}\text { Shawinigan } \\
\text { (7) }\end{array}$} & \multirow[b]{2}{*}{$\begin{array}{l}\text { Chicoutimi } \\
\text { (8) }\end{array}$} \\
\hline & $\begin{array}{l}\text { Baleine } \\
\quad(1 b)\end{array}$ & $\begin{array}{l}\text { Olga } \\
(2 a)\end{array}$ & $\begin{array}{l}\text { St. Marcel } \\
\qquad(3 a)\end{array}$ & $\begin{array}{l}\text { St. Léon } \\
\text { (4) }\end{array}$ & $\begin{array}{l}\text { St. Alban } \\
\text { (5) }\end{array}$ & $\begin{array}{c}\text { St. Barnabé } \\
(6)\end{array}$ & & \\
\hline $\mathrm{SiO}_{2}$ & 59.33 & 52.83 & 53.36 & 55.36 & 59.79 & 58.26 & 61.87 & 62.43 \\
\hline $\mathrm{TiO}_{2}$ & 0.77 & 0.61 & 0.72 & 0.92 & 0.89 & 0.97 & 0.87 & 0.80 \\
\hline $\mathrm{Al}_{2} \mathrm{O}_{3}$ & 16.10 & 17.05 & 16.42 & 16.38 & 15.28 & 16.15 & 15.55 & 16.37 \\
\hline $\mathrm{CaO}$ & 2.90 & 4.41 & 4.26 & 3.60 & 3.73 & 3.51 & 3.62 & 5.40 \\
\hline $\mathrm{K}_{2} \mathrm{O}$ & 3.59 & 3.72 & 3.19 & 3.51 & 3.40 & 3.71 & 3.32 & 2.38 \\
\hline $\mathrm{Na}_{2} \mathrm{O}$ & 4.10 & 2.47 & 2.88 & 3.89 & 2.60 & 3.98 & 3.63 & 3.74 \\
\hline $\mathrm{MgO}$ & 3.78 & 4.06 & 4.75 & 3.95 & 2.88 & 3.23 & 2.70 & 2.06 \\
\hline $\mathrm{Fe}$ (total) & 4.22 & 4.72 & 5.16 & 5.19 & 4.46 & 4.86 & 4.32 & 3.07 \\
\hline $\mathrm{FeO}$ & 3.25 & 2.99 & 4.11 & 3.19 & 2.92 & 3.85 & 3.58 & 2.52 \\
\hline $\mathrm{Fe}_{2} \mathrm{O}_{3}$ & 2.42 & 3.42 & 2.80 & 3.87 & 3.13 & 2.66 & 2.19 & 1.58 \\
\hline $\mathrm{P}_{2} \mathrm{O}_{5}$ & 0.25 & 0.20 & 0.18 & 0.29 & 0.27 & 0.34 & 0.32 & 0.22 \\
\hline $\mathrm{CO}_{2}$ & 0.48 & 3.74 & 3.96 & 2.13 & 1.50 & 0.72 & 0.43 & 1.06 \\
\hline $\mathrm{H}_{2} \mathrm{O}$ (total) & 2.24 & 4.15 & 3.51 & 3.03 & 2.32 & 1.84 & 1.12 & 0.83 \\
\hline $\mathrm{MnO}$ & 0.09 & 0.08 & 0.11 & 0.12 & 0.10 & 0.11 & 0.11 & 0.08 \\
\hline
\end{tabular}


Geotechnical engineering propertieso of Champlain Sea clay vary widely. The undrained shear strength can vary from 30 to $150 \mathrm{kPa}$, sensitivity from 10 to 100 , but higher values have been recorded (Mitchel and Markell, 1974). Natural water content varies beteewn 40 and 80\%, liquid limit between 20 and $70 \%$ and plastic limit between 17 and 30\%. Salt content can vary widely even within a few meters. The state of flocculation at the time of sedimentation is thought to be a major factor affecting clay fabric and hence the next section is dedicated to palaeosalinity study of Champlain Sea clay.

\subsubsection{Palaeosalinity of Champlain Sea clay}

Palaeosalinity is the salinity of the environment in which a sedimentary deposit was laid down. The boron content of the illite minerals in the clay mineral size fraction of many types of sedimentary rocks has been shown to increase with the salinity prevailing during deposition of the rocks (Frederickson \& Reynolds, 1960; Lerman, 1966; Walker, 1968). Frederickson and Reynolds (1960) concluded that the boron content of illite minerals in sedimentary rocks can be used to determine the palaeosalinity. They also concluded that the clay mineral illite contain most of the boron in the clay mineral fraction of sedimentary rocks.

Gillot (1970) conducted a study on a number of samples from Ottawa district to determine the palaeosalinity of Champlain Sea clay. The Engineering properties of the samples used in this palaeosalinity study are summarized in Table 2-3. Sample A and B were collected at the site of the Ottawa sewage plant. Sample C was collected at the junction of Walkley Road and Russell Road, Ottawa. Sample D was collected at H.M.C.S. (C.E.S.) Gloucester, Ontario, and sample E was collected at St. Joachim de Tourelle in eastern Quebec. Particle size analyses by hydrometer and pipette methods show that sample A is predominantly of clay size; sample B, C and D are silty clays; and $\mathrm{E}$ is a silt.

The boron content was determined for size-fractioned samples of Champlain Sea clay and the results are presented in Table 2-4. It has been thought that the fabric is also influenced by the amount of carbonates present so these values are included in Table 2-4.

Table 2-3: Engineering properties of samples (Gillot, 1970)

\begin{tabular}{llllll} 
Sample & A & B & C & D & E \\
\hline
\end{tabular}




\begin{tabular}{|c|c|c|c|c|c|c|}
\hline & Depth (m) & 13.716 & 16.154 & 10.058 & 5.08 & 6.096 \\
\hline Natural water content $(\%)$ & & 60 & 45 & 58 & 70 & 22 \\
\hline Sensitivity & & 56 & 500 & 21 & 100 & - \\
\hline Liquid limit (\%) & & 49 & 30.6 & 53.2 & 43 & 29.1 \\
\hline Plastic limit (\%) & & 23 & 23.4 & 24.7 & 23.5 & 21.4 \\
\hline Plasticity index (\%) & & 26.3 & 7.2 & 28.5 & 19.5 & 7.7 \\
\hline Liquidity index $(\%)$ & & 1.4 & 3.0 & 1.1 & 2.3 & 0.1 \\
\hline
\end{tabular}

Gillot (1970) also performed optical, SEM and X-ray analyses on all the 5 samples to correlate the fabric of Champlain Sea clay to the palaeosalinity. The analyses data show that many particles have an irregular outline and platy morphology and that there is a fair-to-good preferred orientation of the layer structure silicates in the two Ottawa sewage plant samples (A, B). Conversely, a fabric close to random in the rest of the samples is observed. Clay mineral orientation tends to improve with an increasing organic content. And the presence of about more than $10 \%$ of carbonate minerals favours randomness.

The palaeosalinity data deduced from the boron content shows that samples $(A, B, D)$ were deposited in fresher water than normal marine, so that deflocculation may have existed at the time of deposition. This may be the reason for the oriented fabric in the two samples from Ottawa sewage plants (A, B). Sample D fails to show an oriented fabric although the "fresher than normal marine" designation of salinity deduced from the boron data. Clay minerals can be flocculated by water with high electrolyte content; hence Sample D may have been deposited in water with high electrolyte content that causes flocculation. Palaeosalinity designations suggests that the two other samples $(\mathrm{C}, \mathrm{E})$ have been deposited in a near normal marine environment. Both samples have a random fabric, so the two sorts of data are in agreement.

Table 2-4: Palaeosalinity data of Champlain Sea clay sample from Ottawa (Gillot, 1970)

\begin{tabular}{llllll}
\hline Sample & Fraction & Carbonate & Organic & Boron & Palaeosalinity designation \\
\hline & total & 2.1 & 0.27 & & \\
A & $2-0.2$ & & 0.21 & 100 & fresher than normal marine \\
\hline
\end{tabular}




\begin{tabular}{llllll}
\hline & $<0.2$ & & 0.5 & 50 & \\
& total & 3.3 & 0.37 & & \\
& $2-0.2$ & & 0.54 & 10 & fresher than normal marine \\
& $<0.2$ & & 0.98 & 50 & \\
& total & 5.9 & 0.31 & & \\
$\mathrm{C} \quad$ & $2-0.2$ & & 0.3 & 100 & near normal marine \\
& $<0.2$ & & 0.43 & 150 & \\
& total & 2.4 & 0.19 & & \\
$\mathrm{D}$ & $2-0.2$ & & 0.24 & 50 & fresher than normal marine \\
& $<0.2$ & & 0.53 & 25 & \\
& total & 9.7 & 0.24 & & \\
$\mathrm{E}$ & $2-0.2$ & & 0.24 & 250 & near normal marine \\
& $<0.2$ & & 0.40 & 250 & \\
\hline
\end{tabular}

\subsubsection{Leaching and sensitivity}

Many of the sediments like Champlain Sea clay are referred to by geotechnical engineers as "sensitive clays" and sometimes the term "quick clay" is used. When sensitive clays are disturbed their shear strength changes. The quotient between the shear strength of undisturbed clay, as determined by tests performed under undrained conditions, and that of completely remolded clay is known as sensitivity. In practice, the term "quick clay" is used when its sensitivity exceeds 3050 depending on the method used to determine the shear strength (Osterman, 1965). Several classifications have been developed regarding sensitivity, Norsk Geoteknisk Forening (1974) classifies clays' sensitivity according to Table 2-5. However, the Canadian Foundation Engineering Manual (CGS, 2006) has slightly different classification than the Norwegian as shown in Table 2-6.

Table 2-5: Classification of sensitivity values (Norsk Geoteknisk Forening, 1974)

\begin{tabular}{ll}
\hline Low sensitivity & Less than 8 \\
\hline
\end{tabular}




\begin{tabular}{ll} 
Medium high sensitivity & 8 to 30 \\
High sensitivity & More than 30 \\
\hline
\end{tabular}

Table 2-6: Classification of sensitivity according to CFEM (CGS, 2006)

\begin{tabular}{ll}
\hline Low sensitivity & $<2$ \\
Medium sensitivity & $2-4$ \\
Extra (high) sensitivity & $4-8$ \\
Quick & $>16$ \\
\hline
\end{tabular}

The unusual behaviour of Champlain Sea clay has brought many discussions about the probable mechanism behind the abrupt loss of shearing resistance upon disturbance. Theoretical and experimental evidence shows that clay mineral should have an open arrangement in marine deposited clay because of the rapid flocculation of colloidal particles in water with a moderate electrolyte content (Lambe, 1953, 1958; Mitchell 1956; Rosenqvist, 1962; Gillot 1970). This open fabric breaks down when the clay is disturbed, and the particles become oriented in a closer packed configuration. The breakdown of the open structure changes the balance of the interparticle stresses causing the loss of shearing resistance.

The theory of leaching by Rosenqvist $(1953,1962)$ suggested that metastability of the open fabric results from a decrease in salt content of pore solution due to the leaching. Leaching is the process of removing salt by a hydraulic gradient or by diffusion. Laboratory experiments of both mechanisms have been simulated. Hydraulic gradients can be an infiltration of fresh water from the top or as upward movement of artesian ground water. In Canadian clays, leaching was mainly caused by the isostatic uplift of the land. Other factors may be involved in Champlain Sea clay, since there is no correlation between concentration and sensitivity.

Torrence (1974) concluded, from a leaching experience on Norwegian clay, that the sensitivity of the clay increases as the salinity decreases and a sharp drop occurs when the salt content is reduced below $2 \mathrm{~g} / \mathrm{L}$ of pore fluid. Conversely, Bjerrum (1954) and Woo \& Moh (1977) stated that the sharp drop of sensitivity occurs when the salt content is reduced below $10 \mathrm{~g} / \mathrm{L}$ as shown in Figure 
2-2. This difference may be due to the different method of measuring pore water salinity. Bjerrum used dry soil and mixed it with a known volume of water, whereas Torrence measured the electrical conductivity directly on pore water fluid squeezed out from a fresh sample. The latter method seems to be more accurate since field measurements of salinities in Norwegian and Canadian quick clays show that sensitivities higher than 50 usually associated with salts content less than $1 \mathrm{~g} / \mathrm{L}$. Table 2-7 contrasts some geotechnical properties of Norwegian and Canadian clay affected by the salt content.

Leaching also results in an increase in compressibility and a large settlement. Bjerrum (1973) noticed a reduction of preconsolidation pressure due to the leaching changing an "aged" clay to a “fresh" sediment. However, Kazi and Moum (1973) concluded that loading leaching samples does not cause any significant changes in fabric and leaching will affect the interparticle forces but not the flocculated structure.

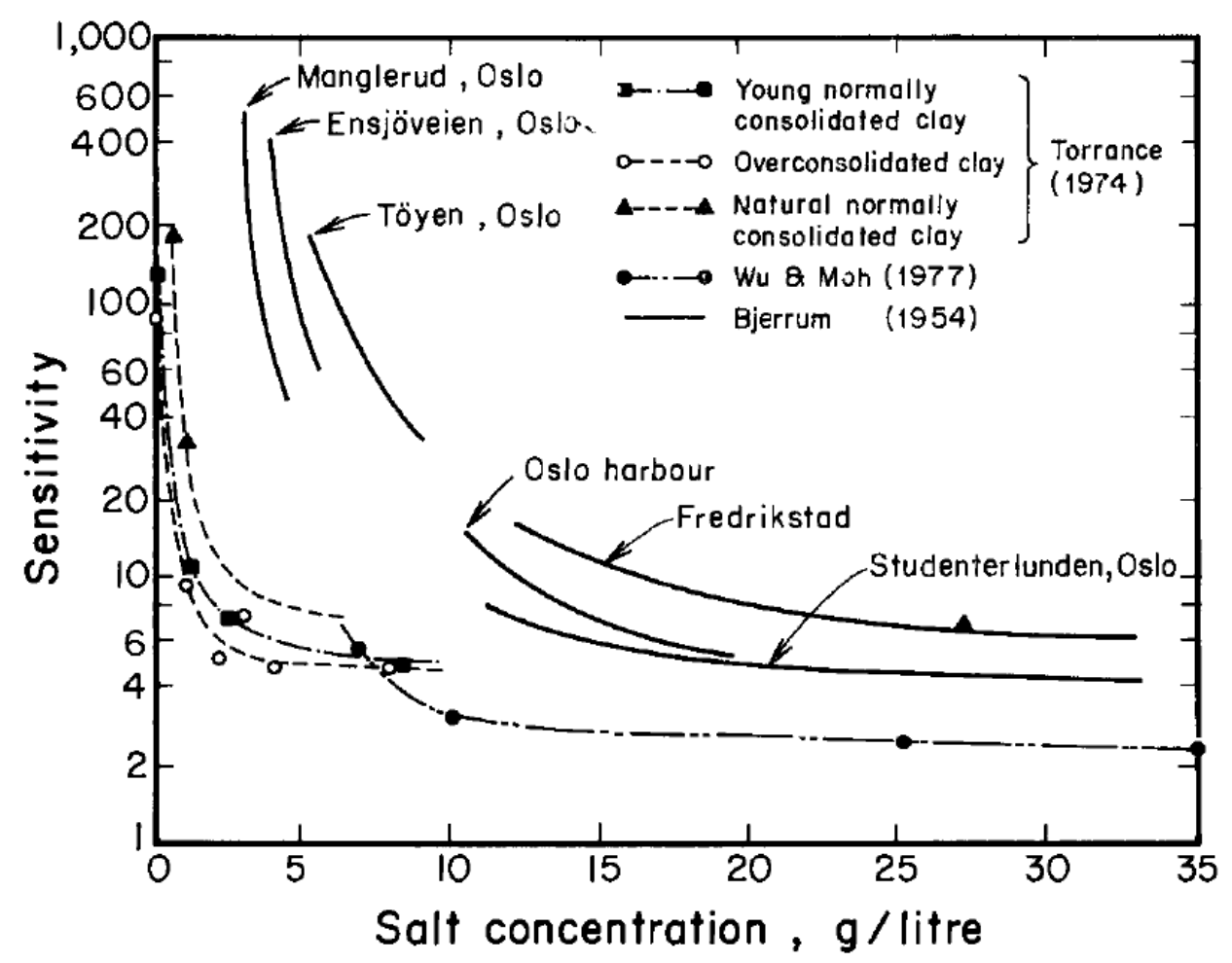

Figure 2-2: Leaching on the sensitivity of Norwegian and Bangkok clays (Brenner et al., 1981) 
Table 2-7: Some geotechnical data on Norwegian and Canadian clays (Brenner et al., 1981)

\begin{tabular}{l|c|c|c|c}
\hline \multirow{2}{*}{ Property } & \multicolumn{2}{|c|}{ Drammen clay (Norway)* } & \multicolumn{2}{c}{ Leda clay (Canada)** } \\
\cline { 2 - 5 } & O. Strandgate & Engene & Ottawa & \multicolumn{2}{c}{ Chelsea } \\
\cline { 2 - 5 } & 35 & 31 & 69 & 55 \\
Natural water content, \% & 37 & 22 & 60 & 31 \\
Liquid limit, \% & 19 & 4 & - & - \\
Plasticity index, \% & 36 & 35 & 64 & 45 \\
$<2 \mu \mathrm{m}$ fraction, \% & 15 & $<1$ & 1.5 & 0.34 \\
Salt content, g/litre & 1.2 & 0.1 & 2.1 & $<0.1$ \\
Remoulded shear strength, kPa & 10 & 80 & $10-20$ & $>200$ \\
Sensitivity & & & & \\
\hline
\end{tabular}

* Data from Kazi \& Moum (1973)

** Data from Torrance (1975)

\subsubsection{Microstructure of Champlain Sea clay}

During the last several decades, geotechnical engineers, soil scientists, engineering geologist and scientists have developed special techniques to investigate the clay microstructure. Among these techniques are: SEM, optical microscopy, XRD and mercury intrusion. Knowing the clay microstructure is fundamental to better understand the geotechnical behaviour of high-water content clays (Mitchell 1956; Lambe 1958).

In this section, the historical development of understanding Champlain Sea clay microstructure is presented. Most of the investigation techniques on clay structure require clay dehydration (Gillot, 1973, 1976). Dehydration can be done with air or oven-drying, critical-point drying and freezedrying. Observing dehydrated samples under the SEM can describe various microstructural features (Gillot 1970, 1979). Many other methods can be used to study the clay structure. Morgenstern and Tchalenko (1967) have used optical method on thin sections to quantify soils anisotropy. Gillot (1970,1979) and Quigley and Thompson (1966) observed the evolution of clay anisotropy during consolidation using XRD on thin sections. Mercury intrusion porosimetry has also been used by Diamond (1970) to study clay structure of compacted clay, permeability, and frost susceptibility of compacted silty soils.

Delage and Lefebvre (1984) observed the structure of intact, remolded and of a medium sensitivity Champlain Sea clay from St. Marcel site using SEM in conjunction with mercury intrusion. Only 
the observations from SEM will be reported here because the mercury intrusion is beyond the scope of this thesis.

Observation of intact sample are presented in Figure 2-3, where Figure 2-3b and c present two magnifications X 7000 (b) and X 15000 (c) on a vertical plane and Figure 2-3d and e present two magnifications X 3000 (d) and X 7000 (e) of a view on a horizontal plane. Figure 2-3 shows that the aggregate is composed of small platelets and separated by a regular porous network. The aggregate diameter has an order of $5 \mu \mathrm{m}$ and separated by an average distance of $1 \mu \mathrm{m}$. Scattered silt particles with same dimensions can be observed among aggregates. On a horizontal plane Figure 2-3d and e the structure is somewhat different. Fewer particle edges are observed and silt grains appears to be more pronounced. This difference in structure between horizontal and vertical planes indicate the existence of certain anisotropy.

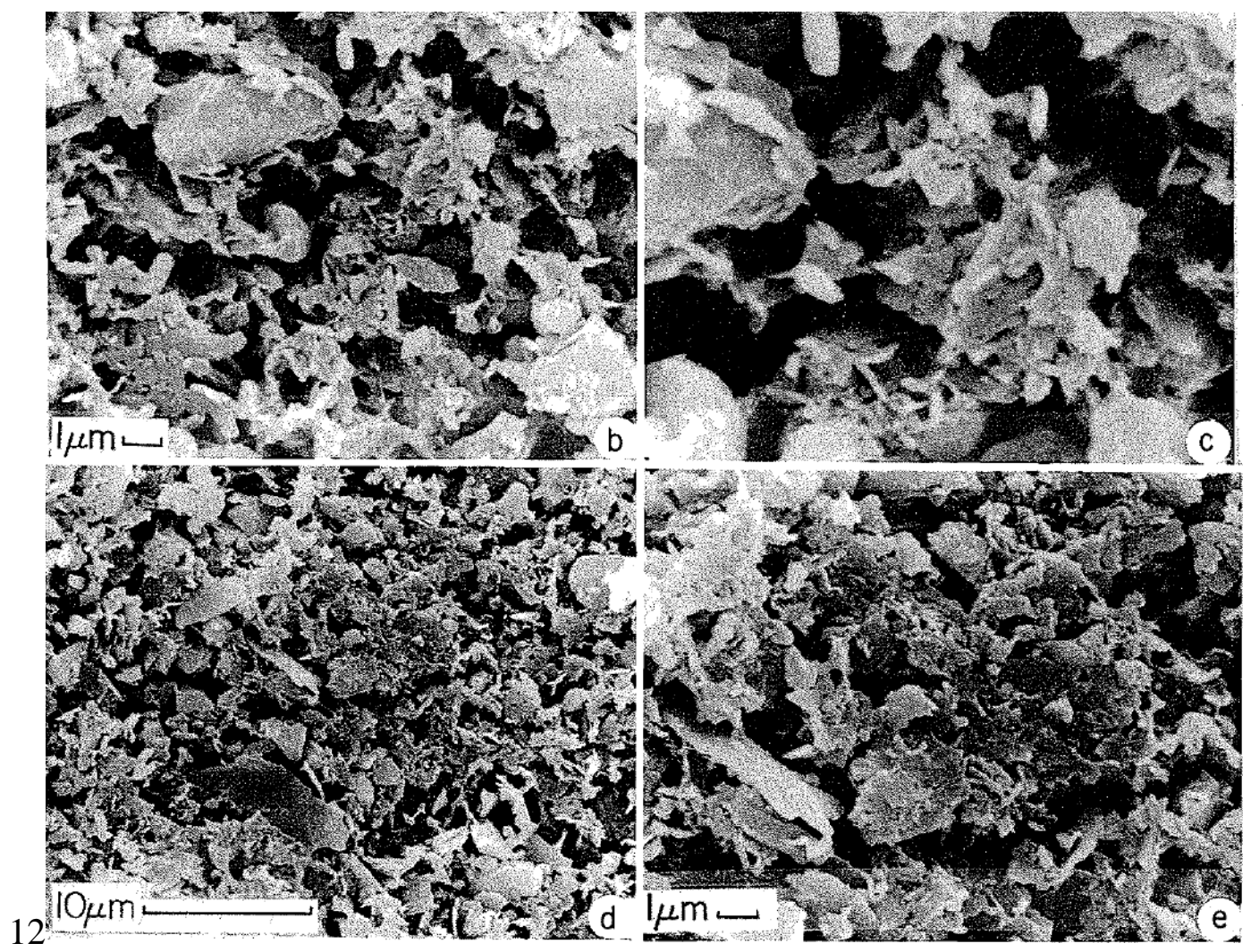

Figure 2-3: Photomicrographs of intact St. Marcel clay, on a vertical plane (b, X 7000; c, X 15000) and on a horizontal plane(d, X 3000; e, X 15000) (Delage \& Lefebvre, 1984)The observations of a remolded sample are shown in Figure 2-4 with two magnifications: Figure2-4a for X3000, and 
Figure2-4b X 7000. Some silt particle of $5 \mu \mathrm{m}$ diameter were observed in Figure 2-4b. Figure 2-4a shows that the remolded structure still characterized by aggregated structure, with large interaggregate pore structure and small intra-aggregate porosity.

The main conclusion on microstructure of Champlain Sea clay using SEM are that: 1) the intact clay has an aggregated structure with interaggregate and intra-aggregate porosity; 2) remolding did not destroy the aggregate and the porosity stay in the same state; and 3) significant anisotropy is observed in the clay structure.

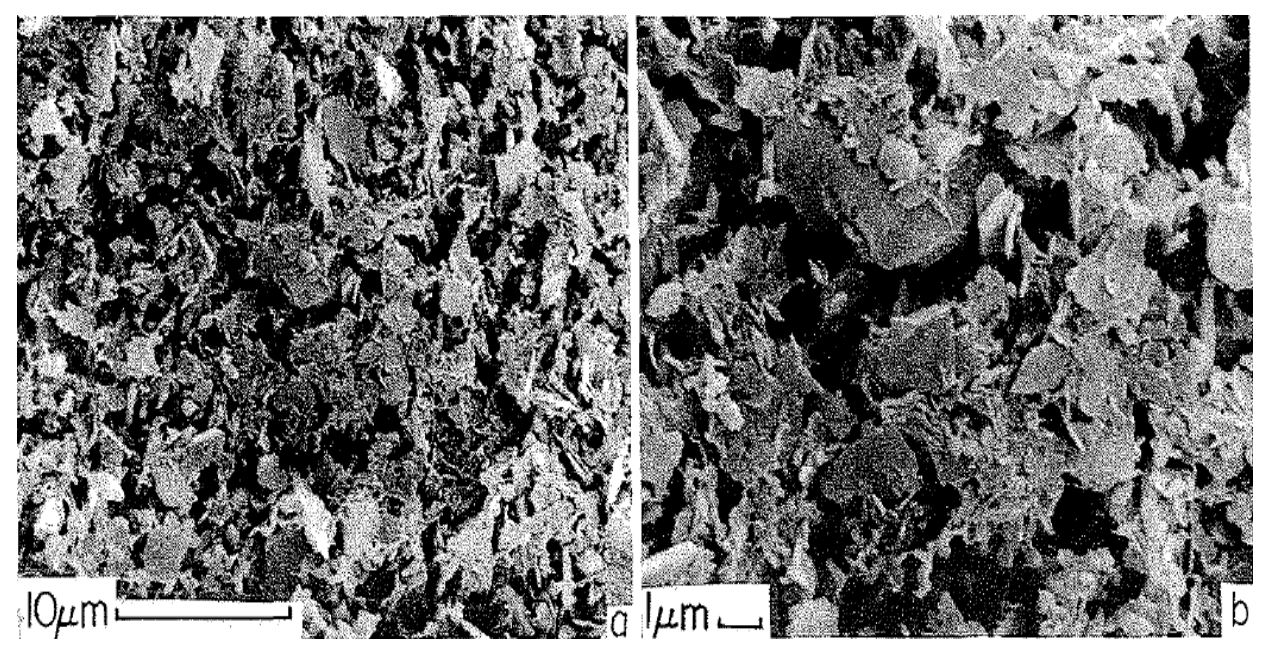

Figure 2-4 Photomicrograph of a remolded sample of St. Marcel clay (a, X3000; b, X7000) (Delage \& Lefebvre, 1984).

Locat et al. (1990) conducted a laboratory investigation on the quicklime stabilization of sensitive Champlain Sea clay. It was found that even at a higher water content above the liquid limit, significant strength increase was obtained when enough time and lime are provided. Lo et al. (1991) have developed an electroosmotic cell to assess the effectiveness of the treatment and to study the mechanism of the electroosmotic process on Champlain Sea clay. They found that the electroosmotic consolidation curve is similar to that of the conventional consolidation curve and the preconsolidation pressure was increased by $51-88 \%$ with an applied voltage up to $6 \mathrm{~V}$. An increase was recorded up to $172 \%$ in shear strength and a decrease in the moisture content by 30 $\%$. Recent laboratory investigations were carried out by Ryerson University Geotechnical Research Team to assess the effectiveness of the deep soil mixing method on Champlain Sea clay. 
Li et al. (2016) studied the application of deep soil mixing to Champlain Sea clay and found UCS strength of samples treated with $144 \mathrm{~kg} / \mathrm{m}^{3}$ of cement has increased 10 times more than the untreated samples, whereas samples treated with same slag/cement content resulted in an increase of 50 times at 28-day of curing. Afroz et al. (2018) studied the feasibility and efficiency of improving the strength and compressibility characteristics of sensitive Champlain Sea clay with ordinary Portland cement. They found that cement increased the strength of the treated sample and reduced compressibility within a short period of time.

\subsection{DEEP SOIL MIXING IN CHAMPLAIN SEA CLAY}

\subsubsection{Introduction of deep soil mixing technique}

There are two common methods to deal with the problematic behaviour of soft and sensitive clays. Pre-consolidation through the installation of vertical drains and loading the soil to reduce the water content. The second method is called the deep soil mixing which will be discussed in the next section.

Currently, there are many techniques to improve the problem of carrying out construction in soft soils by increasing the bearing capacity and reducing settlement. Pre-consolidation and deep soil mixing (DSM) are the two common ways used to address these problems. Pre-consolidation used vertical drains and surcharge to reduce the clay water content. However, this method is time consuming and very costly; therefore, it is not suitable for most engineering projects. On the other hand, DSM is an effective alternative in improving the engineering properties of soft clays for several reasons: both strength and settlement can be improved simultaneously, the method is environmentally friendly, the small timescale of the installation and it is very cost effective compared to other methods. FHWA ( 2013) define DSM as an in-situ soil treatment in which native soils are mixed with cementitious material (referred as binders) to enhance the engineering properties such as strength increase and reduction in permeability and compressibility. DSM is carried out using a machine equipped with mixing blades mounted at the end of a shaft that has nozzles. The binder, either in slurry form (wet method) or powder (dry method), is injected with high pressureinto the soil through the nozzels while the blades rotate. Figure 2-5 shows the installation process of deep mixing columns. DSM has been applied to improve soft soil ground 
since it was invented in Japan in 1970s (Okumura et al., 1974; Terashi et al., 1977; kitazume et al., 2013; Rashid et al., 2015, 2017 )

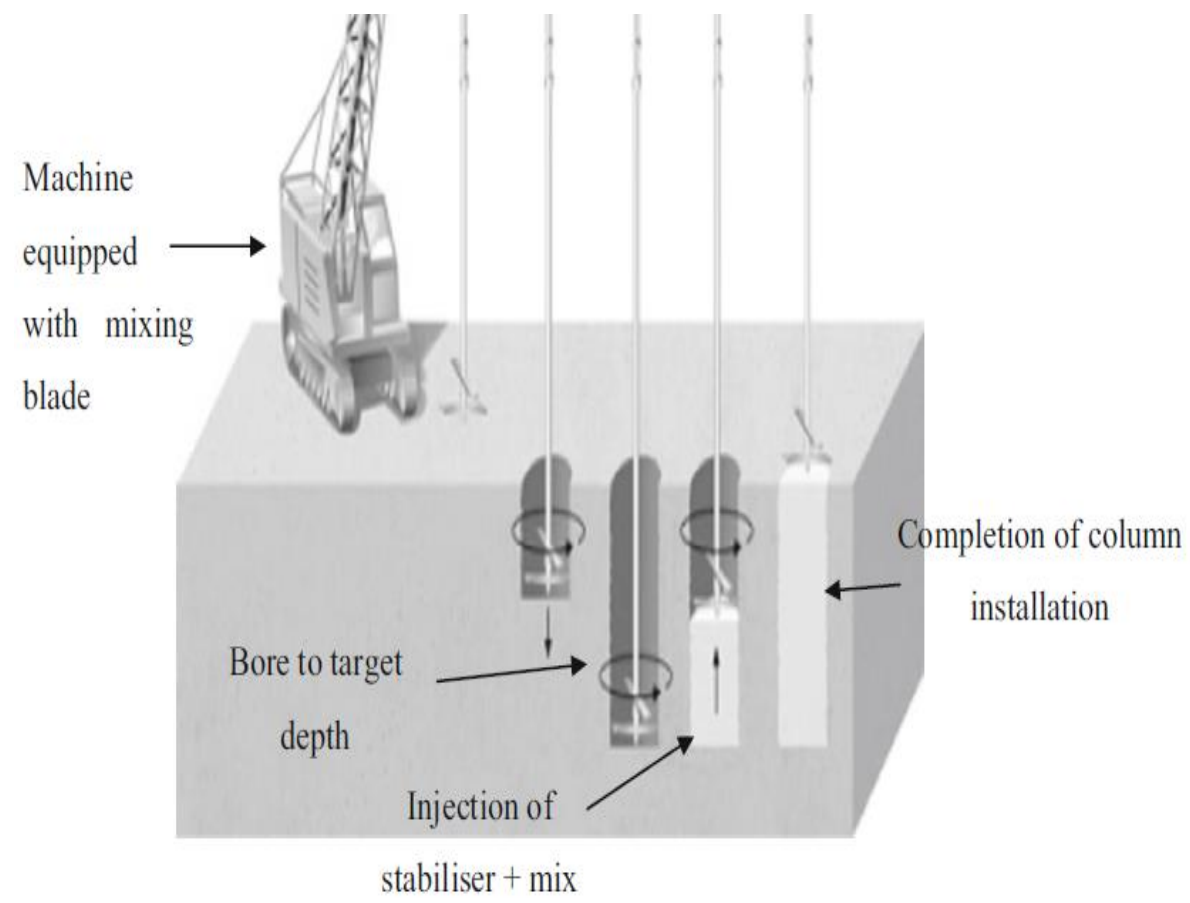

Figure 2-5: Deep soil mixing columns installation process (Hayward Baker, 2004)

Several factors influence the performance of DSM in the field. In general, the degree of improvement is directly proportional to the type of binder, the amount of binder doasge, and the curing time (Chew et al., 2004; Kitazume \& Terashi, 2013). However, recent studies by Horpibulsuk et al. ( 2012) show that the salt content is also an important factor in the strength development of saline clay.

\subsubsection{Factors affecting strength development in soil stabilization}

Portland cement and lime are the most commonly used binders for soil stabilization (Bergado et al., 1996; Chew et al., 2004); however, combining cement or lime with fly ash, gypsum or slag for soils with high water content or soils with high organic matter content proves to be adequate. Bergado et al. (1996) and Chew et al. (2004) reported that cement provided early strength compared to lime, due to the faster hydration rate of cement. Test results from stabilizing Yokohoma Port clay and Osaka Port clay from Japan using Portlan cement and blast-furnace slag 
cement type B suggest that the appropriate selection of the type of binder may be made if the pozzolanic reactivity of soil is evaluated early in the mix design (Kitazume \& Terashi, 2013). Conductivity can indicate the potential for the pozzolanic reactions that are necessary to cementitious bonds formation; however, care should be taken because dissolved salt can increase the conductivity without the presence of clay mineral needed for pozzolanic reaction (FHWA, 2013). Another important parameter that affect the type of binder choice is the soil organic content. Portland cement with furnace salg is suggested to be used in highly organic soils like peat, where the necessary clay mineral for the pozzolanic reaction are of small proportions. Lime is to be avoided in peat. Based on different laboratory tests on Nordic soils with various binder type, EuroSoilStab (2002) presented a summary of the application of different stabilizers.

Table 2-8: Choice of binder based on different type soil conditions (EuroSoilStab, 2002)

\begin{tabular}{lllll}
\hline Binder & Silt & Clay & Organic soils, clay & $\begin{array}{l}\text { Peat } \\
\text { Organic content } \\
\end{array}$ \\
& $0-2 \%$ & $\begin{array}{l}\text { Organic content } \\
0-2 \%\end{array}$ & $\begin{array}{l}\text { Organic content } \\
2-30 \%\end{array}$ & $\begin{array}{l}\text { Organic content } \\
50-100 \%\end{array}$ \\
\hline Cement & $\mathrm{xx}$ & $\mathrm{x}$ & $\mathrm{x}$ & $\mathrm{xx}$ \\
Cement + gypsum & $\mathrm{x}$ & $\mathrm{x}$ & $\mathrm{xx}$ & $\mathrm{xx}$ \\
Cement + furnace slag & $\mathrm{xx}$ & $\mathrm{xx}$ & $\mathrm{xx}$ & $\mathrm{xxx}$ \\
Lime & - & $\mathrm{xx}$ & - & - \\
Lime + cement & $\mathrm{xx}$ & $\mathrm{xx}$ & $\mathrm{x}$ & - \\
Lime + gypsum & $\mathrm{xx}$ & $\mathrm{xx}$ & $\mathrm{xx}$ & - \\
Lime + slag & $\mathrm{x}$ & $\mathrm{x}$ & $\mathrm{x}$ & - \\
Lime + gypsum + slag & $\mathrm{xx}$ & $\mathrm{xx}$ & $\mathrm{xx}$ & - \\
Lime + gypsum + cement & $\mathrm{xx}$ & $\mathrm{xx}$ & $\mathrm{xx}$ & - \\
\hline
\end{tabular}

xxx: very good binder in many cases; xx: good in many cases; $x$ : good in some cases; -: not suitable

Ahnberg et al. (1994) reported that clay soil stabilization usually require a cement content in the range of 5-40\% of soil dry weight. The cement content used in Japanese clays is reporeted to be between 20-30\% (Kitazume \& Terashi, 2013). In USA, Bruce (2001) reported that the range can vary between $10-50 \%$. The difference in cement content reported is mainly due to the difference in soil properties and the construction method used. Soil with a high water content and an organic content requires more binding agent. The influence of Portland cement content on Kawasaki clay was tested by Terashi et al. (1980) and the results are shown in Figure 2-6. It can be concluded that strength increased almost linearly with the binder amount and a minimun binder amount larger 
than $5 \%$ is required to see the effect of DSM. The consctruction method can also dictate the amount of binder needed to reach a certain improvement level. For example, the dry mixing method produces a higher strength compared to the wet method with the similar amount of binder due to the higher total water-to-binder ratio in the latter method. However, in the wet method the binder slurry is easier to mix with the soil as compared to the dry method. As a result, the wet method produces less variation in terms of shear strength. In highly organic soil such as peat, EuroSoilStab (2002) suggested that the amount of binder should exceed a treshhold to allow the commencement of the chemical reaction as shown Figure 2-7.

Figure 2-8 illustrates the effect of the curing period on the unconfined compressive strength (UCS) of several types of clay treated with $10 \%$ of quicklime (Terashi et al.,1977). The strength increase is much dependent on the soil type even the amount of binder is the same, but there is a linear increase trend of strength with the logarithmic scale of curing time. The increase of strength with time is due to the growth of hydration product with time and pozzolanic reaction product for long term curing.

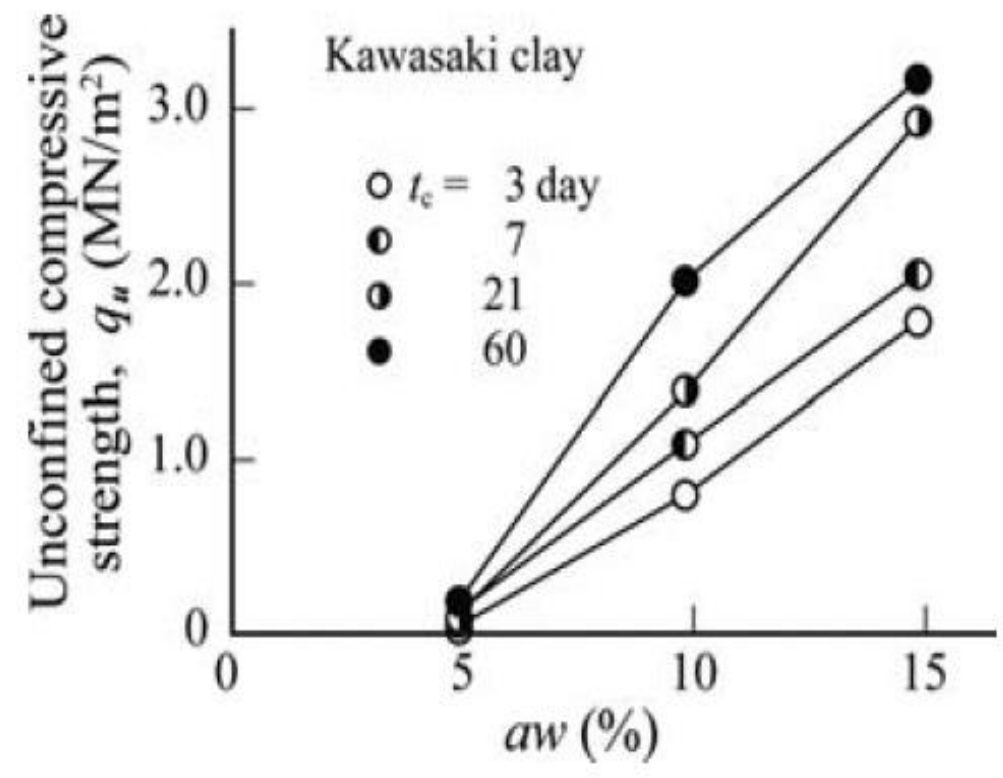

Figure 2-6: The effect of cement dosage on Kawasaki clay (Terashi et al., 1980) 


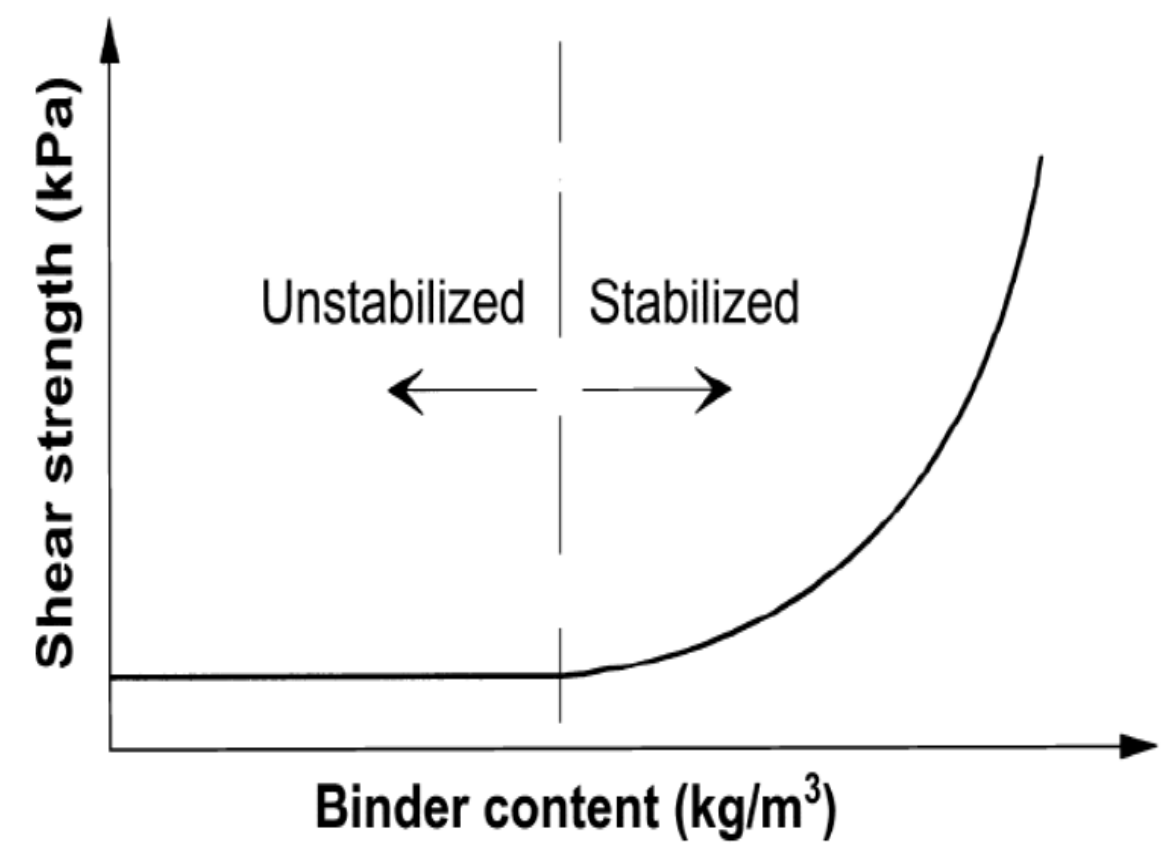

Figure 2-7: Binder dosage and shear strength relationship in peat soils (EuroSoilStab, 2002)

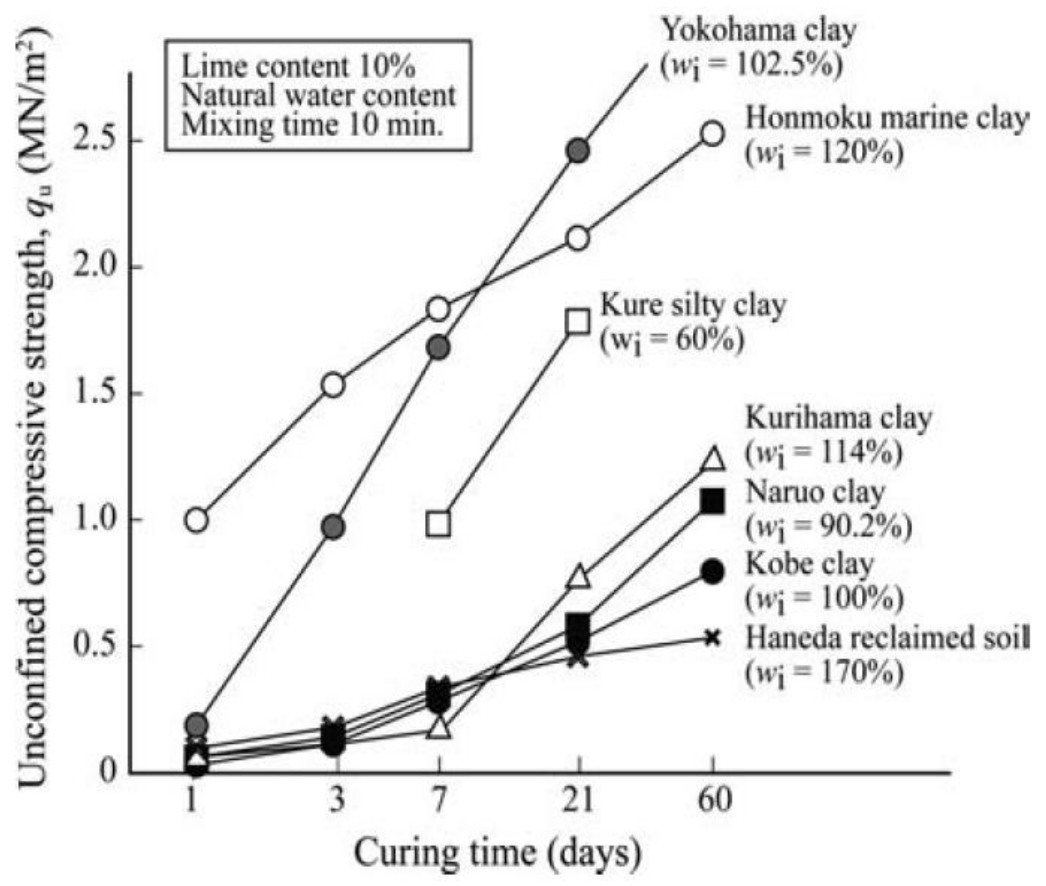

Figure 2-8: Effect of curing time on lime-treated Japanese clay (Terashi et al., 1977) 
The effect of salinity level of marine clay on the strength and compressibility of natural and cement treated marine clay has not been extensively investigated. There are only a few recent studies available in the literature. Horpibulsuk et al., (2012) invistigated the effect of salt content of a marine clay from northeast Thailand and concluded that the increase in salt content for a particular water content decreases the inter-particle attraction of the clay and the cementation bond strength. Figure 2-9 shows the strength developmet of saline clay with different salt content admixed with cement at a constant clay-water content of 53\% and cement dosage of $20 \%$ (Horpibulsuk et al., 2012). Haofeng et al. (2107) invistigated the strength improvement of a salt-rich soil from Jiangsu Province in China mixed with cement and concluded that the cocentration of $\mathrm{Cl}^{-}$was detrimental to the the strength development in the soil mixture.

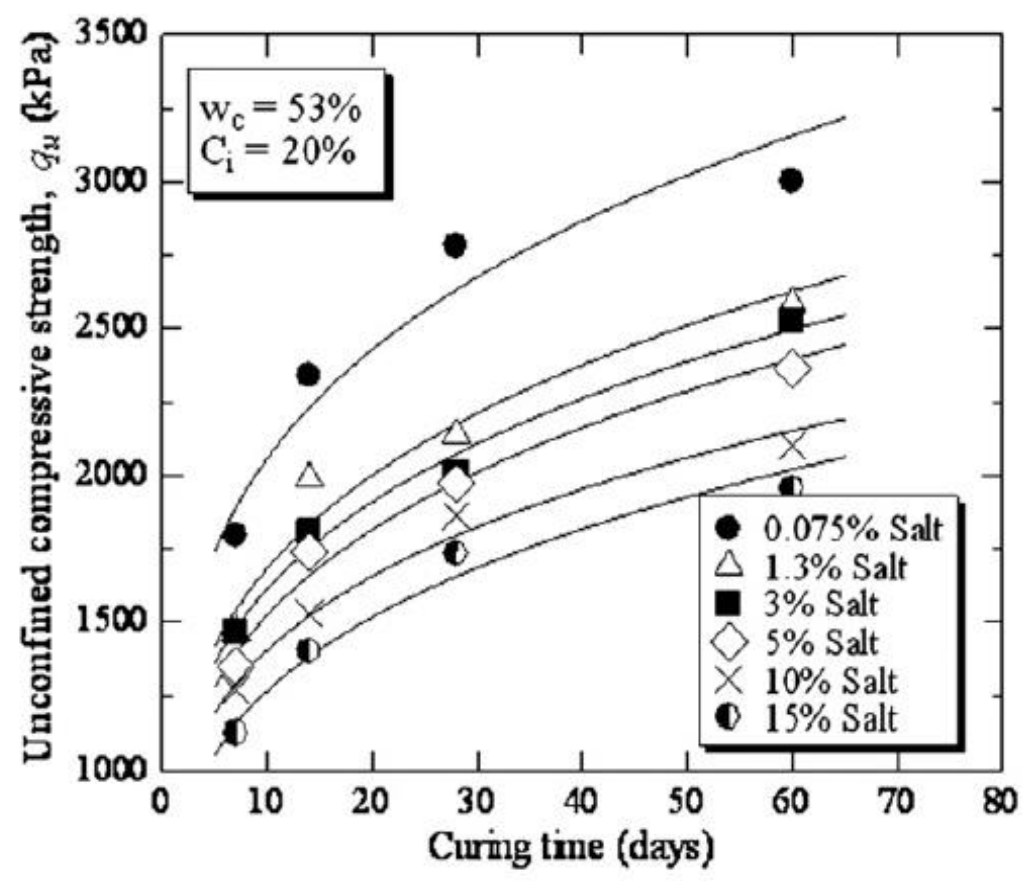

Figure 2-9: Impact of salinity on strength development of treated clay (Horpibulsuk et al., 2012)

\subsubsection{Mechanisms of strength development in stabilized clay}

Strength and stiffness in natural clays are the result of an interaction between their aggregated particles which are described as an "assemblages" of clay particles (Mitchell and Soga, 2005). When soil is mixed with cementitious material, these "assemblages" get enclosed by the cement 
slurry to increase the interaction between the new-formed phases and hence improve the strength (Bergado et al., 1996). Portland cement is the most commonly used binder in geotechnical project because it is available, economic, and easy to store. The four major oxide phases of the Portland cement are: tricalcium silicate $\left(\mathrm{C}_{3} \mathrm{~S}\right)$, dicalcium silicate $\left(\mathrm{C}_{2} \mathrm{~S}\right)$, tricalcium aluminate $\left(\mathrm{C}_{3} \mathrm{Al}\right)$ and tetracalcium aluminoferrite $\left(\mathrm{C}_{4} \mathrm{AF}\right)$. However, only the first two calcium silicate phases are important to soil stabilization. When hydrated these two phases produced calcium hydroxide according to Eq. 2-1 and 2-2.

$$
\begin{array}{ll}
2 \mathrm{C}_{3} \mathrm{~S}+6 \mathrm{H} \rightarrow \mathrm{C}-\mathrm{S}-\mathrm{H}+3 \mathrm{Ca}(\mathrm{OH})_{2} & \text { Eq. } 2-1 \\
2 \mathrm{C}_{2} \mathrm{~S}+4 \mathrm{H} \rightarrow \mathrm{C}-\mathrm{S}-\mathrm{H}+\mathrm{Ca}(\mathrm{OH})_{2} & \text { Eq. } 2-2
\end{array}
$$

When cement is mixed with water, the solution becomes saturated with calcium hydroxide within 12 min Gartner et al. (1985). The calcium hydroxide is as a source of calcium that is necessary for the four stabilization mechanisms: 1) cation exchange, 2) flocculation and agglomeration, 3) calcium silicate hydrate, and 4) pozzolanic reaction. Cation exchange is the first and the quickest stabilization process that occur when cement slurry is mixed with clay. Plasticity of a soil is determined primarily by the amount of montmorillonite minerals (two silica tetrahedra and one alumina tetrahedron) present. This clay minerals are deficient in the charge because of the substitution of aluminum by magnesium. Monovalent cations such as $\mathrm{Na}^{+}$and $\mathrm{K}^{+}$along with dipolar water molecules are attracted to the clay surface to balance the charge deficiency in the system. This results in a diffused separation of two charged surfaces leading to the formation called "double layer" (Mitchell and Soga, 2006). The thicker this double layer, the more active and plastic the soil. However, the monovalent cations are ready to be exchanged with cations of higher valence such as calcium according to the preferential order $\mathrm{Na}^{+}<\mathrm{K}^{+}<\mathrm{Ca}^{2+}<\mathrm{Mg}^{2+}<\mathrm{Al}^{3+}$ (Grim, 1962). Portland cement, of course, will provide the necessary calcium ions so that this exchange occurs, which will cause a significant reduction of the double layer thickness and hence a reduction in the plasticity as shown in Figure 2-10.

Through flocculation and agglomeration process the clay structure can be changed from a plastic fine-grained material to that of a granular soil. Flocculation is the process that change the flat parallel structure to a more random edge-to-face or edge-to-edge orientation. Flocculation is the result of the high electrolyte content, the high $\mathrm{pH}$, and the reduction in the double layer thickness 
through cation exchange (Herzog and Mitchell, 1963). Agglomeration is the process in which the clay particles start to form weak bonds at the edge-surface interfaces of the clay particles because of the deposition of the cementitious material at the clay particle interface. Agglomeration leads to formation of larger aggregates from fine clay particle and improves the texture of the clay soil. The reduction of double layer thickness and the increased internal friction of clay particles due to flocculation and agglomeration result in a reduction of soil plasticity, an increase in shear strength, and an improved texture. Same as cation exchange, flocculation and agglomeration are quick and occur within several hours of mixing. The process of flocculation and agglomeration is shown in Figure 2-11.

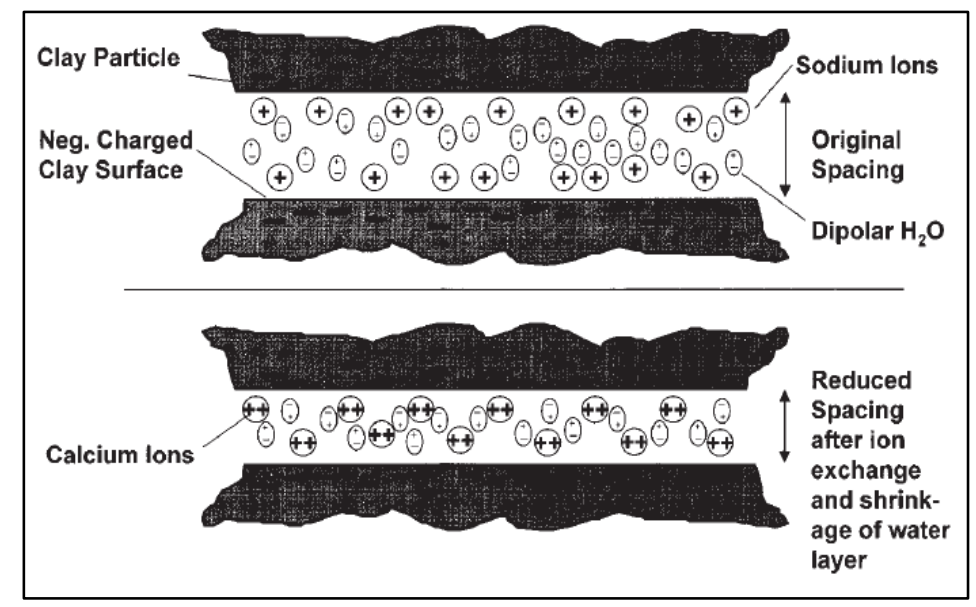

Figure 2-10: Schematic illustration of cation exchange (Brenner et al., 1981)

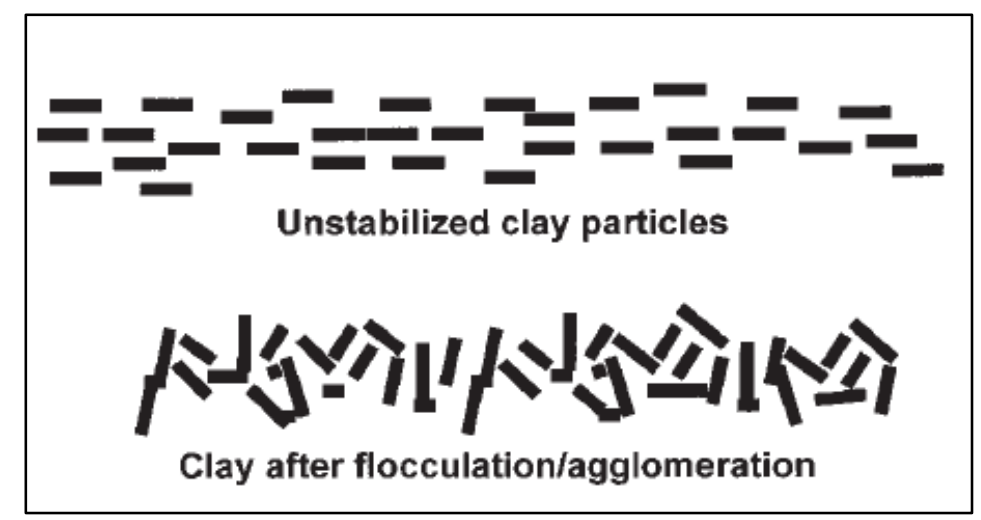

Figure 2-11: Schematic process of flocculation and agglomeration (Brenner et al., 1981) 
Cement hydration as described in Eq. 2-1 and 2-2 produces C-S-H, calcium hydroxide, and can also produce calcium aluminum hydrate C-A-H. C-S-H and C-A-H serve as the "glue" that provide structure and strength the soil-cement mixture. The hydrates stabilize the flocculated clay particle through cementation which mainly occurs within the first month. However, strength gain continues for years due to the continued hydration reaction. The cement develops strong bonds between the hydration products (C-S-H and C-A-H) and the aggregated clay particles previously formed through flocculation and agglomeration. Some studies suggest that the formation of cementitious material also reduces the leaching potential of calcium hydroxide when soil is subjected to hydraulic gradient (Brenner et al., 1981).

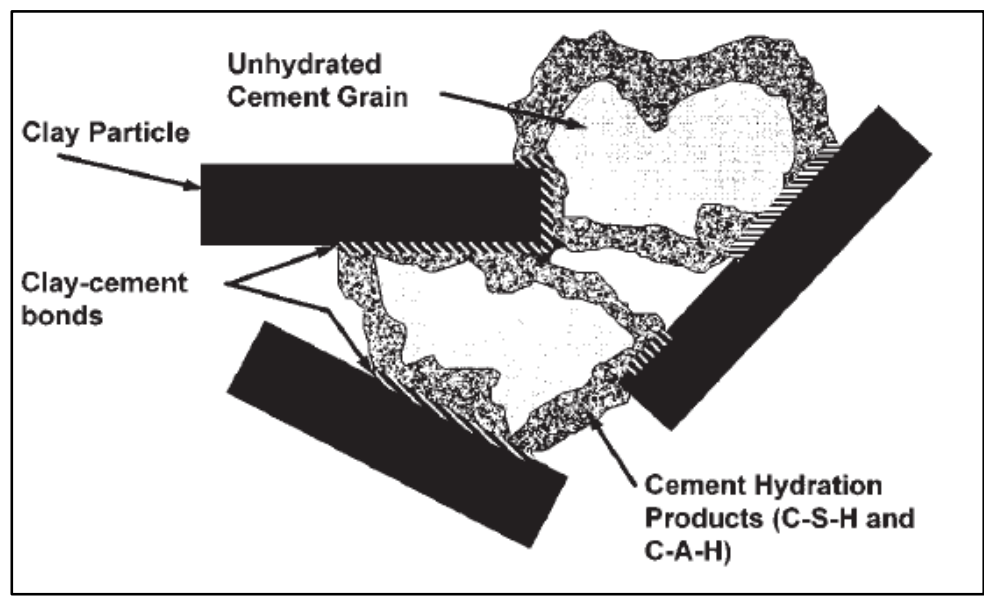

Figure 2-12: Process of cement hydration product in stabilizing clay particles (Brenner et al., 1981)

Pozzolanic reaction as presented in Figure 2-13 is a secondary process of cement-soil system stabilization. In a high-pH environment the reactivity and solubility of the silica and alumina from the clay particle is increased (Herzog and Mitchell, 1963). The calcium ions combine with the dissolved silica and alumina from the clay to from additional hydration products (C-S-H and C-AH) as shown in Equations 3 and 4. Diamond et al. (1964) have claimed that the hydration products are the result of direct precipitation of the reaction product between calcium hydroxide and the adjacent clay surfaces.

$$
\begin{array}{lr}
\mathrm{Ca}(\mathrm{OH})_{2}+\mathrm{SiO}_{2} \rightarrow \mathrm{C}-\mathrm{S}-\mathrm{H} & \text { Eq. 2-3 } \\
\mathrm{Ca}(\mathrm{OH})_{2}+\mathrm{Al}_{2} \mathrm{O}_{3} \rightarrow \mathrm{C}-\mathrm{A}-\mathrm{H} & \text { Eq. 2-4 }
\end{array}
$$


The pozzolanic reaction is slow and takes months and years under the condition that the stabilizer can maintain a high $\mathrm{pH}$ environment for a long period of time. The pozzolanic reaction product strengthen the soil by reducing the plasticity and changing the gradation. If leaching occurs in a reduced $\mathrm{pH}$ condition, the pozzolanic action will be disrupted and the soil can be brought back to its original state.

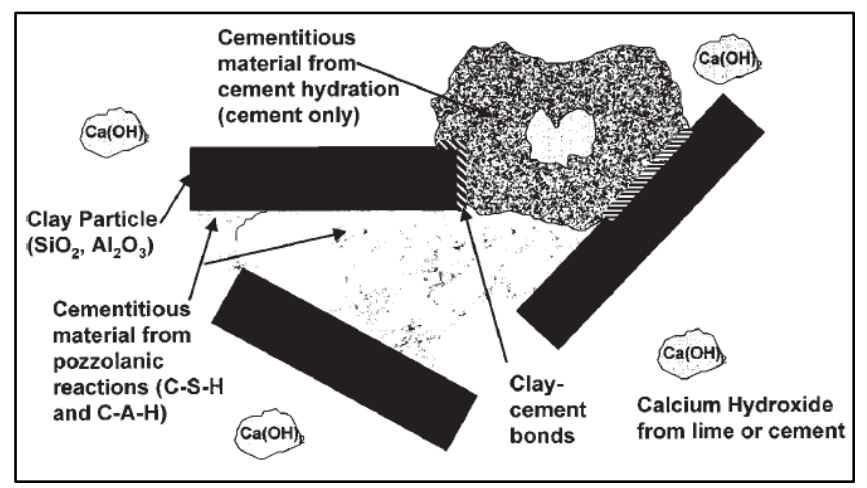

Figure 2-13: Pozzolanic reaction process (Brenner et al., 1981)

\subsection{STRENGTH AND COMPRESSIBILITY OF TREATED CHAMPLAIN SEA CLAY}

A laboratory study conducted by Li et al. (2016) showed that both cement and slag/cement can be used to effectively stabilize Champlain Sea clay samples form Kanata and Arnprior, Ontario. A dosage of $28 \%$ by weight of slag/cement was enough to increase the UCS of the treated clay by 40 times, as shown in Figure 2-14. They also found that mixing natural clay with $40 \%$ by weight of cement has increased the UCS by more than 50 times at the 28-day curing condition, as shown in Figure 2-15. Li (2017) conducted constant rate strain (CRS) tests to assess the compressibility of Kanata clay samples treated with $150 \mathrm{~kg} / \mathrm{m}^{3}$ of cement and cured for 7 days. It was concluded that compressibility in treated samples was significantly reduced. Preconsolidation pressure was increased from $160 \mathrm{kPa}$ to $650 \mathrm{kPa}$, and a decrease in the compression index from 0.67 to 0.11 was obtained due to soil mixing. 


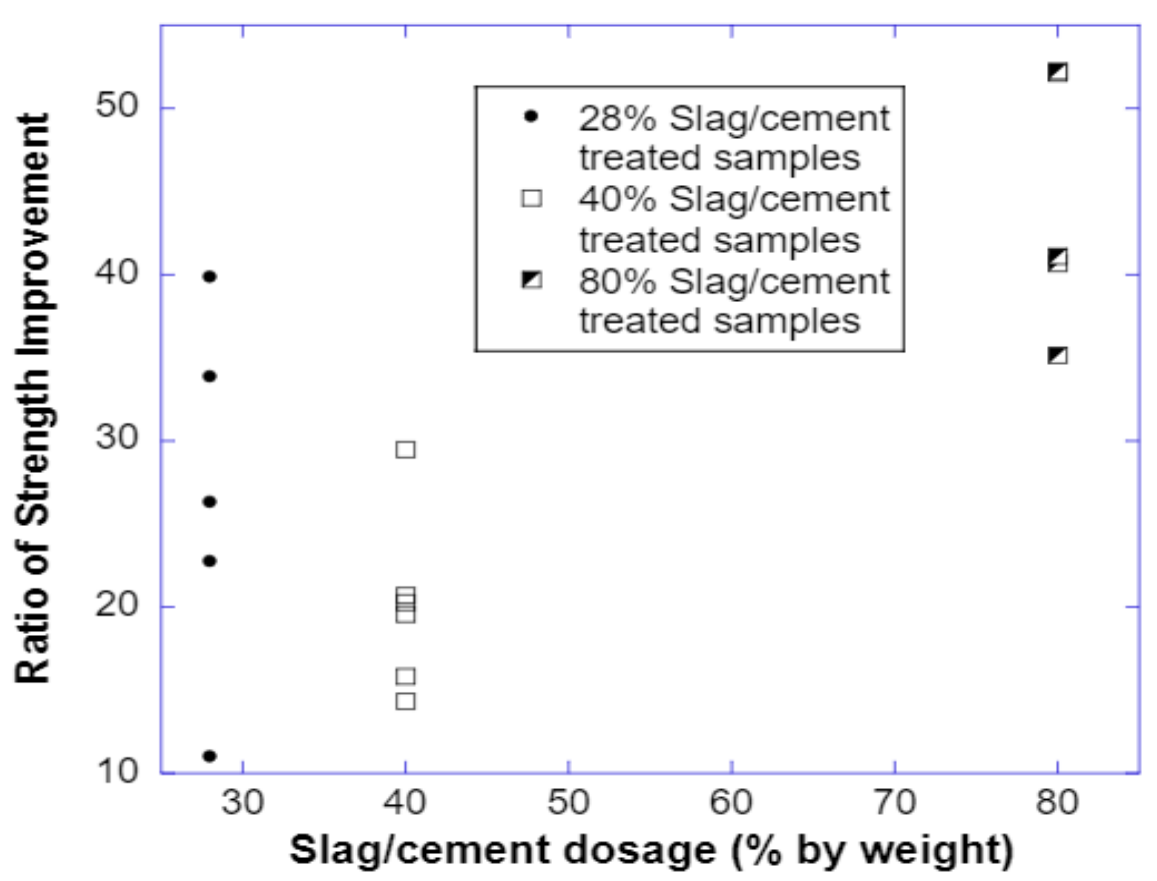

Figure 2-14: Improvement ratio vs. slag/cement dosage of treated Kanata clay (Li, 2017)

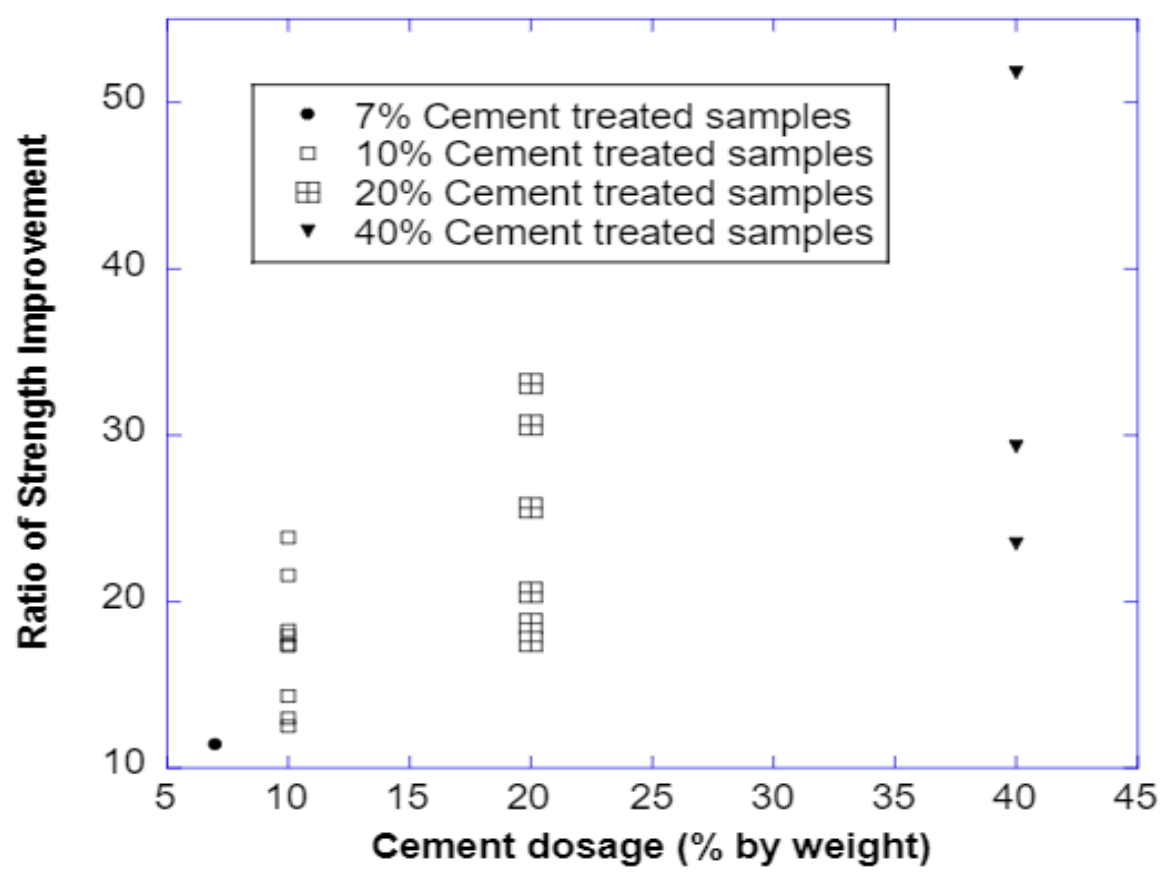

Figure 2-15: Improvement ratio vs. slag/cement dosage of treated Kanata clay (Li, 2017) 
In a laboratory investigation, Afroz et al. (2018) studied the effect of cement dosage and mixing method on Champlain Sea clay. They used wet and dry mixing method. A slurry with a water to cement ratio of $0.7: 1$ was prepared and mixed with the soil in the wet method. In the dry method, the powder cement was directly mixed with the soil. They concluded that the strength increased with cement dosage. They also concluded that samples treated using the dry method gained higher strength than those treated using wet method for the same dosage and curing conditions as shown in Figure 2-16. However, in the dry method the strength gain was not as consistent as in the wet method.

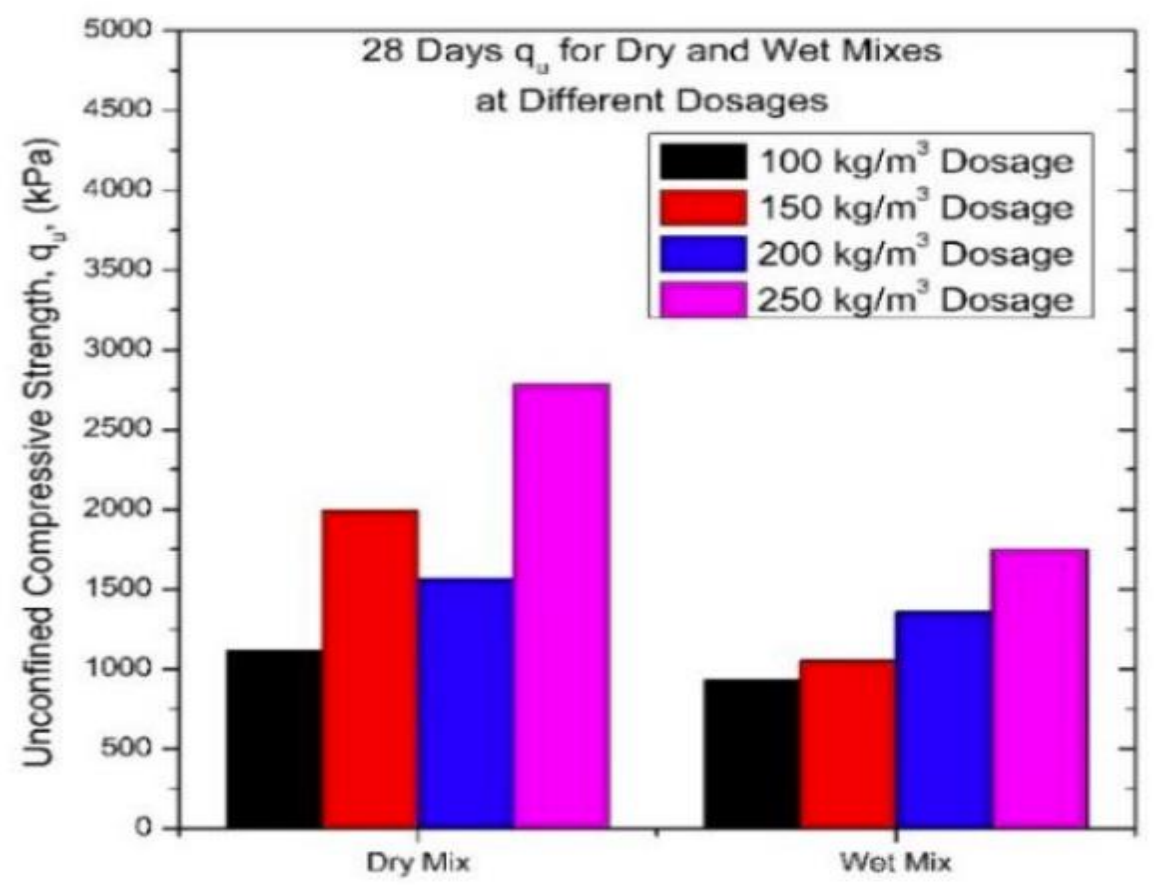

Figure 2-16: Impact of cement dosage and mixing method of cement-treated samples (Afroz et al., 2018)

In an experimental investigation, Liu et al. (2020) studied the effect of salinity level in the pore fluid on the geotechnical engineering properties of Champlin Sea clay. It was found that leaching causes significant property changes in Champlain Sea clay. The plasticity index was reduced by $14 \%$ to $31 \%$ while the liquidity index was reduced by $4 \%$ to $26 \%$. Leaching also resulted in an increase in the sensitivity. An increase in $\mathrm{pH}$ values was also observed in leached samples, as shown in Figure 2-17. In terms of strength change, a reduction of more than $45 \%$ was recorded in 
undrained shear strength, as shown in figure 2-18. A noticeable increase in compressibility was also observed as the preconsolidation pressure was reduced by about one-third due to leaching.

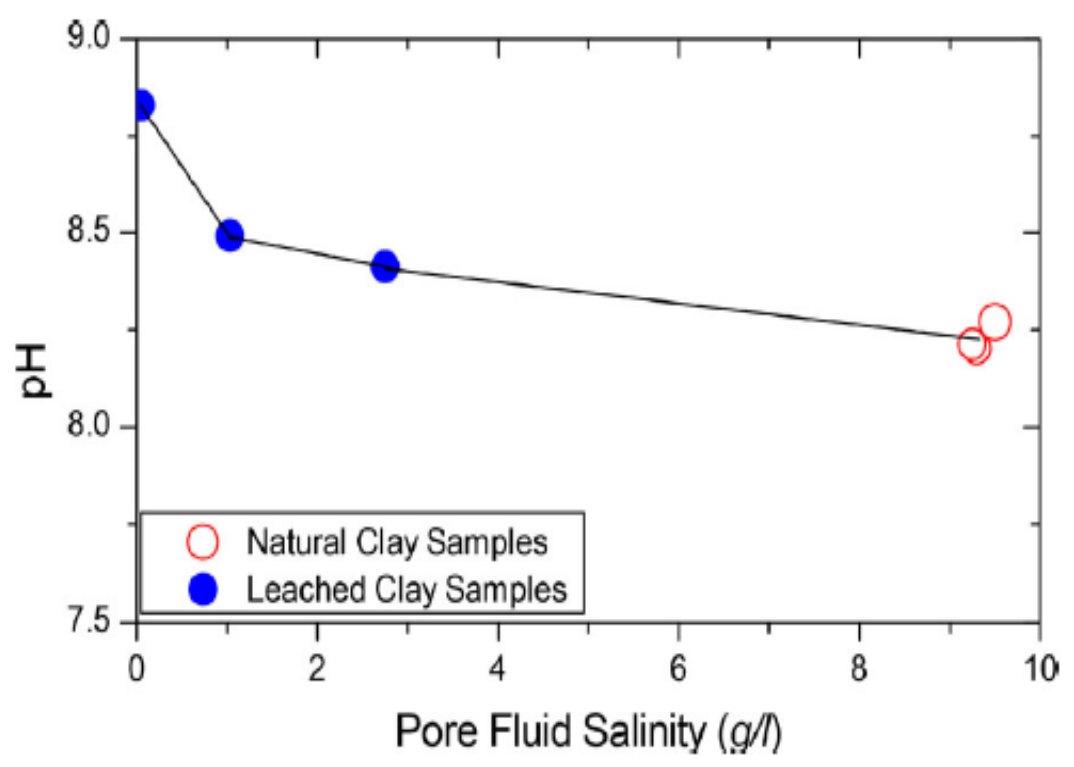

Figure 2-17: Effect of pore fluid salinity on pH values (Liu et al., 2020)

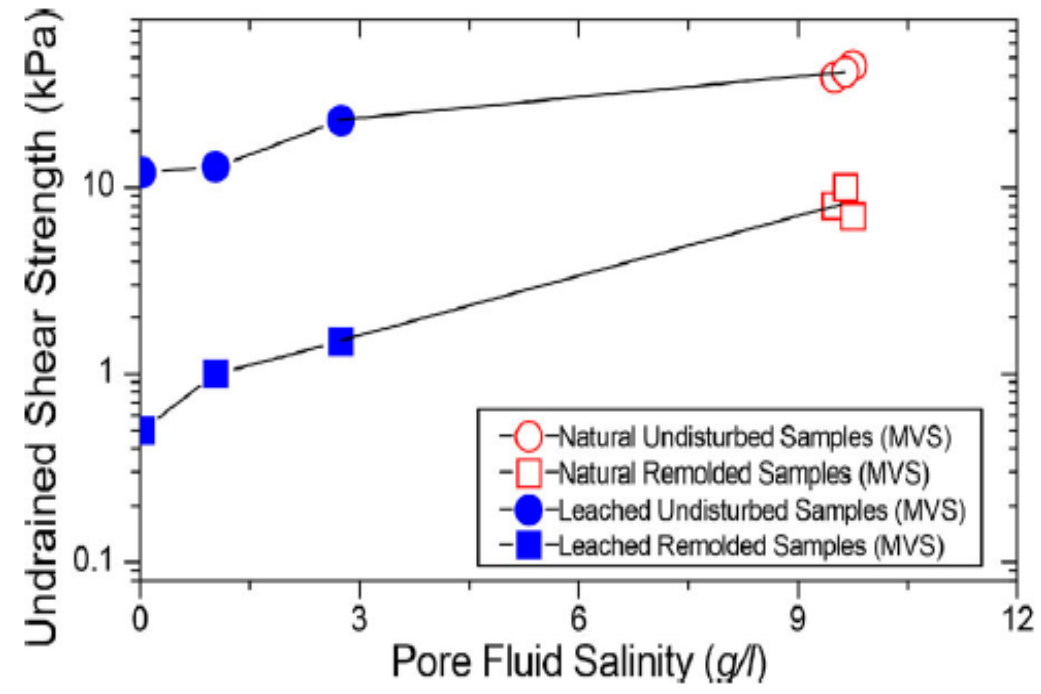

Figure 2-18 Effect of pore fluid salinity on undrained shear strength (Liu et al., 2020) 


\subsection{MICROSTRUCTURE OF CLAY AND SATBILIZED CLAY}

Stabilization and treatment of soft clayey soils using artificial cementation are becoming increasingly important in the field of geotechnical and environment engineering. The basic mechanisms of admixture stabilization were investigated by many highway engineers many years ago. Cementitious additives such as cement and lime are extensively used to solve problems of sub-base and sub-grade in roads and railways constructions. Deep soil mixed columns are used to replace piles for slope stabilization, trenches and deep excavations in soft ground (Bergado et al., 1996). Cementitious additives are also used to reinforce tailing dams' and mine wastes for underground disposal (Mackay and Emery, 1992). The main objective of artificial cementation is to increase the strength and stiffness of the soil by creating bonding between soil particles (Kitazume \& Terashi, 2013; Mary Ellen et al., 2013; Monsif et al., 2019)

Extensive laboratory tests on a variety of treated Japanese marine clay lead to strength gain of the order of $100 \mathrm{kPa}$ to $1 \mathrm{kPa}$ in terms of UCS (Okumura et al., 1974; Okumura and Terashi, 1975; Terashi et al., 1977, 1980). A study on marine clay from eastern Canada by Choquette et al. (1987) concluded that the addition of lime results in an immediate agglomeration of clay particles and a flocculated structure. They also suggested that the use of lime produces platy minerals, which

divides the inter-aggregate space into small micropores. They observed a correlation between the change of structure due to lime addition and the measured strength of the treated clay. Locat et al. (1996) studied the mechanical and hydraulic behaviour of lime-treated inorganic soft clay and suggested that if lime content is higher than $3 \%$, pozzolanic reactions produce cementitious material that fill the pores and reduce the hydraulic conductivity by one order of magnitude. Chew et al. (2004) and Kamruzzaman et al. (2009) investigated the development of microstructure in cement-treated Singapore marine clay by performing SEM and Mercury intrusion porosimetry (MIP) analyses and concluded an increase in the degree of flocculation at higher cement dosages.

Horpibulsuk et al., (2010) investigated the strength development in cement-stabilized silty clay from Thailand based on microstructural considerations using SEM, MIP, and thermal gravity analysis. Their study showed that there is an optimum water content at which the cement is 
effective in treating the soft clay. Figure 2-19 shows SEM photomicrograph of soil specimens treated with the same $10 \%$ cement at different water contents.

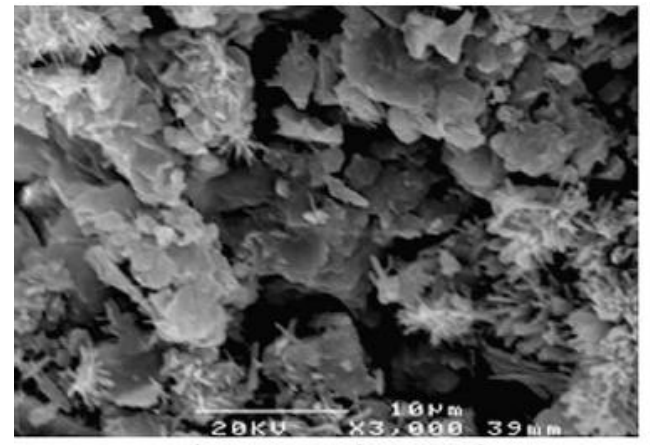

a) $w=14 \%(0.80 \mathrm{WC})$

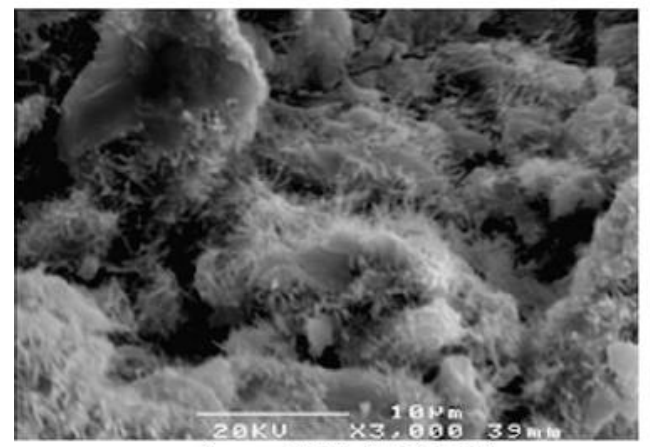

c) $w=20 \%(1.20 \mathrm{WC})$

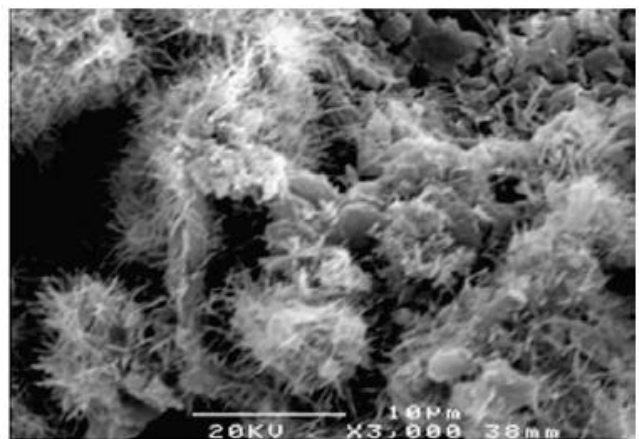

b) $w=17 \%(O W C)$

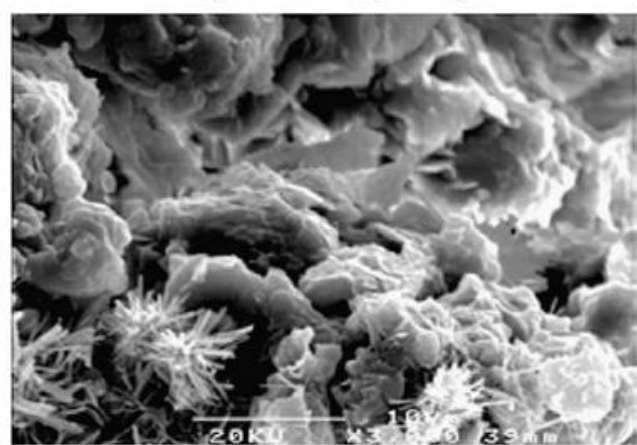

d) $w=24 \%(1.40 \mathrm{WC})$

Figure 2-19: SEM micrographs of the $10 \%$ cement samples compacted at different water contents after 7 days of curing (Horpibulsuk et al., 2010)

Du et al., (2014) conducted a microstructural analysis on a zinc-contaminated kaolin clay stabilized by cement. They used XRD, SEM, and MIP to investigate the changes in phases of major hydration products and microstructural characteristics of the stabilized soil. The study reveals the major hydration reaction products formed at low contamination. From the XRD analysis, these products were identified as $\mathrm{C}-\mathrm{S}-\mathrm{H}$, ettringite, and $\mathrm{C}-\mathrm{A}-\mathrm{H}$, as shown in Figure 2-20. SEM micrographs in Figure 2-21 show the major hydration products of kaolin clay stabilized by $12 \%$ cement cured for 28 days. From Figure 2-21a it can be observed that the morphology of C-S-H and ettringite is well developed leading to flocculation and a fine network of reticulation in the matrix of the stabilized samples. This flocculated fabric could be the result of cation exchange process, in which calcium ions are exchanged by potassium and sodium ions (Locat et al., 1996; Chew et al., 2004). 


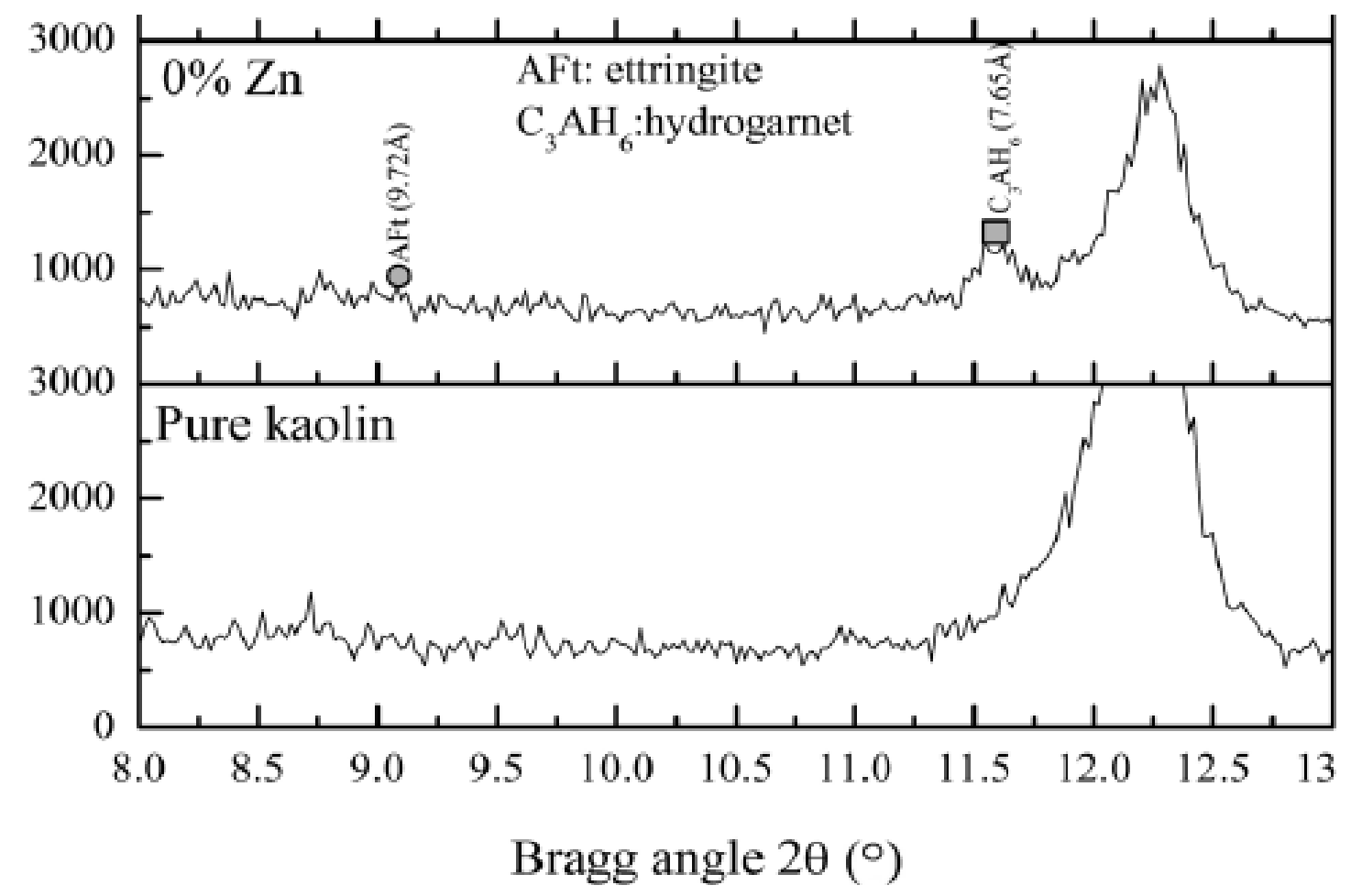

Figure 2-20: X-ray diffraction of kaolin clay stabilized by $12 \%$ cement (Du et al., 2014)

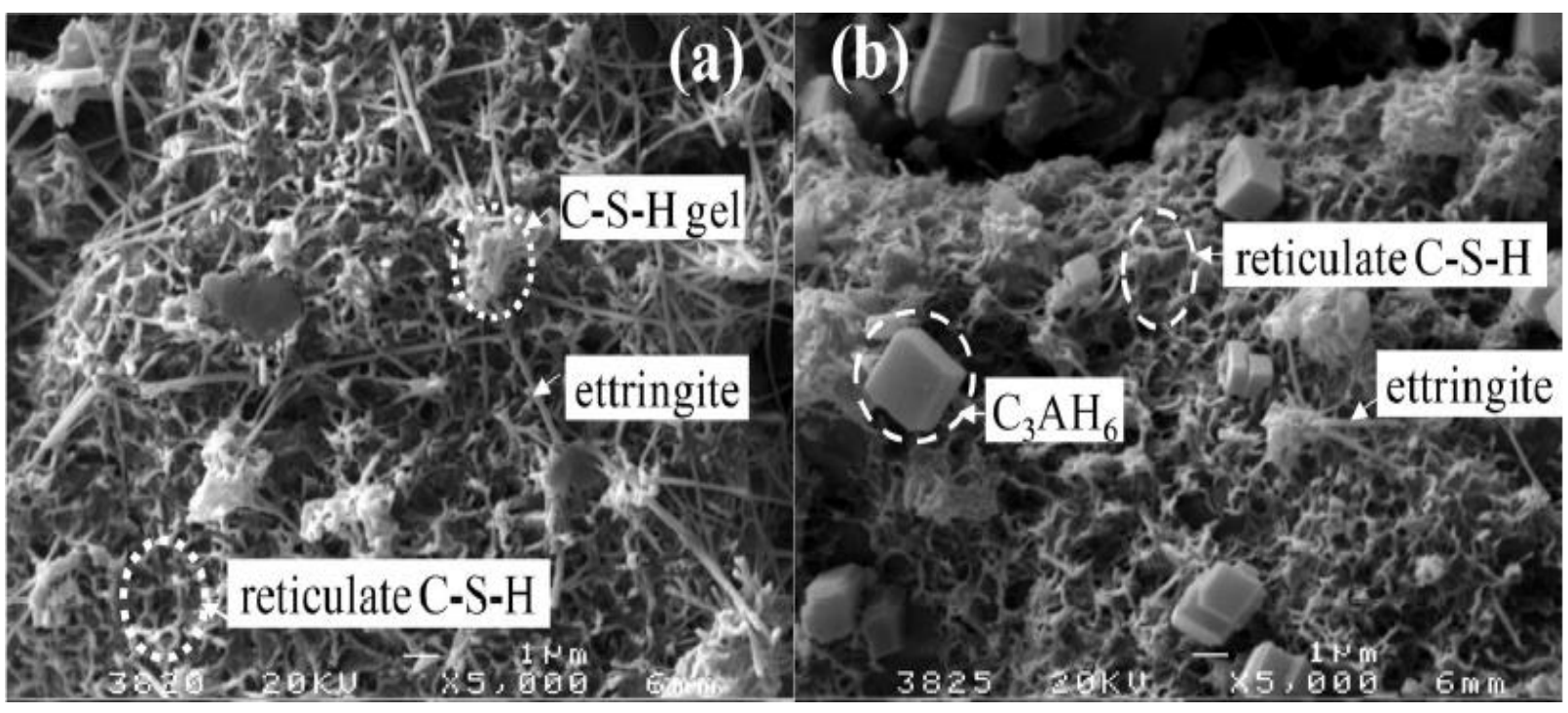

Figure 2-21: Major hydration products of kaolin clay stabilized by cement (Du et al., 2014) 
Sasanian (2011) studied the effect of cement dosage on microstructure changes of Ottawa clay. He concluded that adding cement has resulted in an agglomerated, open structure in the clay and some needle-like crystals (Ettringite) are formed throughout the surface, as shown in Figure 2-22. In samples treated with $3.1 \%$ of cement (Figure 2-22), the clay particles have formed aggregates that are coated with cementitious products. It can be seen that the new cementitious products have a "popcorn-like" morphology. In samples treated with $6.4 \%$ of cement (Figure 2-22 c and d), it can be observed the formation of highly flocculated structure and more ettringite crystals than in samples treated with $3.1 \%$. The ettringite crystals reach as long as $12 \mu \mathrm{m}$ in some places. Figure 2-22 c and d illustrate the two-phase microstructure of the cemented clay, one phase consists of clay aggregates bonded with each other by the charge forces and by the cementitious material, and the second phase is the porous matrix of cementitious material filling the gaps between the aggregates. The degree of flocculation in samples treated by $6.4 \%$ of cement is more compared to those treated by $3.1 \%$ due to the availability of more $\mathrm{Ca}^{2+}$ cations and the higher $\mathrm{pH}$ of the pore fluid.

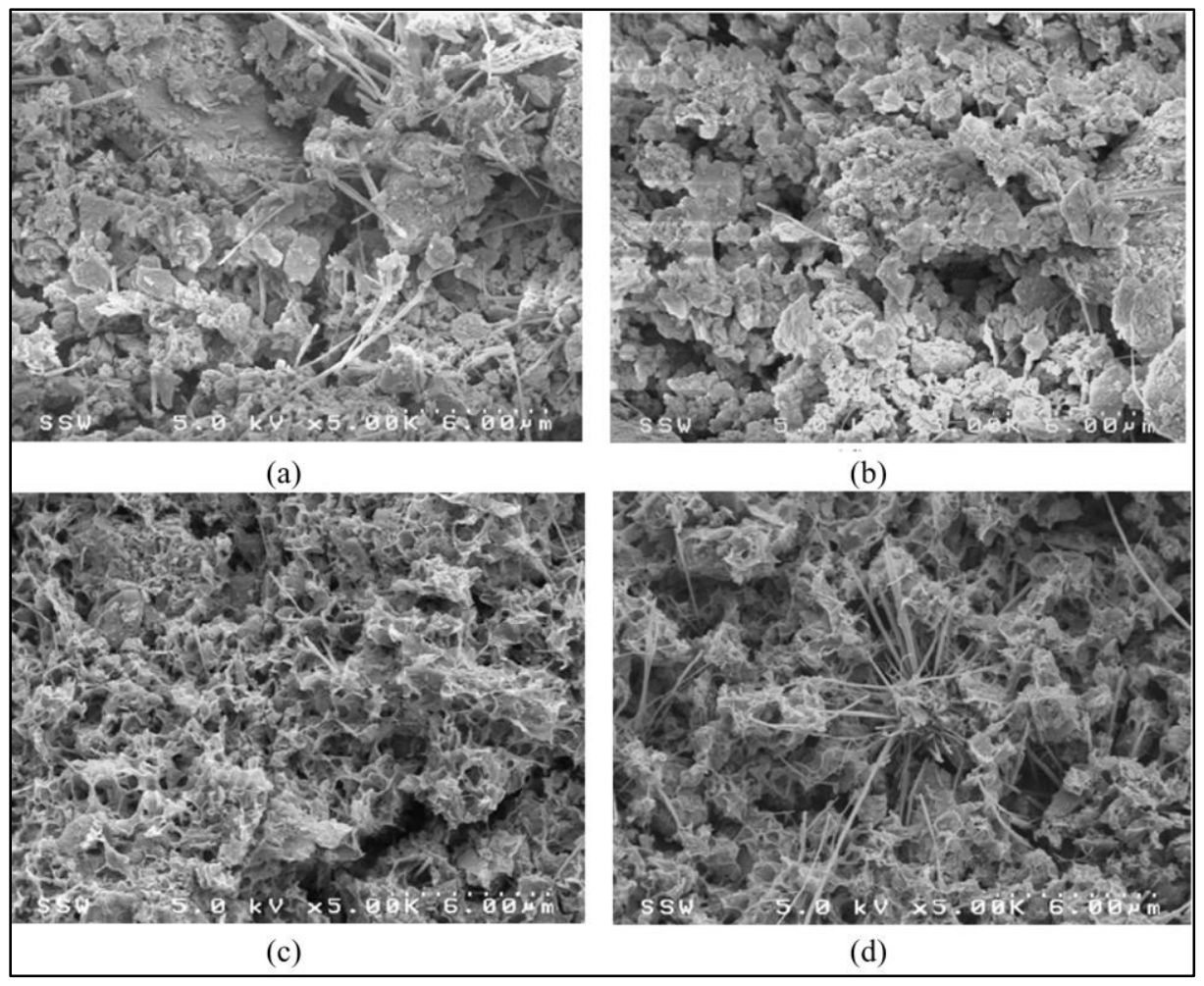

Figure 2-22: SEM micrographs of Ottawa clay treated with Portland cement $3.1 \%(a, b)$ and $6.4 \%(\mathrm{c}, \mathrm{d})$ (Sasanian, 2011) 
It is therefore important to study the relationship between the microstructural changes and bonding of the soil particles due to the introduction of cementitious material and investigate the relationship between the microstructural changes and mechanical behaviour of the material.

\subsection{SUMMARY}

This chapter introduced the mineralogical and chemical composition of Champlain Sea clay in eastern Canada. The environmental conditions at the time of Champlain Sea clay deposition and its relation to the sensitive behaviour of Champlain Sea clay were discussed. Next, the mechanisms of the abrupt loss of strength in the sensitive Champlain Sea clay were described. Furthermore, the microstructure of the untreated and cement-treated Champlain Sea clay and other sensitive clay was introduced. Finally, the four stabilization mechanisms that lead to clay stabilization were discussed in this chapter. 


\section{GEOTECHNICAL PROPERTIES OF CHAMPLAIN SEA CLAY AND EXPERIMENTAL PROGRAM DESIGN}

\subsection{INTRODUCTION}

This chapter is to introduce the physical and mineralogical properties of Champlain Sea clay used in this study. Laboratory tests are performed as part of the mix design process to verify the effect of different parameters in the strength development and the microstructural changes of the cement stabilized Champlain Sea clay.

\subsection{CLAY PHYSICAL AND MINERALOGICAL PROPERTIES}

The samples used in this study were retrieved from a dam site located near the locality of Arnprior, approximately $60 \mathrm{~km}$ West from Ottawa, Ontario. All tests in this study were conducted on samples from a depth between $20.25 \mathrm{~m}$ and $20.85 \mathrm{~m}$, see Appendix B for detailed borehole log at related depth. Intact samples were retrieved from the field using a Laval sampler from a 16-inch diameter steel cased pre-drilled borehole. The clay core was cut into a cylindrical blocks of 200 $\mathrm{mm}$ diameter by $220 \mathrm{~mm}$ in height. Final samples were quickly mounted on sealed plywood, wrapped in cellophane paper, and coated with paraffin wax to restrict air contact, remoulding, or natural water content alteration. Sealed samples were then packed with precaution in a custommade wooden box. Padding material was placed under the plywood and all around the sample to prevent them from being shocked or remoulded during transportation, as shown in Figure 3-1. The clay is visually homogenous, and its color varies from greenish grey to dark grey but mainly grey. Some fish shells were found embedded in the clay which confirms the marine environment of the clay at the time of its deposition.

Extensive laboratory tests were conducted to determine the physical properties of the foundation clays at different depths for evaluating the long-term performance of the dam (Liu et al., 2017). Individual tests were conducted for the specific depth for this study and the results were mostly within the range of Liu et al. (2017) investigations. 

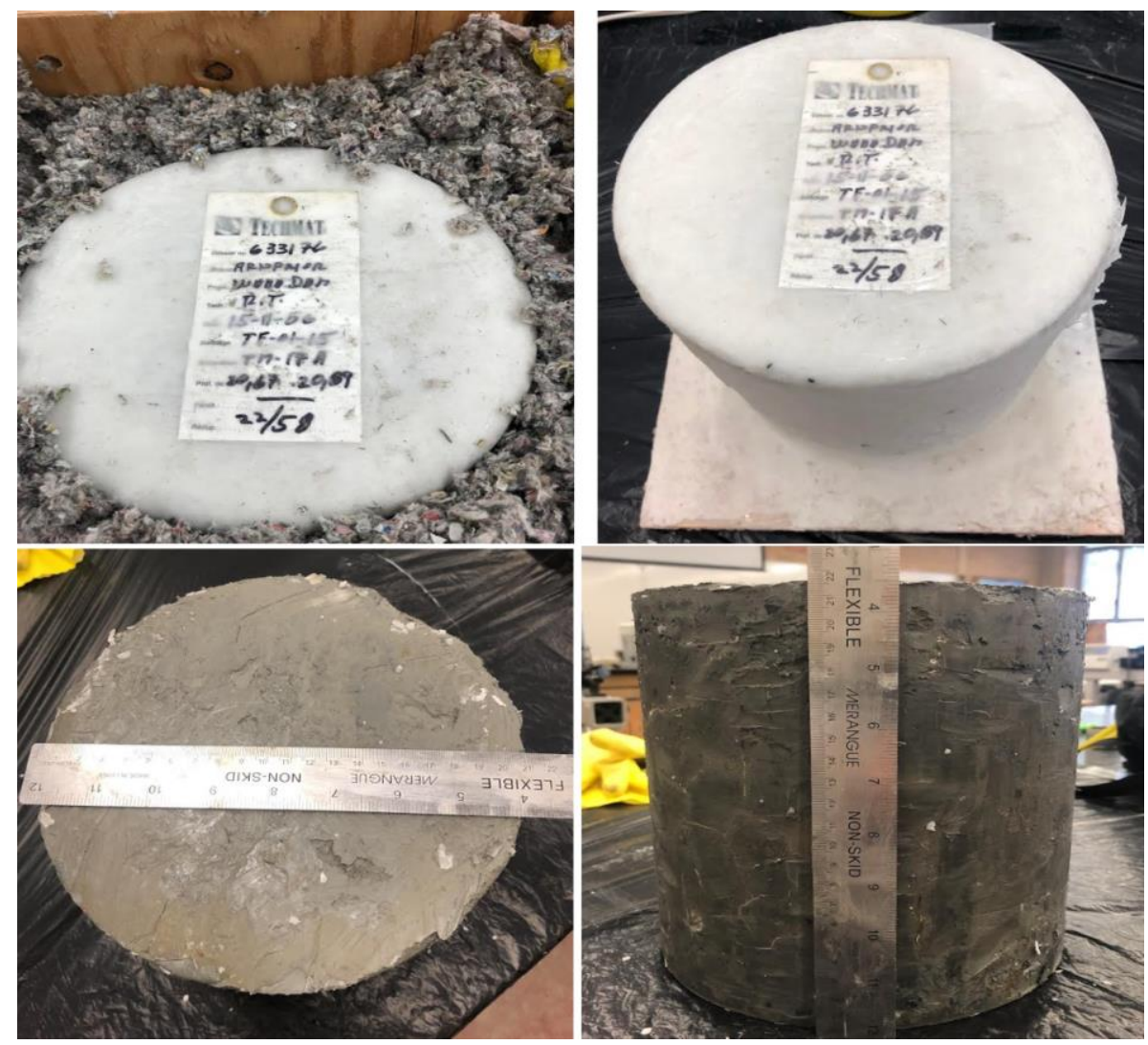

Figure 3-1: Laval clay samples collected from the dam site and used for this study

\subsubsection{Water content}

Water content tests were conducted according to ASTM D2216 standard. The water content of samples from the depth used in this study $(20.25 \mathrm{~m}$ to $20.85 \mathrm{~m}$ ) were measured to be between 76.2 $\%$ and $79.3 \%$. These values are within the range of the study conducted by Liu et al. (2017) as shown in Figure 3-2.

\subsubsection{Natural density}

Natural density was directly measured by determining the mass and volume of an undisturbed sample using a metal ring. Natural density is recorded to be between $1544 \mathrm{~kg} / \mathrm{m}^{3}$ and $1610 \mathrm{~kg} / \mathrm{m}^{3}$ which are similar to those reported by Liu et al. (2017) as shown in Figure 3-3. 


\subsubsection{Specific gravity}

The specific gravity of the clay was determined according to ASTM D854 standard. The average value was measured to be about 2.75 .

\subsubsection{Atterberg limits}

The liquid and plastic limits of the clay sample for this study were found to be $72 \%$ and $27 \%$ respectively. The results of the Atterberg limits tests of samples from different depths by Liu et al. (2017) were plotted along with those obtained previously in the 1987 investigations and in 2017 by Qualitas to produce the plasticity chart shown in Figure 3-4. Qualitas (2016) observed that the upper clay is a $\mathrm{CH}$ type whereas the lower clay is between CL and CH, Liu et al. (2017) did not show a clear correlation. However, the clay samples for this study are inarguably classified as type $\mathrm{CH}$ clay by all investigations.

\subsubsection{Grain size distribution}

The wet method was used to perform the grain size distribution of the clay because it was difficult to break the clay into small particles through mechanical grinding. Hydrometer tests for four samples at different depths were performed and the results are shown in Figure 3-5. 


\section{Water Content $(\%)$}

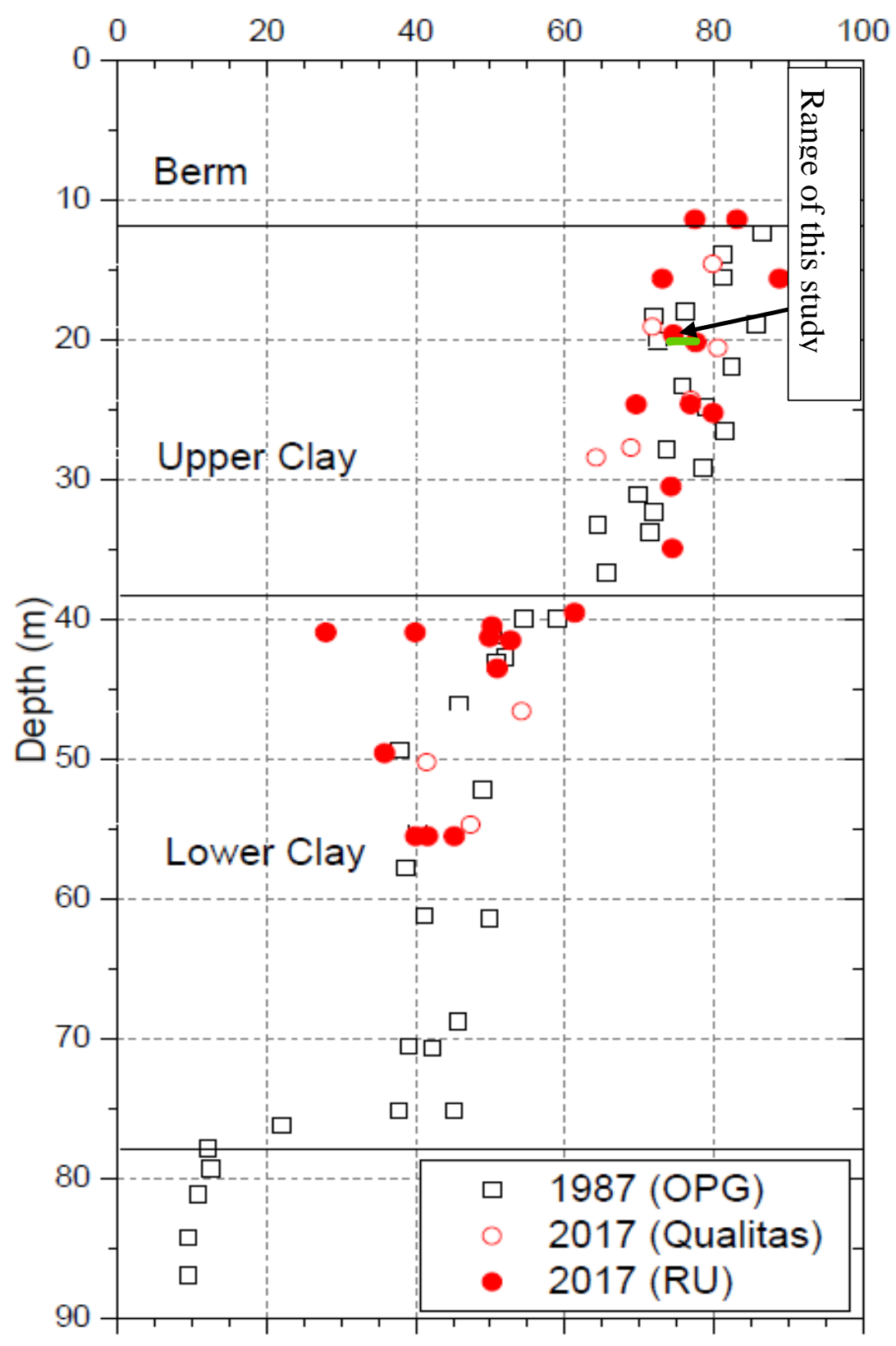

Figure 3-2: The distribution of water content vs. depth in the foundation clay (Liu et al., 2017) 


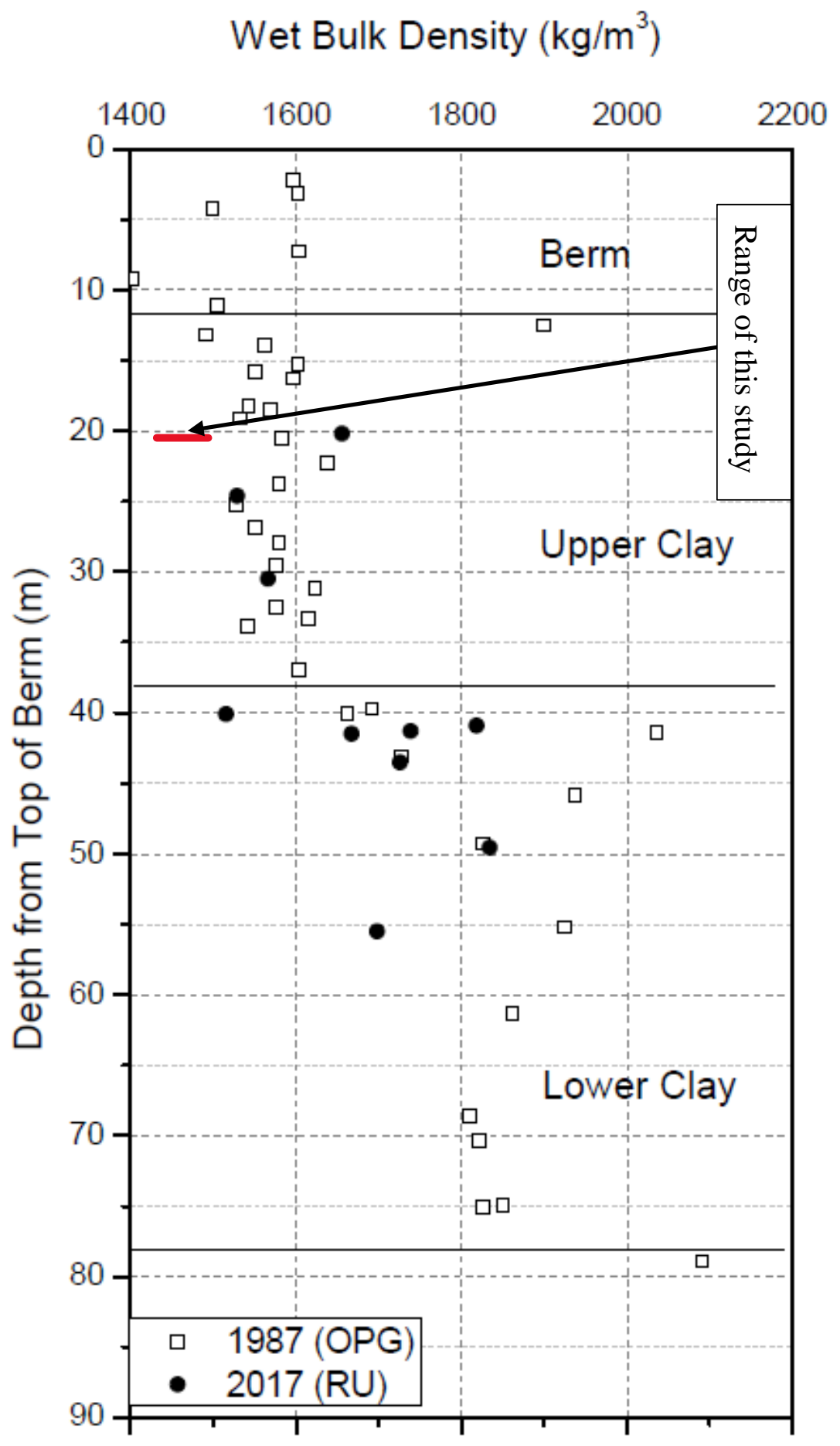

Figure 3-3: Bulk density vs. depth (Liu et al., 2017) 


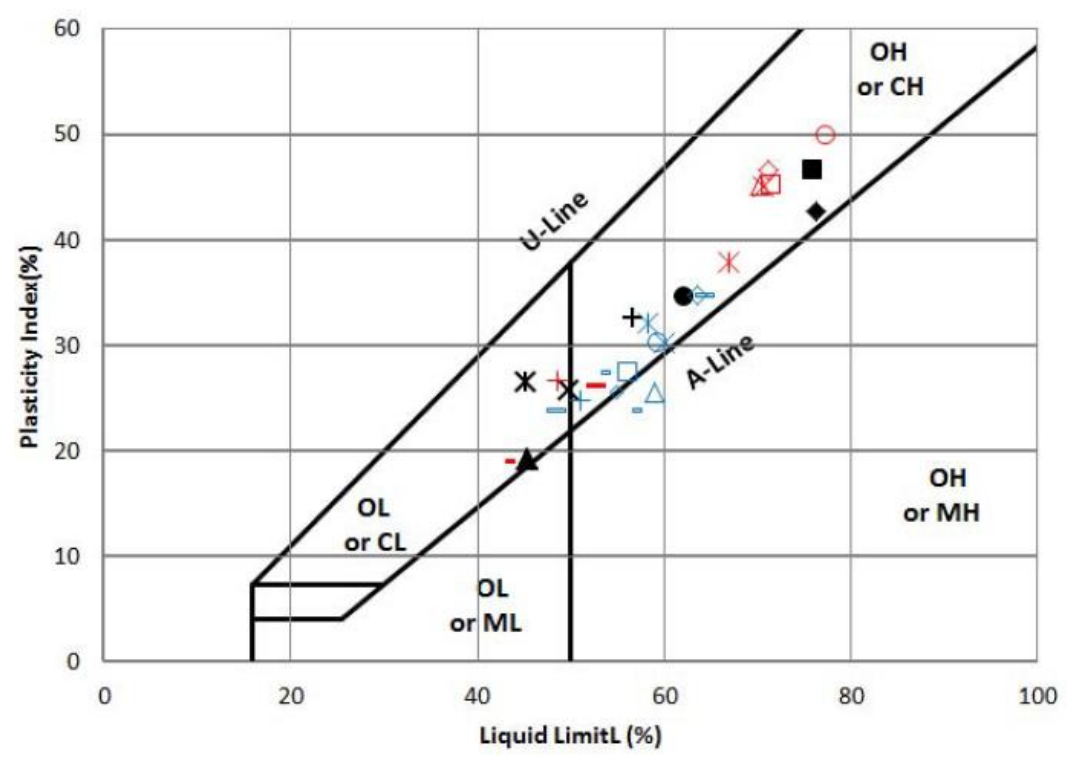

$\downarrow 24.6 \mathrm{~m}$

$\Delta 30.48 \mathrm{~m}$

$40.08 \mathrm{~m}$

- $41.28 \mathrm{~m}$

$\times 41.5 \mathrm{~m}$

X $49.55 \mathrm{~m}$

$+55.5 \mathrm{~m}$

$14.55 \mathrm{~m}$ (Qualitas)

$\triangle 19.06 \mathrm{~m}$ (Qualitas)

$\square 20.55 \mathrm{~m}$ (Qualitas)

24.3m (Qualitas)

$\times 27.7 \mathrm{~m}$ (Qualitas)

* 28.4m (Qualitas)

$+46.55 \mathrm{~m}$ (Qualitas)

- 50.2m (Qualitas)

- 54.68m (Qualitas)

-13.12m (1987)

- 14.13m (1987)

$\Delta 15.13 \mathrm{~m}(1987)$

$\square 16.67 \mathrm{~m}(1987)$

$\triangle 18.15 \mathrm{~m}$ (1987)

$\times 19.63 \mathrm{~m}(1987)$

*21.11m (1987)

$23.18 \mathrm{~m}$ (1987)

$+25.13 \mathrm{~m}$ (1987)

$=27.20 \mathrm{~m}(1987)$

- 29.15m (1987)

$\checkmark 31.22 \mathrm{~m}$ (1987)

Figure 3-4: Plasticity chart of samples at different depths (Liu et al., 2017)

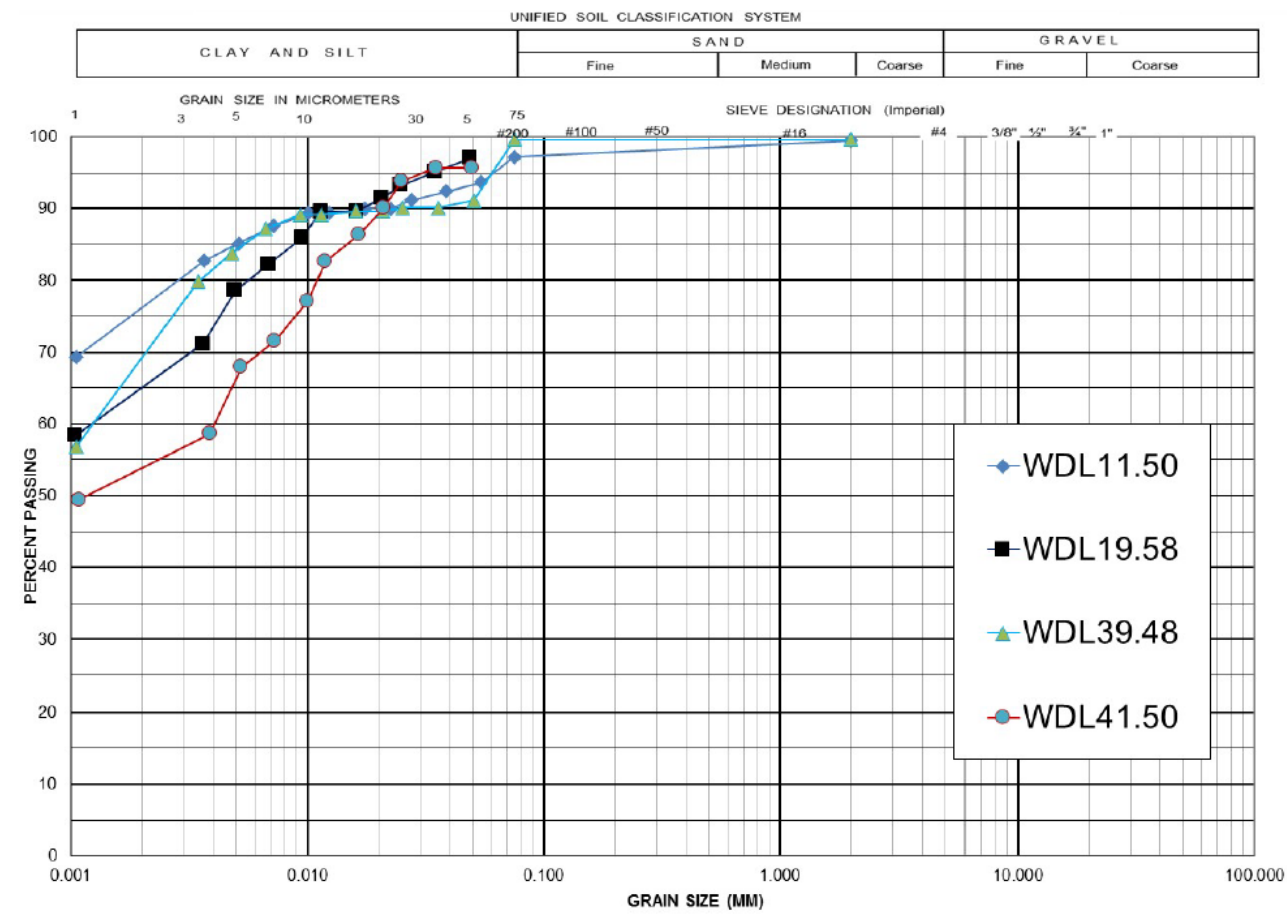

Figure 3-5: Grain size distribution curves of the clay samples (Liu et al., 2017) 


\subsubsection{Pore-fluid salinity}

The diluted fluid method was used in this study to measure the pore-fluid salinity of the clay. This method was thought to give higher values than the squeezed fluid method. For measuring the salinity level of the natural clay, a known mass of oven-dried clay block was dissolved into a known volume of distilled water, and the salinity reading was recorded using Horiba ES-5 portable salinity meter. For this study the salinity was recorded $15.53 \mathrm{~g} / \mathrm{L}$ of salt mass per pore water which is the equivalent of $11.05 \mathrm{~g} / \mathrm{kg}$ of salt mass per dry soil mass. Liu et al. (2107) have conducted many salinity tests of samples from different depths using both aforementioned methods and plot the results along with the results from previous investigations, as shown in Figure 3-6.

\subsubsection{Mineralogical compounds}

Three samples of the clay were dried and analyzed by AGAT Laboratories Ltd. (Qualitas 2016) for bulk and clay XRD mineralogy. The clay fraction was separated from the bulk sample using centrifugal method. The combined bulk and clay XRD results for the three samples are summarized in Table 3-1. The mineralogical composition of the samples consist mainly of illite clay $\left(59 \%\right.$ to $68 \%$ ) [potassium aluminium silicate hydroxide, $\mathrm{KAl}_{2}(\mathrm{OH})_{2}\left(\mathrm{AlSi}_{3}(\mathrm{O}, \mathrm{OH})_{10}\right)$ ], with ( $7 \%$ to $10 \%$ ) of quartz [silicon dioxide, $\mathrm{SiO}_{2}$ ], chlorite (5\% to $10 \%$ ) [iron magnesium aluminium silicate, $\left.(\mathrm{Mg}, \mathrm{Fe})_{5} \mathrm{Al}\left(\mathrm{AlSi}_{3}\right) \mathrm{O}_{10}(\mathrm{OH})_{9}\right]$, plagioclase feldspar (7 \% to $8 \%$ ) [ calcium sodium aluminium silicate, $(\mathrm{Ca}, \mathrm{NA})(\mathrm{Si}, \mathrm{Al})_{4} \mathrm{O}_{8}$ ], kaolinite $(3 \%$ to $6 \%$ ) [ aluminium silicate hydroxide, $\left.\mathrm{Al}_{4} \mathrm{Si}_{4} \mathrm{O}_{10}(\mathrm{OH})_{8}\right)$ ], horenblende (4 \% to $5 \%$ ) [sodium, potassium, calcium, magnesium, iron, aluminium silicate, $\left.(\mathrm{Na}, \mathrm{K})_{10} \mathrm{Ca}_{2}\left(\mathrm{MG}, \mathrm{Fe}^{2+}, \mathrm{Fe}^{3+}, \mathrm{Al}\right)_{5}\left[\mathrm{Si}_{6-7} \mathrm{Al}_{2-1} \mathrm{O}_{22}\right](\mathrm{OH}, \mathrm{F})_{2}\right]$, potassium feldspar $(3 \%)$ [ potassium aluminium silicate, $\mathrm{K}\left(\mathrm{SiAl}_{3} \mathrm{O}_{8}\right)$ ], and pyrite $(2 \%)$ [ iron sulfide, $\mathrm{FeS}_{2}$ ].

The clay fractions in the three samples were $50.15 \%, 50 \%$ and $57.54 \%$. The XRD analysis shows that the clay fraction consists mainly of illite (77\% $87 \%$ ), with minor amounts of chlorite (5\% to $10 \%$ ), kaolinite (3\% to $6 \%$ ), hornblende (2\%), quartz (1\% to $2 \%$ ) and potassium (1\% to $2 \%$ ) and plagioclase (1\% to $2 \%$ ) feldspar, as shown in Table 3-1. 


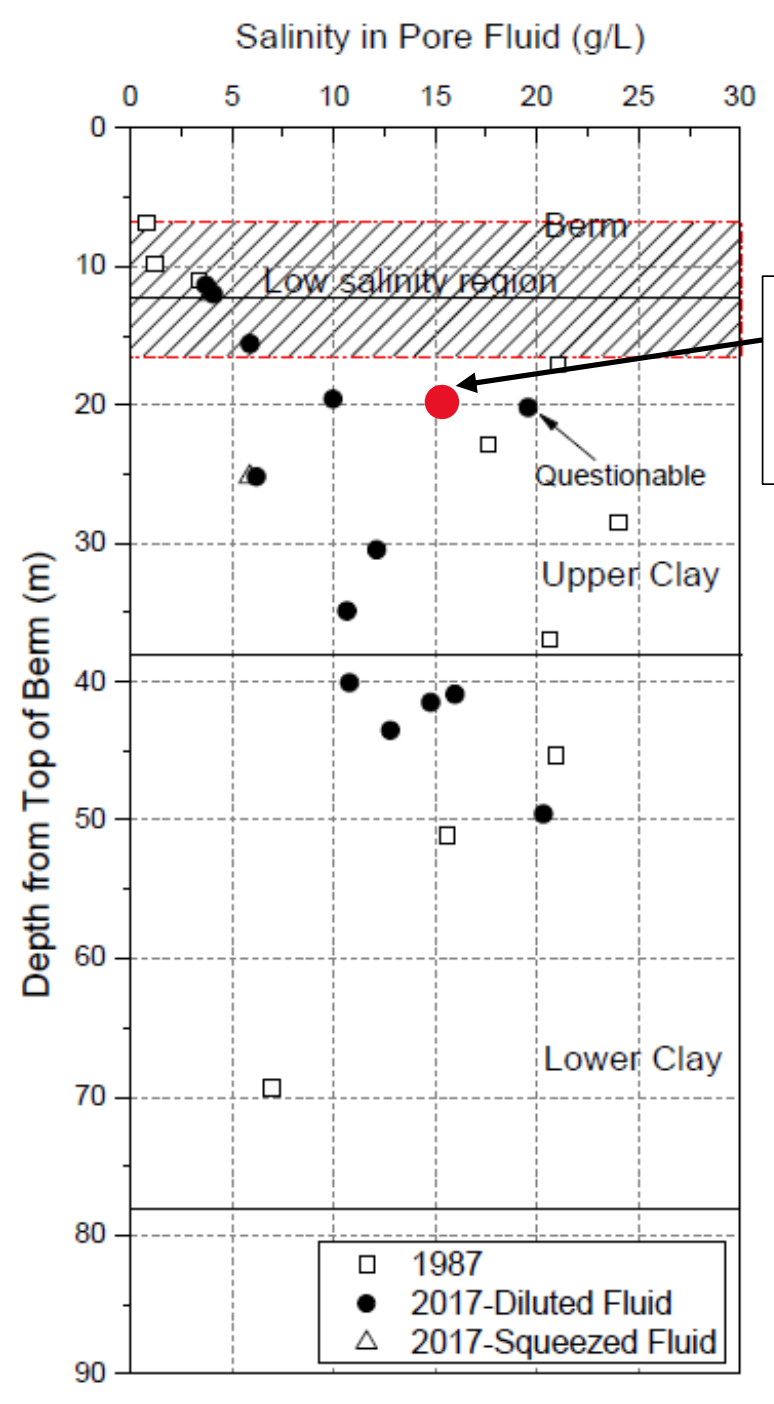

Salinity in Dry Soil $(\mathrm{g} / \mathrm{kg})$

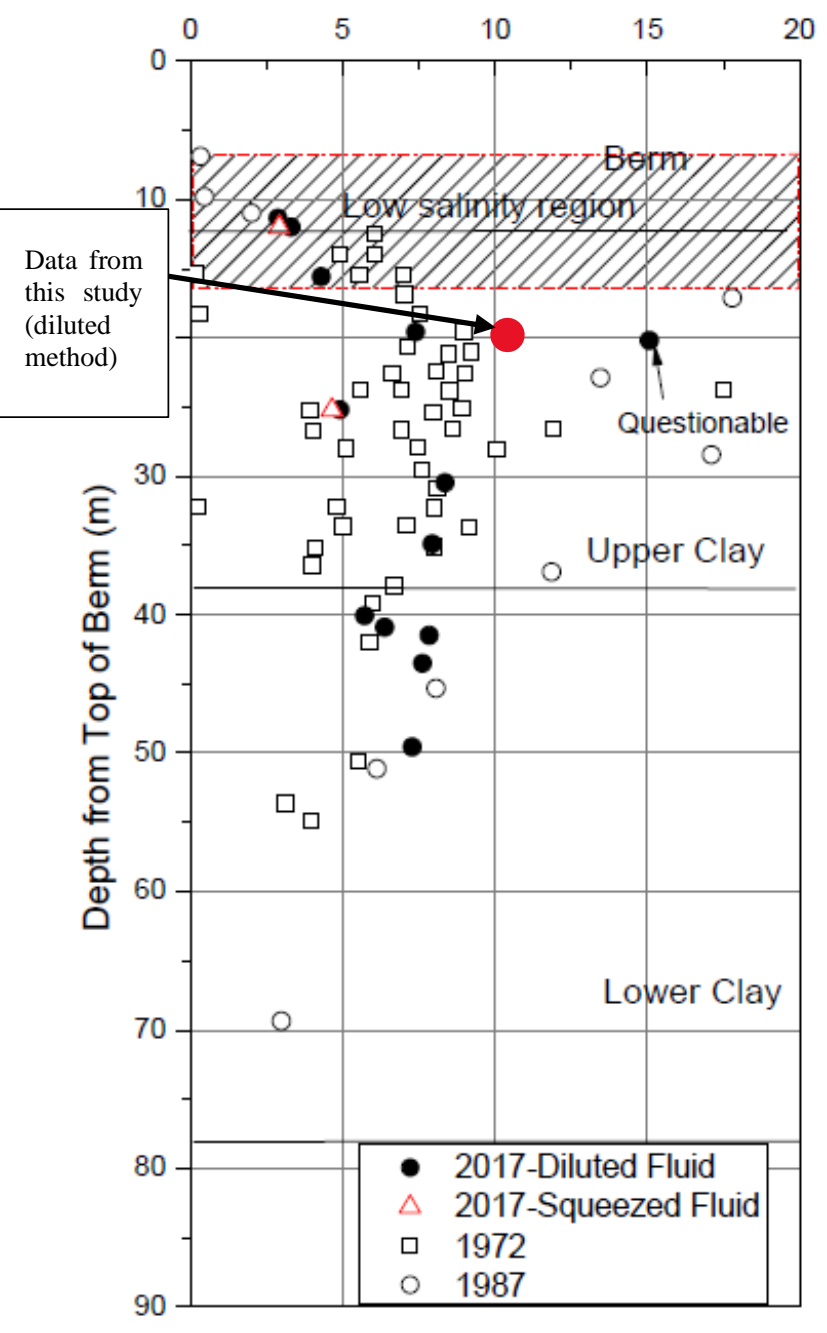

Figure 3-6: Salinity level in the pore fluid of foundation clay (Liu et al., 2017) 
Table 3-1: XRD analysis of Champlain Sea clay (Qualitas, 2016)

\begin{tabular}{|c|c|c|c|c|c|c|c|c|c|c|c|c|c|c|c|c|c|c|}
\hline SAMPLE & TYPE & WEIGHT & & & & & & & & & & & $\leftarrow$ & & CLAYS & - & $\longrightarrow$ & Total \\
\hline ID. & OF ANALYSIS & $\%$ & Qtz & Plag & K-Feld & Cal & Dol & Anhy & Pyr & Musc & Horn & Sider & Kaol & $\mathrm{Chl}$ & III & $\mathrm{ML}$ & Smec & Clay \\
\hline TM-13B & BULK FRACTION: & 49.85 & 12 & 14 & 7 & 0 & 0 & 0 & 3 & 0 & 8 & 0 & 3 & 5 & 48 & 0 & 0 & 56 \\
\hline 1 & CLAY FRACTION: & 50.15 & 1 & 1 & 0 & 0 & 0 & 0 & 1 & 0 & 2 & 0 & 3 & 5 & 87 & 0 & 0 & 95 \\
\hline $18.49-18.71 \mathrm{~m}$ & BULK \& CLAY & 100 & 7 & 7 & 3 & 0 & 0 & 0 & 2 & 0 & 5 & 0 & 3 & 5 & 68 & 0 & 0 & 76 \\
\hline TM-23A & BULK FRACTION: & 50.00 & 20 & 13 & 5 & 0 & 0 & 0 & 4 & 0 & 7 & 0 & 3 & 10 & 38 & 0 & 0 & 51 \\
\hline 2 & CLAY FRACTION: & 50.00 & 1 & 1 & 1 & 0 & 0 & 0 & 0 & 0 & 2 & 0 & 5 & 10 & 80 & 0 & 0 & 95 \\
\hline $24.27-24.49 \mathrm{~m}$ & BULK \& CLAY & 100 & 10 & 7 & 3 & 0 & 0 & 0 & 2 & 0 & 5 & 0 & 4 & 10 & 59 & 0 & 0 & 73 \\
\hline TM-42B & BULK FRACTION: & 42.46 & 16 & 15 & 5 & 0 & 0 & 0 & 4 & 0 & 7 & 0 & 6 & 6 & 41 & 0 & 0 & 53 \\
\hline 3 & CLAY FRACTION: & 57.54 & 2 & 2 & 1 & 0 & 0 & 0 & 1 & 0 & 2 & 0 & 6 & 10 & 77 & 0 & 0 & 93 \\
\hline $35.99-36.21 \mathrm{~m}$ & BULK \& CLAY & 100 & 8 & 8 & 3 & 0 & 0 & 0 & 2 & 0 & 4 & 0 & 6 & 8 & 61 & 0 & 0 & 75 \\
\hline
\end{tabular}

\subsection{SCANNING ELECTRON MICROSCOPY}

\subsubsection{Fundamental principals of scanning electron microscopy}

Researchers have been using Scanning Electron Microscopy (SEM) to investigate the microstructure and composition of exposed surfaces of clay and stabilized clay. SEM is a technique that makes use of the interactions between a focused electron beam and the atoms of the analyzed sample to generate image with ultra-high magnification and resolution that can reach the atomic level. The basic components of a SEM machine are electron gun, lenses, electron detectors, and vacuum chamber as shown in Figure 3-7. A beam of electrons with high energy (0.1-30 keV) is emitted by an electron gun, and the lenses focus the beam onto the specimen as a spot with a size on the order of $10 \mathrm{~nm}$. The interaction between the electron beam and the specimen surface produces electron and X-ray emissions. Emitted electrons are collected by a number of detectors to produce images of the sample surface. Most of SEM machines are equipped with X-ray detectors that allow the collection and analysis of X-rays emitted from the elements present in the sample. $\mathrm{X}$-rays are characteristic of the elements from which they are emitted and provide qualitative and quantitative measurements of the elements. The wide use of SEM stems from the relatively easy sample preparation, high resolution, and non- destructive nature of the technique. 


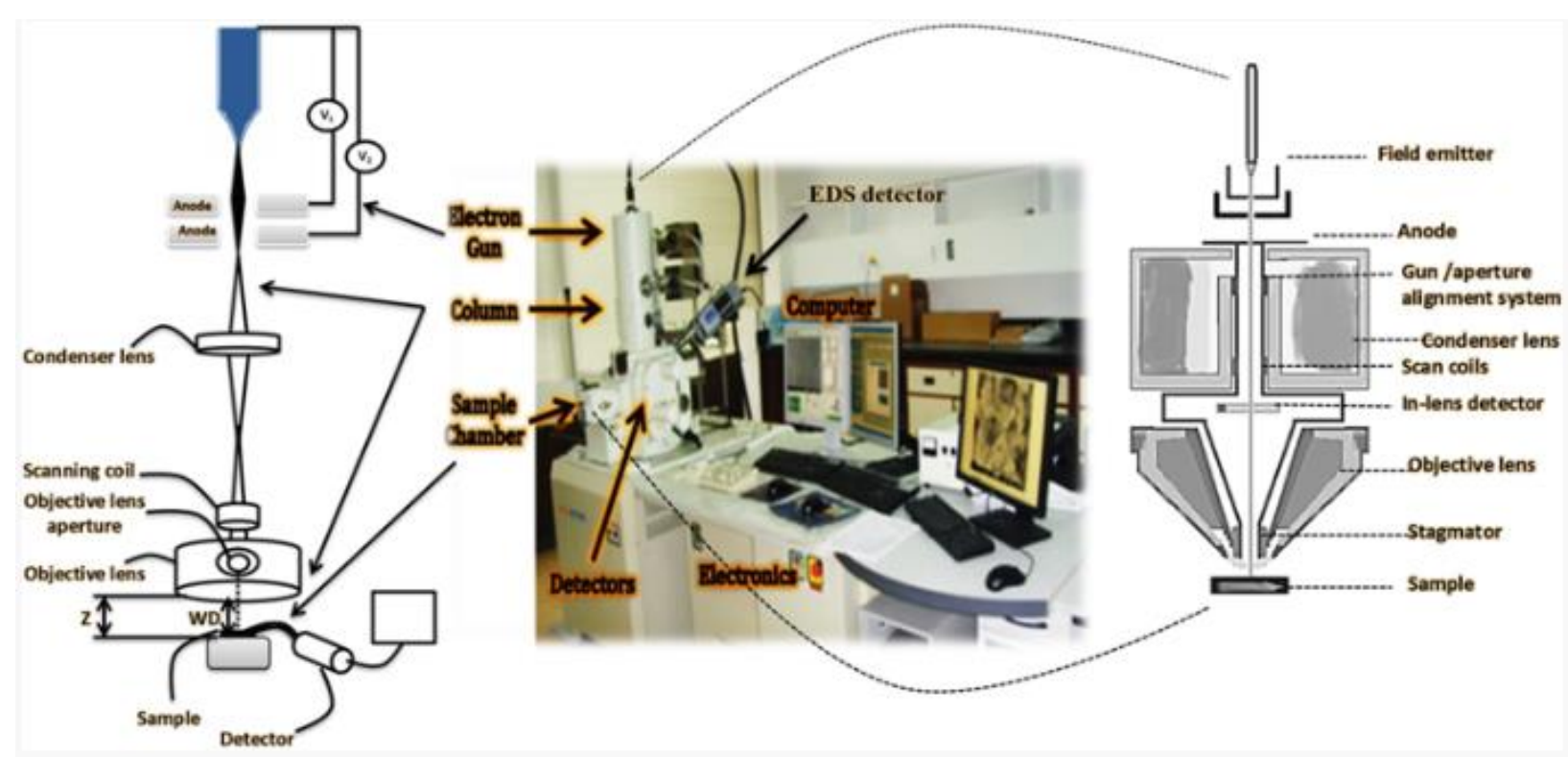

Figure 3-7: Schematics of a SEM machine (Akhtar et al., 2018)

When the beam of electrons hits the sample surface, it excites radiations that depend on the morphology and the composition of the sample. When analyzing the outcoming signals, different results can be obtained. In desktop instruments, three kinds of signals are normally detected: secondary electrons (SE), backscattered electrons (BSE), and X-ray radiation (Reed, 2005).

The Secondary electrons are produced from the emitted weakly bound valence electrons of atoms in the specimen. These scattered electrons are referred as inelastic scattering because of the energy dissipation through interactions with bound electrons. Reed (2005) concluded that the secondary electrons have energy less than $50 \mathrm{eV}$. Because of their low energy, only the secondary electrons produced within a few nanometers of the surface can leave, whereas the secondary electrons generated at a deep level are absorbed by the sample. Therefore, only information about the topography of the sample are collected by the secondary electrons.

Electrons reflected due to interactions between incident beam and atoms from the sample are called the backscattered electrons. These interactions are referred to as elastic scattering because the total kinetic energy of the collision of electrons is conserved. Backscattered electrons have energy greater than $50 \mathrm{eV}$ (Reed, 2005). Backscattered electrons reflected through an angle greater than 
$90^{\circ}$ represent the backscattering coefficient. This coefficient is increasing with atomic number $\mathrm{Z}$. Consequently, backscattered electrons provide composition information of the sample.

$\mathrm{X}$-ray emissions are the results of the interactions between the incident beam of electrons and the sample, they characterize the elements from which they are emitted. X-ray emissions are produced when electrons transit between the bound orbits designated by $K(n=1), L(n=2)$, and $M(n=3)$, where the $\mathrm{n}$ is the quantum number. The incident beam energy must exceed, by at least twice, the electron binding energy for an X-ray to be produced (Goldstein, et al., 2018). The difference between the initial and final energy in the transition process is equal to the $\mathrm{X}$-ray energy. Because each element has a unique energy difference between outer and inner shells, the X-rays that are detected by an Energy Dispersive Spectrometer (EDS) yield an elemental identification. Most of modern SEM machines are equipped with such a detector. EDS data can be obtained at a point, along with a line, or mapped over an area.

\subsubsection{Imaging parameters}

A JEOL JSM-6380 LV SEM was used in this study. Image quality is very important to the information that can be obtained from SEM micrographs. Signal to noise ratio and resolution are the two parameters that control the image quality. Signal to noise ratio depends on the beam current and scan speed, while resolution is a function of the accelerating voltage and working distance. The beam current choice should provide a good balance between the generated signal and sample charging. The term charging is the accumulation of static electric charges from the electrons on the surface of nonconductive material such as clay. The beam current can be controlled by the aperture size which can be achieved by adjusting the condenser and objective lenses. Scan speed is a critical parameter in controlling the noise level in SEM images. Image quality can be improved by using a slow scan speed to reduce the noise level. However, a very slow scan speed can be detrimental to the image quality if there is charging. A good balance between the scan speed and the noise level is thus important to the quality of SEM images of non-conductive samples. In this study, both the beam current and the scan speed were adjusted to get the best possible SEM image quality of Champlain Sea clay samples.

Resolution of SEM images depends on two parameters: accelerating voltage and working distance. Accelerating voltage is the critical parameter for providing a good resolution of SEM images. The 
image resolution increases with an increasing acceleration voltage. The higher the voltage, the deeper the electrons will reach, which results in a good electron yield from a deeper part of the specimen. The increase in electron yield will reduce the edge effect and improve the surface details. However, a low accelerating voltage reduces the charging effect and provides sharp surface details. For EDS analysis, the acceleration voltage must be high enough to provide the critical excitation energy of elements in the sample to excite the characteristic X-rays of the elements. Reed (2005) recommended an acceleration voltage of about two times the critical excitation energy. Depending on the sample conditions during imaging, we found that an accelerating voltage of 5-15 keV provides images with good quality and critical excitation energy for elements of interest. Working distance is the second parameter that affects the SEM images resolution. Working distance is the distance between the specimen and the final condenser lens. The resolution of SEM images increases with decreasing working distance. In this study, a working distance between 7 - $9 \mathrm{~mm}$ was used to provide a good resolution and contrast in the SEM images.

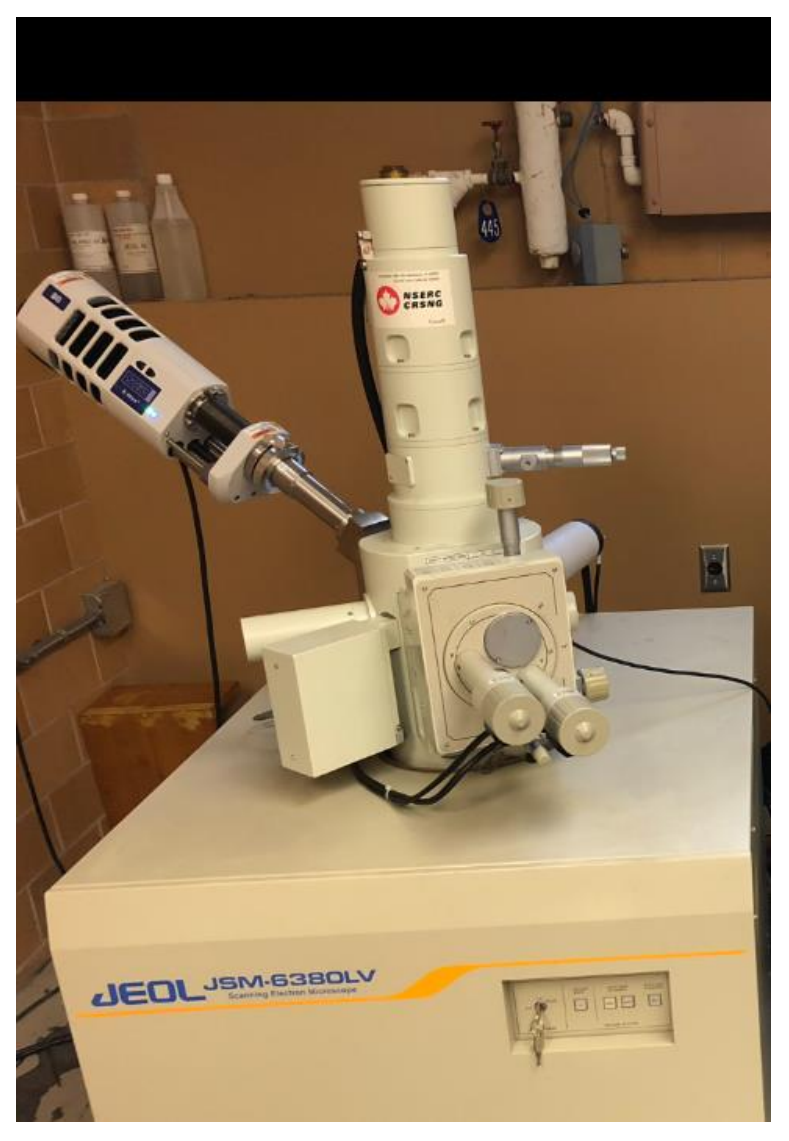

Figure 3-8: Scanning electron microscope machine used for this study 


\subsection{X-RAY DIFFRACTION}

\subsubsection{Fundamental principles of XRD}

The basic components of an X-ray diffractometer include a source of monochromatic radiation and an X-ray detector along a graduated circle centered on the specimen. Divergent slits placed between the X-ray source and the specimen, and divergent slits, placed between the specimen and the detector, eliminate non-diffracted radiation, reduce the background noise, and collimate the radiation. The detector and the specimen holder are mounted so that the detector rotates through $2 \theta$ degrees occurs when the specimen rotates through $\theta$ degrees, as shown in Figure 3-9. The counter records the number of X-rays observed at each angle $2 \theta$ and the X-ray intensity is usually recorded as "counts".

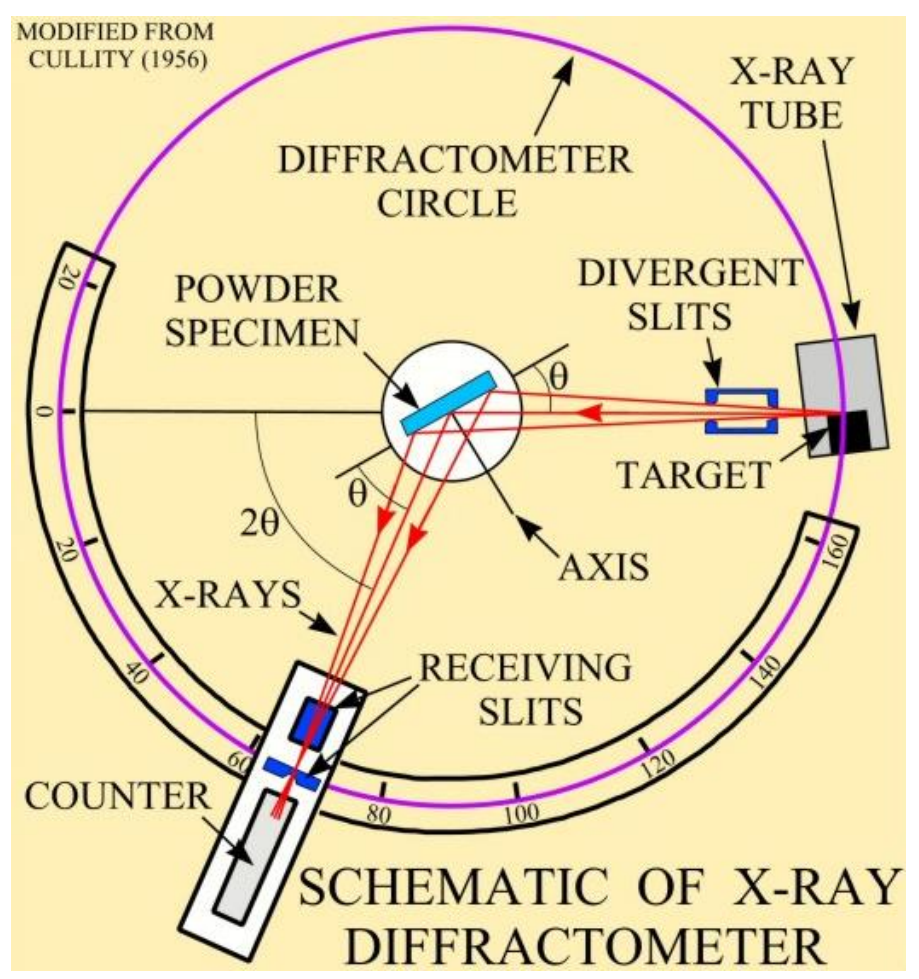

Figure 3-9: Schematic of an X-Ray diffractometer (U. S. Geological survey, 2020)

General scattering occurs when an incident X-ray beam encounters a crystal lattice. Most of this scattering interferes with itself and is eliminated (destructive interference). Diffraction occurs when scattering is in phase with other atomic planes (constructive interference). The relation by 
which diffraction occurs is known as Bragg's law. The diffracted X-rays has a characteristic pattern that is related to the characteristic atomic structure of the crystalline material and hence each phase, a specific chemistry and atomic arrangement, produces a unique diffraction pattern. For example, quartz, cristobalite, and glass are all chemically identical $\left(\mathrm{SiO}_{2}\right)$ but have different atom arrangements resulting in different diffraction patterns.

$$
n \lambda=2 d \sin \theta
$$

Where $\mathrm{n}$ is an integer, $\lambda$ is the wavelength of the incident $\mathrm{X}$-ray, $\mathrm{d}$ is the lattice planes spacing, and $\theta$ is Bragg angle.

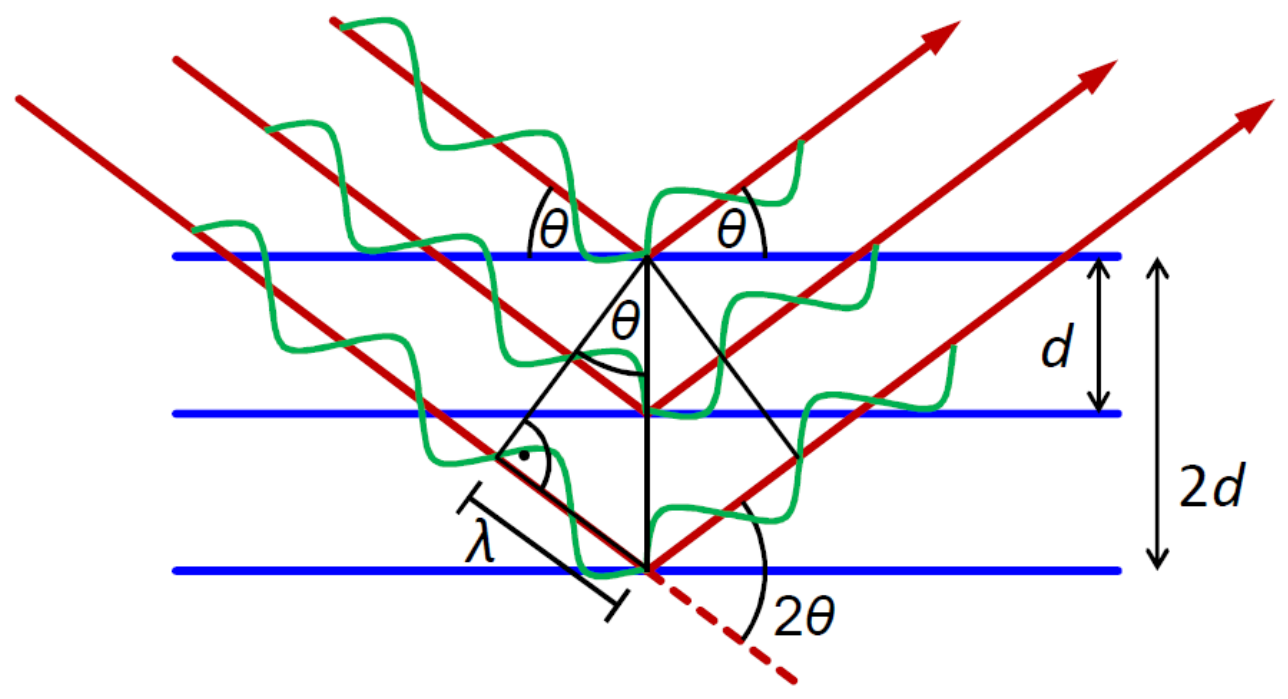

Figure 3-10: Bragg's law (Reed, 2005)

\subsection{SAMPLES PREPARATION AND PROCEDURES}

\subsubsection{Leached clay samples preparation}

In this study, clay samples were tested at five different salinity level: its natural salinity level of $15.53 \mathrm{~g} / \mathrm{L}$, salinized sample at $30.55 \mathrm{~g} / \mathrm{L}$, and leached samples at $0.73 \mathrm{~g} / \mathrm{L}, 1.07 \mathrm{~g} / \mathrm{L}$, and $1.33 \mathrm{~g} / \mathrm{L}$. 
Leached Champlain Sea clay samples were prepared using a leaching apparatus developed Ali (2018), as shown in Figure 3-12. The main components of the apparatus are: 1) distilled water reservoir, 2) pump, 3) solenoid valve and pressure gage 4) pressure switch, 5) pressure tank, 6) pressure regulator, 7) pressure gage, and 8) leaching mould. The apparatus was used to flush distilled deionized water through the undisturbed clay samples under a constant pressure of 100 $\mathrm{kPa}$. This pressure was chosen to be lower than the preconsolidation pressure of the clay samples to avoid any possible consolidation during the leaching process. At the same time, the pressure gradient is large enough to generate a flow rate to leach the samples with a reasonable time.

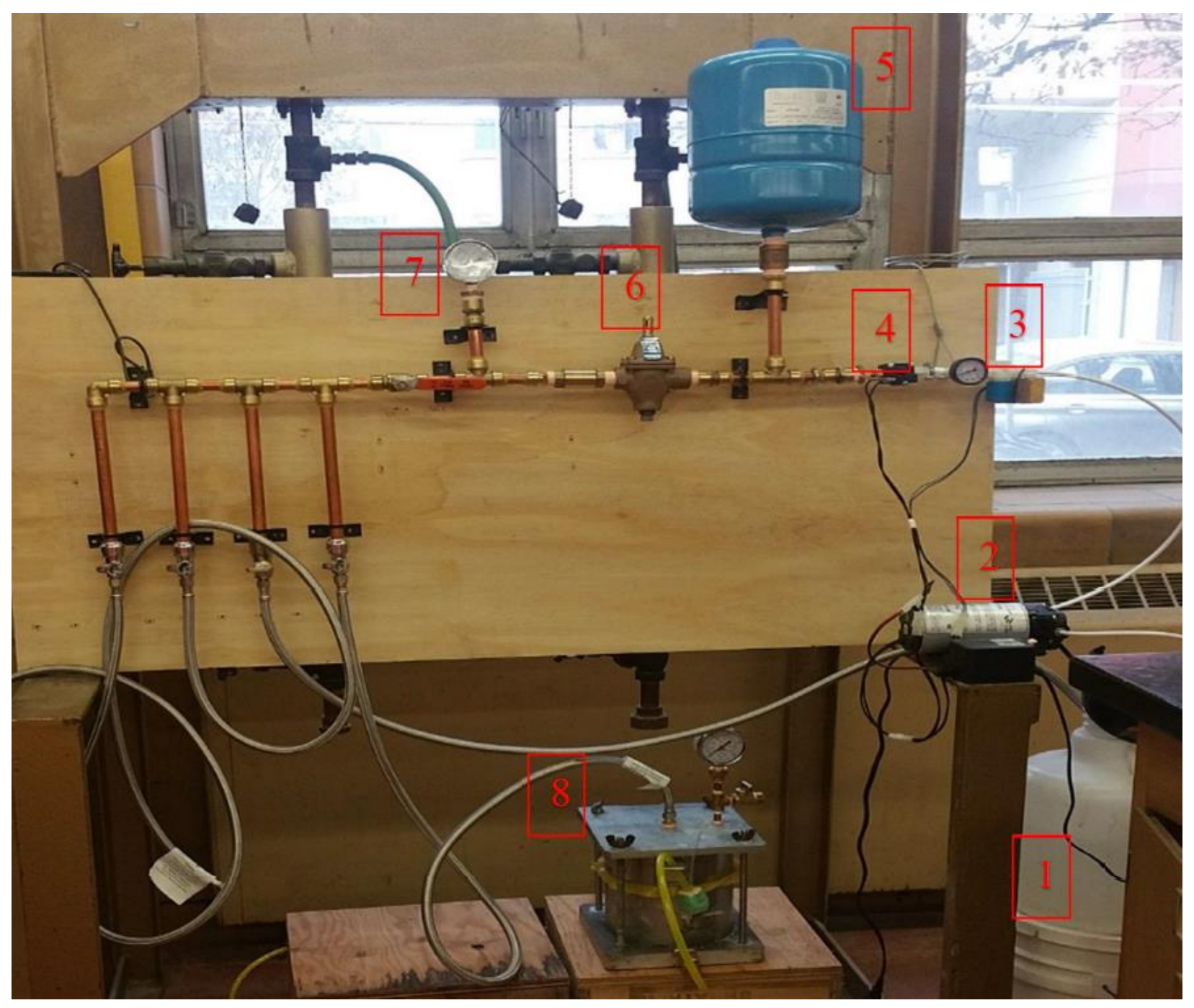

Figure 3-11: The leaching apparatus used in this study 
The leaching mould was chosen of a large size to accommodate more specimens from the same clay sample, including index properties, UCS tests, SEM and XRD analysis. The water passed through the samples until it reached to the bottom and collected in the leachate collection beaker. Paper filters and pore stones were placed on the top and bottom of the samples to distribute the water pressure evenly on the samples. To perform tests on undisturbed samples such as UCS and mini vane shear, the sample was extruded gently from the leaching mould to minimize disturbance, as shown in Figure 3-12.

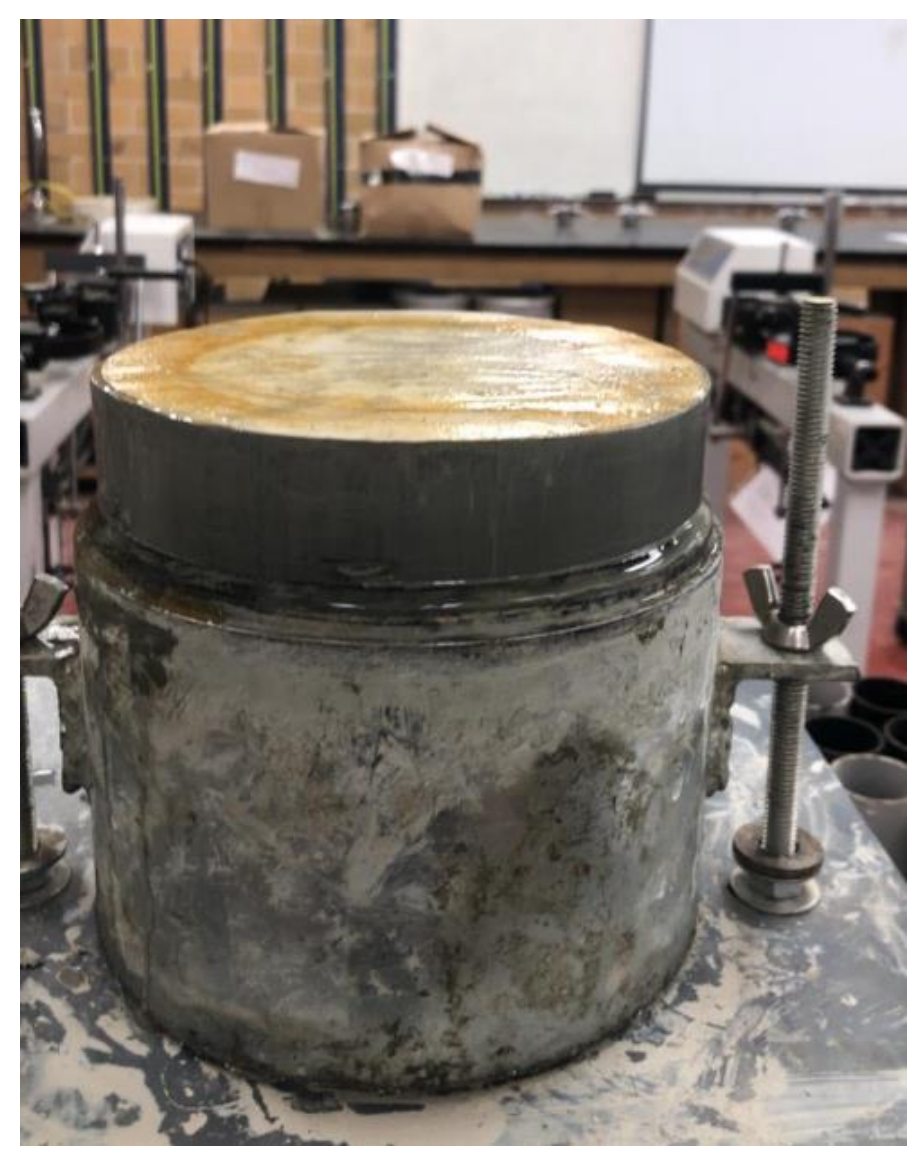

Figure 3-12: A leached clay sample being extruded from the leaching mold

The salinity level of the collected leachate was checked and recorded using Horiba ES-5 portable conductivity/ salinity meter within 24 to 48 hours. After each recording the beaker was replaced by a clean one and the procedure continued until the required salinity level is reached. In this study, 
three natural clay samples at $15.53 \mathrm{~g} / \mathrm{L}$ were leached to three different salinity levels of $0.73 \mathrm{~g} / \mathrm{L}$, $1.07 \mathrm{~g} / \mathrm{L}$, and $1.33 \mathrm{~g} / \mathrm{L}$.

At the end of the leaching process, the salinity level was tested from three different part of the clay sample (top, middle, and bottom) to confirm the uniformity of the leached sample.

\subsubsection{Unconfined compressive strength samples preparation}

For untreated samples, a soil lathe and saw wire were used to trim clay blocks to a cylindrical shape of $50 \mathrm{~mm}$ in diameter and $100 \mathrm{~mm}$ in height as shown in Figure 3-13.

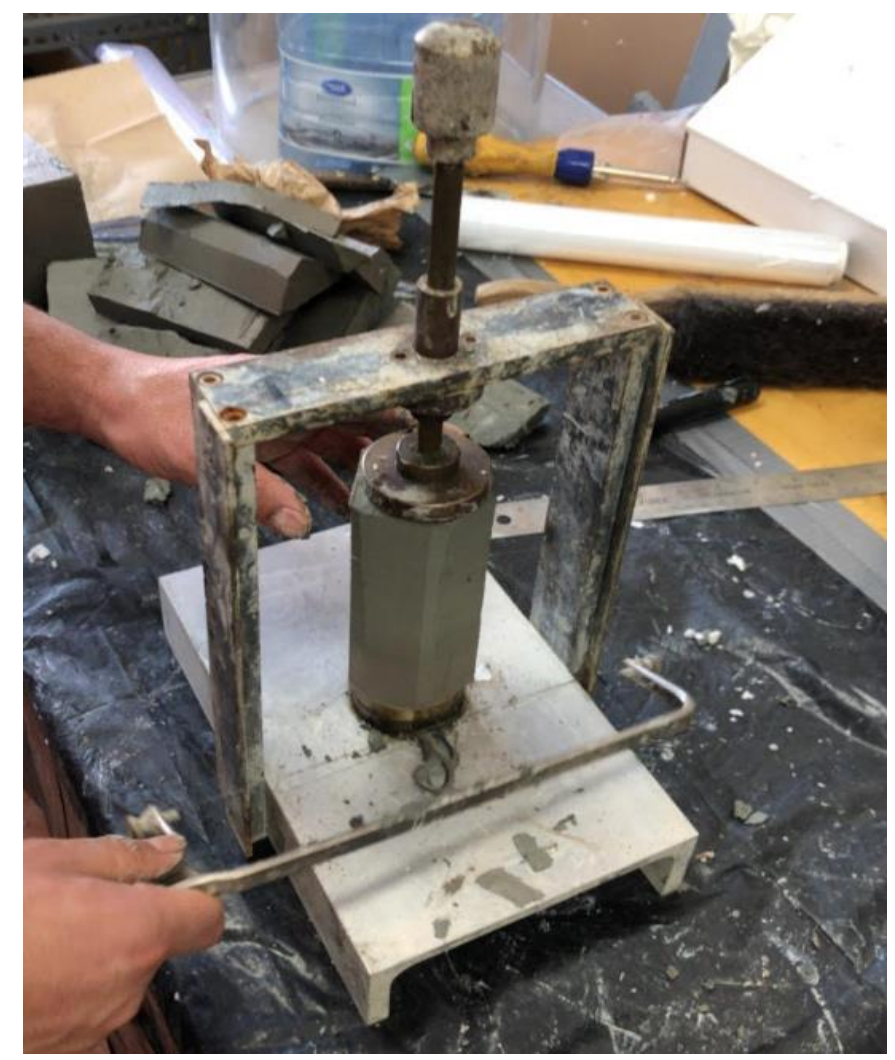

Figure 3-13: Untreated sample preparation for UCS

For treated samples, a 10 speeds Kitchen Aid ultra power mixer was used for all mixing and homogenizing the samples in this study as shown in Figure 3-14. The mixer has a power of 300 Watt and its standard revolutions per minute (RPM) ranging from 60 RPM at stir position to 255 RPM at speed number 10 position. 


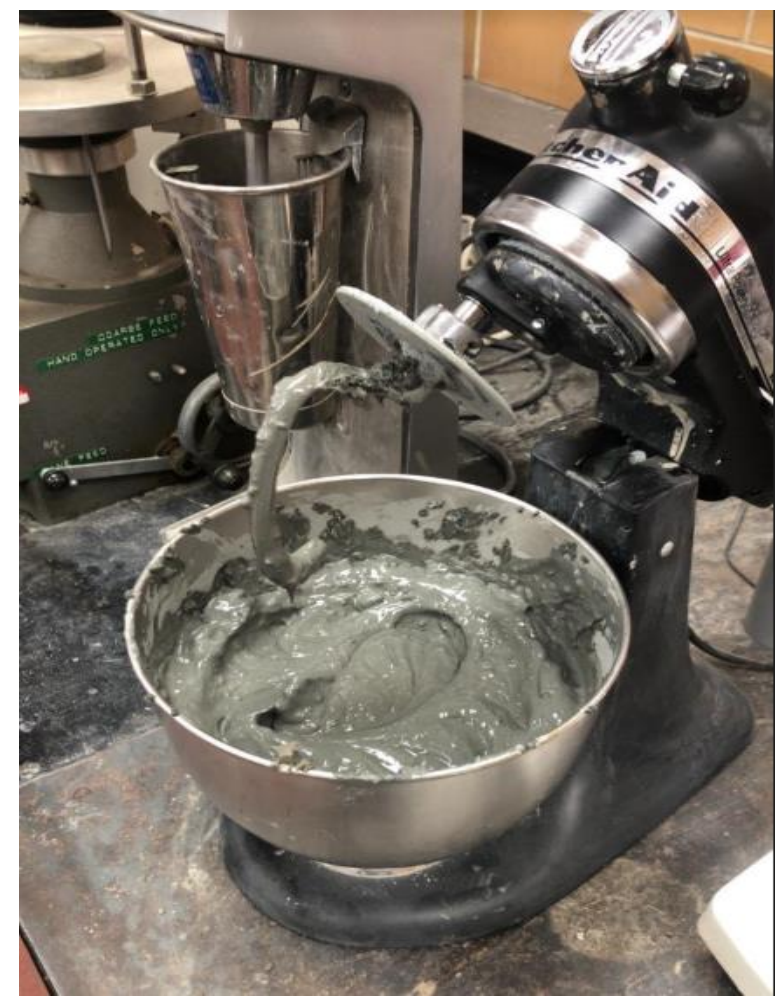

Figure 3-14: A Kitchen Aid ultra power mixer and the electric milk shaker used in this study

First, the clay sample at the desired salinity level was homogenized under the Kitchen Aid mixer at a low mixing speed for 5 min. Champlain Sea clay tend to be clumpy and exhibit a high viscosity during homogenization process; therefore, the mixer was turned off every minute to manually scrape the unmixed soil into the center of the mixing bowl to obtain a homogenized mixture. Second, the slurry was prepared by mixing the required amount of binder with a binder-to-water ratio of 1:1. The slurry was mixed for $5 \mathrm{~min}$ to obtain a homogeneous mixture using in an electric milk shaker as shown in Figure 3-14. Third, the slurry was added to the homogenized clay in the mixing bowl and mixed with a different speed for $10 \mathrm{~min}$ to ensure that the mixing process would not break any produced bond. The mixture was then poured into a plastic mould of $50 \mathrm{~mm}$ in diameter and $100 \mathrm{~mm}$ in height. To avoid trapped air bubbles from forming inside the specimen, moulds were gently tapped on the table. The moulds were then covered by their lids and placed in a curing box at room temperature around $22^{\circ} \mathrm{C}$. All cemented samples were cured for curing periods of $7,14,28,56$, and 300 days before testing. 
UCS tests were conducted in accordance with ASTM D2166 standard using Humboldt Masterloader 3000 machine (HM3000). The machine applies consistent load rate of $1.25 \mathrm{~mm} / \mathrm{min}$ until the end of the test. All samples' surfaces were flat and smooth and have a length to diameter ratio of 2. The two plates were carefully cleaned before the specimen is placed. Stress and deformation data were recorded through an electronic system that has the appropriate accuracy specifications.

The axial strain is calculated as:

$\varepsilon_{\mathrm{a}}=\Delta \mathrm{l} / \mathrm{L}_{0}$

Where:

$\varepsilon_{\mathrm{a}}$ : Axial strain,

$\Delta \mathrm{l}$ : Change in measured axial length and $\mathrm{L}_{0}$ : The initial length of the sample.

The compressive stress is calculated as:

$\sigma=\mathrm{P} / \mathrm{A}_{0}$

Where $\sigma$ : Compressive Stress, P: Load and $\mathrm{A}_{0}$ : The initial cross-section area of the specimen.

Therefore, the Unconfined Compressive Strength is calculated for the maximum load applied:

$\sigma_{\text {UCS }}=\mathrm{P}_{\max } / \mathrm{A}_{0}$

The corrected compressive strength is calculated by using the corrected cross-section area instead of the initial cross-section of the specimen as follow:

$\mathrm{A}_{\text {corrected }}=\mathrm{A}_{0} / 1-\varepsilon_{\mathrm{a}}$

$\sigma_{\text {corrected }}=\mathrm{P}_{\max } / \mathrm{A}_{\text {corrected }}$ the corrected unconfined compressive strength 


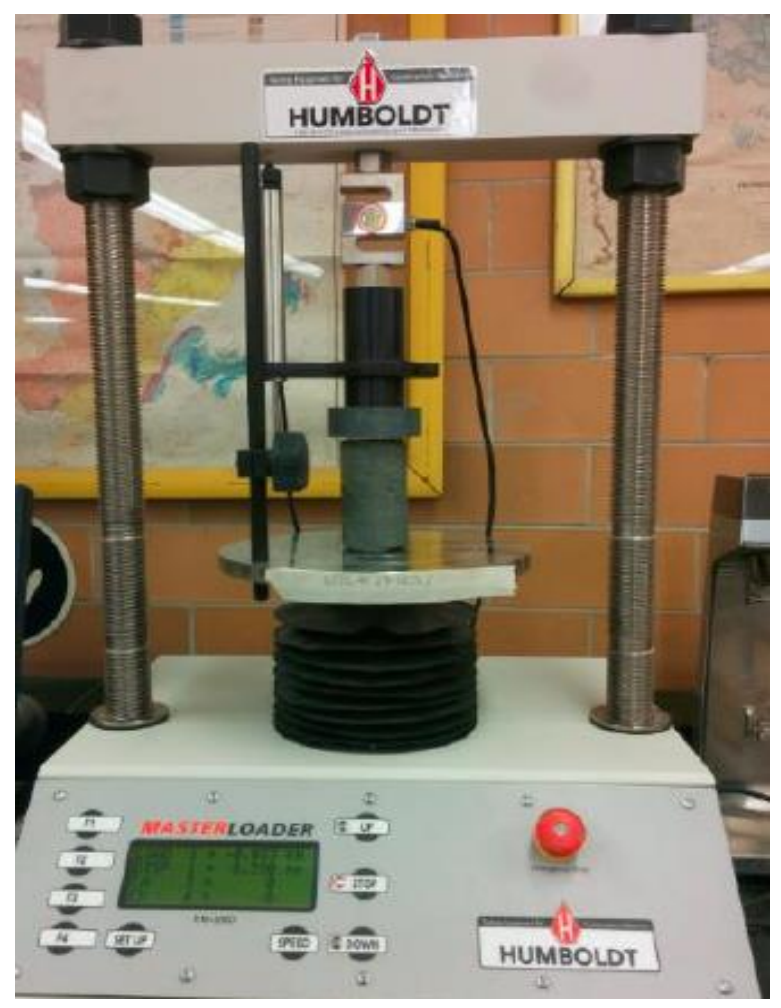

Figure 3-15: Humboldt UCS testing machine

\subsubsection{Scanning electron microscopy specimen preparation}

For cemented treated clay samples, specimens for SEM analysis were prepared in 12-mm diameter by $10-\mathrm{mm}$ high rings from the same mix with the samples prepared for the UCS tests. The mixture was pressed using the thumb and carefully trimmed with a spatula to create a flat surface as shown in Figure 3-16. For uncemented samples, specimen was trimmed with a spatula from the undisturbed clay sample into a cube of $1 \mathrm{~cm}$ each side. The specimen was then kept in a sealed plastic bag submerged in water in the same curing conditions as the UCS specimens. After curing, these SEM specimens were oven-dried for 24 hours in an oven at a temperature of $105{ }^{\circ} \mathrm{C}$. Then, sandpaper with a grit size of 400 (grain size $23 \mu \mathrm{m}$ ) was used to polish the sample to a flat surface for coating and avoiding any cracks formed during the drying process. Finally, specimen was further polished using sandpaper with grit size of $500(19 \mu \mathrm{m})$. It is crucial to polish both surfaces: the surface to be imaged and the other surface perpendicular to it to produce flat surfaces for imaging and reduce the depth of the disturbed surface due to the drying effect. 
An ultra-thin layer of gold was applied on the surface to be imaged to prevent charging of the specimen, which would otherwise occur because of the accumulation of static electric charges. It also increases the amount of the secondary electrons that can be detected from the surface of the specimen and therefore increases the signal to noise ratio resulting in an image resolution improvement. The sample was then mounted using a double stick tape and attached to the mounting stub. Two specimens can be mounted at a time, because of the small size of the samples, as shown in Figure 3-16.

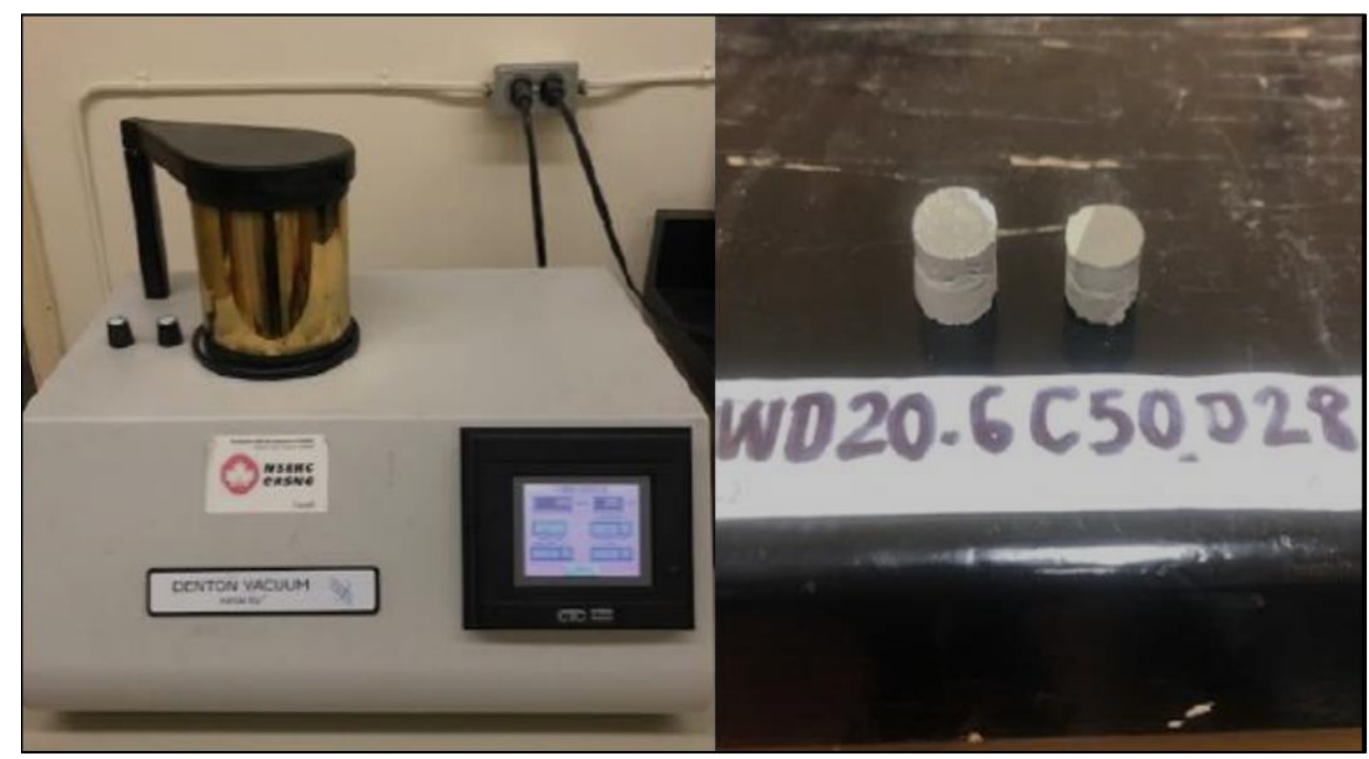

(a)

(b)

Figure 3-16: (a) Gold laboratory Vacuum thin film thermal evaporator, (b) two gold coated specimen for SEM

\subsubsection{X-rays diffraction specimen preparation}

From the same mix of the UCS tests, small cylindrical specimens of 35-mm diameter by 7-mm in height were prepared for XRD analysis. These samples were air-dried for 24 hours, and polished with sandpaper with a grit size of 400 (grain size $23 \mu \mathrm{m}$ ) to a flat surface. Finally, sandpaper with grit size of $500(19 \mu \mathrm{m})$ was used to further polish the specimen. Figure 3-17 shows a sample ready to be analyzed in the X'Pert X-ray diffraction machine. 


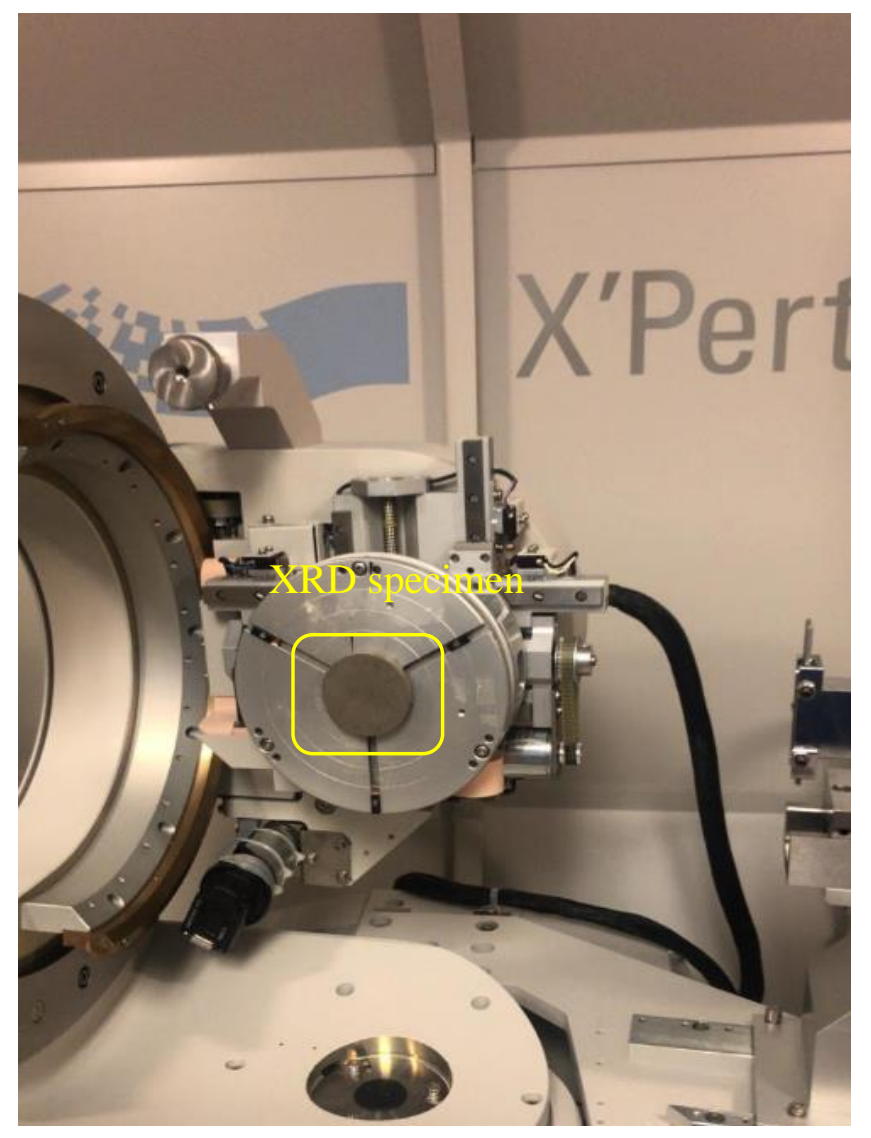

Figure 3-17: An XRD sample set-up in X'Pert X-ray diffraction machine

\subsubsection{Samples tag and numbering rules}

Each sample is designated with a tag according to the sample conditions. The first two letters of the natural clay represent the origin of the clay (WD for Waba Dam foundation clay). Followed by the sample depth in meters. Followed by the binder type and dosage. Followed by the curing time and the salinity level between brackets at the end of the tag. For example: WD21.6C50D28(1.33 g/L) means Waba Dam clay, from a depth of $\mathbf{2 1 . 6 m}$, treated with cement dosage of $50 \mathrm{~kg} / \mathrm{m}^{3}$, tested at curing day of 28 days of curing and leached to a salinity level of $\mathbf{1 . 3 3}$ g/L.

\subsection{EXPERIMENTAL PARAMETERS}

Previous researches show that the final strength of the treated soil may be influenced by many factors such as soil type, binder type, binder dosage, curing time, mixing method. Locat et al. 
(1990) have used a total of 6 quicklime dosages ranged from 0 to $10 \%$ by dry mass of the solid to treat soil from different sites from eastern Canada. Although the optimum quicklime dosage was about $4 \%$ by previous studies, Locat et al. (1990) selected $10 \%$ dosage to ensure that enough reaction products would be generated to ease SEM investigations. Li et al. (2016) have used cement and slag/cement on Champlain Sea clays from Arnprior and Kanata, Ontario to assess the effect of binder types on the treated soil. For cement, the dosages ranged from 57 to $400 \mathrm{~kg} / \mathrm{m}^{3}$ and higher dosages of slag/cement (290 to $828 \mathrm{~kg} / \mathrm{m}^{3}$ ) were used. All samples were cured up to 56 days. In this study, the effect of binder type with lower dosages and higher curing times were investigated. The effect of pore fluid salinity level on cement-treated clay was also investigated.

\subsubsection{Binder types}

All the binder types were delivered from a local cement manufacturing plant. Four types of binder were selected for this study. General use Portland cement (GU), cement kiln dust (CKD) with two cement to CKD ratios of $1: 1$ and 3:1, respectively, , cement/slag (CS) with a cement to slag ratio of $3: 1$ by weight and blended Portland cement with $8 \%$ of silica fume by weight (HSF).

CKD is a significant by-product of the cement manufacturing process. CKD is created in the kiln during the production of cement clinker. The dust is a particulate mixture of partially calcinated and unreacted raw feed, clinker dust and ash, enriched with alkali sulfates, halides and other volatiles. Its size distribution, chemical and physical properties depend on several production factors such as raw feed material, type of kiln operation, dust collection system, and fuel type. A typical composition of CKD is shown in Table 3-2. The most important element for soil stabilization supplied by CKD is calcium; however, it needs to be in the form of free lime $(\mathrm{CaO})$ otherwise it acts just as a filler. In this study, a blended binder CKD with cement was supplied and no chemical analysis was conducted on CKD.

Table 3-2: Typical composition of cement kiln dust (Haynes \& Kramer, 1982)

\begin{tabular}{|c|c|c|c|}
\hline Constituent & \% by weight & Constituent & \% by weight \\
\hline $\mathrm{CaCO}_{3}$ & 55.5 & $\mathrm{Fe}_{2} \mathrm{O}_{3}$ & 2.1 \\
\hline $\mathrm{SiO}_{2}$ & 13.6 & $\mathrm{KCl}$ & 1.4 \\
\hline $\mathrm{CaO}$ & 8.1 & $\mathrm{MgO}$ & 1.3 \\
\hline $\mathrm{K}_{2} \mathrm{SO}_{4}$ & 5.9 & $\mathrm{Na}_{2} \mathrm{SO}_{4}$ & 1.3 \\
\hline $\mathrm{CaSO}_{4}$ & 5.2 & $\mathrm{KF}$ & 0.4 \\
\hline $\mathrm{Al}_{2} \mathrm{O}_{3}$ & 4.5 & Others & 0.7 \\
\hline
\end{tabular}


Slag is a by-product of the conversion of iron to steel process. The chemical composition of steel slag is highly variable; thus, the chemical composition depends on the raw material and process. Summarizes the chemical composition and some physical properties of Portland cement and blast furnace slag. Cement/slag can be used for mass concrete and pavement applications due to its special features. In this study, the purpose of using cement/slag binder is to determine if slag can be used to replace a portion of the cement in stabilizing the marine Champlain Sea clay.

Table 3-3:Chemical composition (mass \%) and some physical properties of Portland cement (PC) and blast furnace slag (BFS) (Shi, 2002)

\begin{tabular}{lllllllllllll}
\hline Item & $\mathrm{SiO}_{2}$ & $\mathrm{Al}_{2} \mathrm{O}_{3}$ & $\mathrm{Fe}_{2} \mathrm{O}_{3}$ & $\mathrm{CaO}$ & $\mathrm{MgO}$ & $\mathrm{SO}_{3}$ & $\mathrm{Na}_{2} \mathrm{O}$ & $\mathrm{K}_{2} \mathrm{O}$ & LOI & Total & Density $\left(\mathrm{kg} / \mathrm{m}^{3}\right)$ & Blaine fineness $\left(\mathrm{m}^{2} / \mathrm{kg}\right)$ \\
\hline $\mathrm{PC}$ & 20.7 & 3.7 & 3.0 & 62.9 & 4.2 & 2.6 & 0.1 & 0.6 & 0.3 & 98.1 & 3140 & 340 \\
$\mathrm{BFS}$ & 35.3 & 9.9 & 0.6 & 34.7 & 14.6 & 4.0 & 0.3 & 0.4 & 0 & 99.8 & 2920 & 495 \\
\hline
\end{tabular}

Silica fume is a pozzolanic material which is a by-product of the silicon smelting process. Silica fume is known by its production of high-strength concrete. In concrete industry, it is used for two different reasons: to replace a portion of the cement to reduce the cost; and as an additive to improve concrete properties for fresh and hardened conditions. In this study, the use of silica fume is more to investigate its effect on the strength development of soil-cement mixture.

\subsubsection{Binder dosages design}

To study the effect of the general use Portland cement dosage on the improvement of stabilized Champlain Sea clay three dosages were selected: 50,100 and $200 \mathrm{~kg} / \mathrm{m}^{3}$ of the mixed soil volume, identified as GU50, GU100 and GU200 respectively. The effect of binder type was investigated using four more binder types: CKD with two cement to CKD ratios (CKD1:1 and CKD3:1), CS3:1, and HSF with the dosages as shown in Table 3-4. The dosage was chosen to fix the amount of cement in $50 \mathrm{~kg} / \mathrm{m}^{3}$ in the cases. All the mixes for salinity level investigation were dosed with $50 \mathrm{~kg} / \mathrm{m}^{3}$ of general use Portland cement. 
Table 3-4: Binder types and dosages used in this study

\begin{tabular}{llcc}
\hline Binder ID & Binder Type & $\begin{array}{c}\text { Cement Dosage } \\
\left(\mathbf{k g} / \mathbf{m}^{\mathbf{3}}\right)\end{array}$ & $\begin{array}{c}\text { Additive Dosage } \\
\left(\mathbf{k g} / \mathbf{m}^{\mathbf{3}}\right)\end{array}$ \\
\hline GU200 & General Use Portland cement & 200 & 0 \\
GU100 & General Use Portland cement & 100 & 0 \\
GU50 & General Use Portland cement & 50 & 0 \\
HSF50 & Cement with 8\% silica fume & 50 & 0 \\
CS67 & Cement-slag with 3:1 ratio & 50 & 17 \\
CKD67 & Cement-Cement Kiln Dust with 3:1 & 50 & 17 \\
CKD100 & Cement-Cement Kiln Dust with 1:1 & 50 & 50 \\
\hline
\end{tabular}

\subsubsection{Salinity level}

A total of five levels of salinity samples were investigated in this study. The natural clay with salinity a level of $15.53 \mathrm{~g} / \mathrm{L}$, salinized sample to $30.55 \mathrm{~g} / \mathrm{L}$, and three leached samples at $0.73,1.07$, and $1.33 \mathrm{~g} / \mathrm{L}$.

The salinized specimens were prepared by adding and mixing $1 \%$ of sodium chloride salt by weight to the natural clay. The mixture was kept in a plastic bag in a humid chamber for at least one week before using it. This allows for full interaction between the added salt and the clay. Sample at $1.33 \mathrm{~g} / \mathrm{L}$ samples were leached for 8 weeks and those at $1.07 \mathrm{~g} / \mathrm{L}$ were leached for 12 weeks, and the leaching process of samples at $0.73 \mathrm{~g} / \mathrm{L}$ lasted 15 weeks.

\subsection{SUMMARY}

This chapter presented the physical properties of the soil used in this study. Then, an overview and the fundamentals principals of the equipment used in this study were discussed. Furthermore, the binder dosage, sample mixing procedure and the experimental parameters were presented. The next chapter will present the results of strength development, microstructure analysis, and mineralogical changes of natural, and leached clays mixed with different binders. 


\section{STRENGTH AND MICROSTRUCTURE ANALYSES OF STABILIZED CHAMLAIN SEA CLAY}

\subsection{INTRODUCTION}

In this chapter, the experimental results of natural and leached clay mixed with different binders and dosage will be introduced. The UCS was used to gage the strength development of clay samples under different conditions. SEM provides a useful tool to visualize particle structure and bonding agents developed between soil particles due to cementation. XRD was used to analyze the phase composition of clay samples at different salinity levels. First, strength and microstructure analyses of intact, leached, and salinized Champlain Sea clay will be presented. Then, the effect of different binder' types on strength development and microstructure changes of Champlain Sea clay will be explained. Finally, the effect of salinity level on strength and phase composition of leached clay at different level as well as salinized samples will be presented.

\subsection{MICROSTRUCTURE AND STRENGTH OF CHAMPLAIN SEA CLAY AT DIFFERENT SALINITY LEVELS}

\subsubsection{Natural clay}

The stress-stress curve obtained from the UCS test of the natural soil sample is shown in Figure 4-1. The values of peak UCS, $\mathrm{q}_{\mathrm{u}}$, for the three tests were 73,82 , and $97 \mathrm{kPa}$ resulting in average undrained shear strength, $\mathrm{c}_{\mathrm{u}}$, of $42 \mathrm{kPa}$ with a standard deviation of 6.06. The increase in UCS after the peak in sample WD21.6UCS1 could be explained by the failure mode of the sample as shown in Figures 4-1 and 4-2. The localized failure of the sample at its end of the cylinder could have generated extra strength after the peak.

The intact clay micro-structure of an oven-dried clay sample was observed using SEM. Figure 4-3 presents SEMs photomicrographs at two different magnifications of X 5000 (a) and X 10000 (b) of a view plane parallel to the bedding plane.

The observed structure in the photomicrographs of Figure 4-3 is an aggregated structure. The aggregates are composed of small platelets and separated by a porous network. The aggregate diameter is on the order of $3 \mu \mathrm{m}$. Some silt particles are scattered among the aggregates with a 
diameter larger than $5 \mu \mathrm{m}$. Figure 4-3b highlights a silt particle of diameter around $6 \mu \mathrm{m}$, the same figure shows some platelets are stuck on the silty grain side and edge.

The texture of the untreated clay consisted of many sheet-like particles as shown in Figure 4-4. The flaky and plate-like particles could be identified as illite with some scattered kaolinite minerals. The texture of the illitic structure is composed of thin plates and aggregates, some of these individual illite platelets could be seen at the left and the right of the micrograph in Figure 4-4.

XRD analysis (Qualitas, 2016) have shown that the clay fraction of a sample from almost same depth as the one shown in Figure $4-4$ is $50.15 \%$ by weight. However, the micrograph shown in Figure 4-4 gives the impression of a larger proportion of platy minerals, this may be due to the fact that some aggregate may contain nonclayey tiny particles. In addition, the analysis has quantified the clay mineral by weight while microscope observations consider volume. Clayey particles will occupy a much larger volume than nonclayey particles and will seem to be more apparent due to its platy morphology.

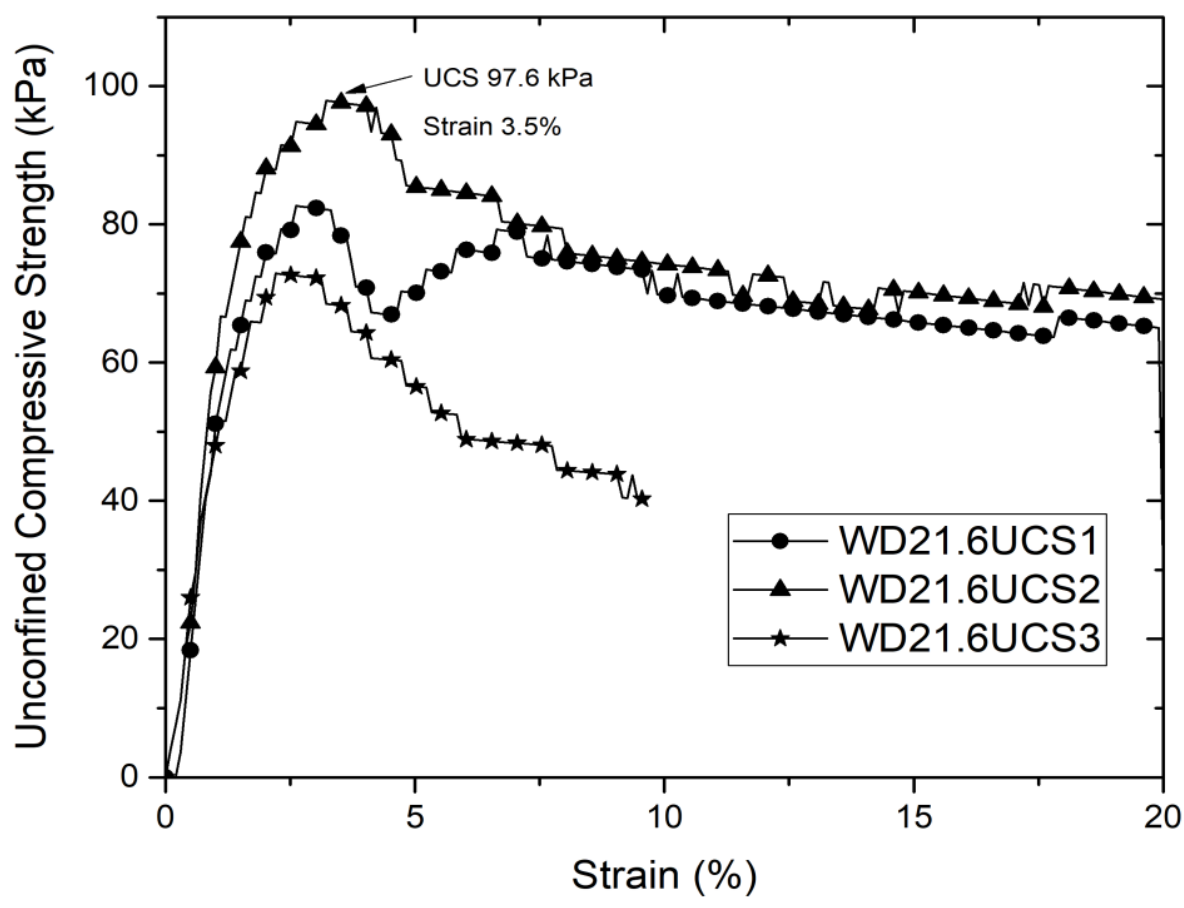

Figure 4-1: Stress-strain curve natural soil samples. 


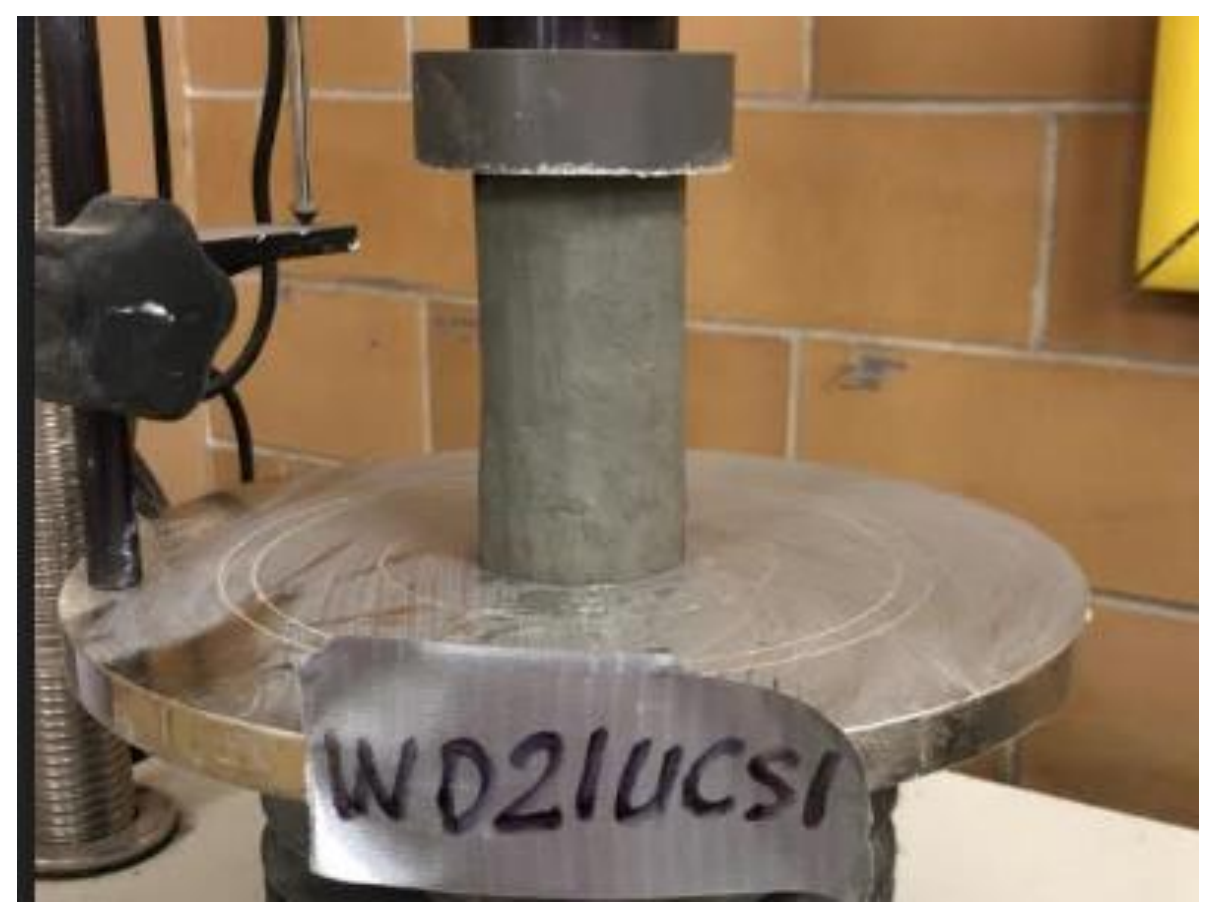

(a) Before UCS test

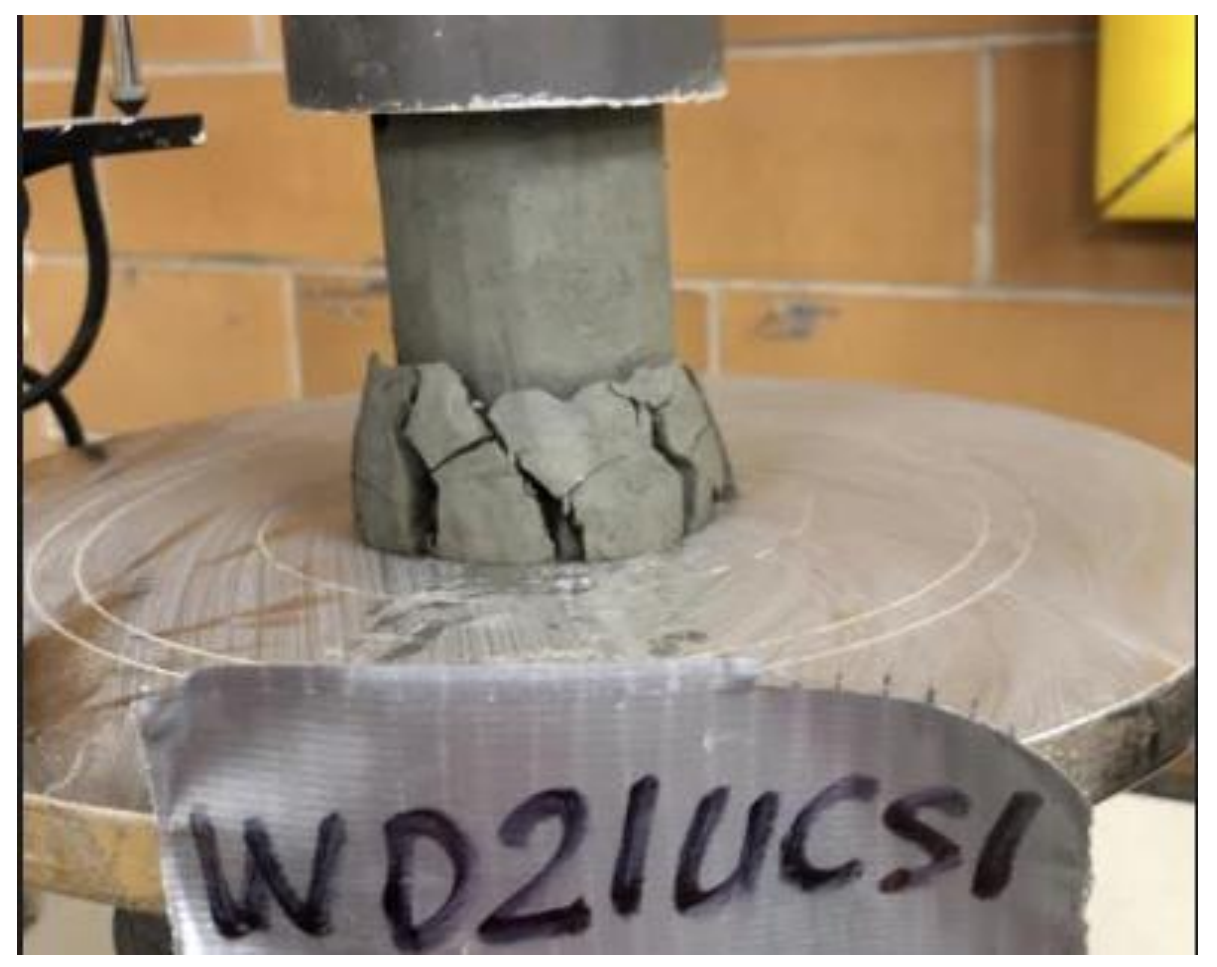

(b) After UCS test

Figure 4-2: Failure mode of natural clay sample under UCS 


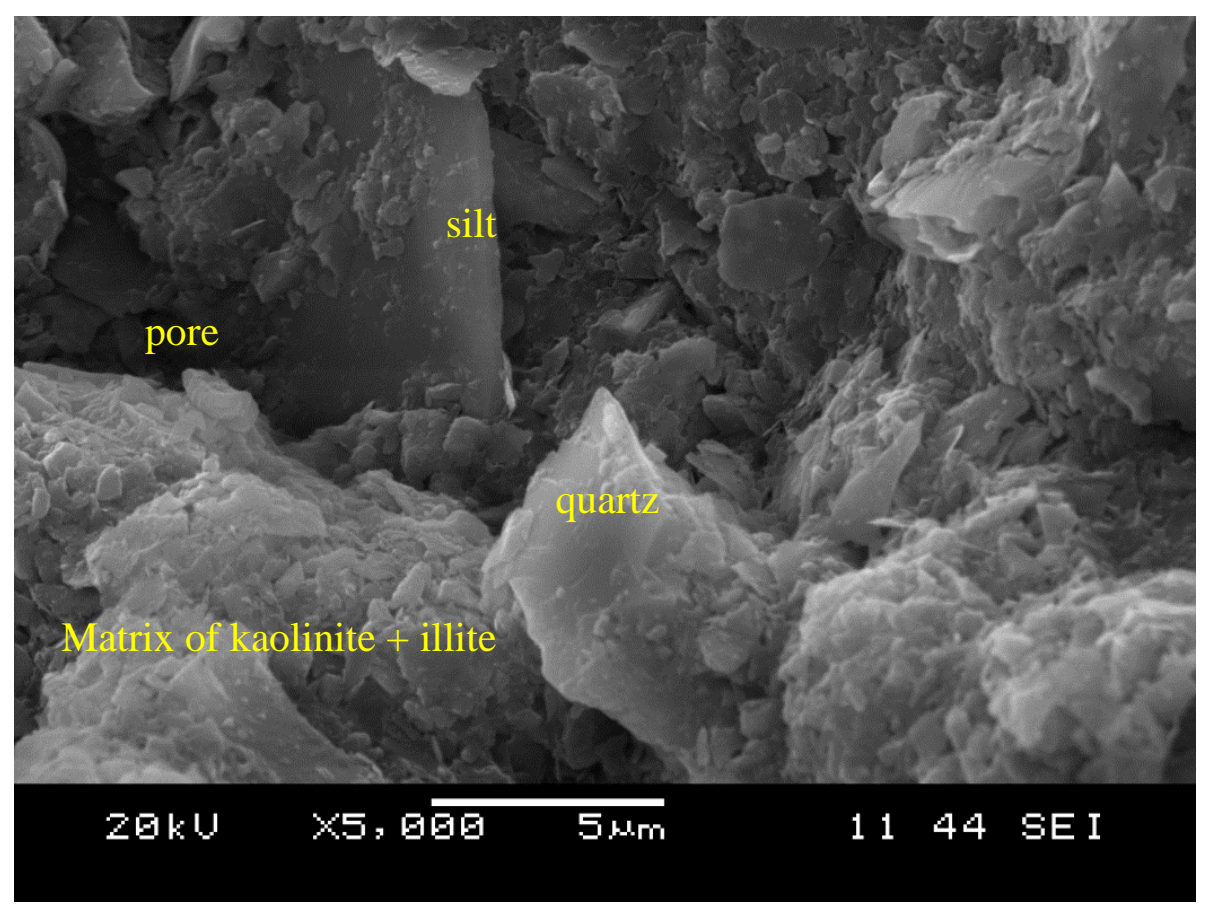

(a) Intact clay

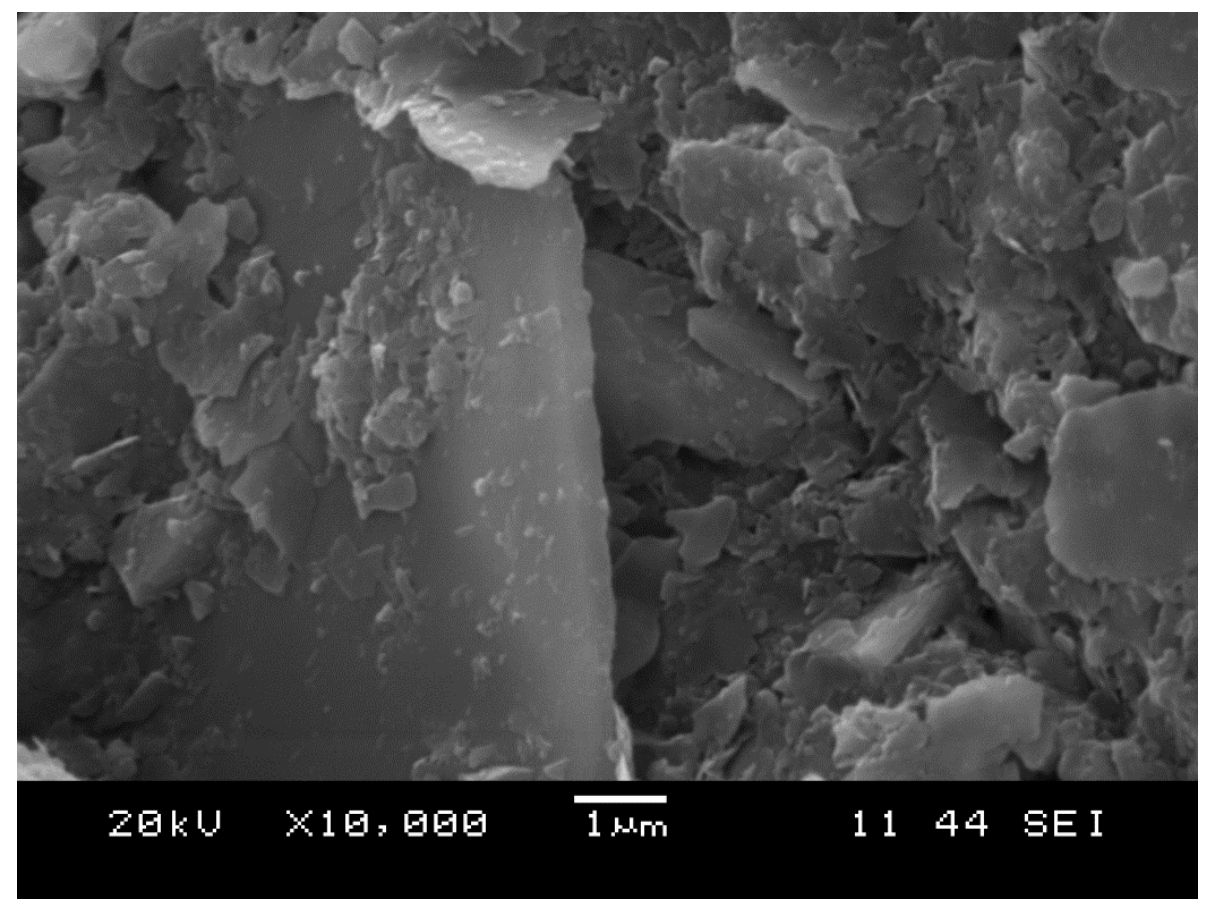

(b) Intact clay

Figure 4-3: SEM micrographs of intact clay (a) magnified X 5000 (b) close-up on a silt particle 


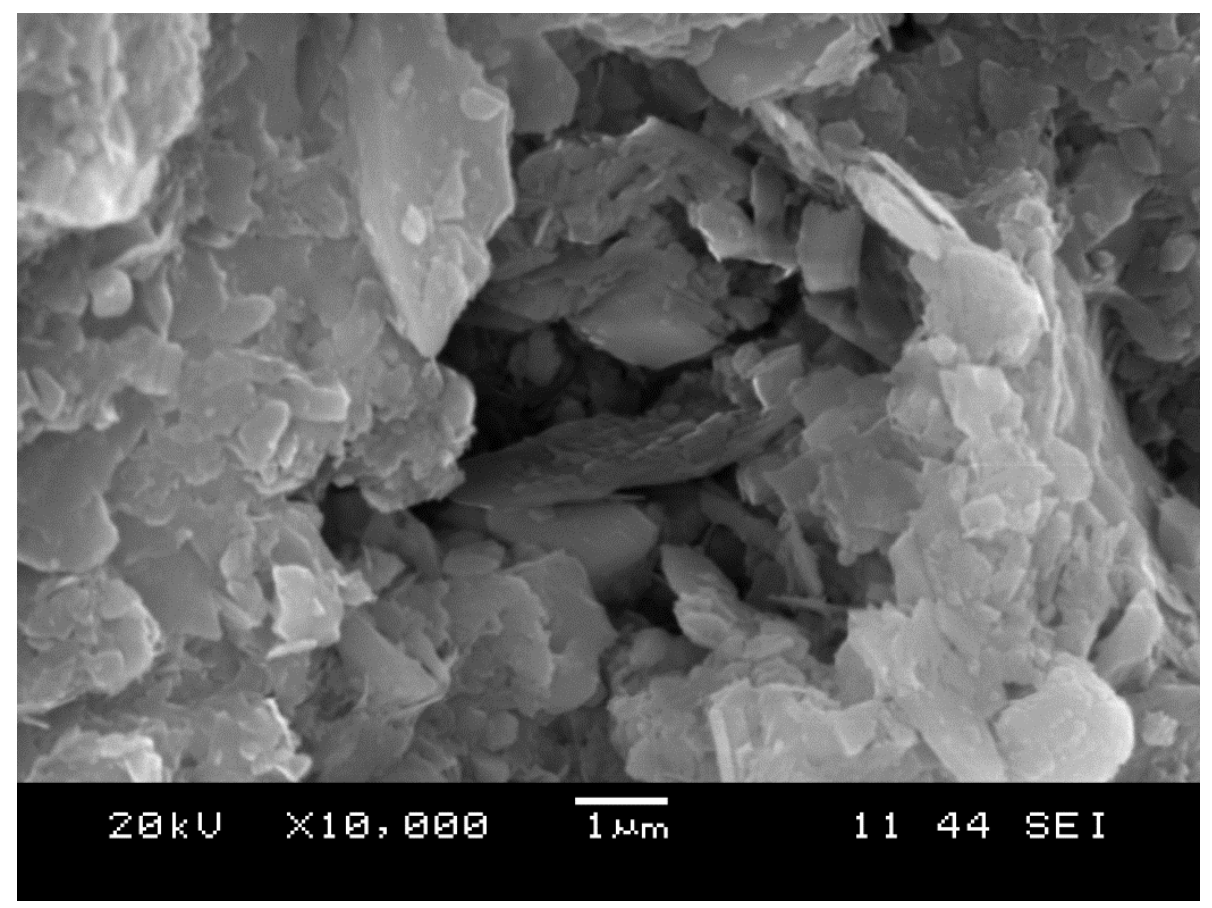

Figure 4-4:SEM photomicrograph of untreated Champlain Sea clay

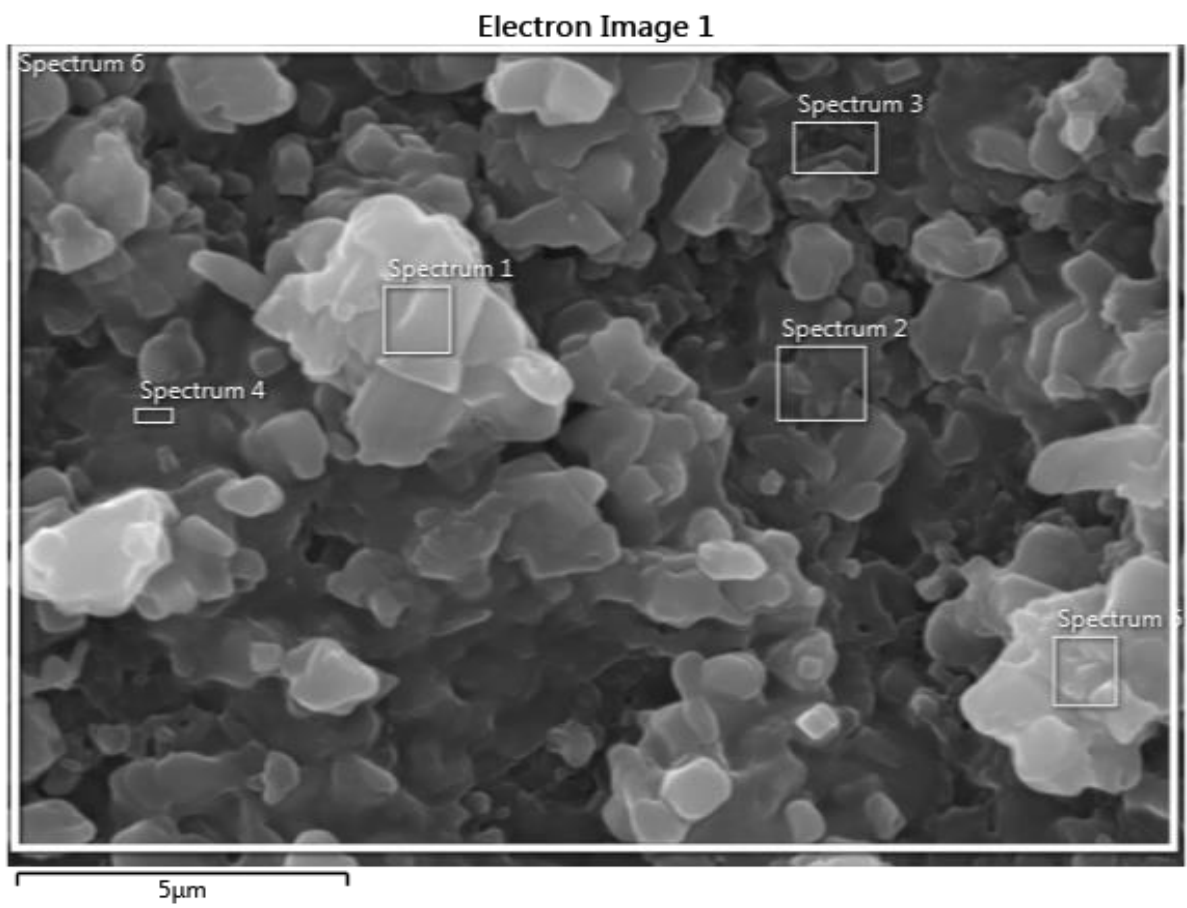

Figure 4-5: Spectra of EDS analysis for untreated clay 
The results of a localized and an average elemental composition analysis of an untreated sample is shown in Figure 4-6 and Figure 4-7, respectively. Figure 4-6 shows that the area under analysis (spectrum 1) is composed mainly of sodium (Na) and chlorine $(\mathrm{Cl})$ with about $33.4 \%$ by weight. The high amount of sodium and chloride can be attributed to the sedimentation marine environment of Champlain Sea clay. The average elemental composition of the clay sample (spectrum 6) also shows high sodium and chlorine elements with $37.6 \%$ by weight. Champlain Sea clay are composed mainly of silicon ( $\mathrm{Si}$ ), aluminum (Al), calcium (Ca), iron $\mathrm{Fe}$ and sulfur ( $\mathrm{S}$ ), i.e. $23.1 \%$ by weight. $\mathrm{Si}$ and $\mathrm{Al}$ and $\mathrm{Ca}$ are the most abundant and contribute more than $17.9 \%$ by weight. Magnesium $(\mathrm{Mg})$ reaches $1.1 \%$ by weight and can be attributed to smectite.

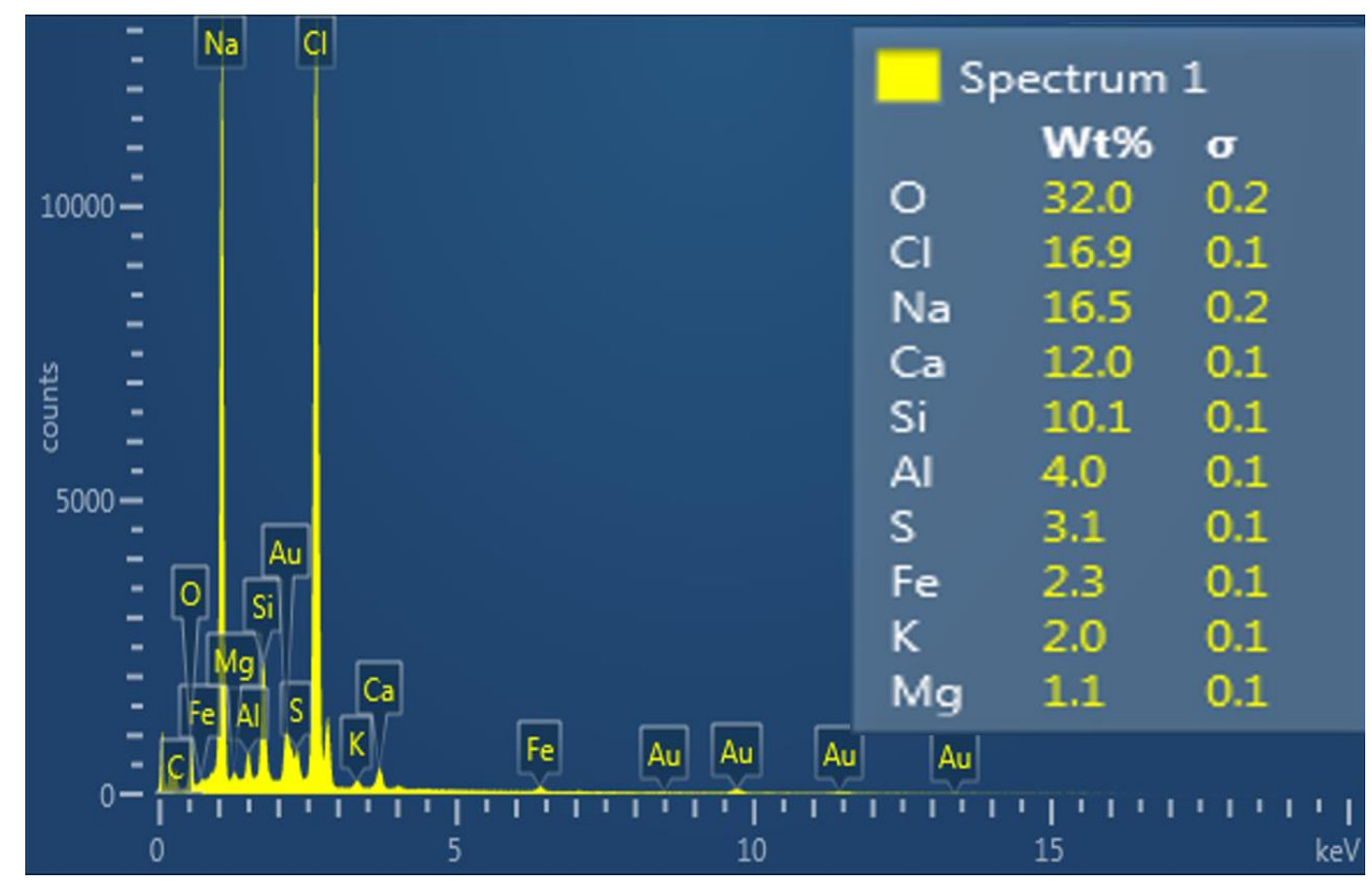

Figure 4-6: Localized elemental composition of untreated clay 


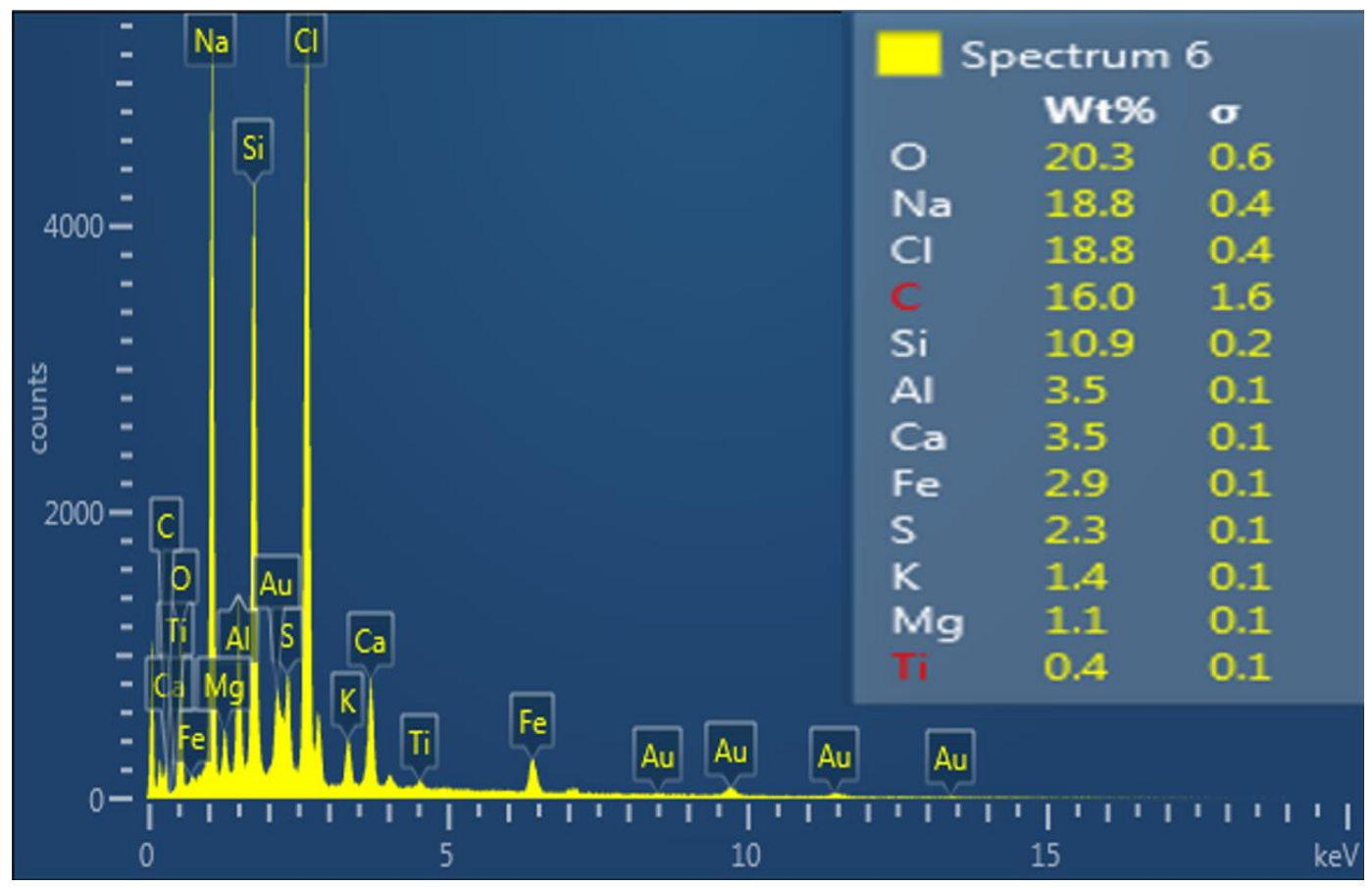

Figure 4-7: Average elemental composition of untreated clay

\subsubsection{Leached clay}

The UCS tests were performed on leached clay to assess the effect of salinity level on the strength of untreated clay. The results are shown in Figure 4-8. As a general trend, UCS of leached clay decreases as the salinity level decreases, however, a sharp decrease of strength is observed when salinity level drops below $1 \mathrm{~g} / \mathrm{L}$. For example, clay leached to $1.07 \mathrm{~g} / \mathrm{L}$ reached a UCS of 49.10 $\mathrm{kPa}$, whereas sample leached to $1.33 \mathrm{~g} / \mathrm{L}$ does not show a big decrease compared to natural clay samples. Figure 4-9 a photograph showing the failure mode of a leached sample at $0.73 \mathrm{~g} / \mathrm{L}$. The leached sample exhibits an axial splitting crack failure mode as opposed to the natural clay sample where the failure was localized at the end of the cylinder. 


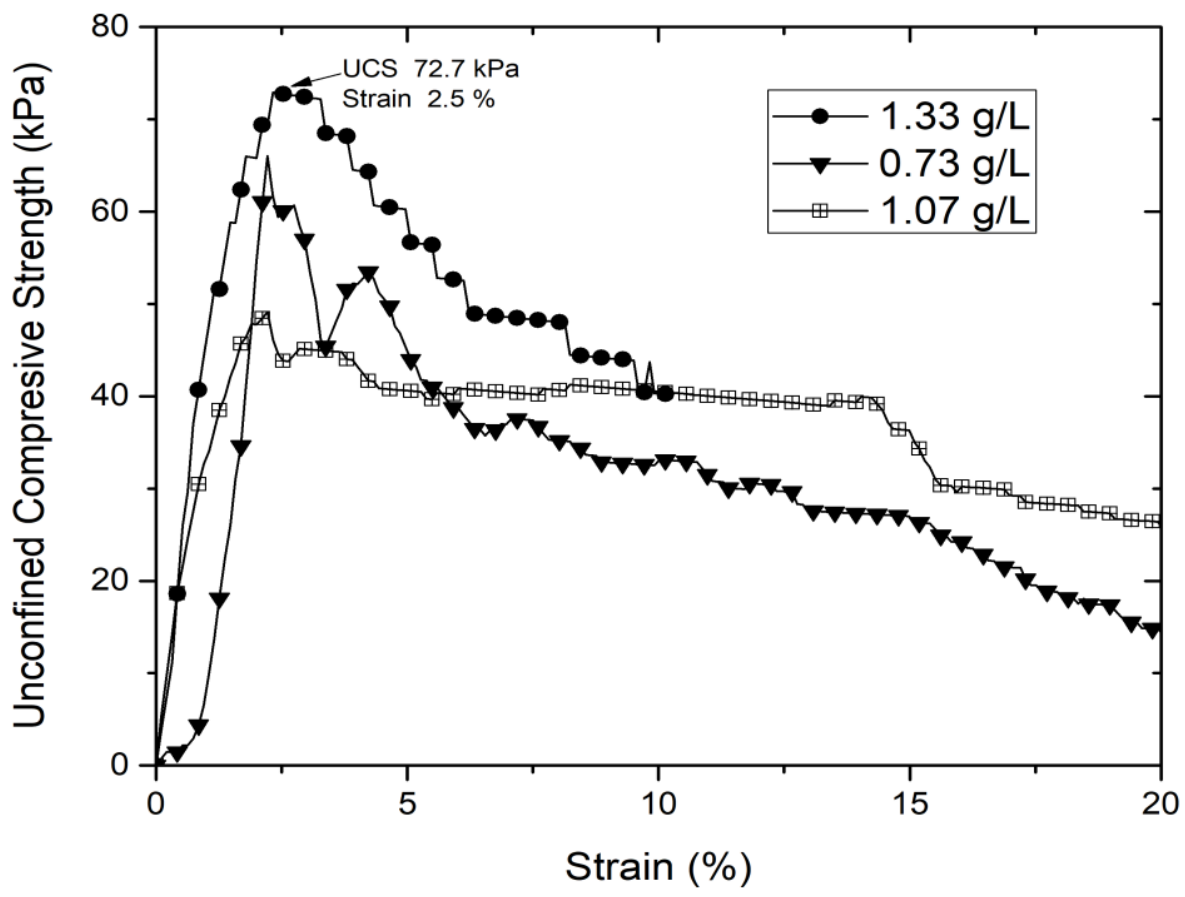

Figure 4-8: Stress-strain curve for clay leached to different salinity level

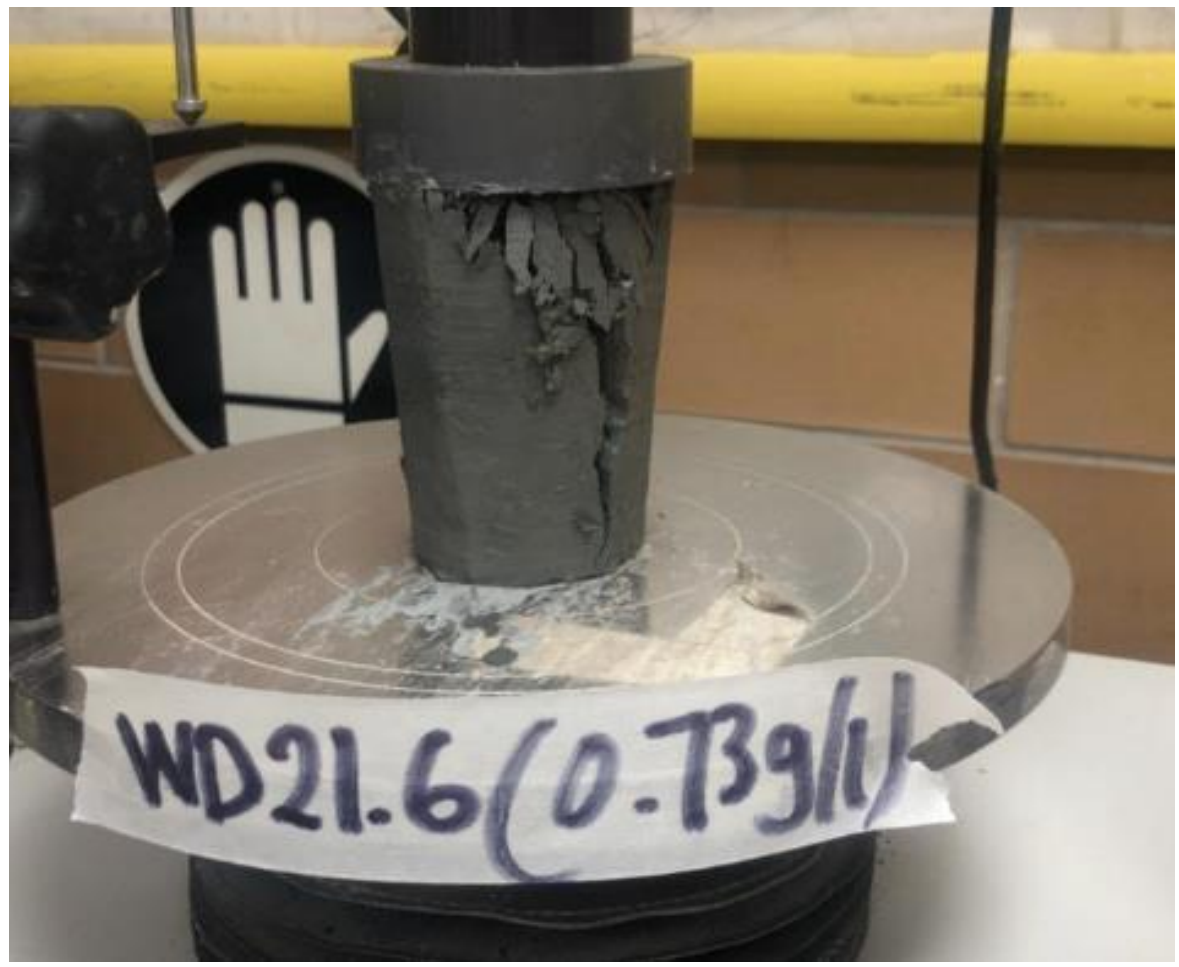

Figure 4-9: Photograph of the failure mode of a leached sample at $0.73 \mathrm{~g} / \mathrm{L}$ 
The structure of the clay particle after being leached from 15.53 to $0.73 \mathrm{~g} / \mathrm{L}$ is shown in Figure 4-10. Figure 4-11 shows the average elemental composition of the leached sample. As compared to natural clay elemental composition, the leached one has lost all the chlorine element and the sodium drops from $18.8 \mathrm{wt}$. \% in the natural clay to $1.7 \mathrm{wt}$ \% in the leached salt.

The morphological patterns, particle arrangements, and interactions observed in Figure 4-10 are different from those observed in the previous SEM images of natural clay. Compared to natural clay as shown in Figure 4-4, the leached clay exhibits less flocculation, and thin platelets shape, while that of natural clay presents a flocculated and bulky shape. The pore sizes were close in both samples. Therefore, leaching caused the aggregated structure of Champlain Sea clay to change to individual tiny platelet structure. Therefore, a de-flocculation mechanism could be introduced to interpret the effect of salinity on strength.

The leachate collected from the leaching process was evaporated in an oven over time. The precipitated salt was then analyzed under SEM and EDS as shown in Figure 4-12 and Figure 4-13. The salt was identified as sodium chloride as more than 69 wt. \% of the elemental composition of the salt is made of sodium and chlorine as shown in the EDS analysis in Figure 4-13.

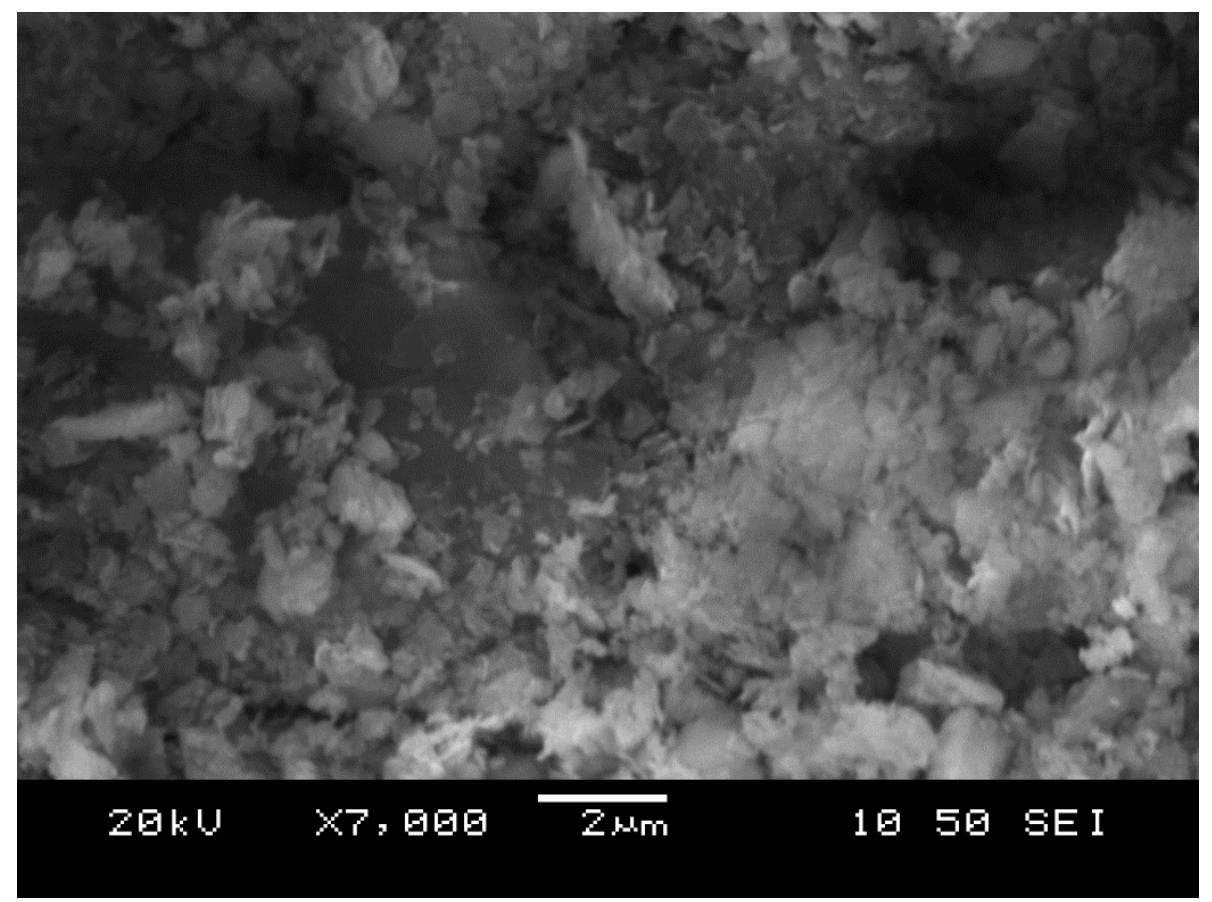

Figure 4-10: SEM micrograph of leached clay sample to $0.73 \mathrm{~g} / \mathrm{L}$ 


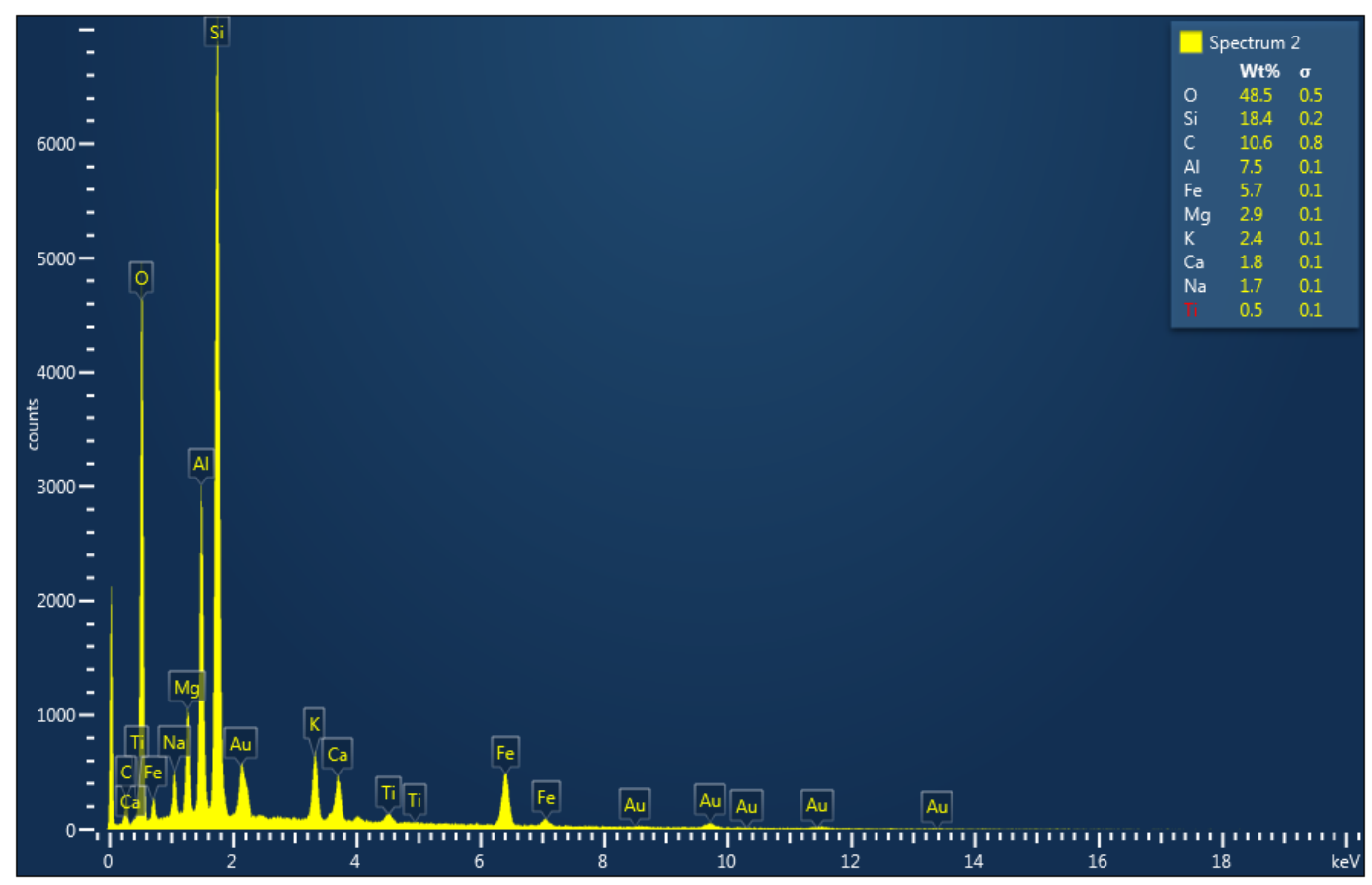

Figure 4-11: Average elemental composition of Leached clay to $0.73 \mathrm{~g} / \mathrm{L}$

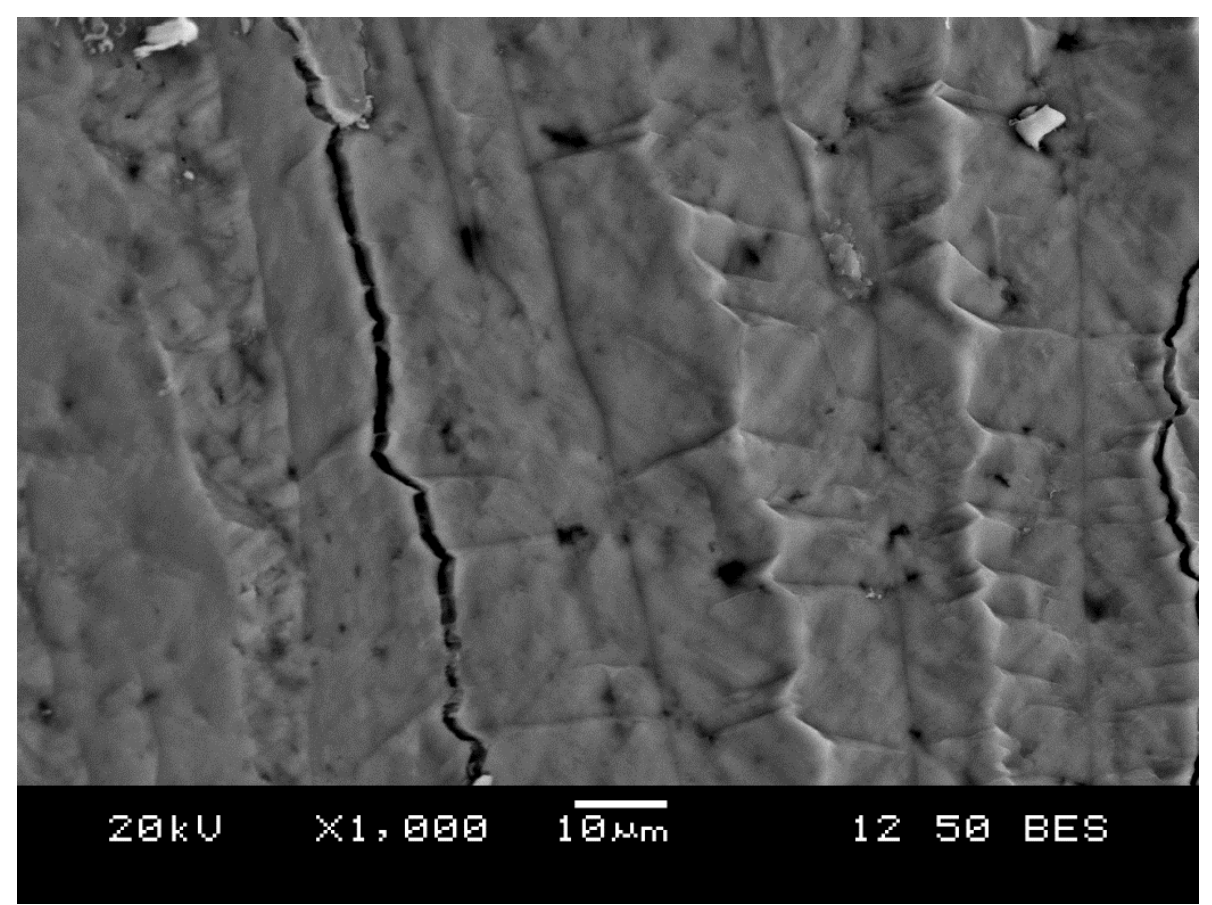

Figure 4-12: SEM micrograph of salt collected from the leachate 


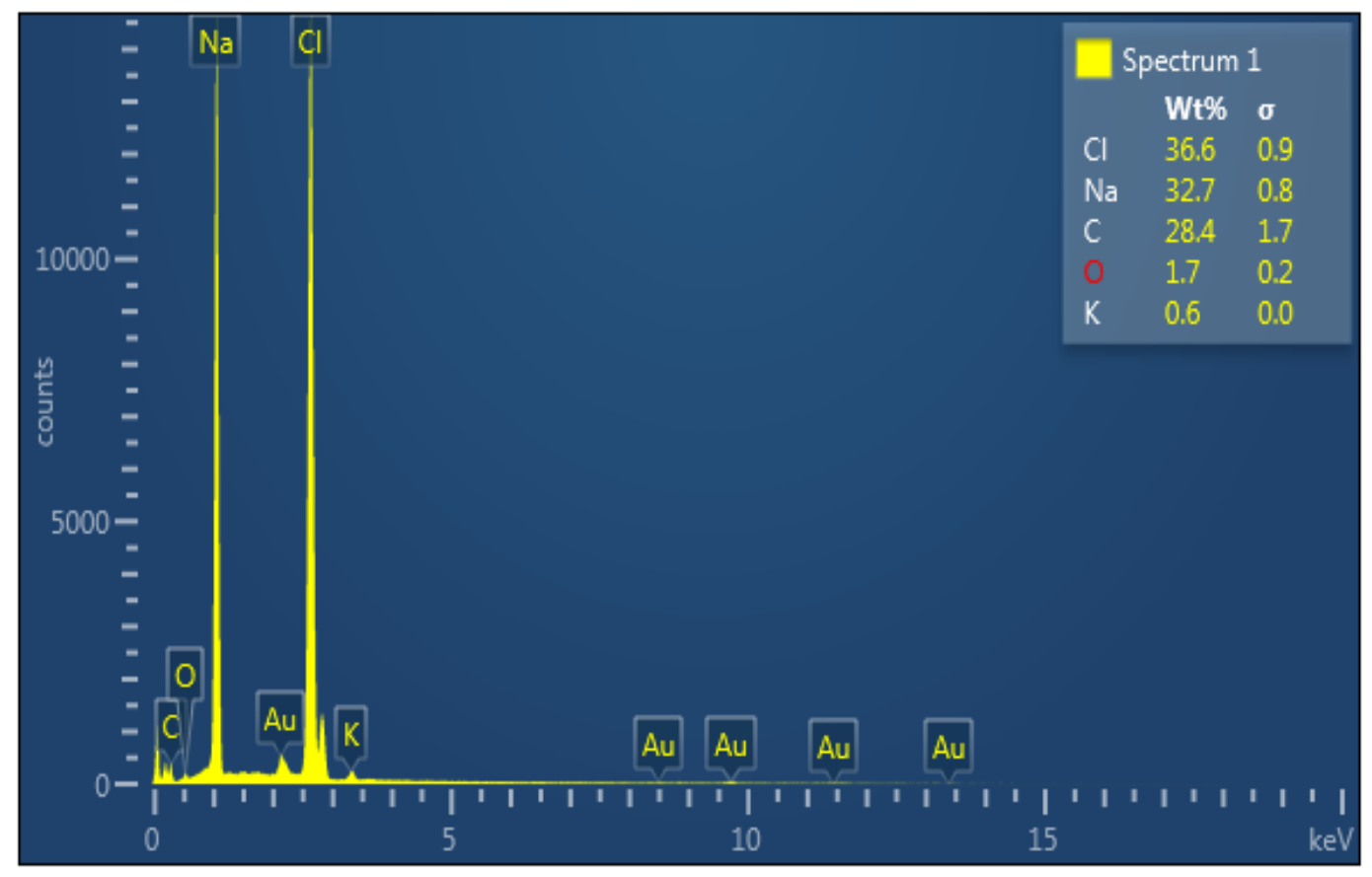

Figure 4-13: Leached salt elemental composition

\subsubsection{Salinized clay}

The salinity of natural clay was increased from 15.53 to $30.55 \mathrm{~g} / \mathrm{L}$ by adding $1 \%$ by weight of table salt to natural clay. The UCS tests were not performed on the salinized clay because mixing clay with salt to reach the required salinity has disturbed the clay and was not possible to obtain undisturbed clay samples with high salinity level. However, when the salt was added, the mixing process was more resistant than normal clay. Therefore, it can be concluded that there is an increase in shear strength in clay with a high salinity concentration in the pore fluid.

Figure 4-14 shows an SEM micrograph of a sample with a salinity level of $30.55 \mathrm{~g} / \mathrm{L}$ magnified by X5000. The high level of flocculation observed in the SEM micrograph can be explained by the diffused double layer theory, the added salt has increased the pore fluid concentration leading to a reduction in the double diffusion layer systems. When the double diffusion layer compressed, repulsive forces decrease much more than the attractive forces promoting the fine particles to be flocculated. Therefore, an increase in salinity in Champlain Sea clay increases the degree of flocculation, as shown in Figure 4-14. This flocculation could be the reason behind the observed 
increase in shear strength during salinization process. The influence of salinity level on the diameters of aggregates and pores was not significant. However, a redistribution or pores was observed in the salinized specimen due to flocculation. The average elemental composition of the salinized clay to $30.55 \mathrm{~g} / \mathrm{L}$ is shown in Figure 4-15. The EDS graph shows that both sodium element and chlorine represent more than $94 \mathrm{wt}$. \% of the total weight of the specimen elements.

\subsection{IMPACT OF BINDER DOSAGE}

The natural clay samples were mixed with cement at three different dosages of 50, 100, and 200 $\mathrm{kg} / \mathrm{m}^{3}$ and cured for 7, 14, 28 and 300 days before the UCS tests. The microstructure changes after mixing and curing were also investigated using SEM.

\subsubsection{Unconfined compressive strength}

Significant strength improvement was observed after the soil is mixed with cement as shown in Table 4-1. Initial trials at low cement dosage of $50 \mathrm{~kg} / \mathrm{m}^{3}$ by the mixture volume, yielded a significant shear strength improvement for Champlain Sea clay. The average of UCS tests yielded $613,721,845$, and $1027 \mathrm{kPa}$ for samples cured for 7, 14, 28, and 300 days respectively. The trend of strength increase with an increasing curing time is clearly observed. Samples cured for 28 days were improved 10 times compared to UCS of natural clay.

When cement dosage was increased to $100 \mathrm{~kg} / \mathrm{m}^{3}$, the UCS values increased more substantially. The average UCS values of 1770, 1964, 2112.5, and $2615 \mathrm{kPa}$ were recorded for samples cured for $7,14,28$, and 300 days. This increase in UCS is mainly due to the cement dosage increase. Samples treated with $100 \mathrm{~kg} / \mathrm{m}^{3}$ under a 28 days curing reached an improvement ratio of almost 26. This increase in strength could be due to the increase in cement hydration product and the reduction in water content of the treated clay.

As the cement dosage was increased to $200 \mathrm{~kg} / \mathrm{m}^{3}$, an improvement ratio of almost 34 was observed for samples cured for 28 days. One outlier was identified in this experiment, Sample WD21.6C200D28UCS1 reached the peak UCS of $2103 \mathrm{kPa}$, whereas, Sample WD21.6C200D28UCS2, the second UCS test for the same condition, reached $2844 \mathrm{kPa}$. The big difference between the two samples may be due to the inconsistent compaction in the first sample, 
which was excluded for further analysis. The average UCS values of 2006, 2523, 2844, and 4594 $\mathrm{kPa}$ were recorded for samples cured for 7, 14, 28, 300 days.

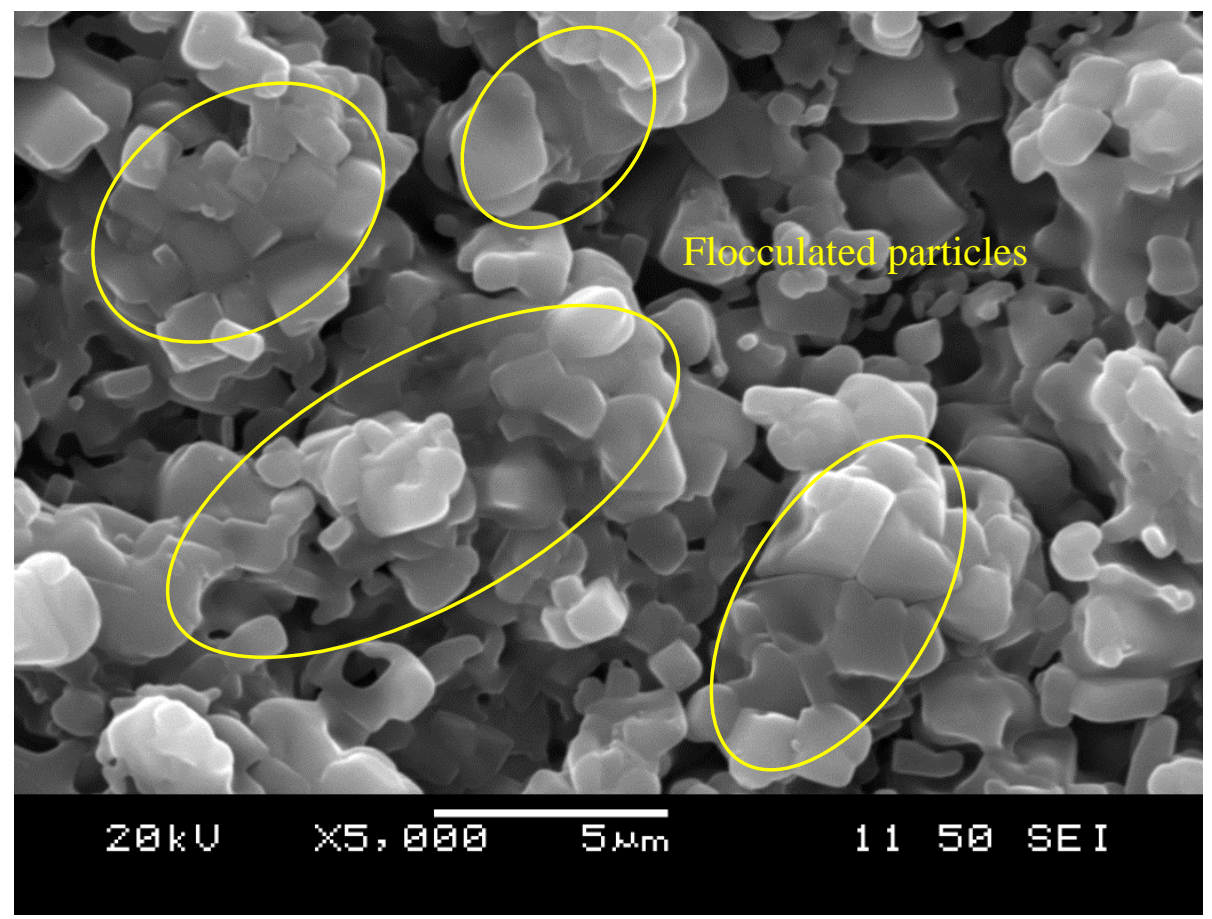

Figure 4-14: SEM micrograph of salinized clay to $30.55 \mathrm{~g} / \mathrm{L}$

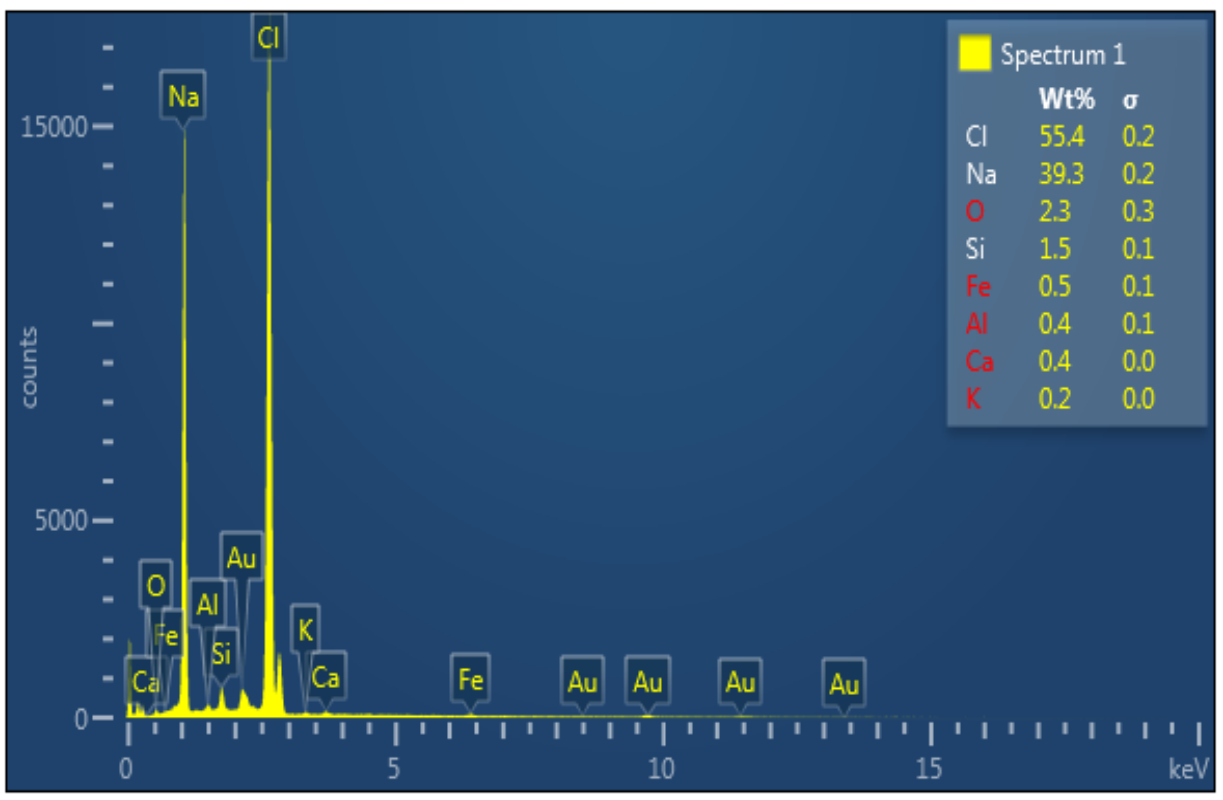

Figure 4-15: Average elemental composition of salinized clay to $30.55 \mathrm{~g} / \mathrm{L}$ 
Table 4-1: Peak UCS values of cement treated Champlain Sea clay

\begin{tabular}{|c|c|c|c|c|c|c|c|}
\hline $\begin{array}{l}\text { Mix } \\
\text { ID }\end{array}$ & Sample ID & $\begin{array}{l}\text { Binder } \\
\text { Type }\end{array}$ & $\begin{array}{l}\text { Dosage } \\
\left(\mathrm{kg} / \mathrm{m}^{3}\right)\end{array}$ & $\begin{array}{c}\text { Curing } \\
\text { Time } \\
\text { (days) }\end{array}$ & $\begin{array}{l}\text { Peak } \\
\text { UCS } \\
(\mathrm{kPa})\end{array}$ & $\begin{array}{l}\text { Failure } \\
\text { strain, } \\
\varepsilon_{\mathrm{f}}(\%)\end{array}$ & $\begin{array}{c}\text { Dry } \\
\text { density, } \\
\gamma_{\mathrm{d}} \\
\left(\mathrm{kg} / \mathrm{m}^{3}\right) \\
\end{array}$ \\
\hline \multirow{8}{*}{ GU50 } & WD21.6C50D07UCS1 & $\overline{\mathrm{GU}}$ & 50 & 07 & 607 & 1.61 & 873 \\
\hline & WD21.6C50D07UCS2 & GU & 50 & 07 & 619 & 0.99 & 865 \\
\hline & WD21.6C50D14UCS1 & GU & 50 & 14 & 739 & 1.37 & 871 \\
\hline & WD21.6C50D14UCS2 & GU & 50 & 14 & 703 & 1.87 & 874 \\
\hline & WD21.6C50D28UCS1 & GU & 50 & 28 & 876 & 1.00 & 860 \\
\hline & WD21.6C50D28UCS2 & GU & 50 & 28 & 814 & 0.87 & 869 \\
\hline & WD21.6C50D300UCS1 & GU & 50 & 300 & 1021 & 1.59 & 875 \\
\hline & WD21.6C50D300UCS2 & GU & 50 & 300 & 1034 & 1.79 & 871 \\
\hline \multirow{8}{*}{ GU100 } & WD21.6C100D07UCS1 & GU & 100 & 07 & 1700 & 1.62 & 871 \\
\hline & WD21.6C100D07UCS2 & GU & 100 & 07 & 1840 & 1.37 & 877 \\
\hline & WD21.6C100D14UCS1 & GU & 100 & 14 & 1954 & 0.99 & 870 \\
\hline & WD21.6C100D14UCS2 & GU & 100 & 14 & 1974 & 1.37 & 869 \\
\hline & WD21.6C100D28UCS1 & GU & 100 & 28 & 1825 & 1.24 & 868 \\
\hline & WD21.6C1000D28UCS2 & GU & 100 & 28 & 2400 & 1.25 & 872 \\
\hline & WD21.6C100D300UCS1 & GU & 100 & 300 & 2771 & 1.29 & 869 \\
\hline & WD21.6C100D300UCS2 & GU & 100 & 300 & 2460 & 1.09 & 884 \\
\hline \multirow{7}{*}{ GU200 } & WD21.6C200D07UCS1 & GU & 200 & 07 & 2064 & 1.75 & 862 \\
\hline & WD21.6C200D07UCS2 & GU & 200 & 07 & 1948 & 1.75 & 881 \\
\hline & WD21.6C200D14UCS1 & GU & 200 & 14 & 2446 & 1.49 & 876 \\
\hline & WD21.6C200D14UCS2 & GU & 200 & 14 & 2600 & 1.24 & 877 \\
\hline & WD21.6C200D28UCS1 & GU & 200 & 28 & 2103 & 0.99 & 863 \\
\hline & WD21.6C200D28UCS2 & GU & 200 & 28 & 2844 & 0.99 & 881 \\
\hline & WD21.6C200D300UCS1 & GU & 200 & 300 & 4594 & 1.1 & 871 \\
\hline
\end{tabular}


Stress-strain curves of samples treated with $50 \mathrm{~kg} / \mathrm{m}^{3}$ cured for 7, 14, 28 and 300 days are shown in Figure 4-16. Samples treated with $50 \mathrm{~kg} / \mathrm{m}^{3}$ and cured for 300 days reached an UCS value of $1021 \mathrm{kPa}$ and the failure strain was recorded to be about 2.0\%. From Figure 4-16 it can be observed that not only the strength was increased with cement content and curing time, but also the stiffness was remarkably increased compared to natural clay.

Stiffness and strength of samples treated with 100 and $200 \mathrm{~kg} / \mathrm{m}^{3}$ increased with curing time as shown in Figure 4-17 and Figure 4-18 respectively. Samples cured for 300 days reached an UCS of $2771 \mathrm{kPa}$ and failed at $1.62 \%$ strain. The stiffness of the samples did not show a big difference after the 14 days of curing. Those treated with $200 \mathrm{~kg} / \mathrm{m}^{3}$ reached an UCS of $4594 \mathrm{kPa}$ and failed at $1.12 \%$ strain. Samples cured for 300 days showed the highest stiffness among other samples with different curing times.

The average of the peak UCS value evaluated at each curing period shown in Table 4-1were plotted against curing time and it is shown in Figure 4-20. Experimental results showed that UCS were significantly increased when compared with the strength of the untreated soil. In addition, it was found that the strength increases when cement dosage and curing time increase. However, the strength gain rate, represented by the slope of the curves, is different for different cement dosage. Samples with cement dosages of 50 , and $100 \mathrm{~kg} / \mathrm{m}^{3}$ show almost a similar strength gain rate as the segment of their curves are almost parallel. While samples treated with $200 \mathrm{~kg} / \mathrm{m}^{3}$ show a higher strength gain rate especially after the 28-day curing period. This may be due to the sufficient amount of hydration product calcium hydroxide in the higher dosage case, as will be discussed from SEM micrographs, that contribute to the pozzolanic reaction producing more calcium silicate hydrate responsible for the strength gain. The higher strength gain rate may also be due to the availability of cement particles for further hydration as opposed to the limited amount of cement particles in the 50 and $100 \mathrm{~kg} / \mathrm{m}^{3}$ mixes.

As a general trend, the stiffness and strength increase with increasing curing time and cement dosage. The increase rate in shear strength is proportional to the amount of binder mixed with the soil and the curing time. 


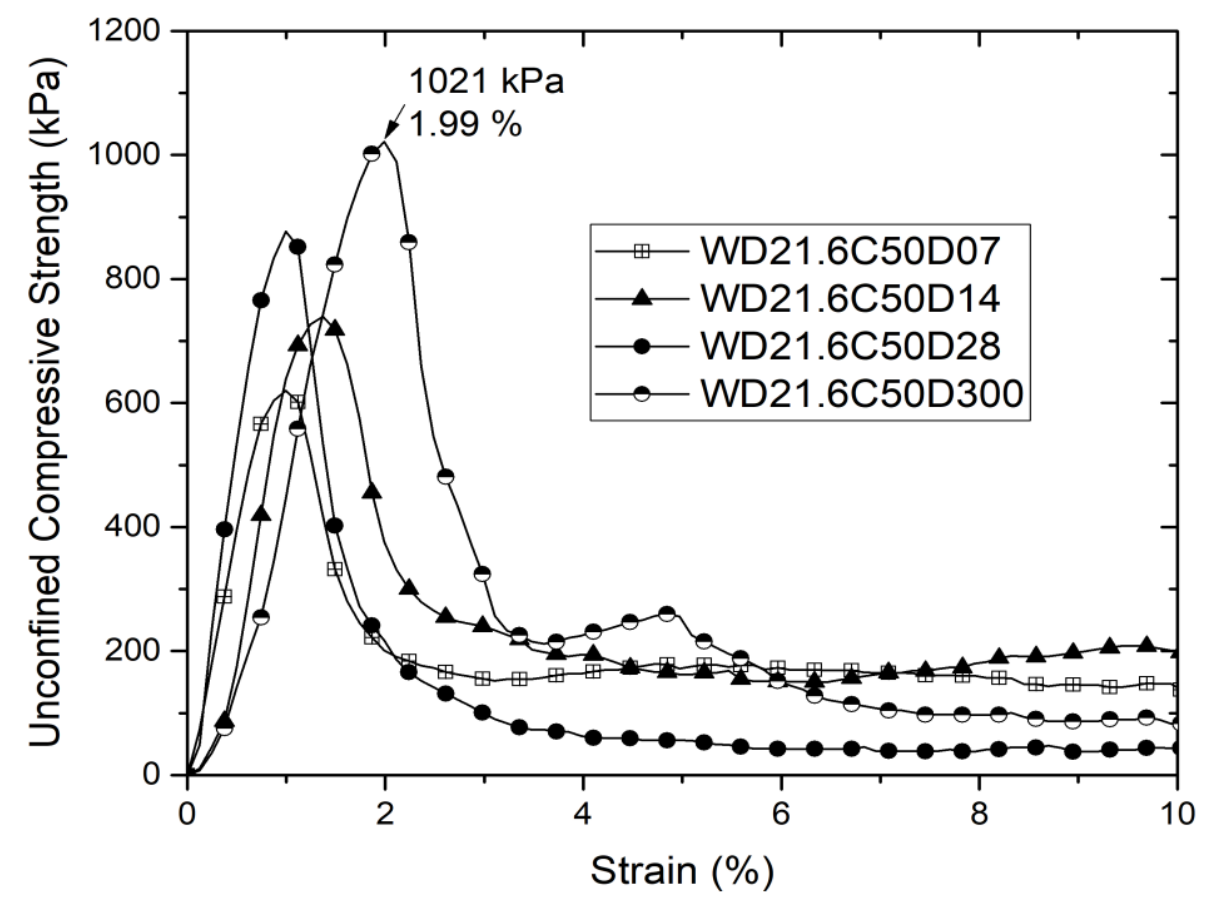

Figure 4-16: Stress-strain curves of treated clay with $50 \mathrm{~kg} / \mathrm{m}^{3}$ cured for 7, 14, 28, and 300 days

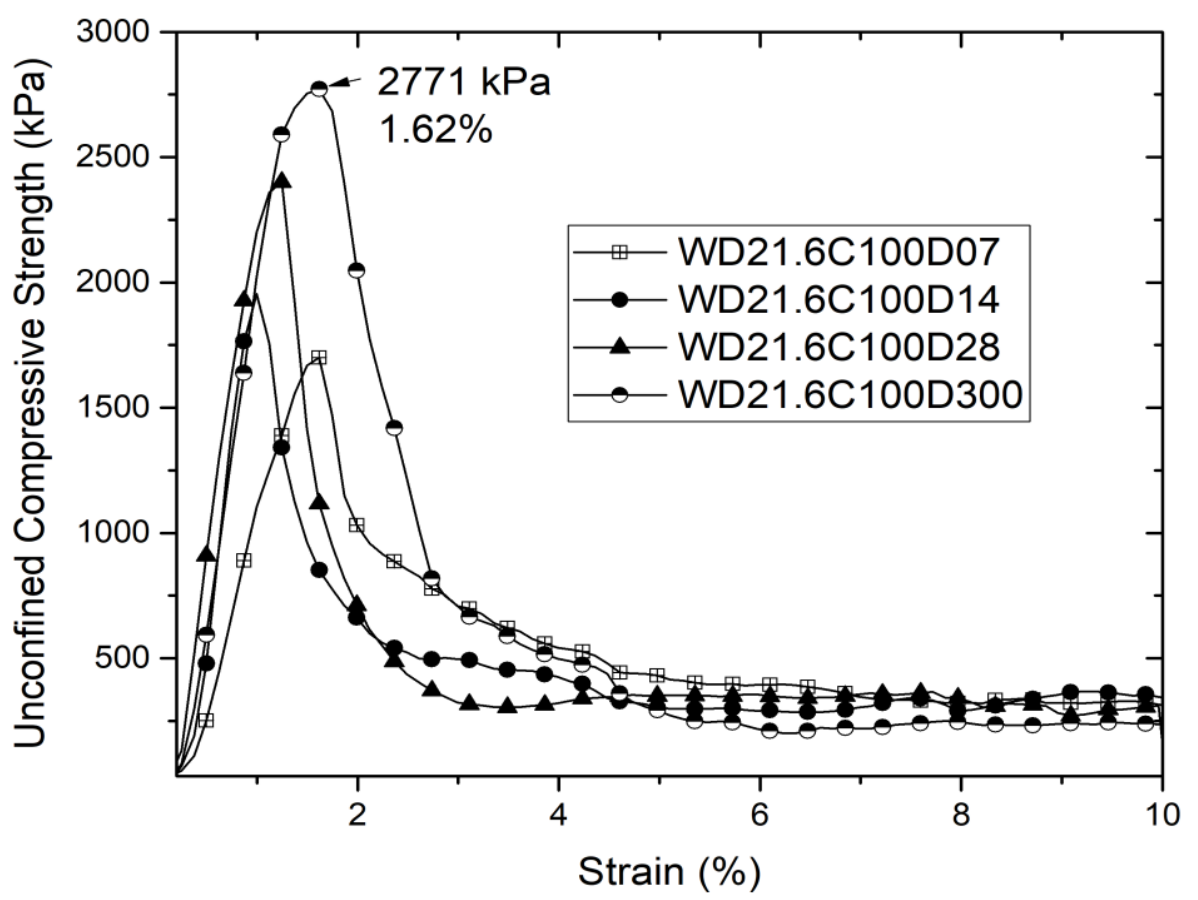

Figure 4-17: Stress-strain curves of treated clay with $100 \mathrm{~kg} / \mathrm{m}^{3}$ cured for 7, 14, 28 and, 300 days 


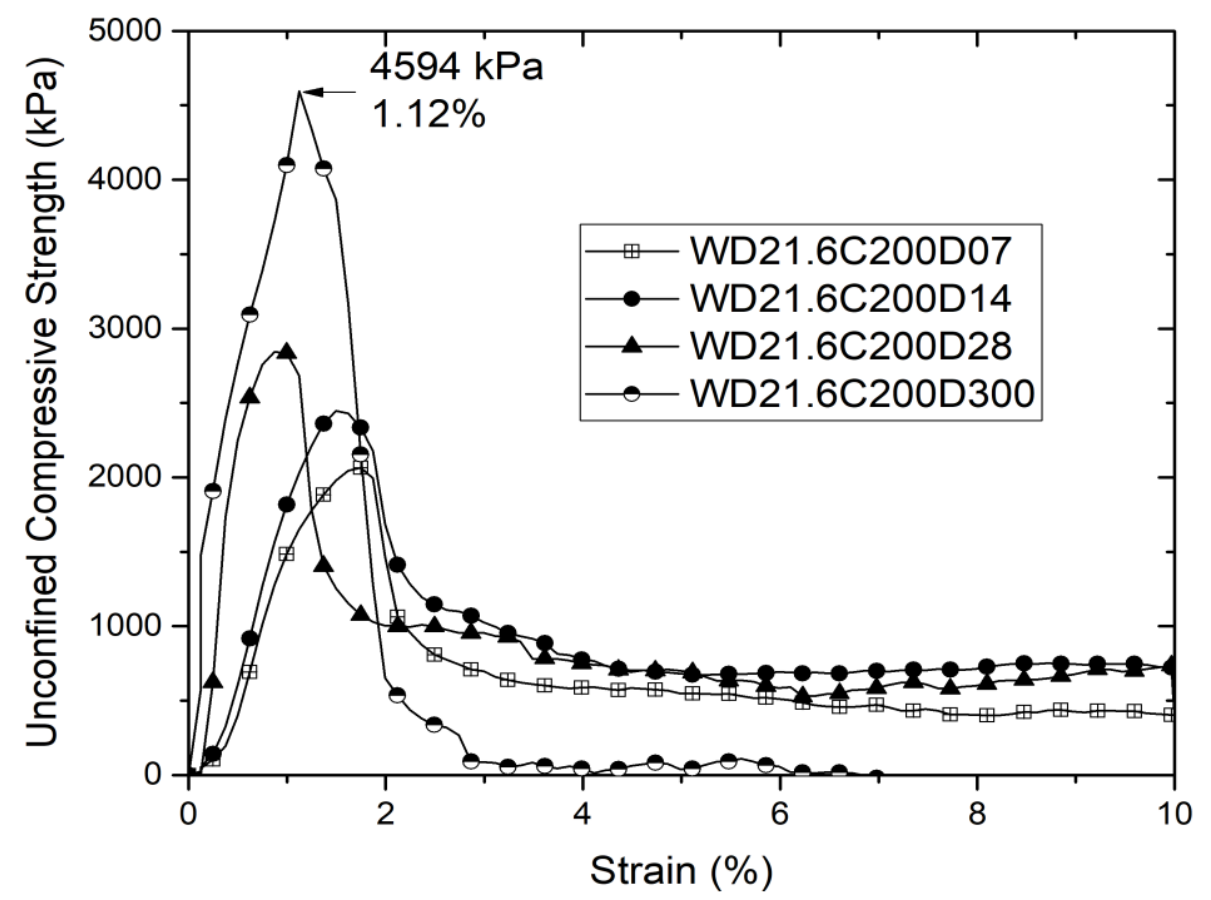

Figure 4-18: Stress-strain curves of treated clay with $200 \mathrm{~kg} / \mathrm{m}^{3}$ cured for 7, 14, 28, and 300 days

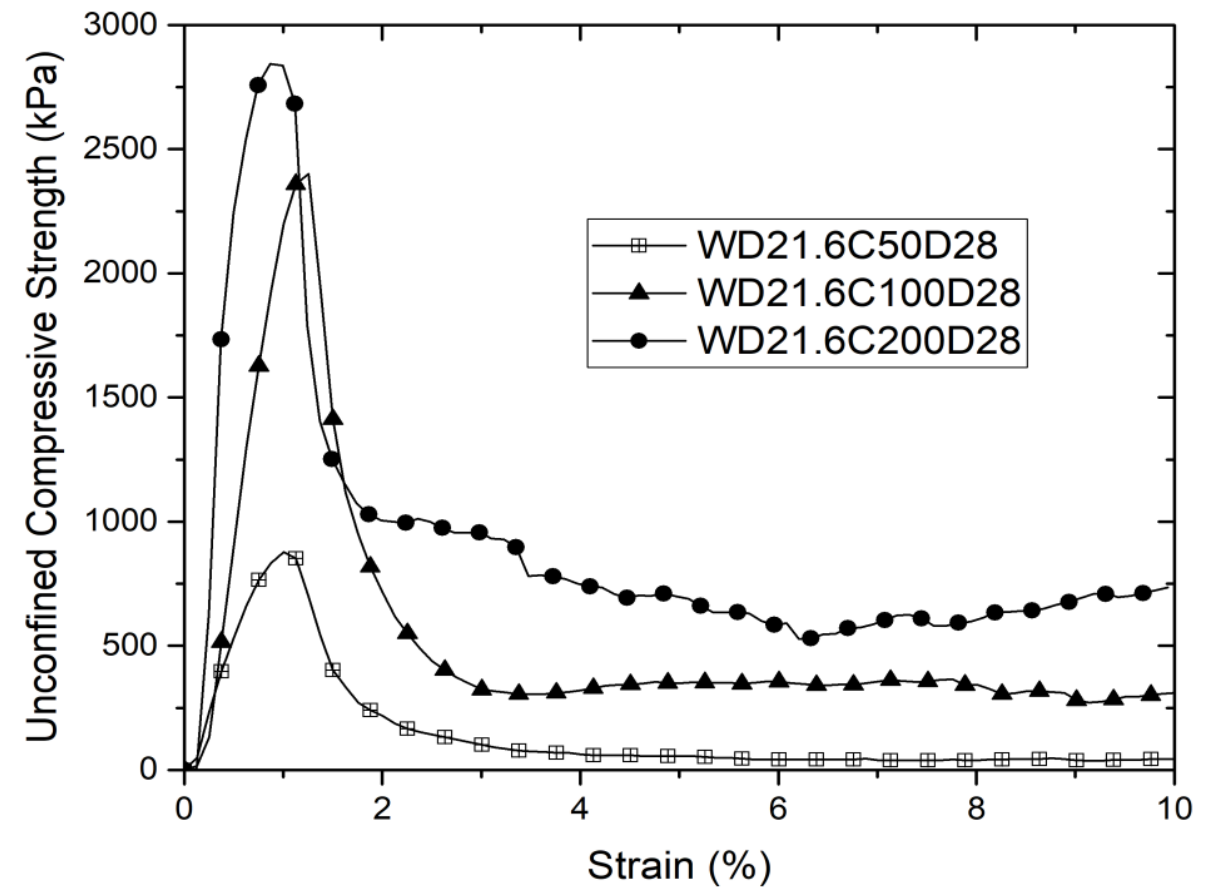

Figure 4-19: Stress-strain curves of treated clay with $50,100,200 \mathrm{~kg} / \mathrm{m}^{3}$ cured for 28 days 


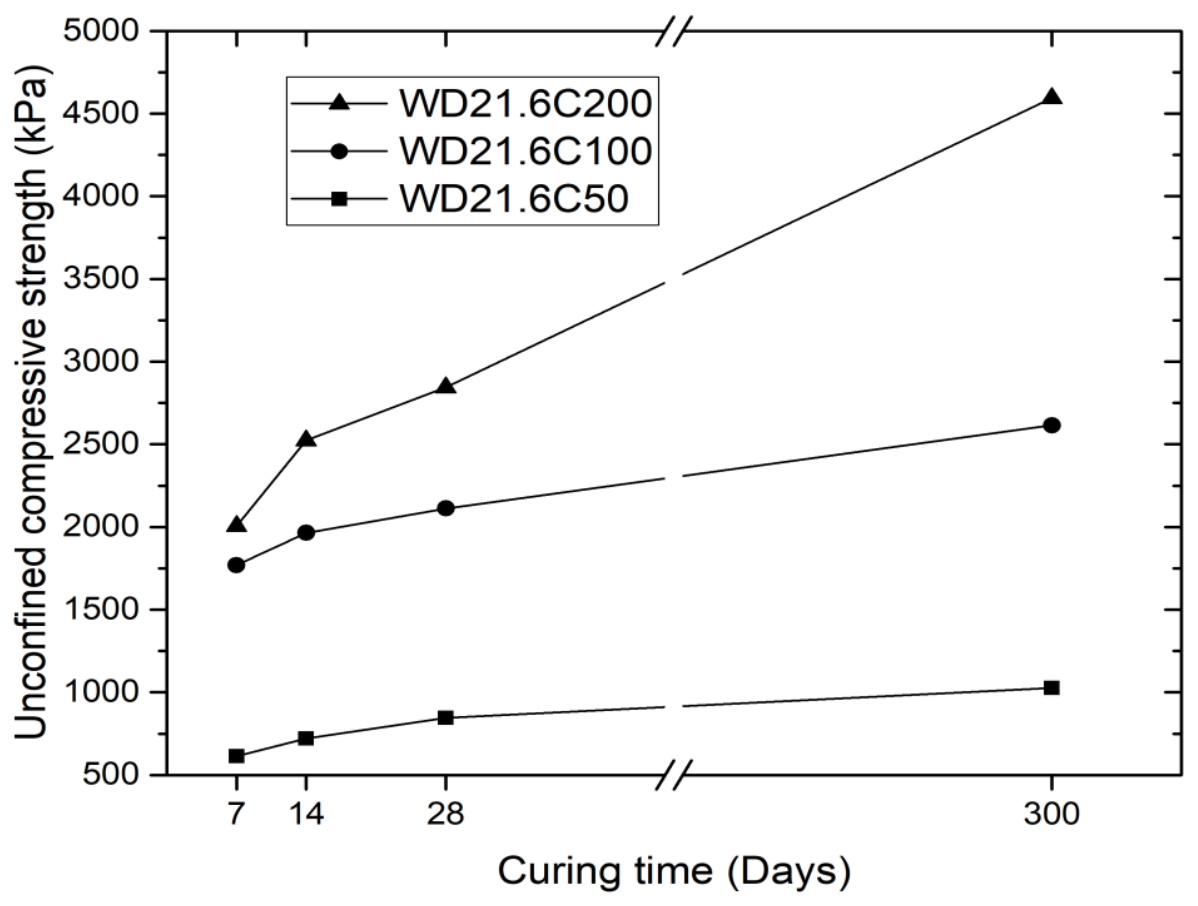

Figure 4-20: UCS vs. curing time of samples treated with 50,100 , and $200 \mathrm{~kg} / \mathrm{m}^{3}$

\subsubsection{Microstructure changes of cemented samples}

In previous section the microstructures of the untreated clay were presented. Figure 4-21 shows the texture of the untreated soil used in this experiment as the baseline for comparison with those of treated samples. In this section the microstructure of the cement-soil mixture will be presented. Figure 4-22 shows SEM micrographs of clay samples treated with the same cement dosage 50 $\mathrm{kg} / \mathrm{m}^{3}$ under different curing times of 7, 14, and 28 days. Microstructure of the sample cured for 7 days, as shown in Figure 4-22a, did not show a big difference from the untreated samples due to insufficient curing time at low dosage of $50 \mathrm{~kg} / \mathrm{m} 3$. However, with an increasing curing time the hydration product clearly changes the microstructure of the cemented soil sample, as shown in Figure 4-22b for 14 days of curing and Figure 4-22c for 28 days of curing. The interaggregate pores were filled and the single platelets were glued together to form bigger aggregates. Soil microstructure of the stabilized soil was relatively denser than that of the untreated soil. There is not a significant change in the microstructure of 14-day cured sample and the 28-day cured sample. This observation is also in agreement with the UCS tests results, two 14-day cured sample reached an average UCS value of $721 \mathrm{kPa}$, compared to that of $845 \mathrm{kPa}$ for two 28-day cured samples. 
This could be due to the unavailability of cement for further hydration after 14 days of curing. Thus, a cement dosage more than $50 \mathrm{~kg} / \mathrm{m}^{3}$ is needed to ensure a strength increase with time.

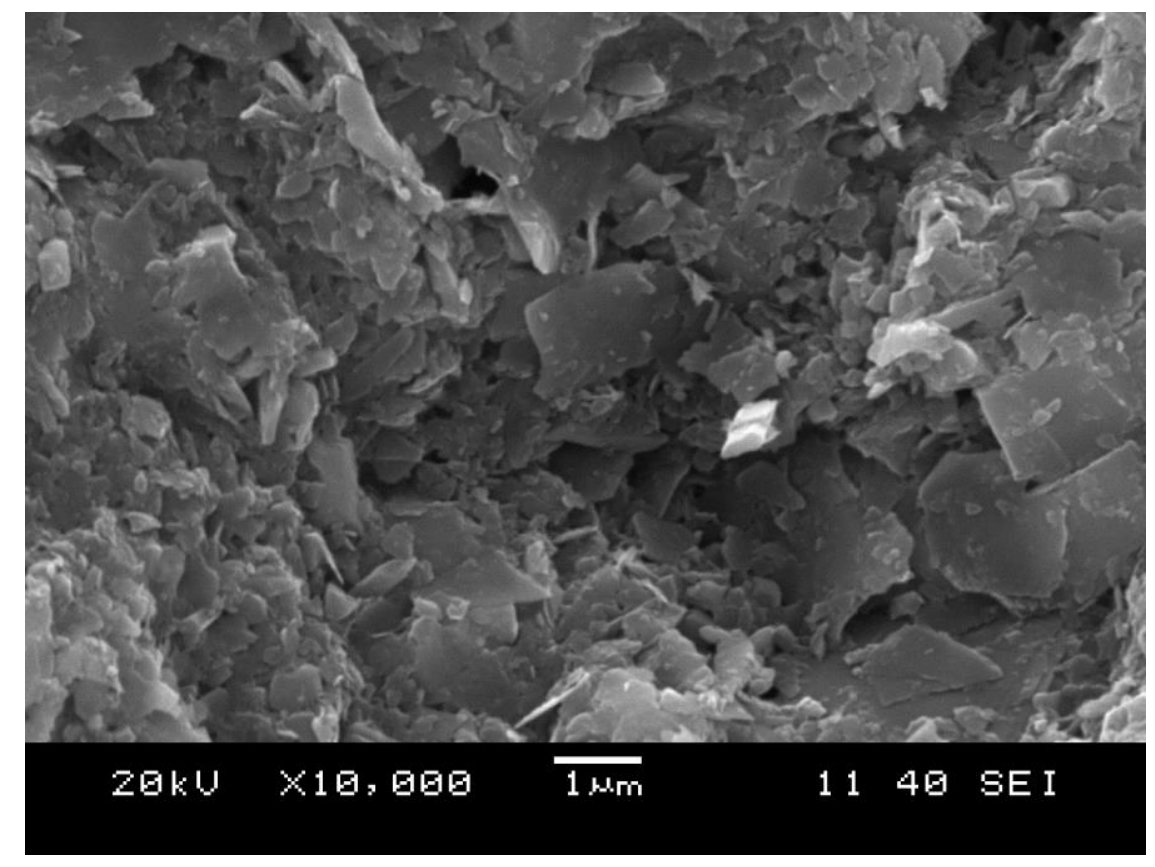

Figure 4-21: SEM micrograph of untreated soil sample

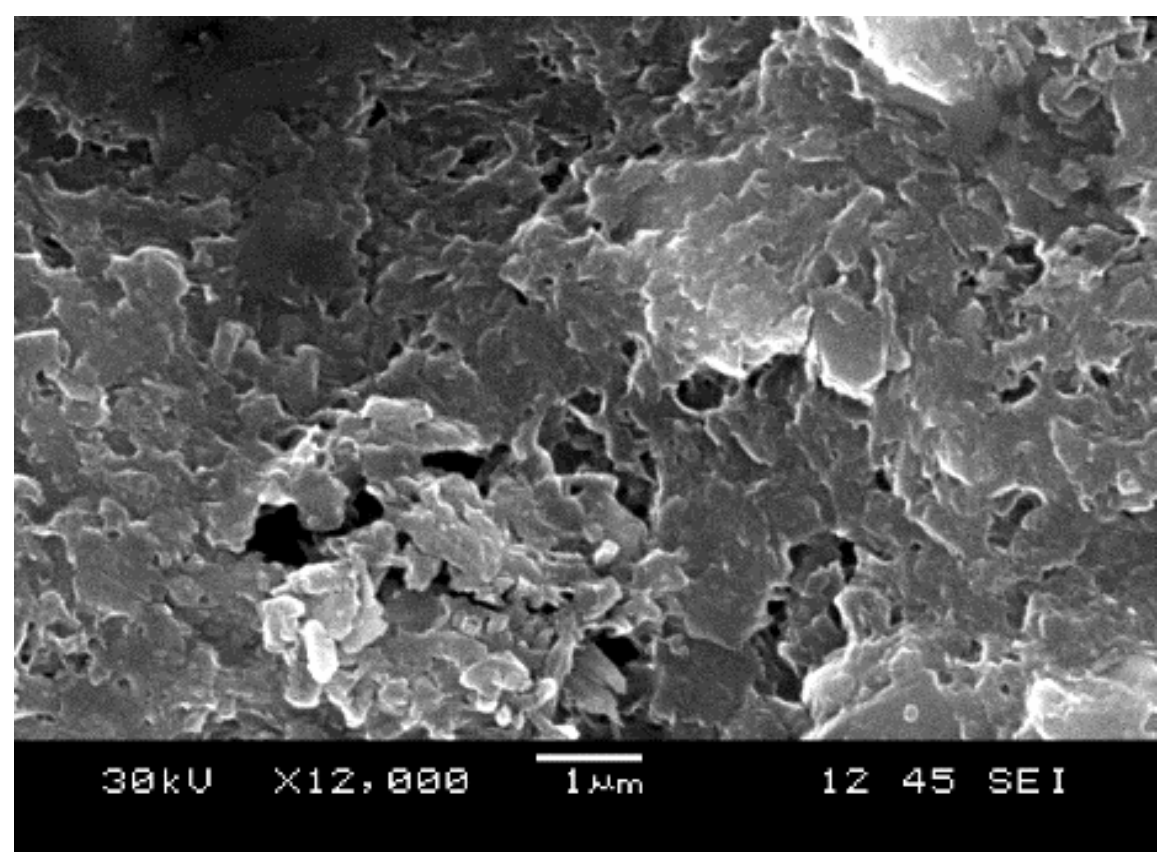

(a) Natural clay treated with $50 \mathrm{~kg} / \mathrm{m}^{3}$ of cement cured for 7 days 


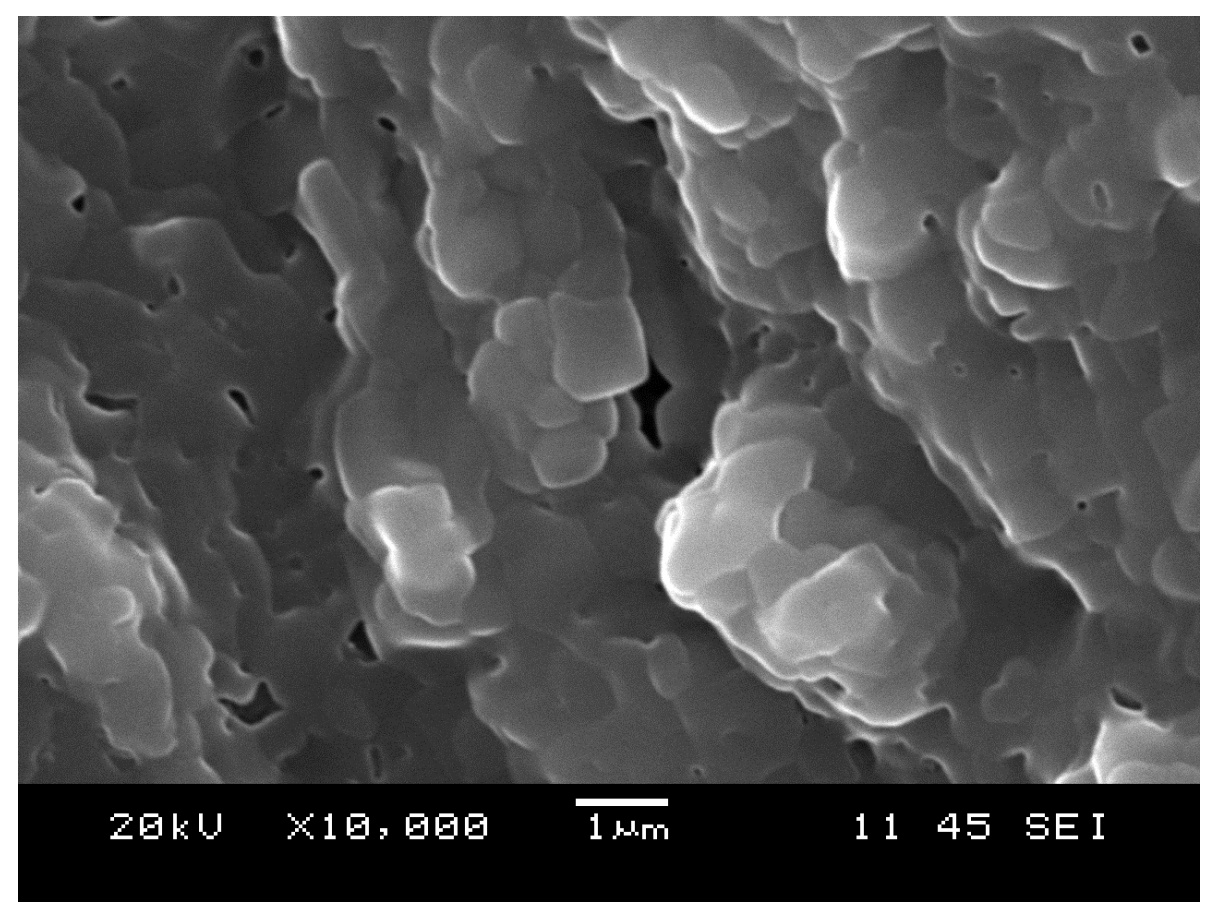

(b) Natural clay treated with $50 \mathrm{~kg} / \mathrm{m}^{3}$ of cement cured for 14 days

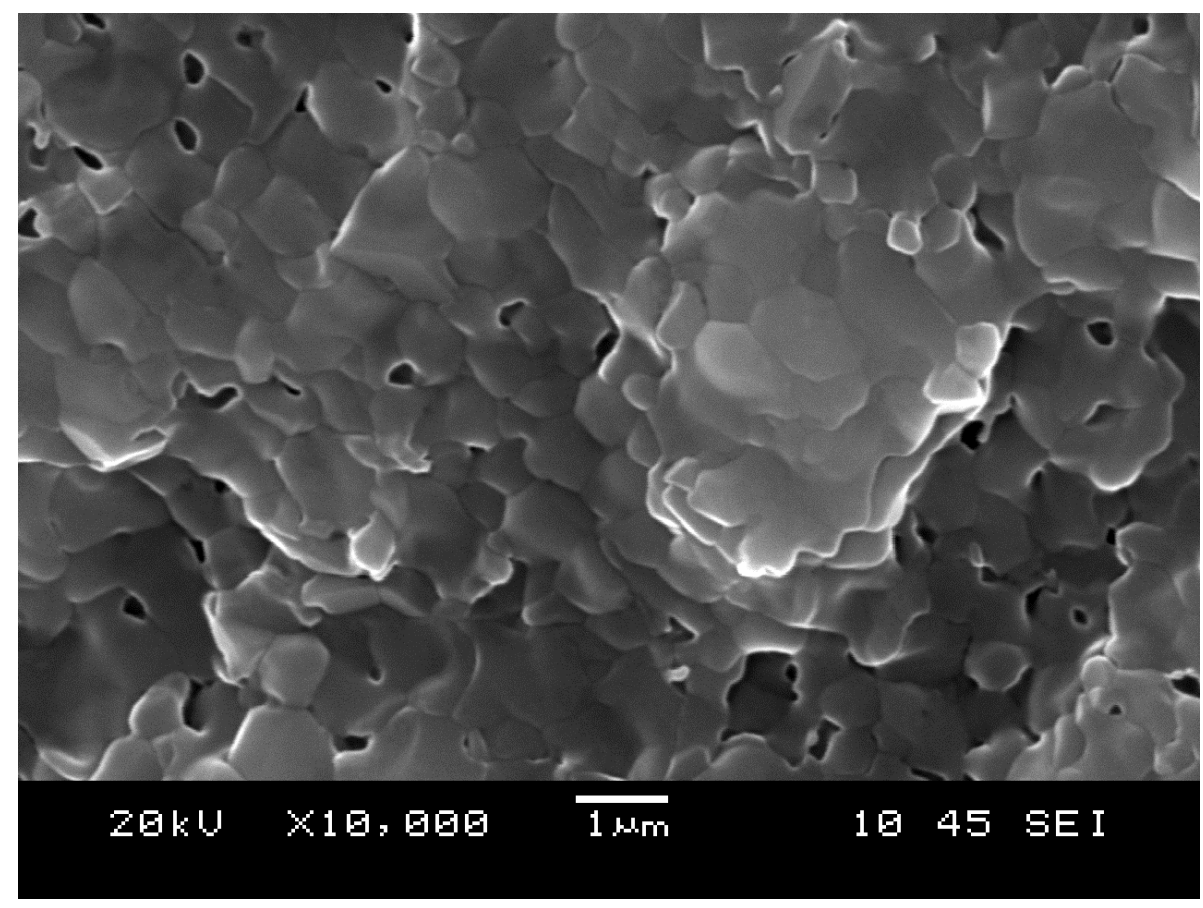

(c) Natural clay treated with $50 \mathrm{~kg} / \mathrm{m}^{3}$ of cement cured for 28 days

Figure 4-22: SEM micrograph of clay sample treated with $50 \mathrm{~kg} / \mathrm{m}^{3}$ cured for 7,14 , and 28 days 
As the cement dosage was increased to $100 \mathrm{~kg} / \mathrm{m}^{3}$, significant changes in soil microstructure due to cement hydration could be observed in SEM micrographs showed in Figure 4-23. An early formation of hydration products was observed in the 7-day cured sample, as shown in Figure 4-23a. Substantial growths of reaction products can be observed as the curing time increased to 14 days. Figure 4-23b with a higher magnification level than other figures reveals the formation of cementitious bridges in the form of needle-like crystals called ettringite (marked by rectangles) between clay aggregates and the formation CSH fabrics on the surface of the stabilized soil. In the 28-day cured sample, substantial pores were closed and more CSH were hardened on the surface of the stabilized soil. These major reaction products filled up the voids previously filled with water which results in strength increase.

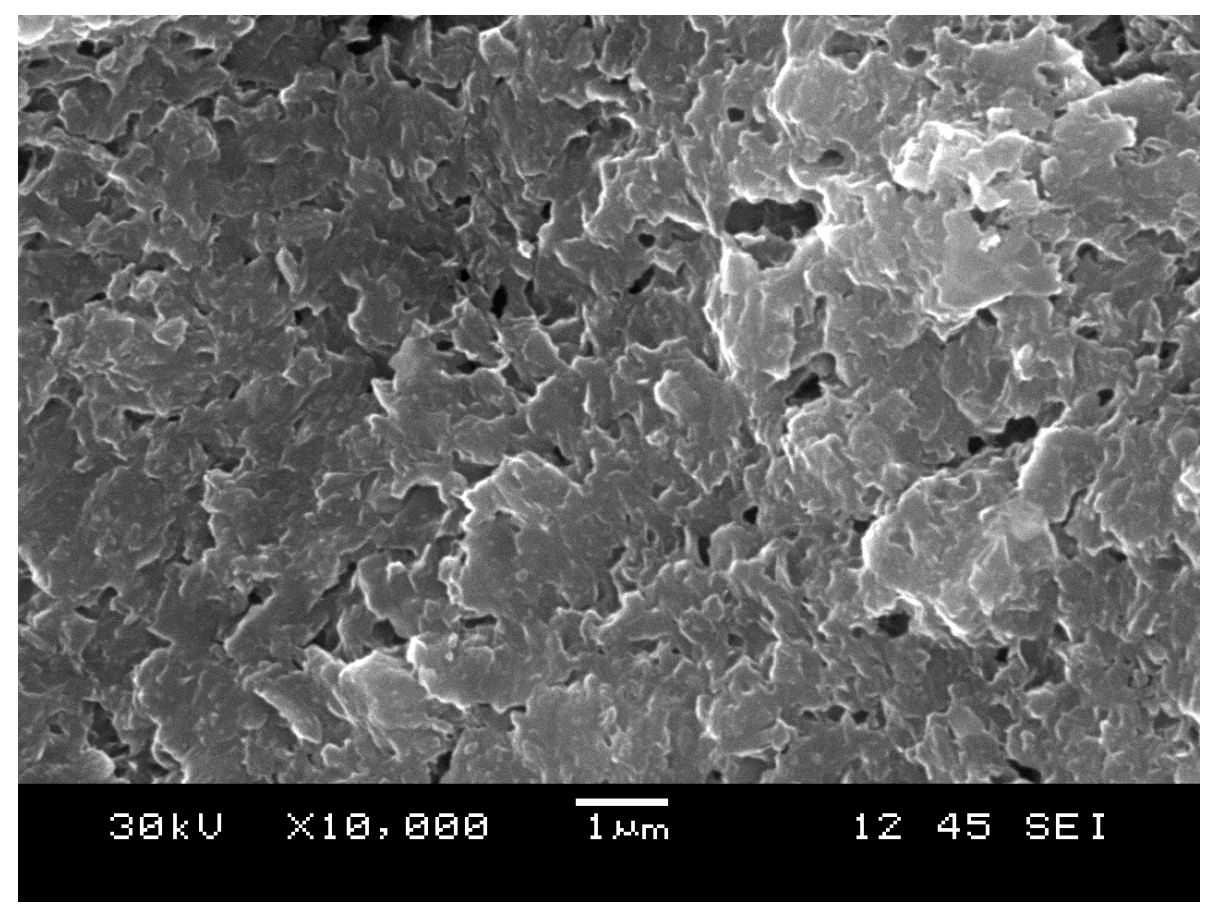

(a) Natural clay treated with $100 \mathrm{~kg} / \mathrm{m}^{3}$ of cement cured for 7 days 


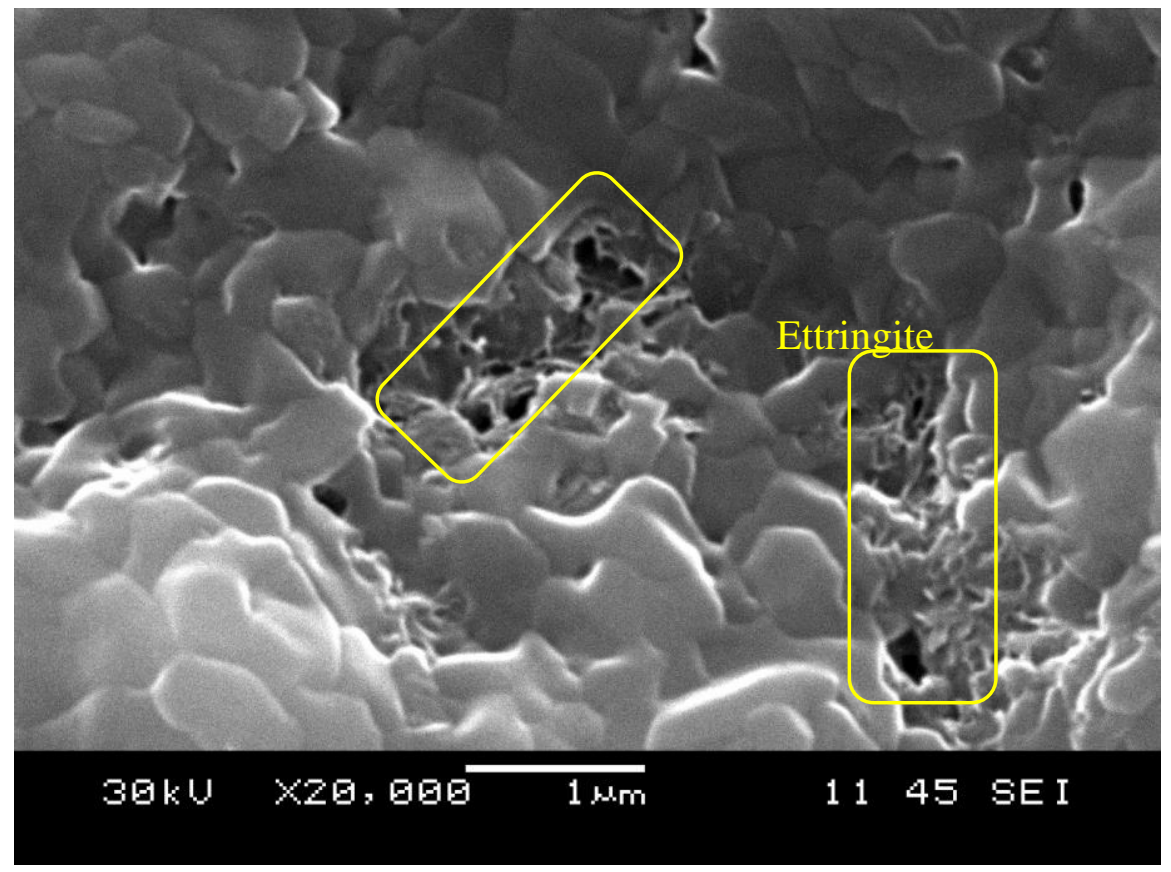

(b) Natural clay treated with $100 \mathrm{~kg} / \mathrm{m}^{3}$ of cement cured for 14 days

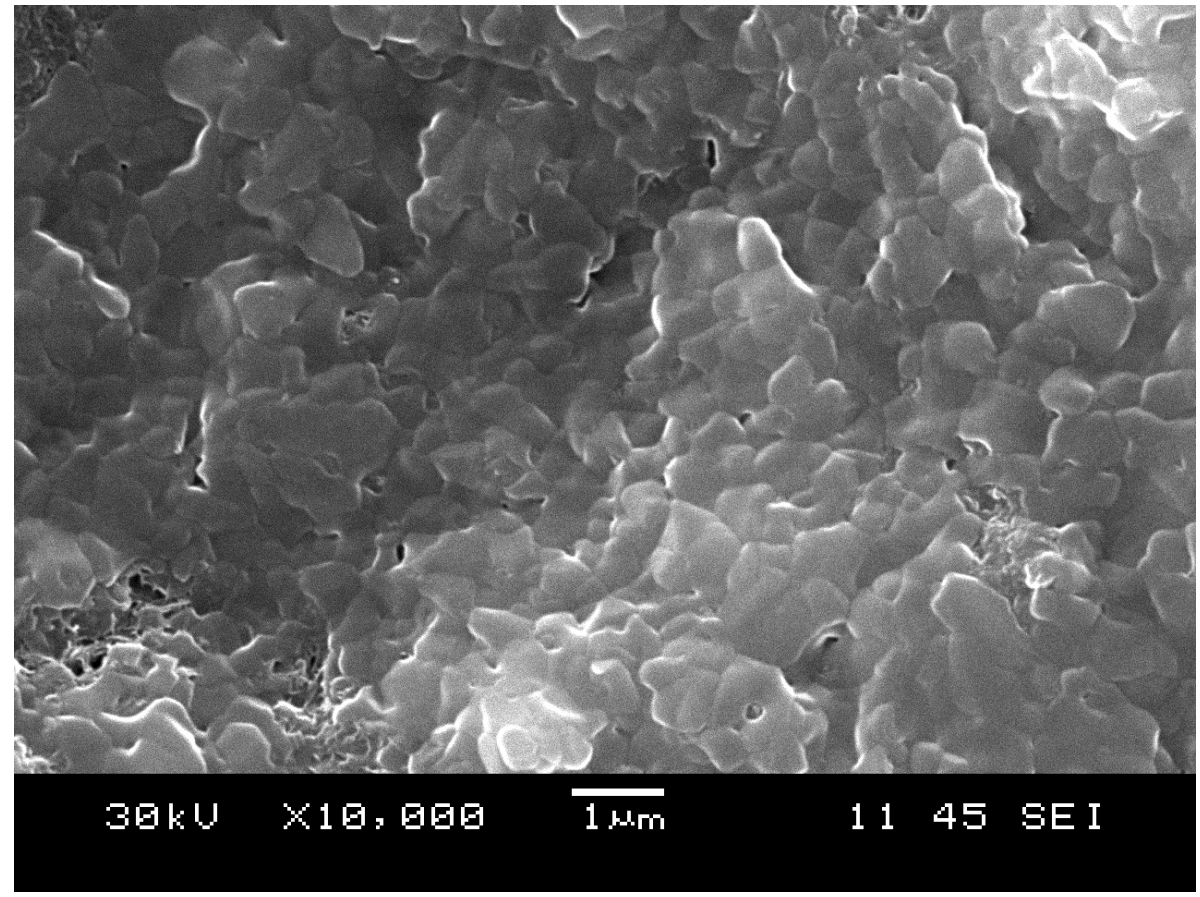

(c) Natural clay treated with $100 \mathrm{~kg} / \mathrm{m}^{3}$ of cement cured for 28 days

Figure 4-23: SEMs of clay samples treated with $100 \mathrm{~kg} / \mathrm{m}^{3}$ cured for 7, 14, and 28 days 


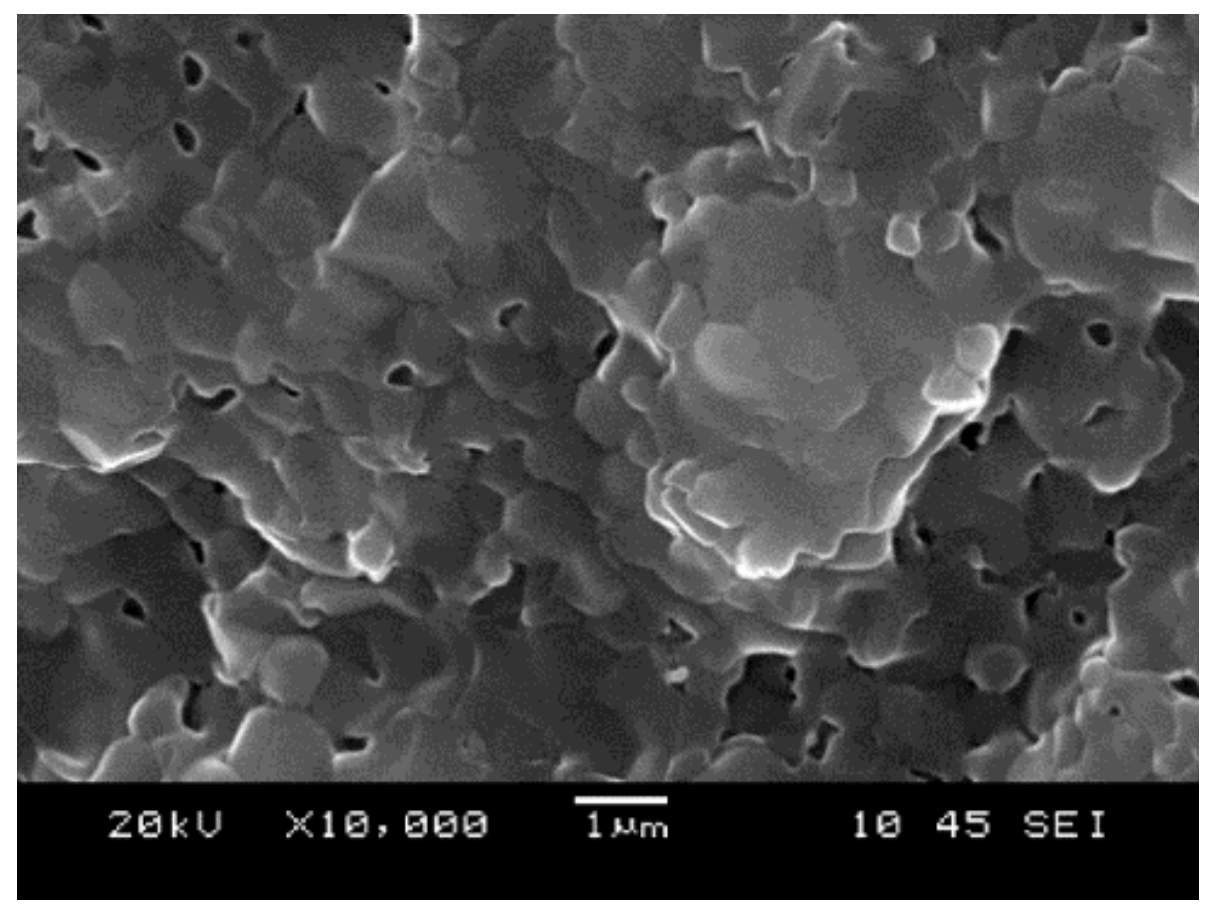

(a) Natural clay treated with $200 \mathrm{~kg} / \mathrm{m}^{3}$ of cement cured for 7 days

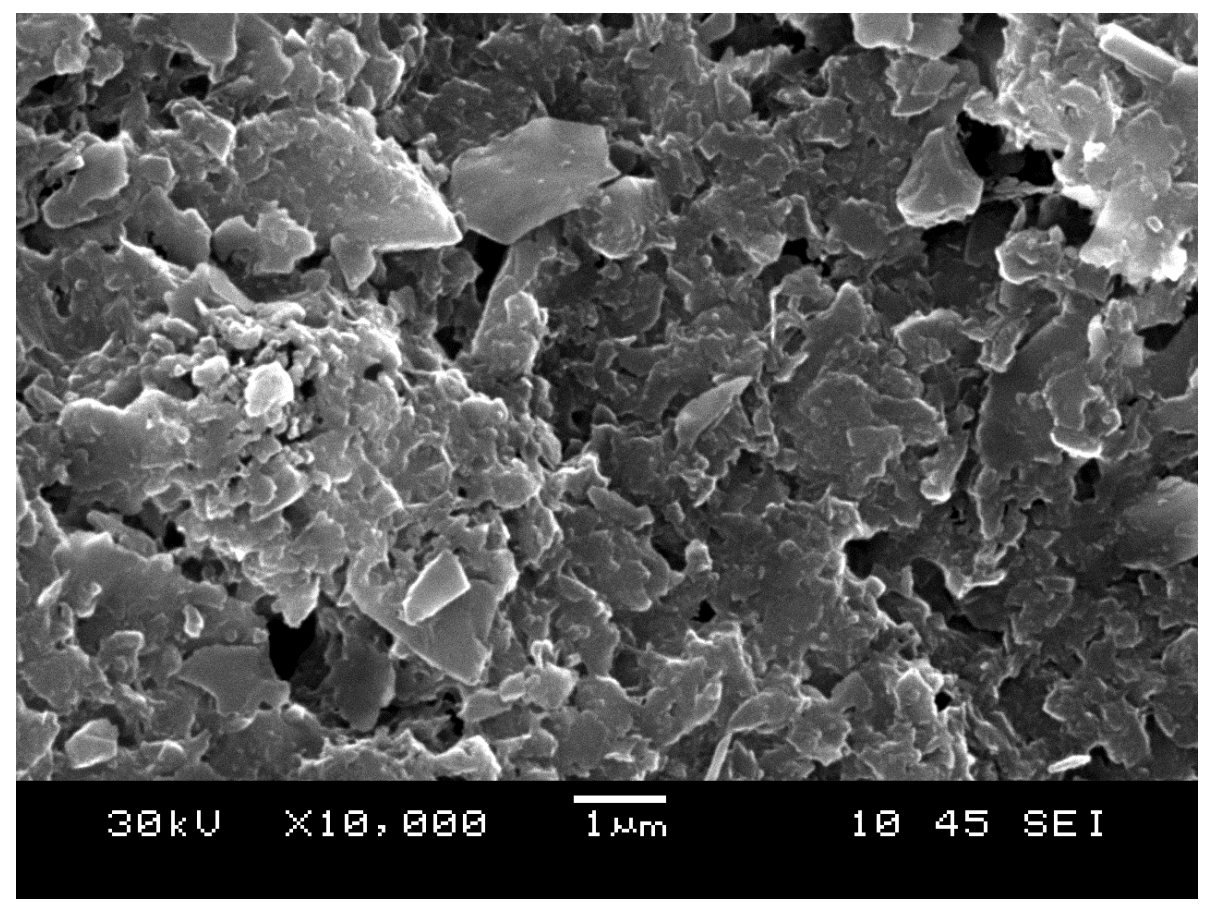

(b) Natural clay treated with $200 \mathrm{~kg} / \mathrm{m}^{3}$ of cement cured for 14 days 


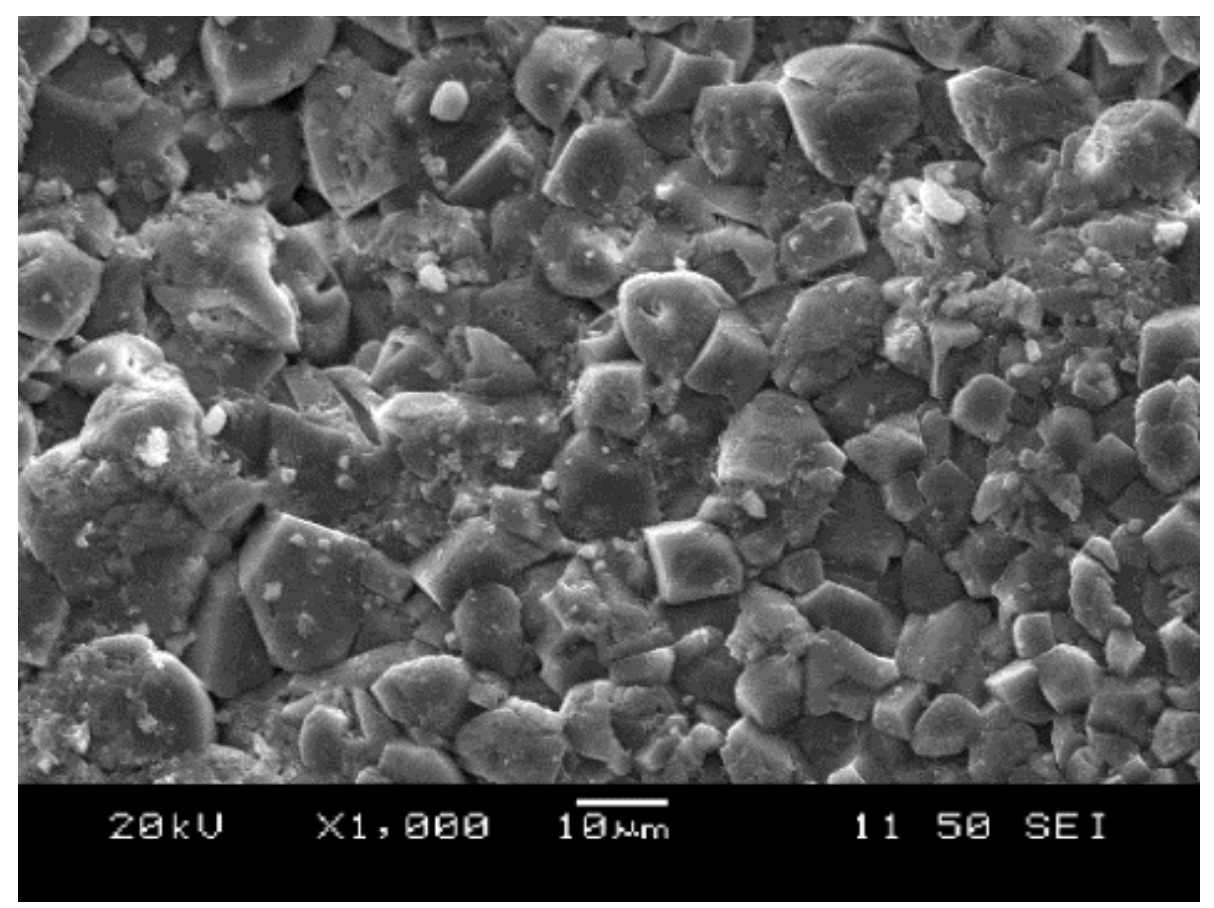

(c) Natural clay treated with $200 \mathrm{~kg} / \mathrm{m}^{3}$ of cement cured for 28 days

Figure 4-24: SEMs of clay samples treated with $200 \mathrm{~kg} / \mathrm{m}^{3}$ cured for 7,14, and 28 days

SEM micrographs of clay samples treated with $200 \mathrm{~kg} / \mathrm{m}^{3}$ are presented in Figure 4-24. As expected, the higher the cement content, the higher the volume of the reaction product in the soil. The sample with $200 \mathrm{~kg} / \mathrm{m}^{3}$ cement showed higher reaction products than the sample treated with 50 and $100 \mathrm{~kg} / \mathrm{m}^{3}$ cement. Figure 4-24c illustrates the abundance of the hydration product called calcium hydroxide for sample cured for 28 days. The high volume of calcium hydroxide reacted with soil silica and soil alumina leading to the formation of pozzolanic reaction products. These pozzolanic products bind together the clay particles or clusters of clay particles and created a stronger matrix of soil.

It is believed that the poor quality of SEM micrographs of clay treated with 50 and $100 \mathrm{~kg} / \mathrm{m}^{3}$ at 7-day curing time was due to the high amount of water inside the samples despite oven-drying them for 24 hours before the test. As the curing time or the cement dosage increased to $200 \mathrm{~kg} / \mathrm{m}^{3}$, this phenomenon was less pronounced as longer curing or high cement dosage allow faster consumption of pore water leading to a better image quality by reducing the charging effect. 


\subsection{IMPACT OF BINDER TYPE}

A total of four different binder types are used in this study: general use Portland cement (GU), cement with $8 \%$ of weight of silica fume (HSF), cement-slag (CS), cement kiln dust (CKD). The natural clay samples were mixed with these binders and were cured for 7, 14, 28 and 300 days and tested for the strength using SEM images.

Silica fume is added to Portland cement in concrete industry to improve its properties, in particular its compressive strength. In this study cement with $8 \%$ of silica fume by weight is mixed with clay to investigate its influence on the strength and microstructure of the treated soil.

Slag also has the potential to produce pozzolanic reaction under alkaline conditions (Kitazume \& Terashi, 2013). In this study, slag was mixed with cement in 3:1 ratio by weight with a dosage of $67 \mathrm{~kg} / \mathrm{m}^{3}$ (CS67) to measure its strength improvement against other binder types. If proved to be a suitable binder, slag can reduce the project cost in large scale ground improvement projects.

If CKD can be used for ground improvement, it should be possible to achieve some environmental enhancement through reduction of waste stockpiles and some economic advantage to the cement industry through transformation of significant waste to usable material. In this study two cementto-CKD ratios were used, cement-to-CKD ratio of $3: 1$ with a dosage of $67 \mathrm{~kg} / \mathrm{m}^{3}$ (CKD67) and cement-to-CKD ratio of 1:1 with a dosage of $100 \mathrm{~kg} / \mathrm{m}^{3}$ (CKD100). In all the above dosages studies, the amount of cement was maintained at the same level for comparison purpose.

\subsubsection{Unconfined compressive strength}

Table 4-2 summarizes the peak UCS values of clay samples mixed with different binder types and cured at different times. For the 300-day curing condition, only one sample for each mixing conditions was tested. These UCS results will be compared to samples treated with 50 and 100 $\mathrm{kg} / \mathrm{m}^{3}$ to compare each binder efficiency for treating Champlain Sea clay.

Figure 4-25 shows the stress-strain curves of clay samples treated $50 \mathrm{~kg} / \mathrm{m}^{3}$ of cement blended with silica fume (HSF50). The peak UCS of samples treated with HSF50 reached $880 \mathrm{kPa}$ at a failure strain of $0.8 \%$. The UCS of samples cured for 7, 14 and 28 days did not differ much (350 to $500 \mathrm{kPa}$ ). The stiffness of samples treated with HSF50 also increased with increasing curing 
time. Compared with mixes treated with only GU cement under the same mixing and curing conditions, GU50 cement showed better results than HSF50 mixes.

Stress-strain curves of samples treated with $67 \mathrm{~kg} / \mathrm{m}^{3}$ of cement/slag (CS67) and cured for 7, 14, 28, and 300 days are shown in Figure 4-26. Samples cured for 300 days reached a peak UCS of $1912 \mathrm{kPa}$ and failed at a strain of $0.66 \%$. Samples cured for 7 days reached an average UCS of 502 $\mathrm{kPa}$ and those cured for 28 days reached $684 \mathrm{kPa}$. The stiffness also increased with increasing curing time. When compared with samples treated with $50 \mathrm{~kg} / \mathrm{m}^{3}$ of cement, samples treated with CS67 showed less strength for curing conditions under 28 days. However, when curing time increased to 300 days, the UCS of CS67 sample exceeded those of treated with GU50 and reached almost $73 \%$ strength of GU100 sample.

Samples treated with $67 \mathrm{~kg} / \mathrm{m}^{3}$ of CKD (CKD67) did not differ from those treated with $50 \mathrm{~kg} / \mathrm{m}^{3}$ of cement blended with silica fume (HSF50). In term of strength, performance of CKD 67 samples stayed below those treated $50 \mathrm{~kg} / \mathrm{m}^{3}$ of GU (GU50) for all curing conditions. Stress- strain curves of CKD67 cured for 7,14, 28, 300 days are shown in Figure 4-27.

Figure 4-28 presents the stress-strain curves of samples treated with $100 \mathrm{~kg} / \mathrm{m}^{3}$ of CKD (CKD100). CKD100 cured for 300 days recorded a UCS value of $2196 \mathrm{kPa}$ which is almost 2.14 times the strength of soil treated with $50 \mathrm{~kg} / \mathrm{m}^{3} \mathrm{GU}$ cement. CKD100 also reached $86 \%$ strength of those treated with $100 \mathrm{~kg} / \mathrm{m}^{3} \mathrm{GU}$ for 300 days of curing. These results proved the efficiency of using CKD to replace a portion of cement in ground improvement without sacrificing the strength.

Figure 4-29 presents the average of UCS of two clay samples mixed with different binder against curing times. Samples treated with $50 \mathrm{~kg} / \mathrm{m}^{3}$ of HSF and $67 \mathrm{~kg} / \mathrm{m}^{3}$ of CKD did not show a big difference in term of strength development for all curing time. Samples treated with $50 \mathrm{~kg} / \mathrm{m}^{3}$ of GU cement shows the higher UCS up to the 28 days of curing, then samples treated with $67 \mathrm{~kg} / \mathrm{m}^{3}$ of CS and $100 \mathrm{~kg} / \mathrm{m}^{3}$ of CKD gained strength at a faster rate than other binders to reach an UCS comparable to those treated with $100 \mathrm{~kg} / \mathrm{m}^{3}$ of GU cement. This rapid strength gain of samples treated with CKD and CS binder is due to the pozzolanic reaction resulted from the calcium hydroxide produced by the binder hydration and silica and alumina from the soil. 
Table 4-2: Peak UCS values of treated Champlain Sea clay with different binders' types

\begin{tabular}{|c|c|c|c|c|c|c|c|}
\hline $\begin{array}{l}\text { Mix } \\
\text { ID }\end{array}$ & Sample ID & $\begin{array}{l}\text { Binder } \\
\text { Type }\end{array}$ & $\begin{array}{l}\text { Dosage } \\
\left(\mathrm{kg} / \mathrm{m}^{3}\right)\end{array}$ & $\begin{array}{l}\text { Curing } \\
\text { Time } \\
\text { (days) }\end{array}$ & $\begin{array}{l}\text { Peak } \\
\text { UCS } \\
(\mathrm{kPa})\end{array}$ & $\begin{array}{l}\text { Failure } \\
\text { strain, } \\
\varepsilon_{\mathrm{f}}(\%)\end{array}$ & $\begin{array}{c}\text { Dry } \\
\text { density } \\
\gamma_{\mathrm{d}} \\
\left(\mathrm{kg} / \mathrm{m}^{3}\right)\end{array}$ \\
\hline \multirow{6}{*}{ HSF50 } & WD21.6HSF50D07UCS1 & $\mathrm{HSF}$ & 50 & 07 & 348 & 1.40 & 852 \\
\hline & WD21.6HSF50D07UCS2 & HSF & 50 & 07 & 345 & 1.70 & 846 \\
\hline & WD21.6HSF50D14UCS1 & HSF & 50 & 14 & 407 & 1.39 & 851 \\
\hline & WD21.6HSF50D14UCS2 & HSF & 50 & 14 & 410 & 1.29 & 852 \\
\hline & WD21.6HSF50D28UCS1 & HSF & 50 & 28 & 512 & 1.91 & 858 \\
\hline & WD21.6HSF50D300UCS1 & HSF & 50 & 300 & 880 & 0.8 & NA \\
\hline \multirow{7}{*}{ CS67 } & WD21.6CS67D07UCS1 & $\mathrm{CS}$ & 67 & 07 & 504 & 1.07 & 880 \\
\hline & WD21.6CS67D07UCS2 & $\mathrm{CS}$ & 67 & 07 & 498 & 1.28 & 877 \\
\hline & WD21.6CS67D14UCS1 & $\mathrm{CS}$ & 67 & 14 & 610 & 1.27 & 893 \\
\hline & WD21.6CS67D14UCS2 & $\mathrm{CS}$ & 67 & 14 & 572 & 0.88 & 891 \\
\hline & WD21.6CS67D28UCS1 & $\mathrm{CS}$ & 67 & 28 & 674 & 1.09 & 886 \\
\hline & WD21.6C67D28UCS2 & $\mathrm{CS}$ & 67 & 28 & 694 & 0.50 & 896 \\
\hline & WD21.6CS67D300UCS1 & $\mathrm{CS}$ & 67 & 300 & 1913 & 0.66 & NA \\
\hline \multirow{6}{*}{ CKD67 } & WD21.6CKD67D07UCS1 & CKD & 67 & 07 & 391 & 1.38 & 851 \\
\hline & WD21.6CKD67D07UCS2 & CKD & 67 & 07 & 386 & 1.19 & 856 \\
\hline & WD21.6CKD67D14UCS1 & CKD & 67 & 14 & 483 & 2.36 & 857 \\
\hline & WD21.6CKD67D14UCS2 & CKD & 67 & 14 & 432 & 1.67 & 865 \\
\hline & WD21.6CKD67D28UCS1 & CKD & 67 & 28 & 466 & 0.80 & 876 \\
\hline & WD21.6CKD67D300UCS1 & CKD & 67 & 300 & 928 & 0.55 & NA \\
\hline \multirow{7}{*}{ CKD100 } & WD21.6CKD100D07UCS1 & CKD & 100 & 07 & 537 & 1.78 & 829 \\
\hline & WD21.6CKD100D07UCS2 & CKD & 100 & 07 & 468 & 1.28 & 822 \\
\hline & WD21.6CKD100D14UCS1 & CKD & 100 & 14 & 501 & 1.48 & 838 \\
\hline & WD21.6CKD100D14UCS2 & CKD & 100 & 14 & 672 & 1.97 & 848 \\
\hline & WD21.6CKD100D28UCS1 & CKD & 100 & 28 & 669 & 0.89 & 845 \\
\hline & WD21.6CKD100D28UCS2 & CKD & 100 & 28 & 680 & 0.79 & 843 \\
\hline & WD21.6CKD100D300UCS1 & $1 \mathrm{CKD}$ & 100 & 300 & 2196 & 0.75 & NA \\
\hline
\end{tabular}




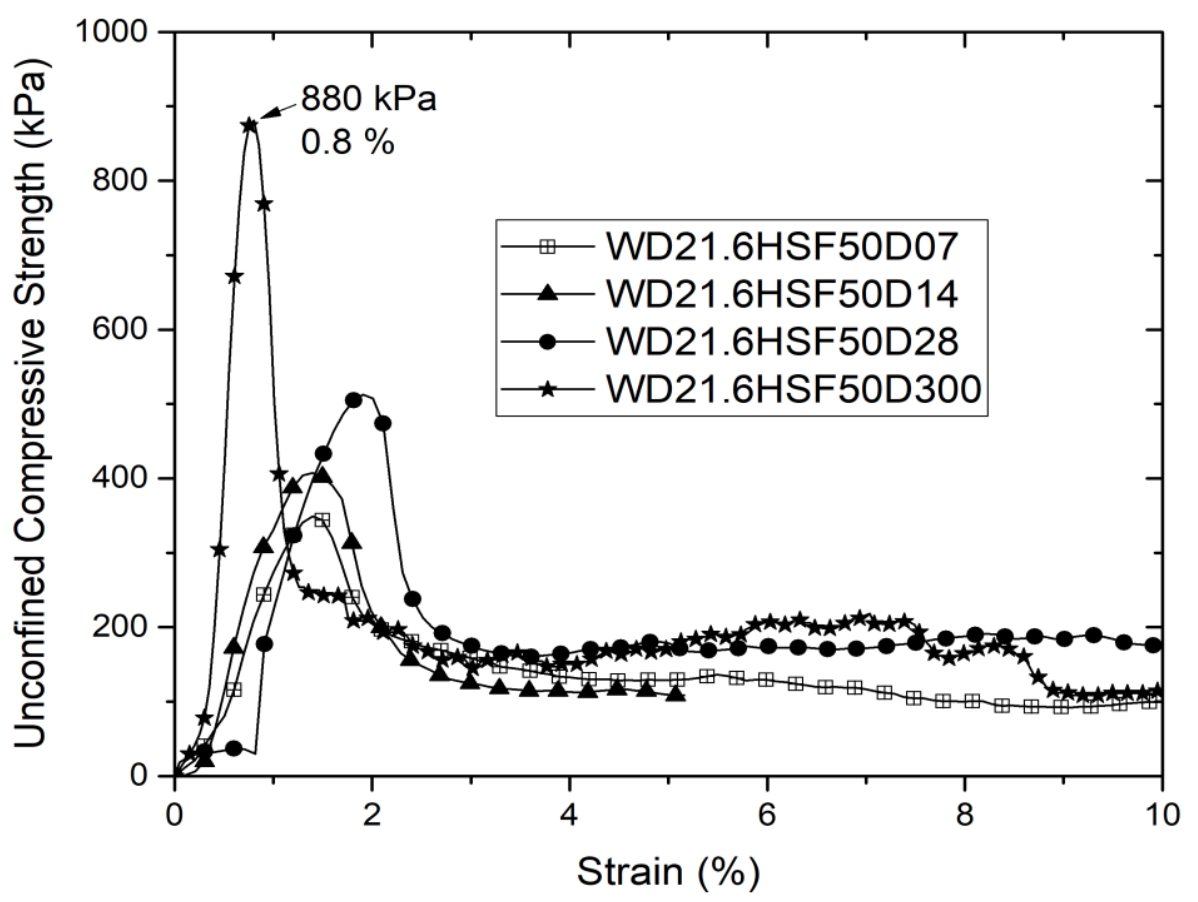

Figure 4-25: Strain-strain curves for soil treated with $50 \mathrm{~kg} / \mathrm{m}^{3}$ of HSF

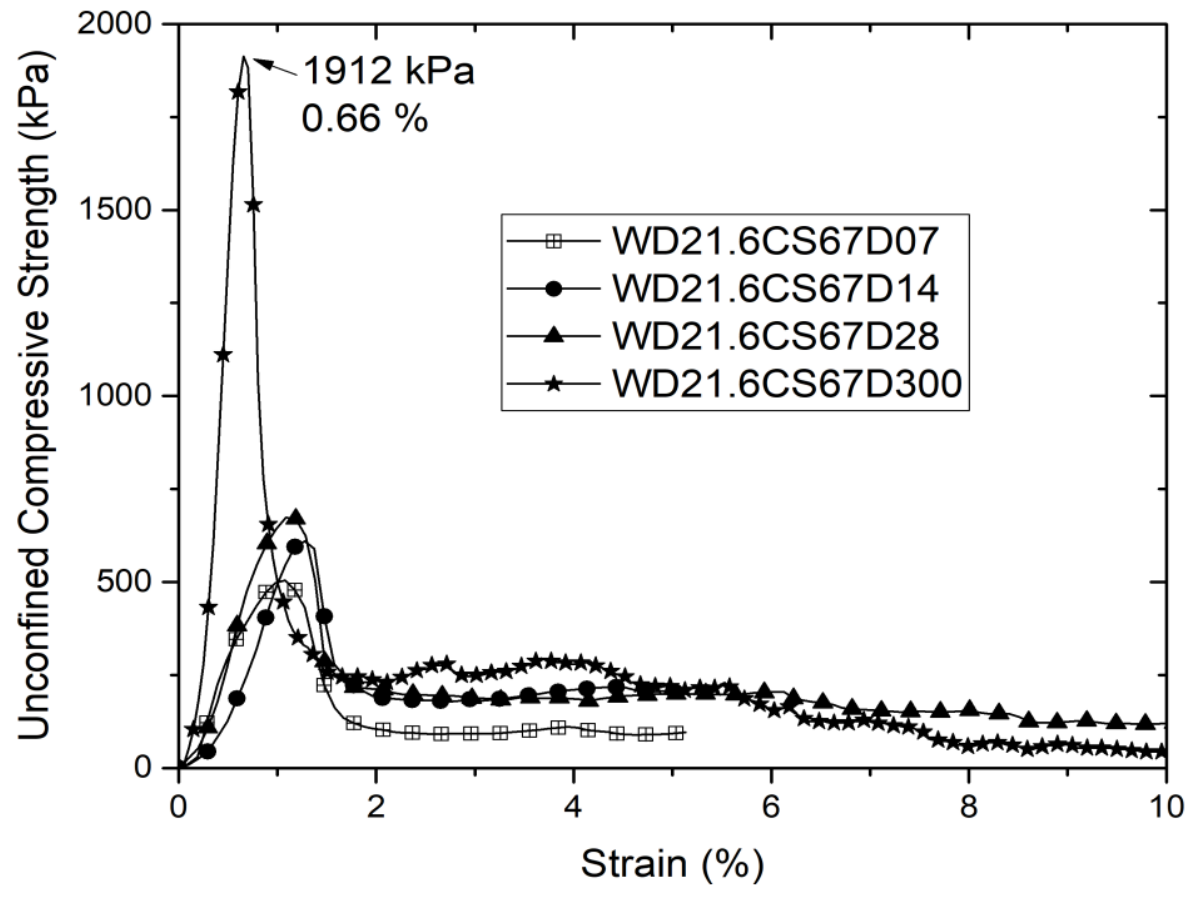

Figure 4-26: Strain-strain curves for soil treated with $67 \mathrm{~kg} / \mathrm{m}^{3}$ of CS 


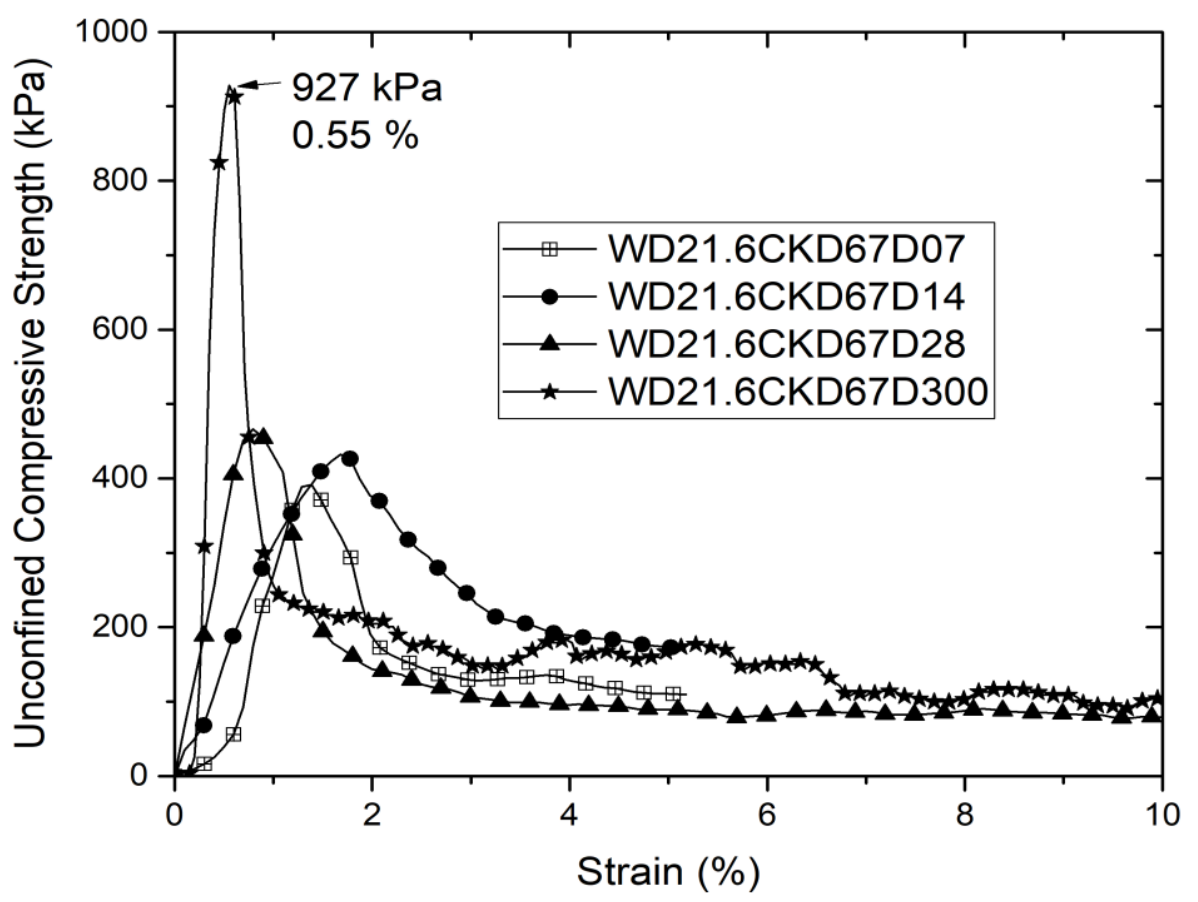

Figure 4-27: Strain-strain curves for soil treated with $67 \mathrm{~kg} / \mathrm{m}^{3}$ of CKD

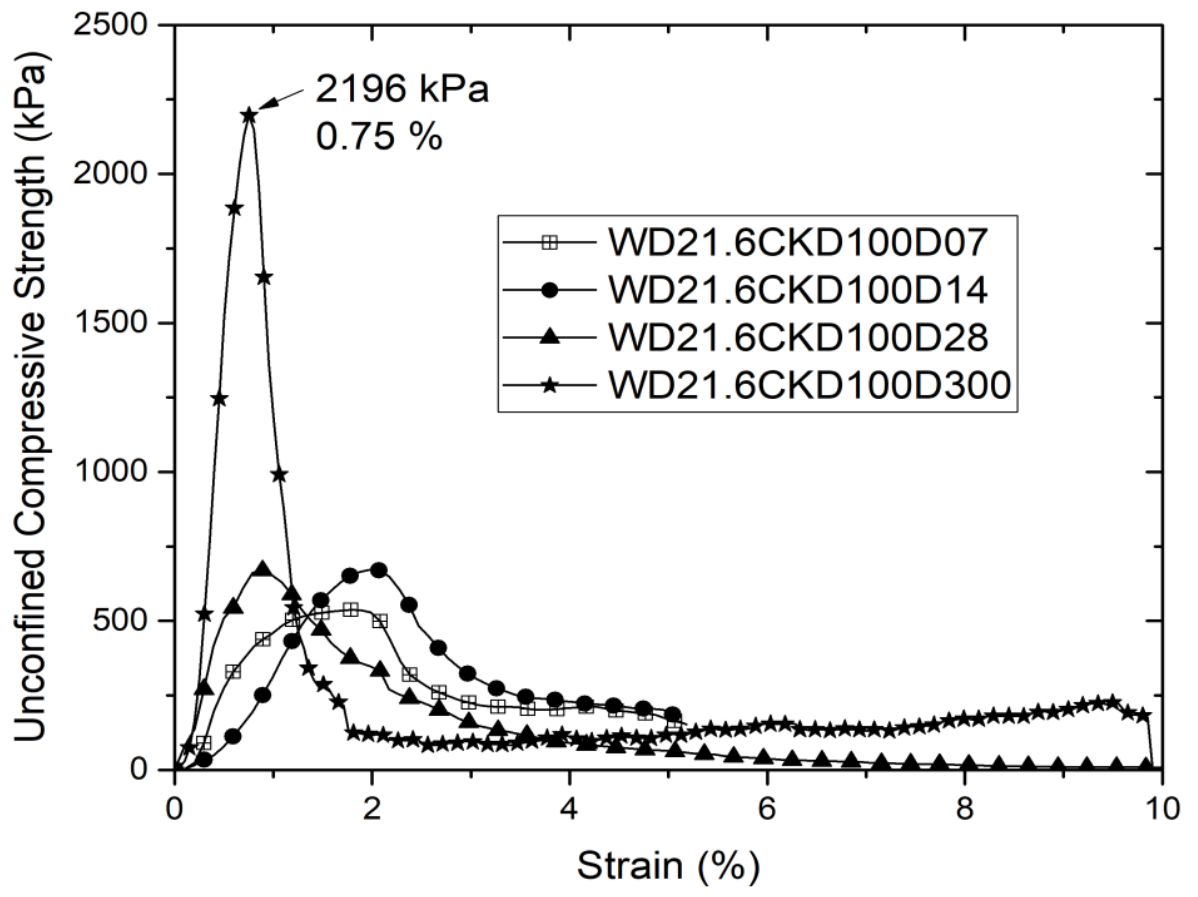

Figure 4-28: Strain-strain curves for soil treated with $100 \mathrm{~kg} / \mathrm{m}^{3}$ of CKD 


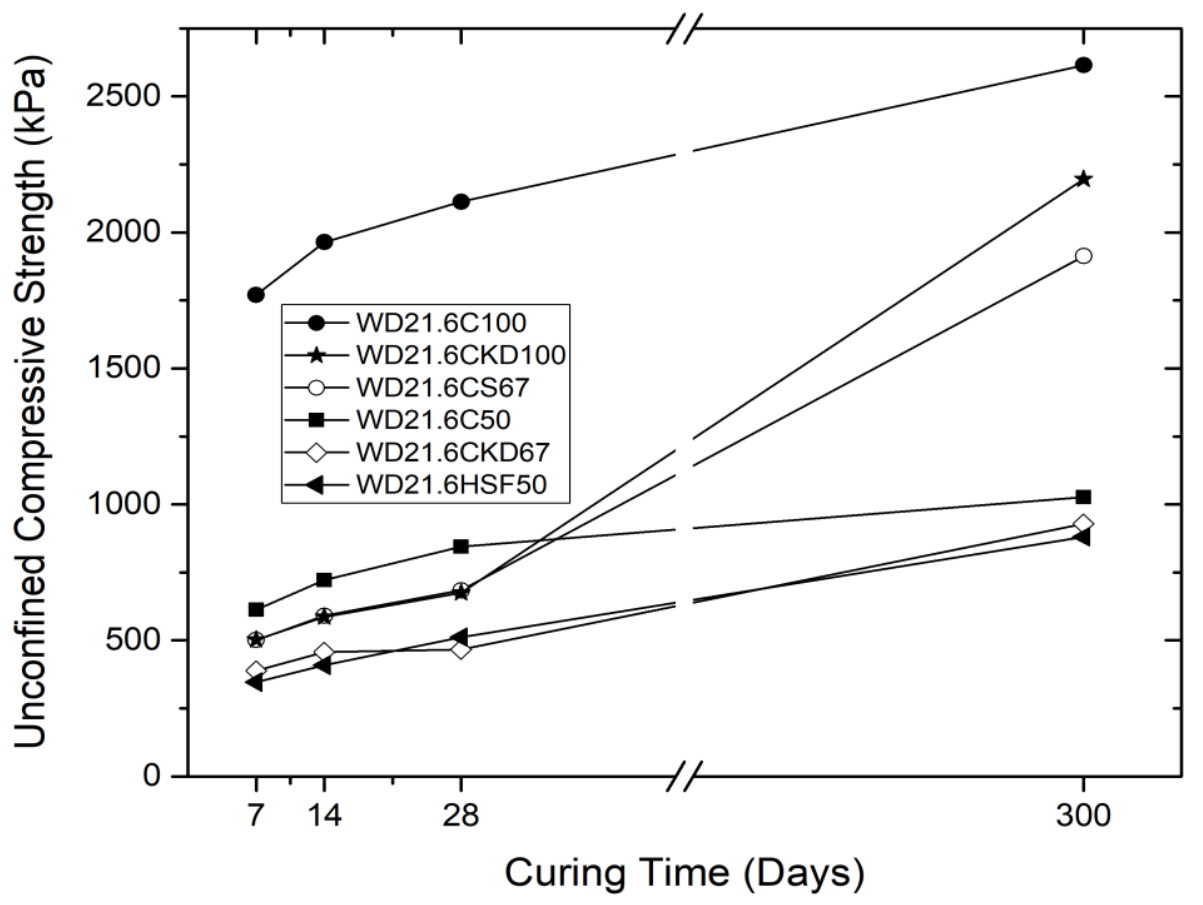

Figure 4-29: UCS vs. curing times of clay samples treated with different binders

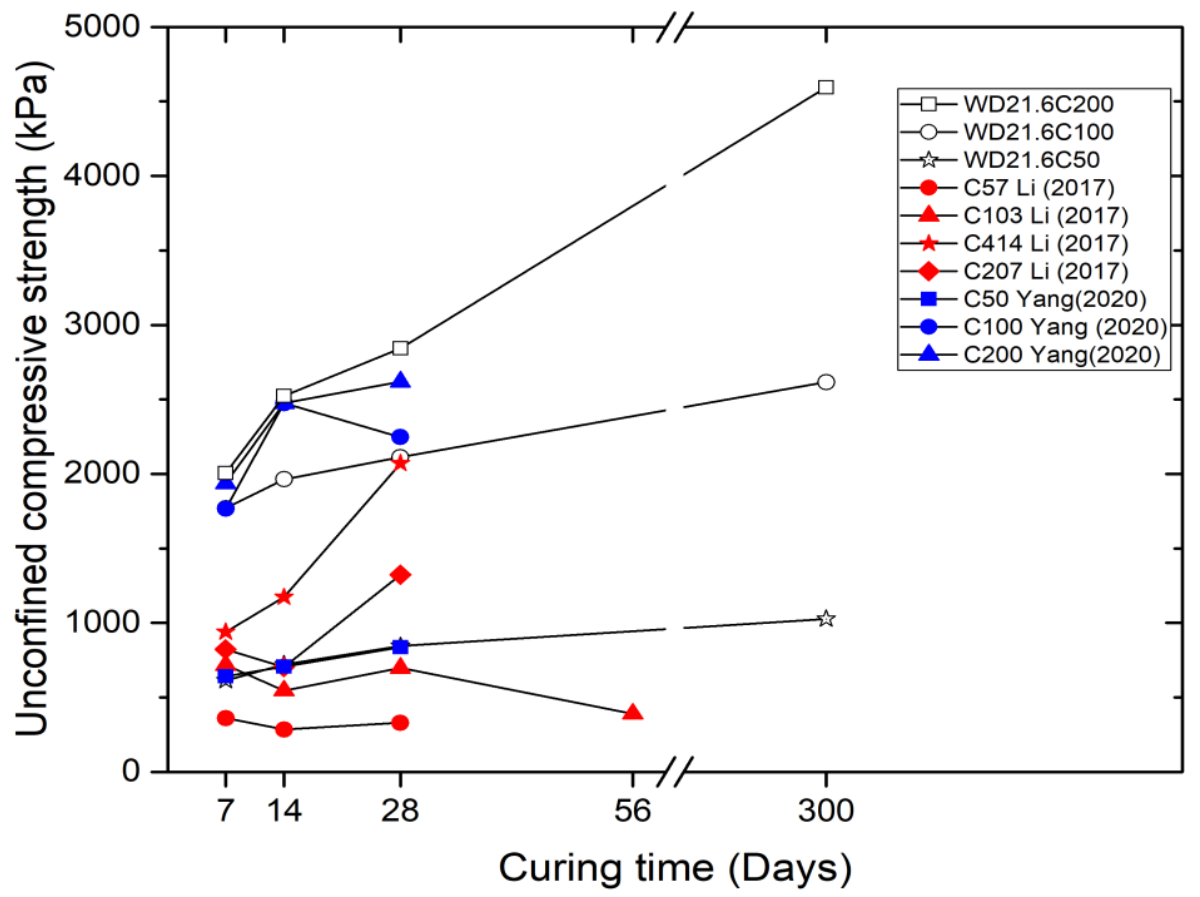

Figure 4-30: Effect of cement dosage and curing time on treated Champlain Sea clay 


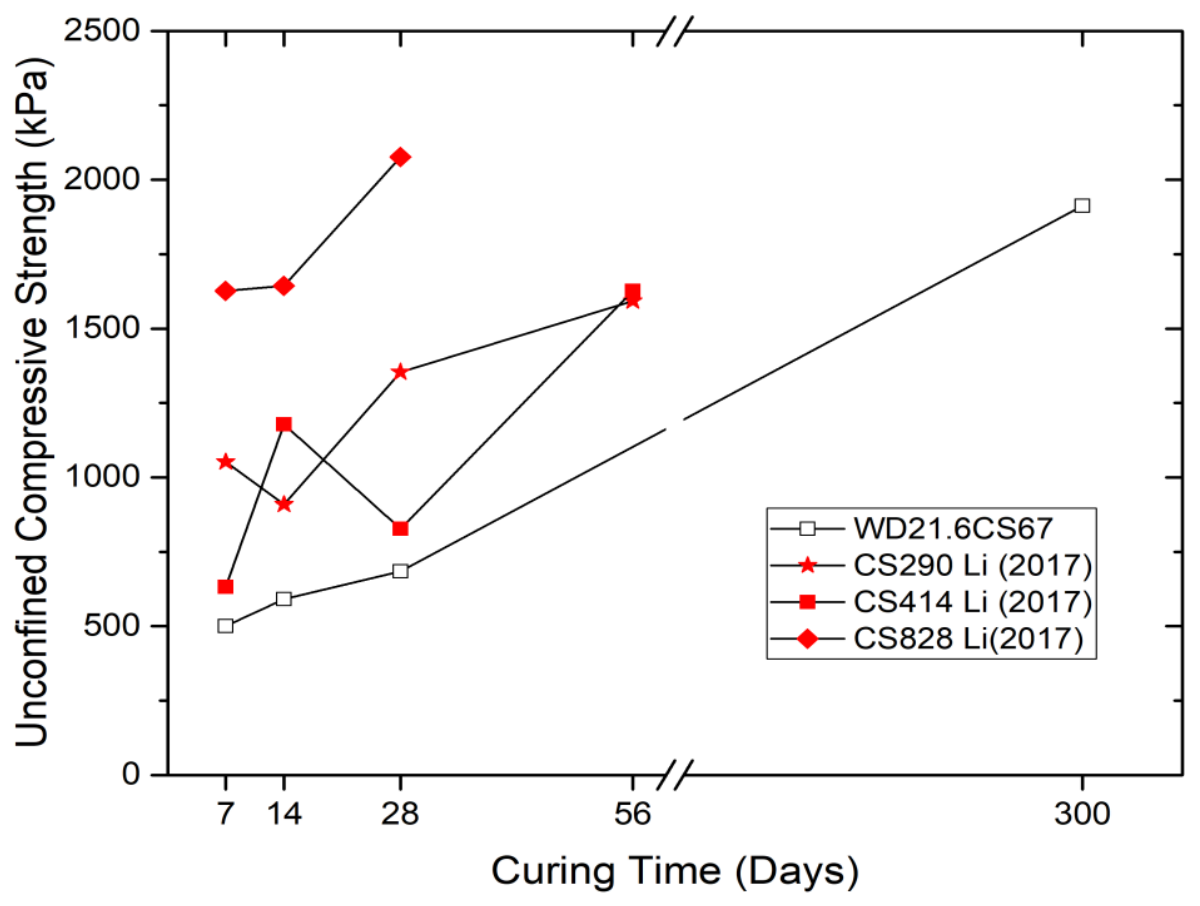

Figure 4-31: Effect of slag/cement dosage and curing time on treated Champlain Sea clay

Microstructure changes of clay treated with different binders

(c) Natural clay treated with $50 \mathrm{~kg} / \mathrm{m}^{3}$ of HSF cured for 28 days

Figure 4-32 shows the surface morphology of the Champlain Sea clay stabilized with $50 \mathrm{~kg} / \mathrm{m}^{3}$ of HSF at different curing times 7, 14, and 28 days. At 7 days of curing ( Natural clay treated with $50 \mathrm{~kg} / \mathrm{m}^{3}$ of HSF cured for 28 days

Figure 4-32a) the clay particles started to get coated with the hydration products. As the curing time increased to14 and 28 days, bigger aggregates are observed to develop as shown in (c) Natural clay treated with $50 \mathrm{~kg} / \mathrm{m}^{3}$ of HSF cured for 28 days

Figure 4-32b and Figure 4-32c. This implies that with increasing of curing time more bonding among the clay particles are developed. However, the amount of hydration product was not significant to cause particles to aggregate.

SEM micrographs of samples treated with $67 \mathrm{~kg} / \mathrm{m}^{3}$ of CKD cured for 7, 14, and 28 are shown in Figure 4-33. Figure 4-33a and Figure 4-33b show quite similar surface morphology for 7,14 and 28 days of curing time, which may be due to the insufficient binder content to cause changes in 
the morphology of the soil-binder mixture. This is also confirmed from the UCS tests as their strength development with curing time was not significant. It is also observed that samples treated with CKD67 show little aggregation.

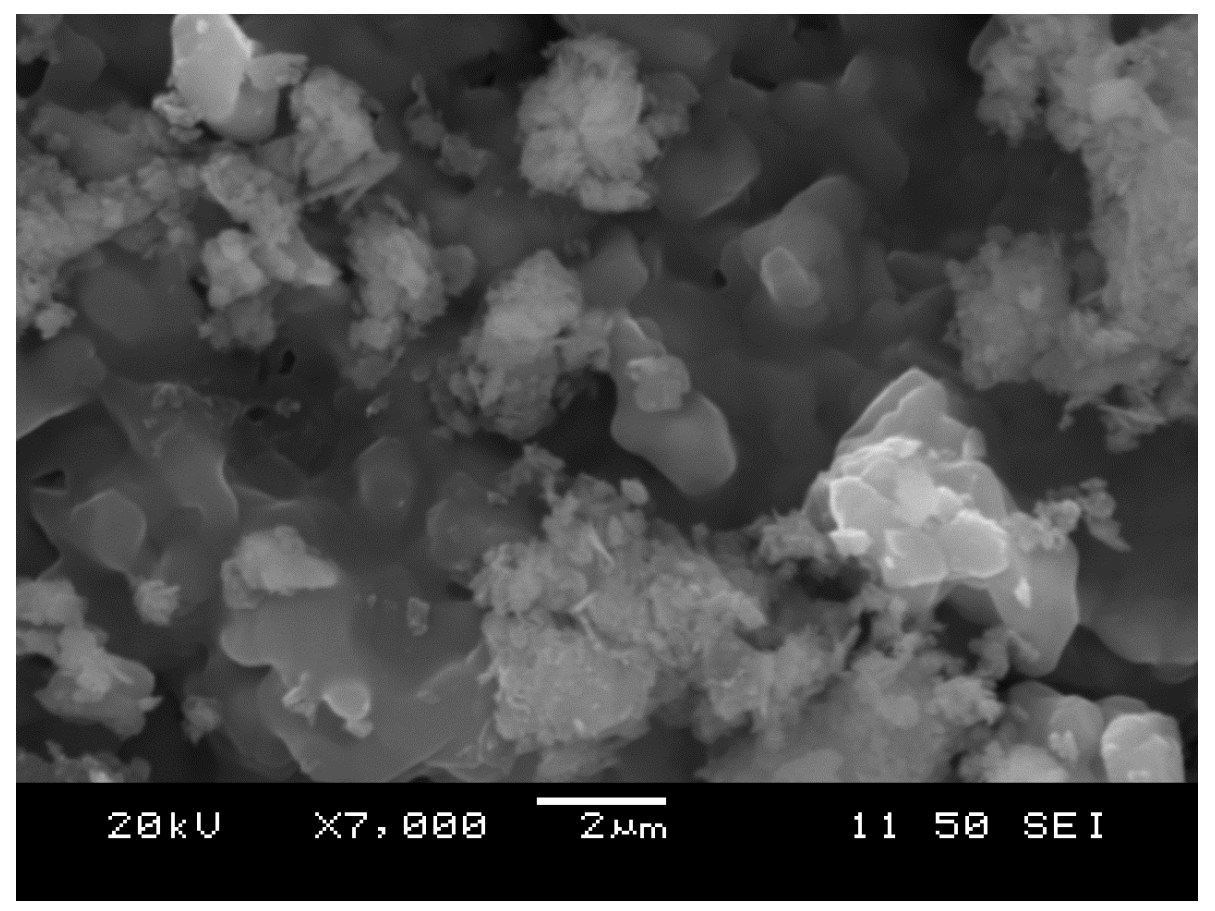

(a) Natural clay treated with $50 \mathrm{~kg} / \mathrm{m}^{3}$ of HSF cured for 7 days 


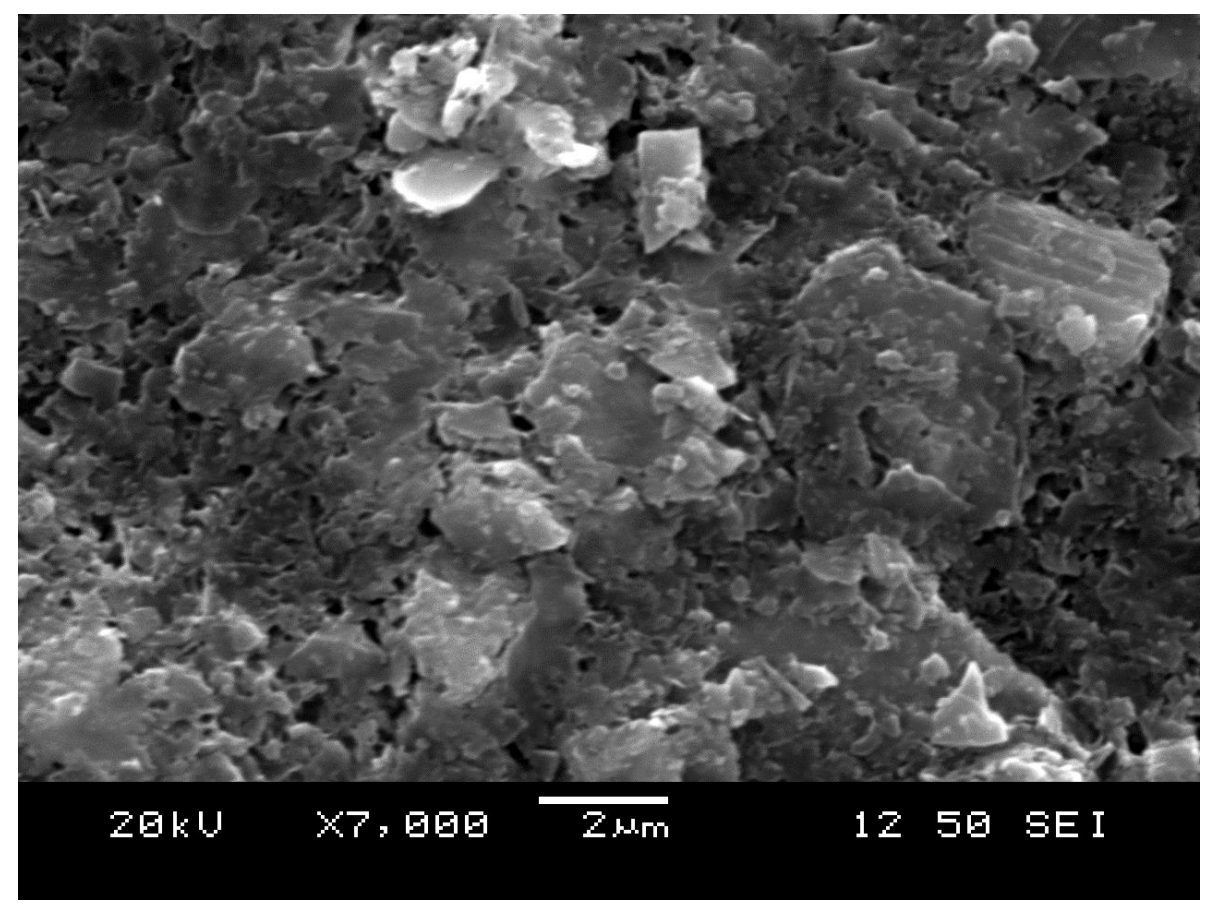

(b) Natural clay treated with $50 \mathrm{~kg} / \mathrm{m}^{3}$ of HSF cured for 14 days

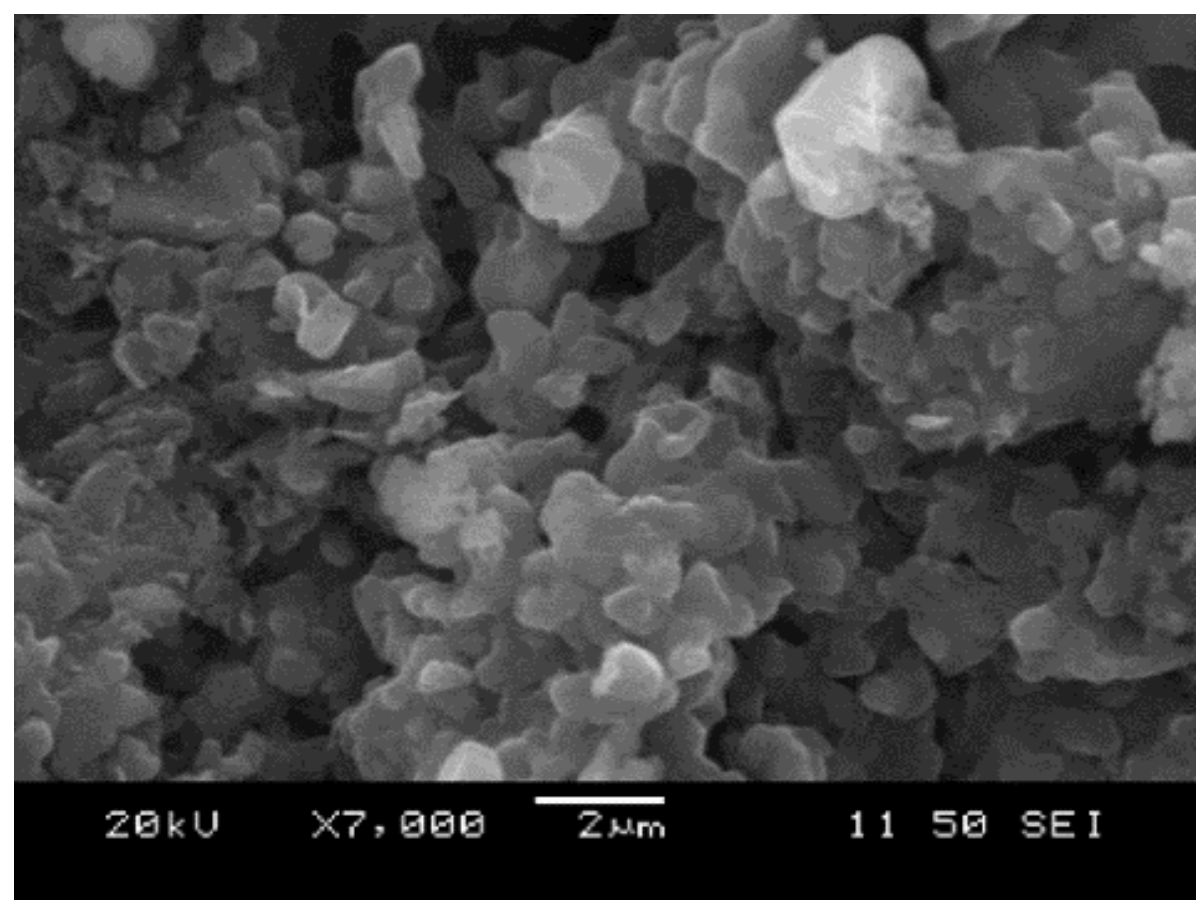

(c) Natural clay treated with $50 \mathrm{~kg} / \mathrm{m}^{3}$ of HSF cured for 28 days

Figure 4-32: SEM micrographs of clay samples treated with $50 \mathrm{~kg} / \mathrm{m}^{3}$ of $\mathrm{HSF}$ 


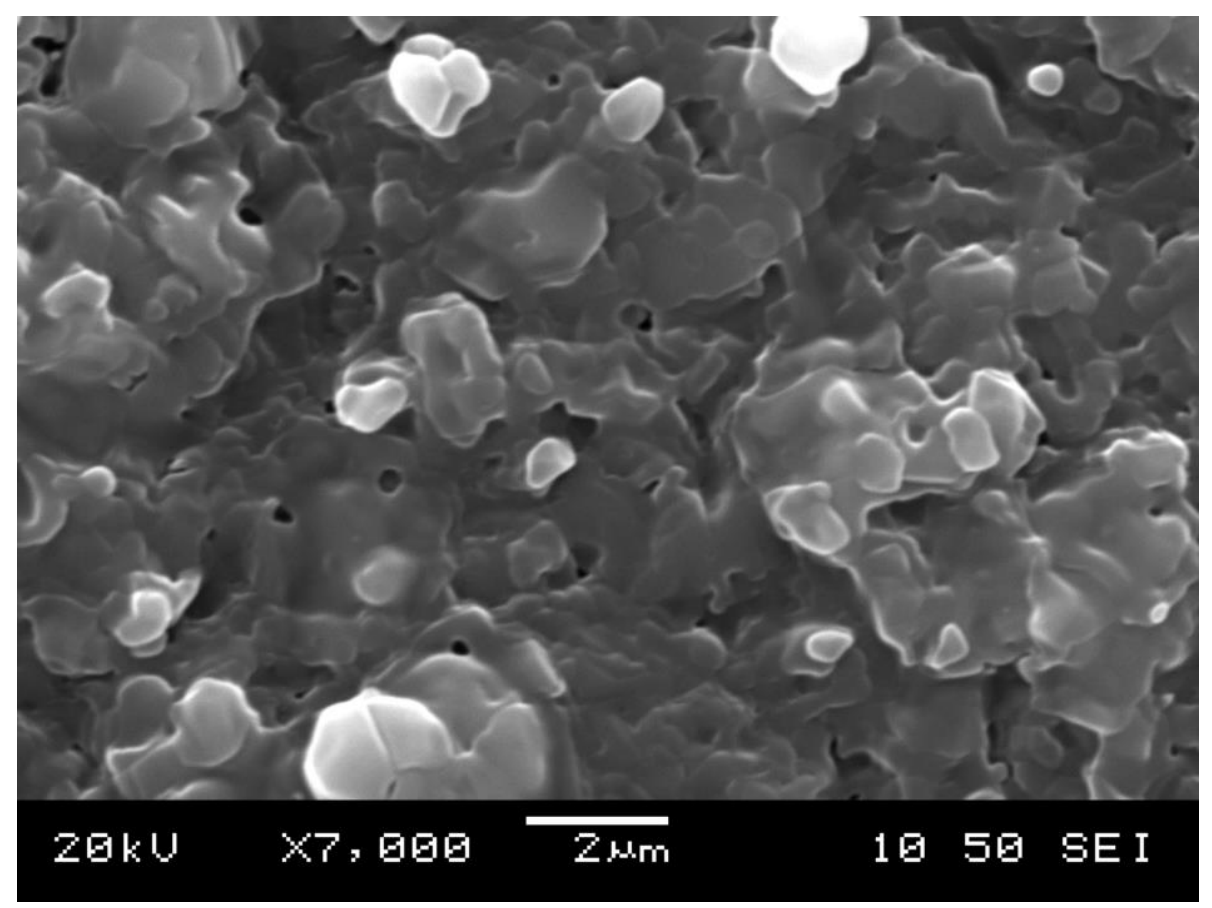

(a) Natural clay treated with $67 \mathrm{~kg} / \mathrm{m}^{3}$ of CKD cured for 7 days

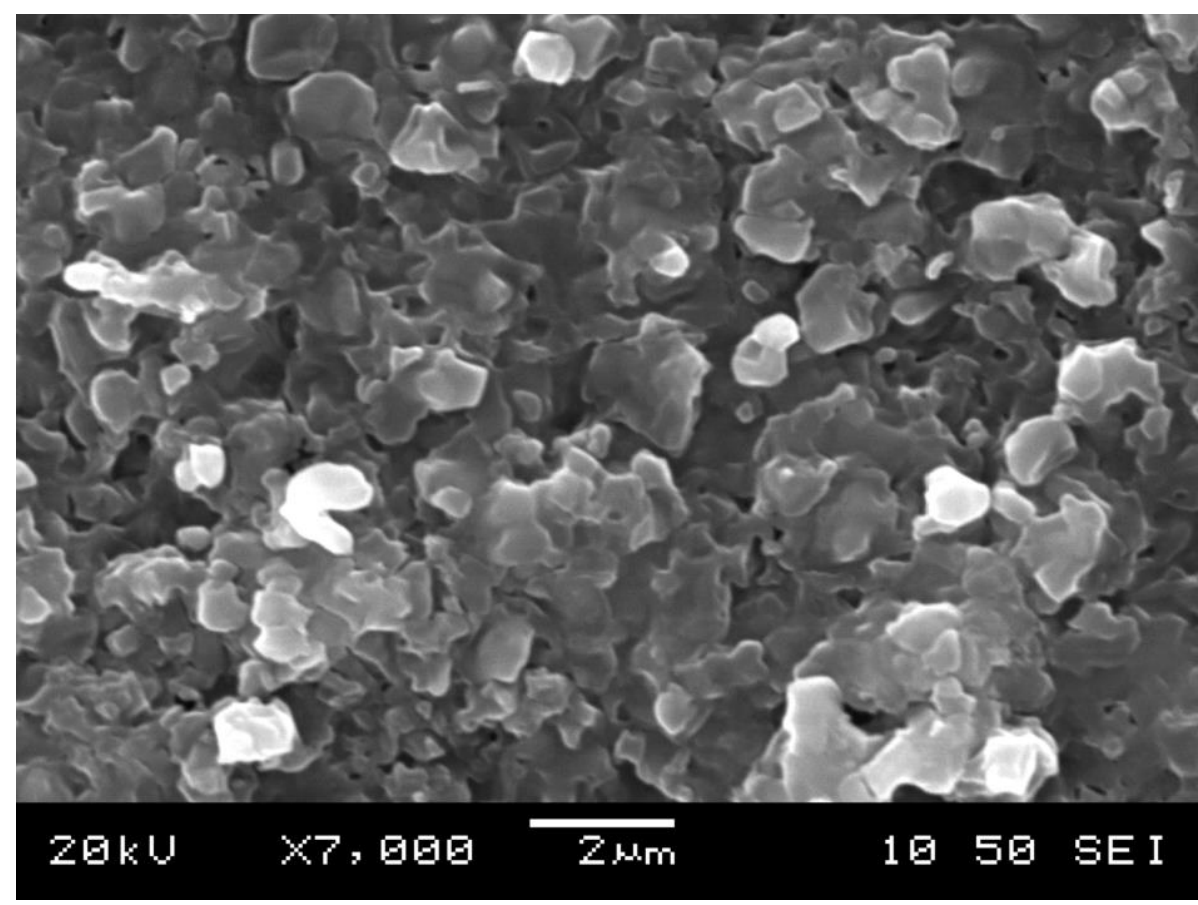

(b) Natural clay treated with $67 \mathrm{~kg} / \mathrm{m}^{3}$ of CKD cured for 14 days 


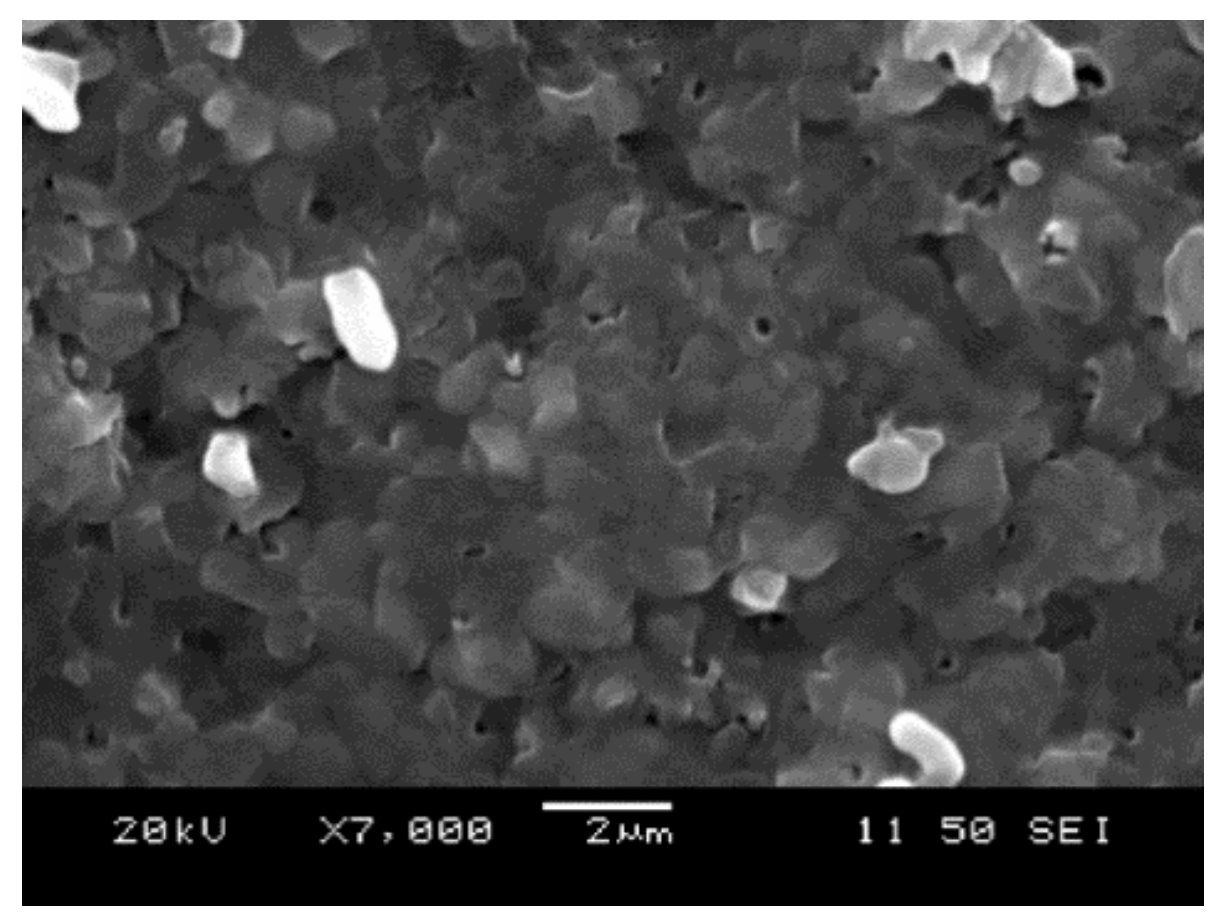

(c) Natural clay treated with $67 \mathrm{~kg} / \mathrm{m}^{3}$ of CKD cured for 28 days

Figure 4-33: SEM micrographs of clay samples treated with $67 \mathrm{~kg} / \mathrm{m}^{3}$ of CKD

Significant changes in the soil microstructure due to cement/slag hydration could be observed from SEM micrographs shown in Figure 4-34. Error! Reference source not found. Figure 4-34a i llustrates the coated clay particles by the early stage formation of the hydration products. The hydration products growth caused a significant reduction in voids. Substantial amount of hydration products was observed as curing time increased to 14 days, as shown in Figure 4-34b. As curing time increased to 28 days, small clay particles started to form big aggregates as shown by the yellow oval shape in Figure 4-34c. the aggregate size is more than ten times the size of the clay particles. Besides the reduction in voids, the aggregate interlock could be another mechanism by which the shearing resistance is improved. 


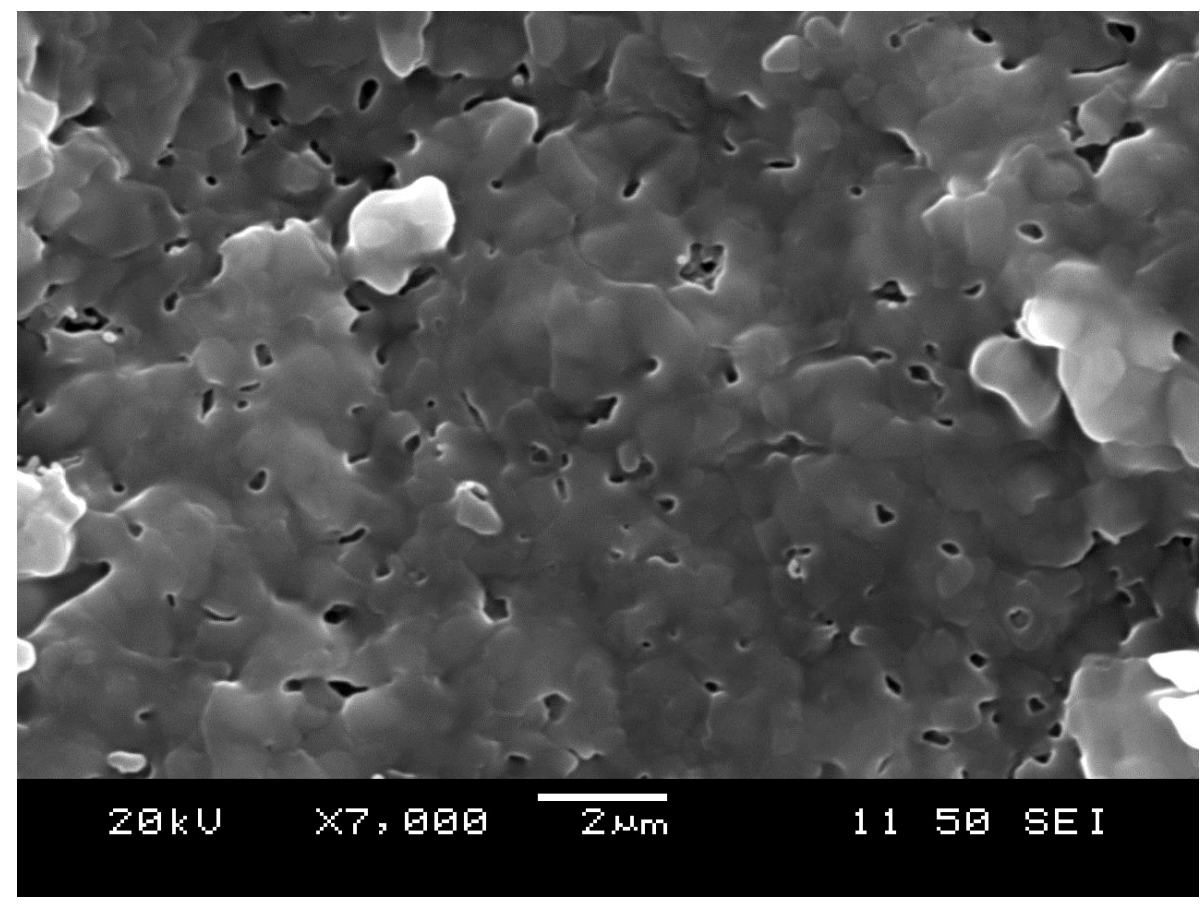

(a) Natural clay treated with $67 \mathrm{~kg} / \mathrm{m}^{3}$ of CS cured for 7 days

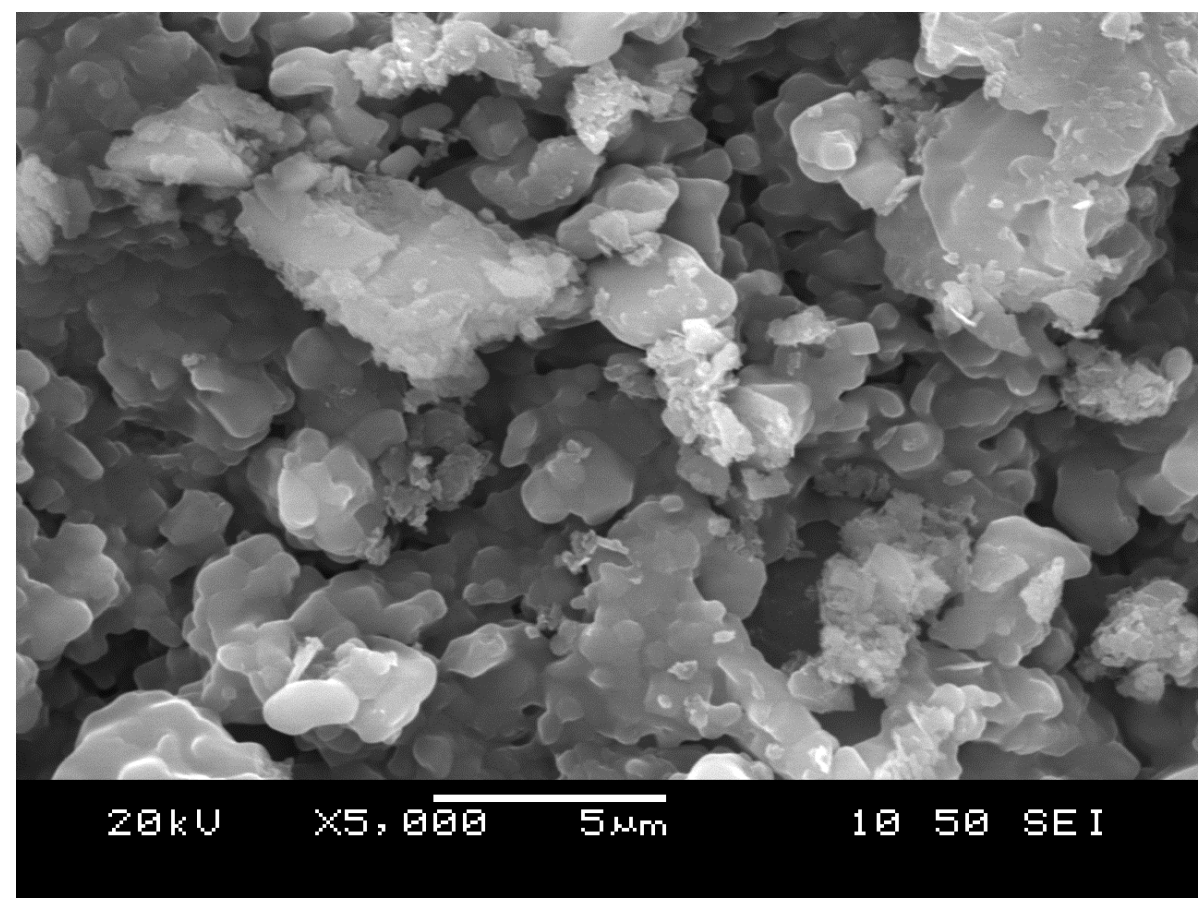

(b) Natural clay treated with $67 \mathrm{~kg} / \mathrm{m}^{3}$ of CS cured for 14 days 


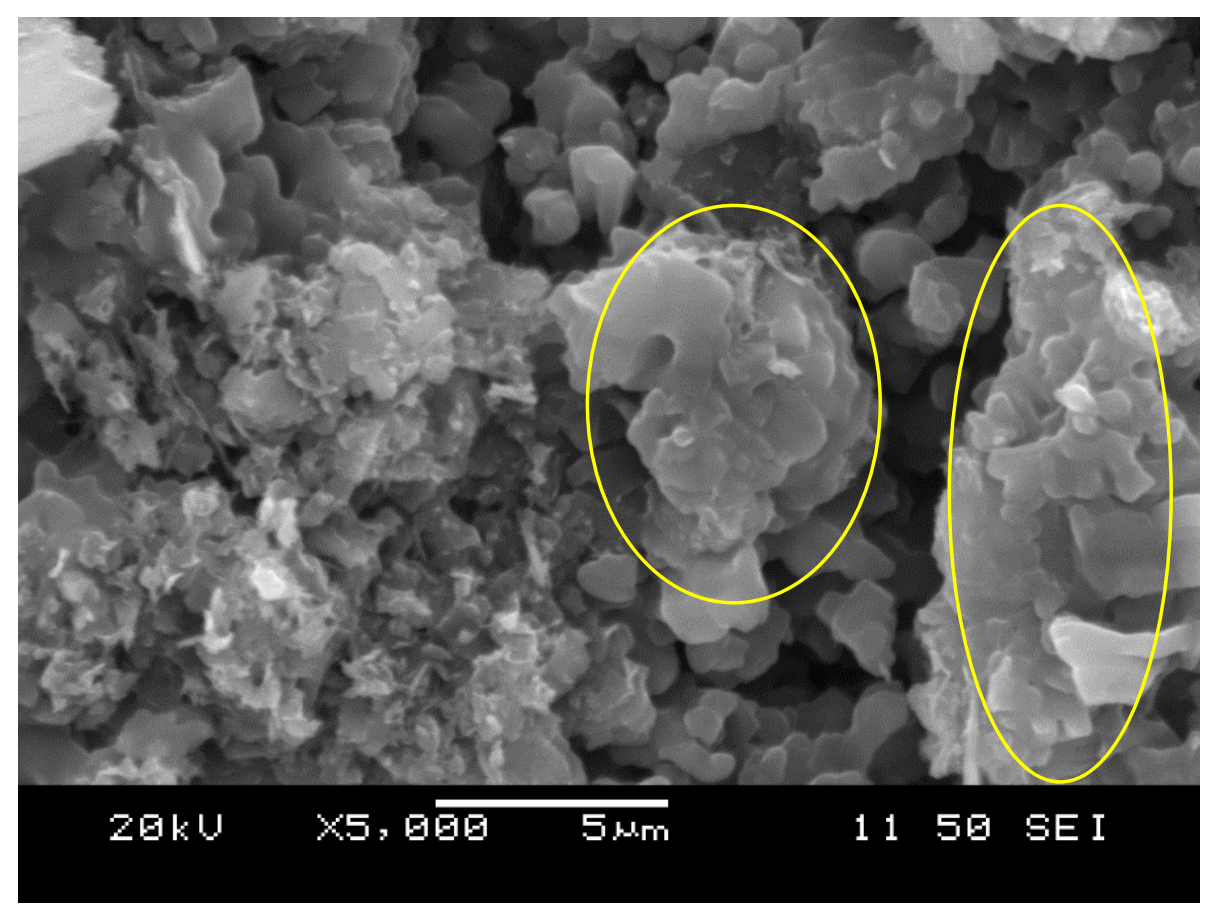

(c) Natural clay treated with $67 \mathrm{~kg} / \mathrm{m}^{3}$ of CS cured for 28 days

Figure 4-34: SEM micrographs of clay samples treated with $67 \mathrm{~kg} / \mathrm{m}^{3}$ of CS

Natural clay treated with $100 \mathrm{~kg} / \mathrm{m}^{3}$ of CKD cured for 28 days

Figure 4-35 shows the results of the SEM images of Champlain Sea clay samples treated with 100 $\mathrm{kg} / \mathrm{m}^{3}$ of CKD (CKD100) cured for 7, 14, and 28 days. At early ages, the clay particles start to get coated with the hydration product. As the curing time increased to 14 days, big aggregate clumps started to get formed and indicated by the yellow circles in (c) Natural clay treated with $100 \mathrm{~kg} / \mathrm{m}^{3}$ of CKD cured for 28 days

Figure 4-35b. Substantial reduction in the voids were observed. The microstructure changes at the early ages of CKD100 is similar to that of the CS67 samples. Over time, the hydration products in the pores are clearly seen in the soil-binder clusters tend to be larger.

From the strength and microstructure analysis of clay samples treated with different binders, samples treated with CKD100 and CS67 show the highest strength and microstructure changes compared to HSF50 and CKD67. 


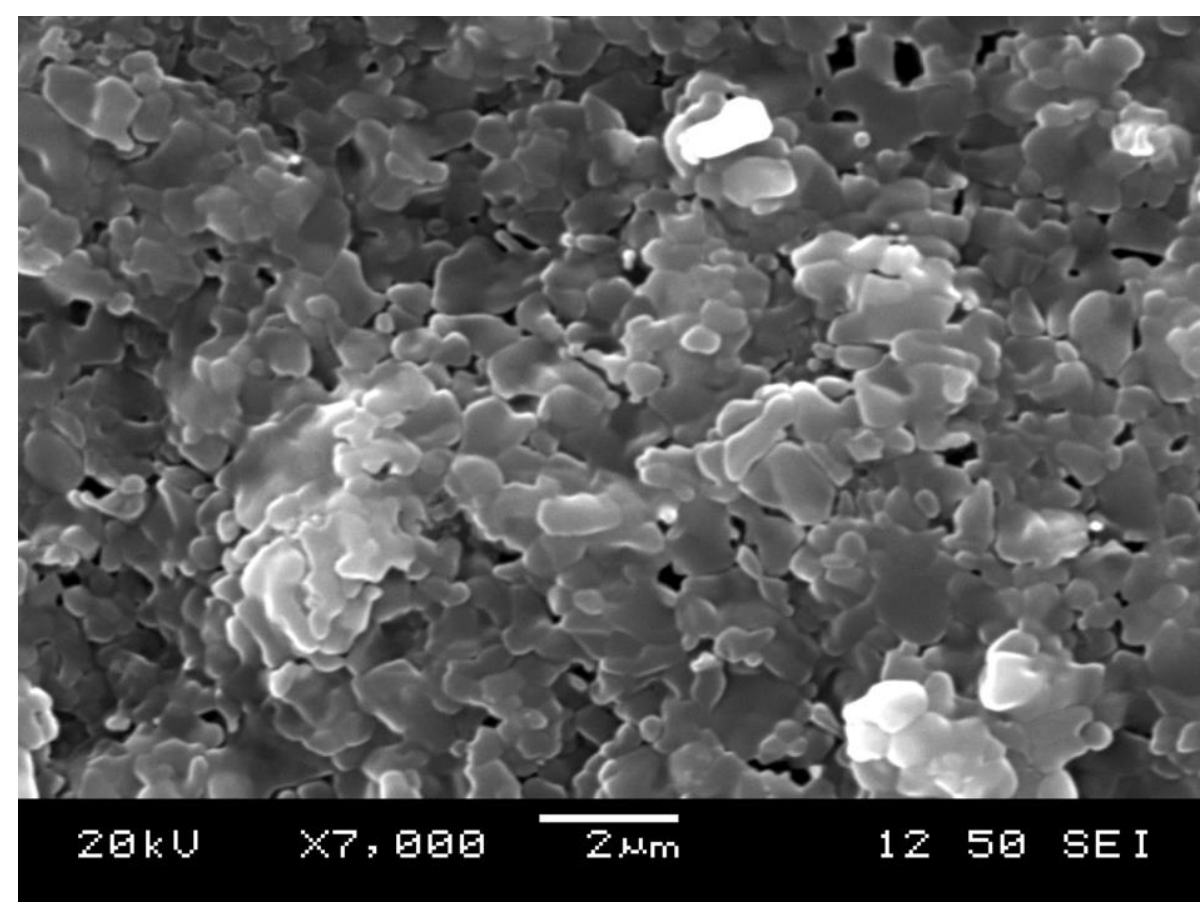

(a) Natural clay treated with $100 \mathrm{~kg} / \mathrm{m}^{3}$ of CKD cured for 7 days

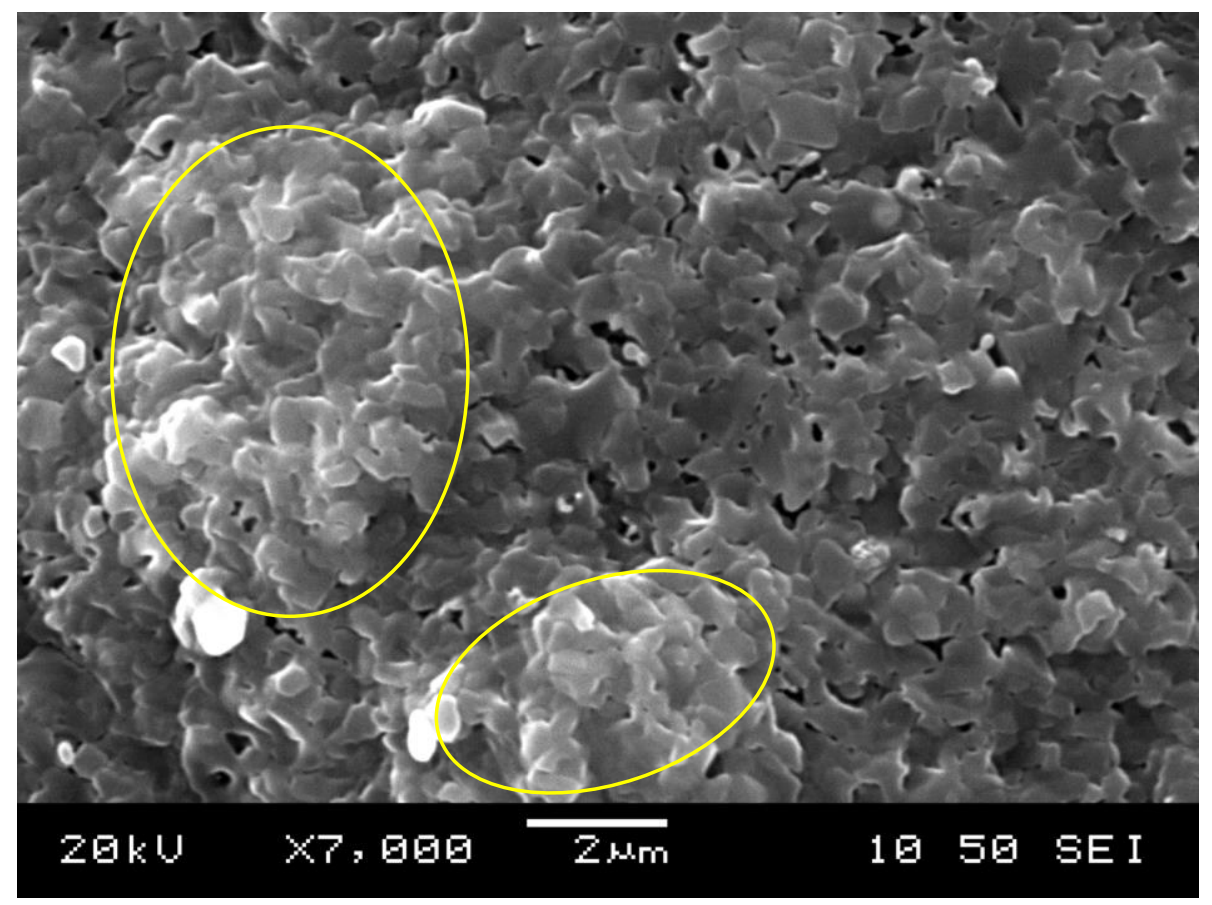

(b) Natural clay treated with $100 \mathrm{~kg} / \mathrm{m}^{3}$ of CKD cured for 14 days 


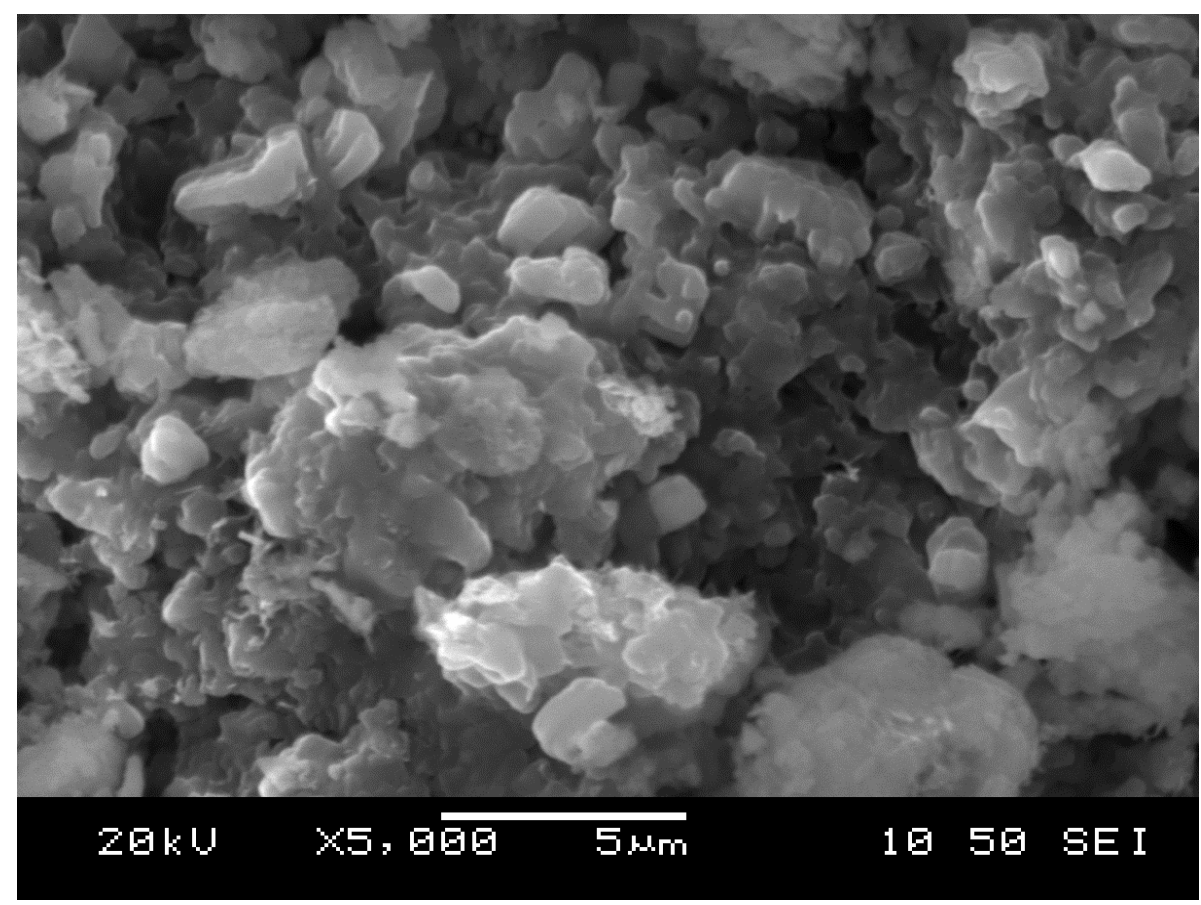

(c) Natural clay treated with $100 \mathrm{~kg} / \mathrm{m}^{3}$ of CKD cured for 28 days

Figure 4-35: SEM micrographs of clay samples treated with $100 \mathrm{~kg} / \mathrm{m}^{3}$ of CKD

\subsection{IMPACT OF SALINITY LEVEL IN THE PORE FLUID}

The impact of salinity level in the pore fluid on the strength development and mineralogical changes of clay samples treated with $50 \mathrm{~kg} / \mathrm{m}^{3}$ of general use Portland cement were investigated in this study. A total of five salinity levels were planned in this study: $15.53 \mathrm{~g} / \mathrm{L}$ of natural clay condition, three leached levels of $1.33,1.07$, and $0.73 \mathrm{~g} / \mathrm{L}$, and one salinized sample of $30.55 \mathrm{~g} / \mathrm{L}$. However, due to a technical break down of the XRD machine, only three samples were investigated for their mineralogical changes using XRD namely, 30.55, 1.33, and $1.07 \mathrm{~g} / \mathrm{L}$ samples. The results from SEM with EDS provide information on hydration products that substantiate the identification of chemical compounds by XRD. The results form XRD of stabilized clay samples cured for 28 days show the evidence of the effect of salinity level on the cement hydration products.

\subsubsection{Unconfined compressive strength}

Table 4-3 summarizes the peak UCS values of clay samples at different pore fluid salt concentrations mixed with general use Portland cement and cured for different curing times. 
Figure 4-36presents the stress-strain curves of Champlain Sea clay at different salinity levels treated with $50 \mathrm{~kg} / \mathrm{m}^{3}$ of general use Portland cement. The figure shows that samples with the salinity level of $1.33 \mathrm{~g} / \mathrm{L}$ showed a comparatively higher UCS value at 28 days compared to other samples in other salt levels. At 28 days of curing, samples with $1.33 \mathrm{~g} / \mathrm{L}$ salt concentration showed the highest peak UCS value of $1374 \mathrm{kPa}$. As the salt level decreased to 1.07 and $0.73 \mathrm{~g} / \mathrm{L}$, a slight decease in UCS values was observed. The natural clay at a salinity level of $15.53 \mathrm{~g} / \mathrm{L}$ showed the least peak UCS of $877 \mathrm{kPa}$. Samples with salinity level of $30.55 \mathrm{~g} / \mathrm{L}$ showed an average USC value close to the natural clay.

The strength development with curing time of Champlain Sea clay at different salt concentrations is shown in Figure 4-37. It is noted that the leached samples did not show a significant strength increase with an increasing curing time from 7 days to 14 days. The strength of salinized samples decreased at 14 days before reaching an UCS value close to that of the natural clay at 28 days of curing. All leached clay showed a higher strength than that of the natural clay. This may be interpreted that the presence of salt reduces the cementation of bond strength in Champlain Sea clay admixed with cement.

Table 4-3: Peak UCS values of cement treated Champlain Sea clay at different salt level

\begin{tabular}{ccccccc}
\hline Sample Id & $\begin{array}{c}\text { Binder } \\
\text { Type }\end{array}$ & $\begin{array}{c}\text { Dosage } \\
\left(\mathrm{kg} / \mathrm{m}^{3}\right)\end{array}$ & $\begin{array}{c}\text { Salt } \\
\text { level } \\
(\mathrm{g} / \mathrm{L})\end{array}$ & $\begin{array}{c}\text { Curing } \\
\text { Time (days) }\end{array}$ & $\begin{array}{c}\text { Peak } \\
\text { UCS } \\
(\mathrm{kPa})\end{array}$ & $\begin{array}{c}\text { Failure } \\
\text { strain, } \\
\varepsilon_{\mathrm{f}}(\%)\end{array}$ \\
\hline WD21.6C50D07UCS1 & $\mathrm{GU}$ & 50 & 0.73 & 07 & 749 & 1.40 \\
WD21.6C50D07UCS2 & $\mathrm{GU}$ & 50 & 0.73 & 07 & 749 & 1.40 \\
WD21.6C50D14UCS1 & $\mathrm{GU}$ & 50 & 0.73 & 14 & 573 & 1.69 \\
WD21.6C50D28UCS1 & $\mathrm{GU}$ & 50 & 0.73 & 28 & 1022 & 1.42 \\
WD21.6C50D28UCS2 & $\mathrm{GU}$ & 50 & 0.73 & 28 & 973 & 1.59 \\
WD21.6C50D07UCS1 & $\mathrm{GU}$ & 50 & 1.07 & 07 & 745 & 1.39 \\
WD21.6C50D07UCS2 & $\mathrm{GU}$ & 50 & 1.07 & 07 & 650 & 1.50 \\
WD21.6C50D14UCS1 & $\mathrm{GU}$ & 50 & 1.07 & 14 & 743 & 1.20 \\
WD21.6C50D28UCS1 & $\mathrm{GU}$ & 50 & 1.07 & 28 & 934 & 1.20 \\
WD21.6C50D28UCS2 & $\mathrm{GU}$ & 50 & 1.07 & 28 & 917 & 1.50 \\
WD21.6C50D07UCS1 & $\mathrm{GU}$ & 50 & 1.33 & 07 & 965 & 1.39 \\
WD21.6C50D07UCS2 & $\mathrm{GU}$ & 50 & 1.33 & 07 & 1037 & 1.50 \\
\hline
\end{tabular}




\begin{tabular}{lllllll}
\hline WD21.6C50D14UCS1 & GU & 50 & 1.33 & 14 & 809 & 1.29 \\
WD21.6C50D14UCS2 & GU & 50 & 1.33 & 14 & 1150 & 1.19 \\
WD21.6C50D28UCS1 & GU & 50 & 1.33 & 28 & 1374 & 1.28 \\
WD21.6C50D28UCS2 & GU & 50 & 1.33 & 28 & 1123 & 1.00 \\
WD21.6C50D07UCS1 & GU & 50 & 15.53 & 07 & 607 & 1.61 \\
WD21.6C50D07UCS2 & GU & 50 & 15.53 & 07 & 620 & 0.99 \\
WD21.6C50D14UCS1 & GU & 50 & 15.53 & 14 & 740 & 1.37 \\
WD21.6C50D14UCS2 & GU & 50 & 15.53 & 14 & 704 & 1.87 \\
WD21.6C50D28UCS1 & GU & 50 & 15.53 & 28 & 877 & 1.00 \\
WD21.6C50D28UCS2 & GU & 50 & 15.53 & 28 & 814 & 0.87 \\
WD21.6C50D07UCS1 & GU & 50 & 30.55 & 07 & 842 & 1.88 \\
WD21.6C50D07UCS2 & GU & 50 & 30.55 & 07 & 871 & 2.00 \\
WD21.6C50D14UCS1 & GU & 50 & 30.55 & 14 & 832 & 1.50 \\
WD21.6C50D14UCS1 & GU & 50 & 30.55 & 14 & 798 & 1.48 \\
WD21.6C50D28UCS1 & GU & 50 & 30.55 & 28 & 951 & 1.69 \\
WD21.6C50D28UCS2 & GU & 50 & 30.55 & 28 & 778 & 1.39 \\
\hline
\end{tabular}

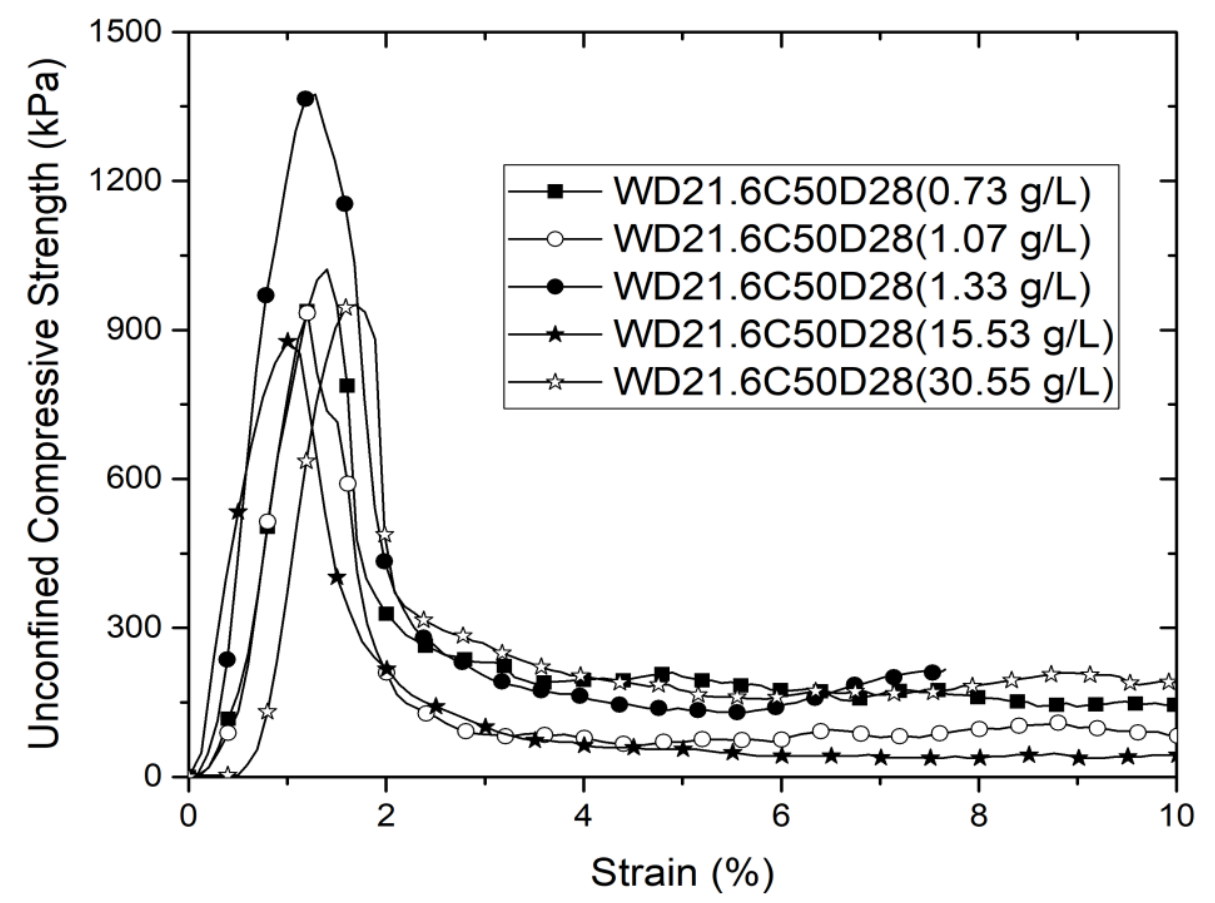

Figure 4-36: Stress-strain curves of cement-treated Champlain Sea clay samples 


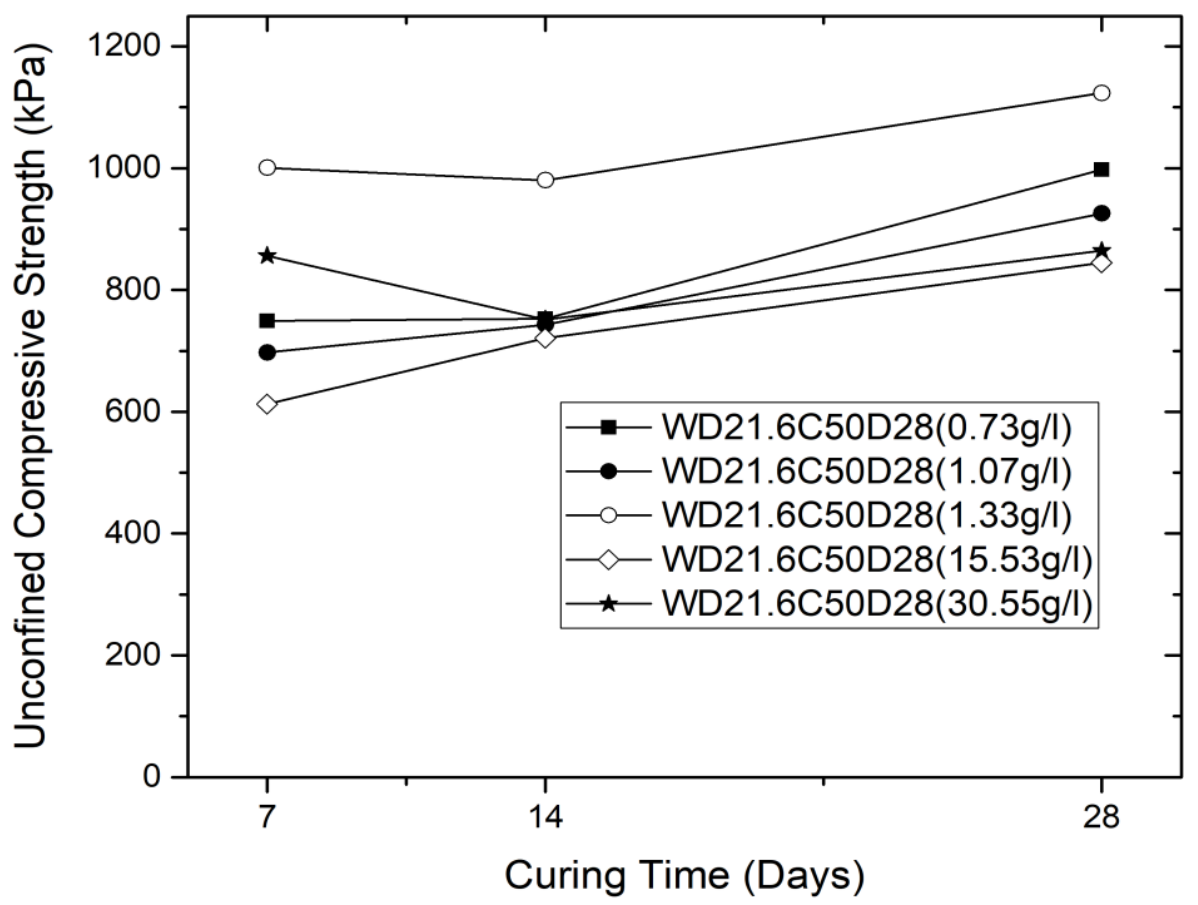

Figure 4-37: UCS vs curing time of clay of cement-treated clay samples at different salinity levels

The relationship between salt concentration and the average of two UCS samples at 28 days of Champlain sea clay treated with a cement dosage of $50 \mathrm{~kg} / \mathrm{m}^{3}$ is shown in Figure 4-38. It is observed that there is an optimum salinity level that corresponds to the highest UCS at 28 days curing period. The natural clay sample leached from $15.53 \mathrm{~g} / \mathrm{L}$ to $1.33 \mathrm{~g} / \mathrm{L}$ show a significant strength increase compared to all other samples. An increase of $47.7 \%$ in the UCS value from 845 to $1248 \mathrm{kPa}$ is observed for leached sample at $1.33 \mathrm{~g} / \mathrm{L}$. Samples leached to lower salt values of 1.07, and 0.73 $\mathrm{g} / \mathrm{L}$ show an increase in UCS compared to that of natural sample but not as high as $1.33 \mathrm{~g} / \mathrm{L}$ samples. Samples salinized to $30.55 \mathrm{~g} / \mathrm{L}$ did not show significant changes compared to natural ones.

Based on the UCS results, it is clear that the presence of the salt has a negative effect on the strength development of Champlain Sea clay. In order to confirm the observation of the optimum UCS at a certain salt concentration further XRD analysis was conducted in the next section to investigate the effect of salt content on the mineralogical changes of Champlain Sea clay admixed with cement. 

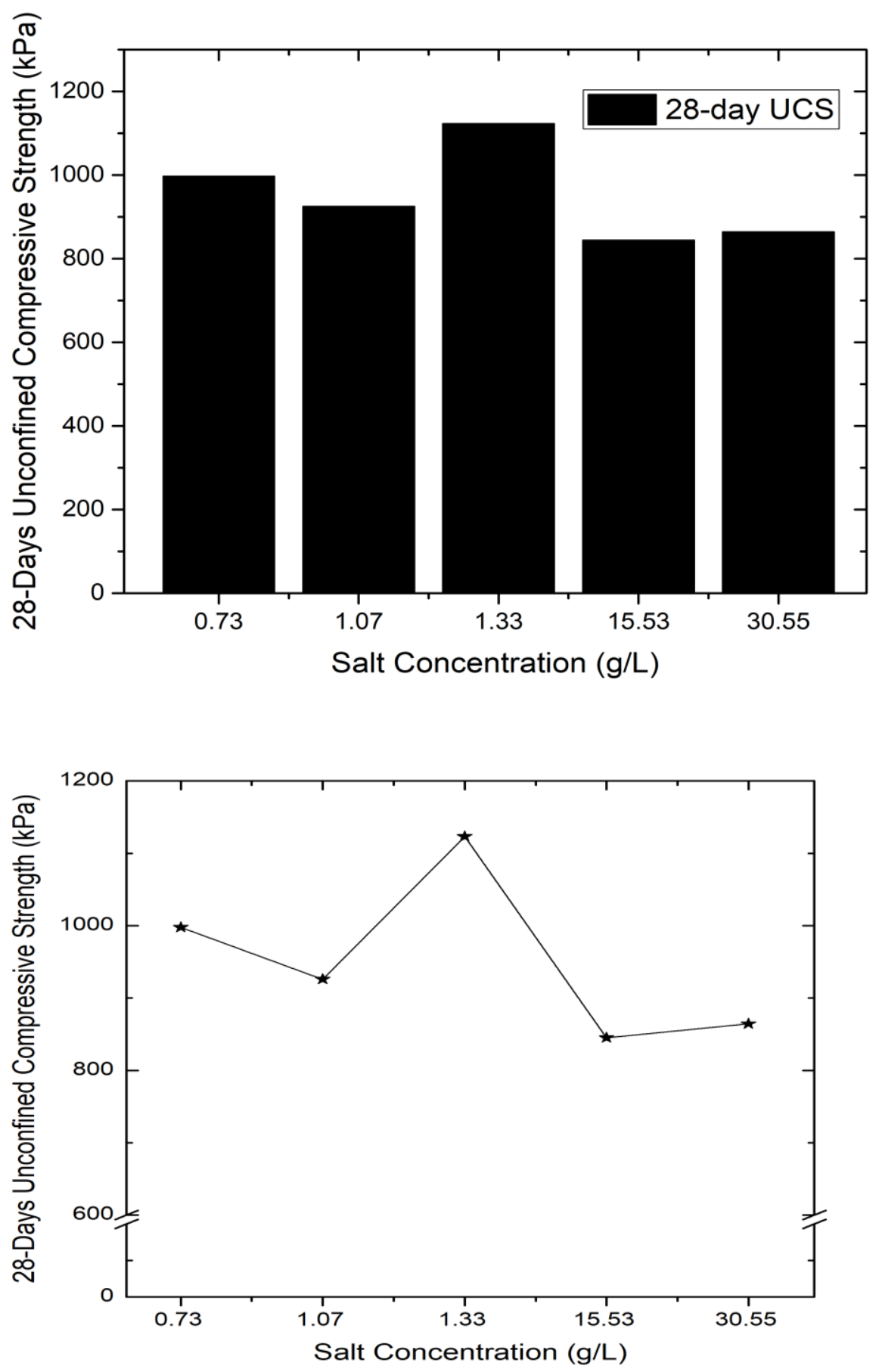

Figure 4-38: 28-days UCS of cement treated Champlain Sea clay vs. salt concentration 


\subsubsection{Microstructure changes of cement -treated clay at different salinity levels}

The SEM examinations of the leached untreated specimens reveals that leaching induces the formation of individual fragments of soil resulting from de-flocculation of the soil grains and aggregates, as shown in Figure 4-39 and Figure 4-40. Leaching leads to an increase in inter-grain porosity. As a consequence, the porous network grows and the mean pore size between the soil grains increases which could lead to an increase in surface area of the clay samples. However, salinized specimens show an aggregated structure similar to the cement treated clay microstructure, as shown in Figure 4-41.

For cement treated specimens, the SEM examination shows the presence of cementitious products linking the soil particles. Figure 4-42 to Figure 4-44 show the development of calcium silicate hydrates and calcium aluminium silicate hydrates covering the soil grains and filling the inter-aggregate voids after 28 days of curing period. These products are systematically associated with hydrated cement.

In order to further examine the effect of salt level on the hydration reaction products, an EDS analysis was conducted. The element distribution within each sample was then determined.

Figure 4-45 shows the elemental composition of natural Champlain Sea clay at its original salt concentration of $15.53 \mathrm{~g} / \mathrm{L}$ treated with $50 \mathrm{~kg} / \mathrm{m}^{3}$ cement and cured for 28 days. Generally, the mixture contains element such as silicon $(\mathrm{Si})$, calcium $(\mathrm{Ca})$, and aluminium $(\mathrm{Al})$, which may be carried along in the forms of silicates $\left(\mathrm{SiO}_{2}\right)$, calcium oxide $(\mathrm{CaO})$, and aluminum oxide $\left(\mathrm{Al}_{2} \mathrm{O}_{3}\right)$. Sodium (Na) and chlorine originates from sodium chloride salt. Other minor elements of the alkali groups, including magnesium $(\mathrm{Mg})$, potassium $(\mathrm{K})$ are also found in the soil-cement mix.

The elemental distribution of leached clay admixed with cement after 28 of curing is shown in Figure 4-46 and Figure 4-47. The sodium chloride was most leached as indicated by the absence of the chlorine element from the EDS analysis. However, sodium appeared in a small quantity (2.4 $\mathrm{wt} \%$ for $1.33 \mathrm{~g} / \mathrm{L}$ sample, and $2.3 \mathrm{wt} \%$ for $1.07 \mathrm{~g} / \mathrm{L}$ sample), this sodium leftover could be from sodium oxide $\left(\mathrm{Na}_{2} \mathrm{O}\right)$.

Specimens salinized to $30.55 \mathrm{~g} / \mathrm{L}$ show higher sodium and chlorine elements contents (more than $50 \mathrm{wt} \%$ ), which could explain the major changes in the bonding structure of the soil-cement mix. 


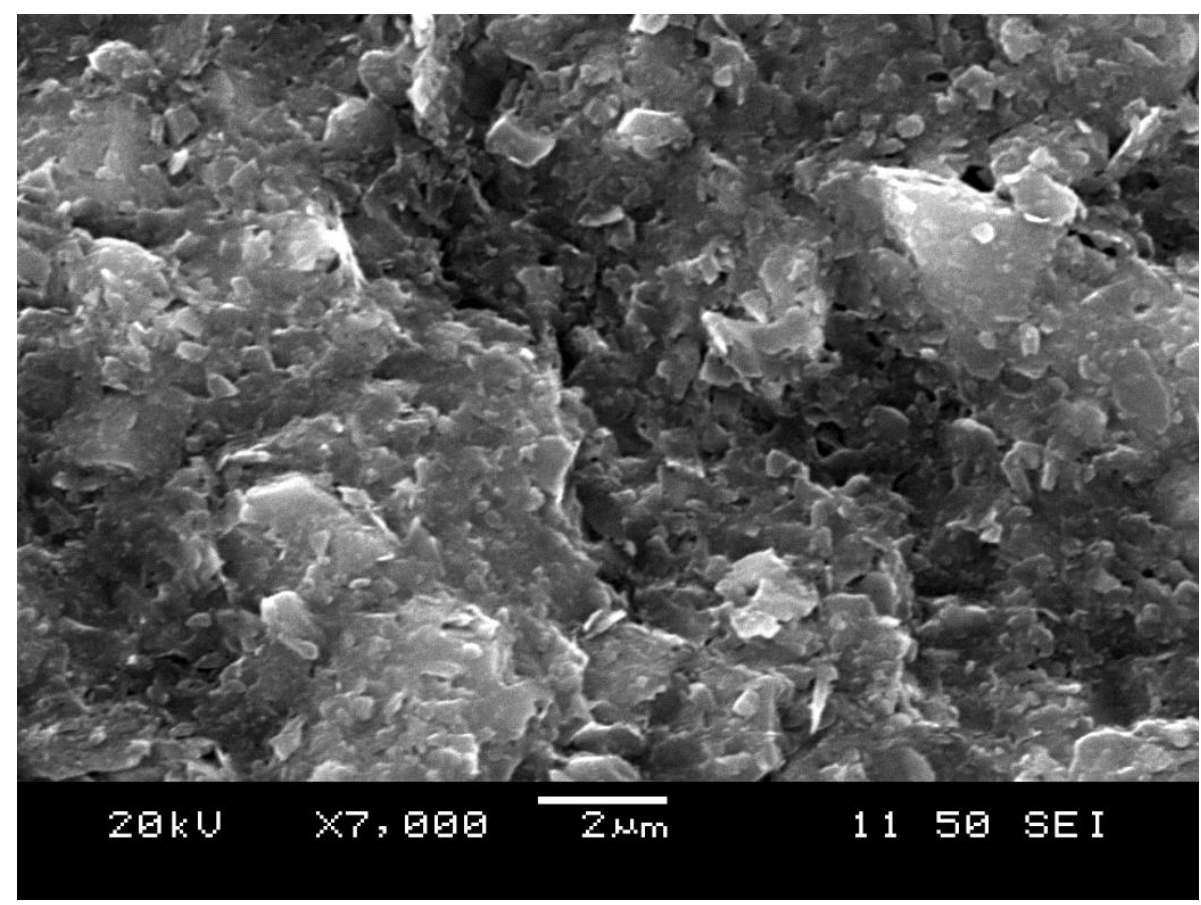

Figure 4-39: SEM micrograph of Champlain Sea clay leached to $1.33 \mathrm{~g} / \mathrm{L}$

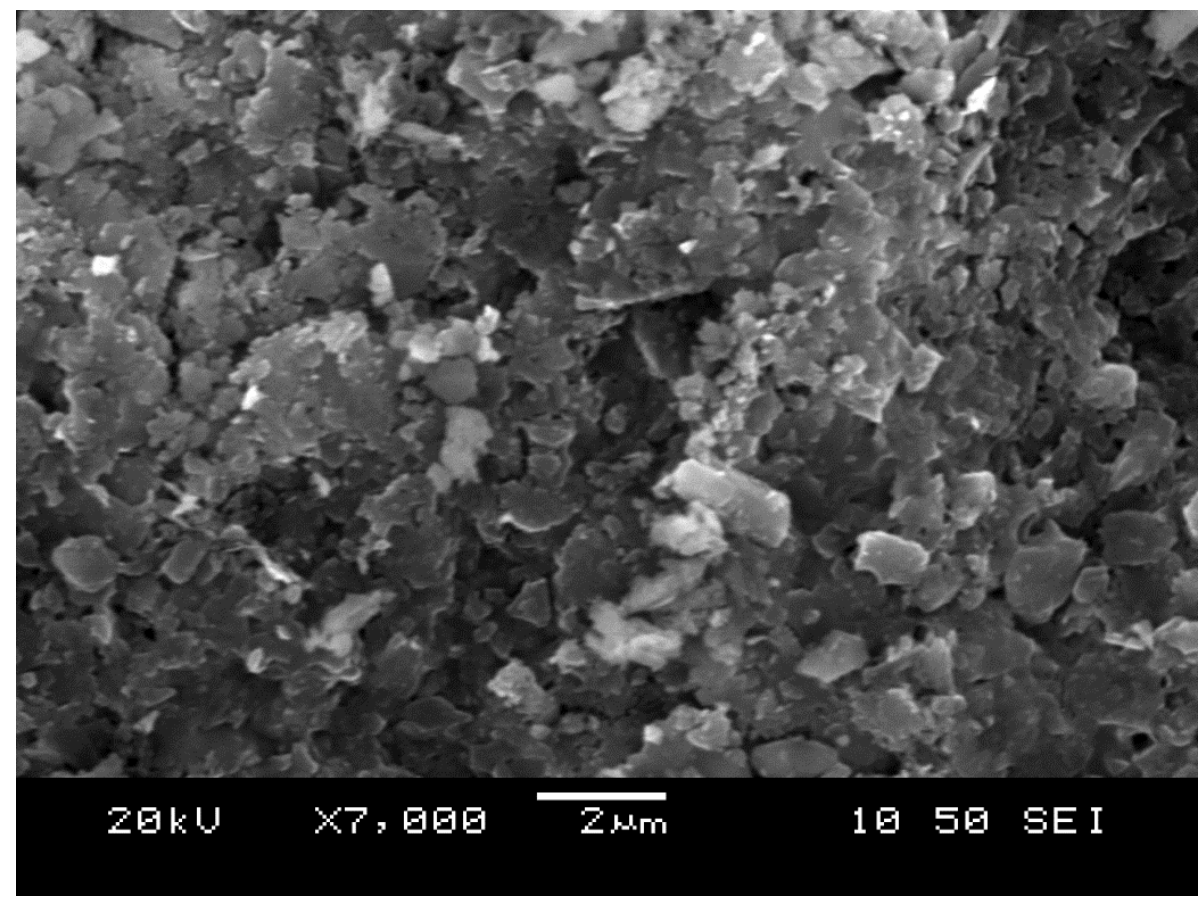

Figure 4-40: SEM micrograph of Champlain Sea clay leached to $1.07 \mathrm{~g} / \mathrm{L}$ 


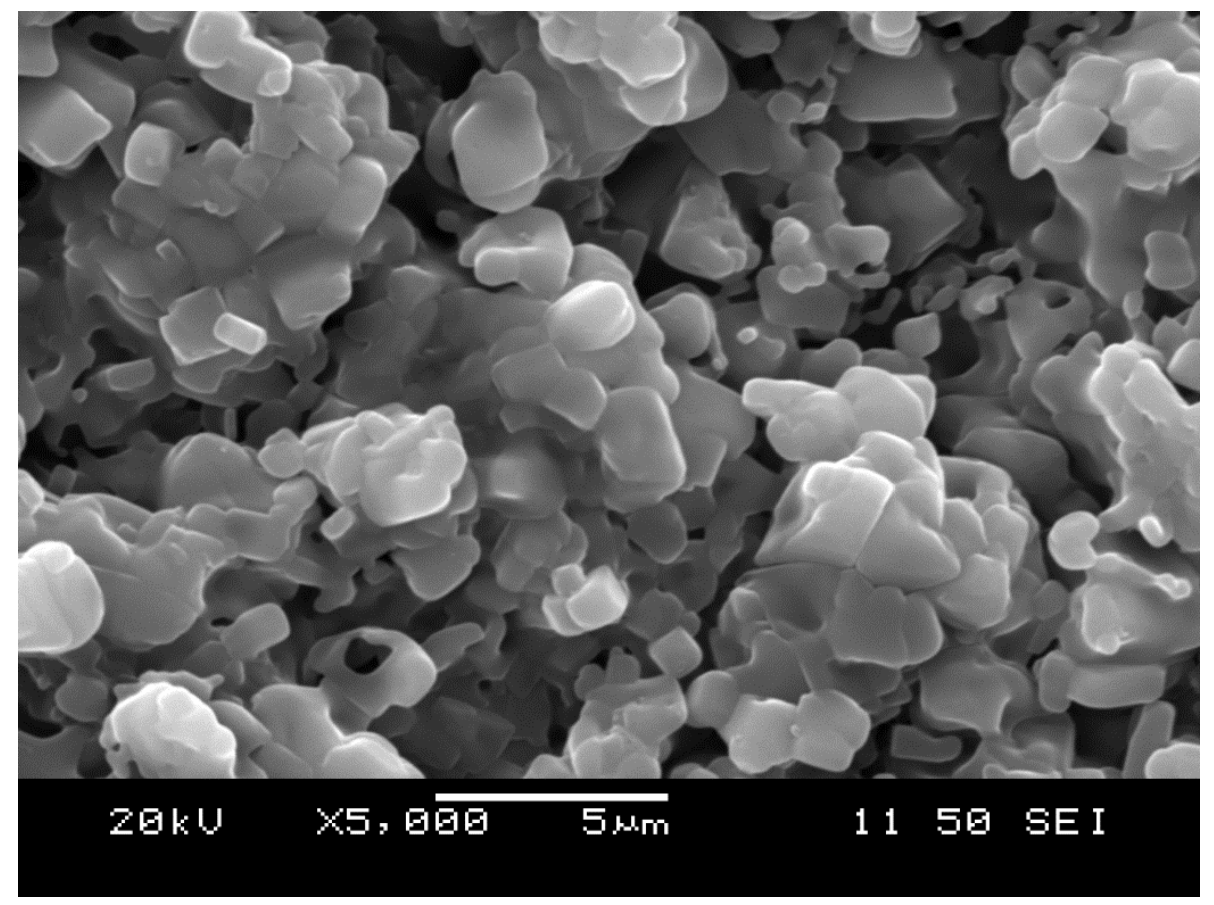

Figure 4-41: SEM micrograph of Champlain Sea clay salinized to $30.55 \mathrm{~g} / \mathrm{L}$

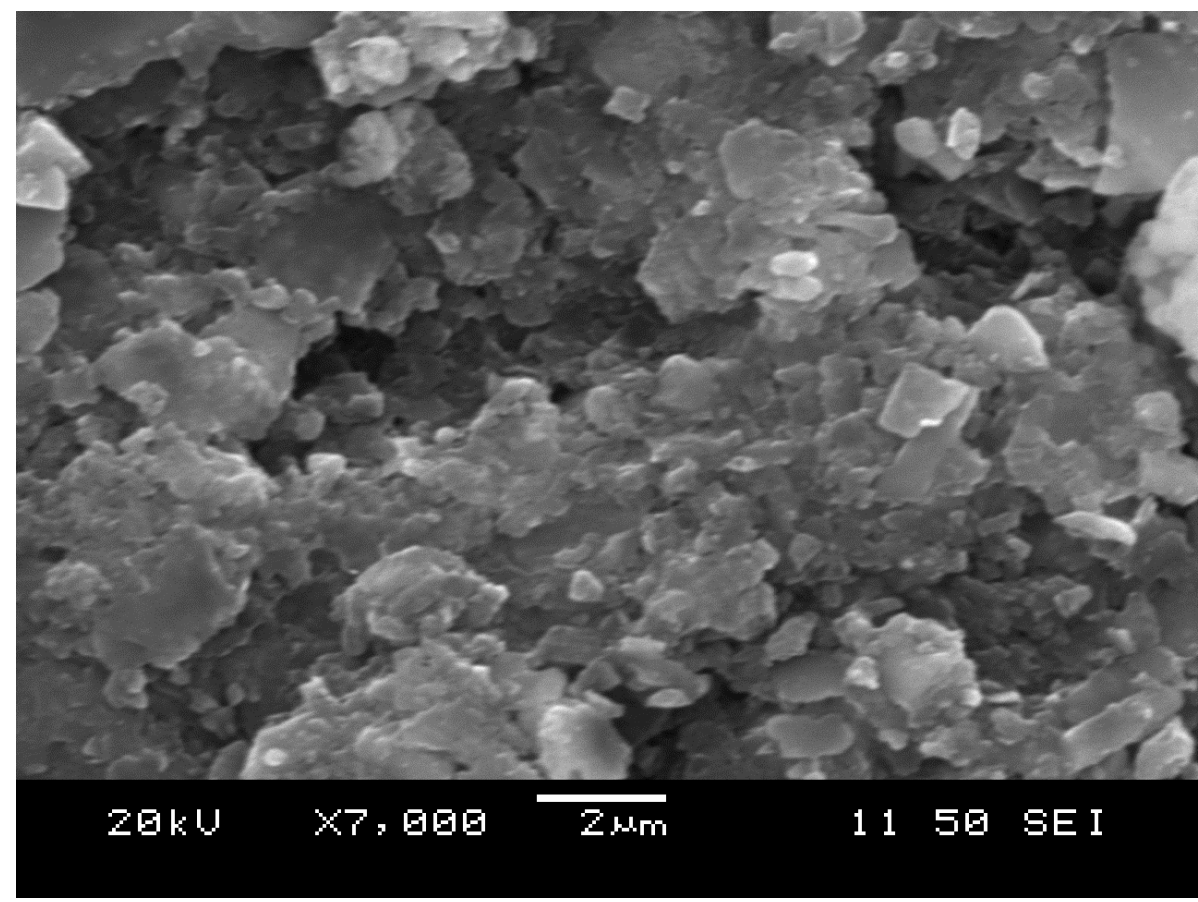

Figure 4-42: SEM micrograph of leached $(1.33 \mathrm{~g} / \mathrm{L})$ Champlain Sea clay treated with $50 \mathrm{~kg} / \mathrm{m}^{3}$ cement and cured for 28 days 


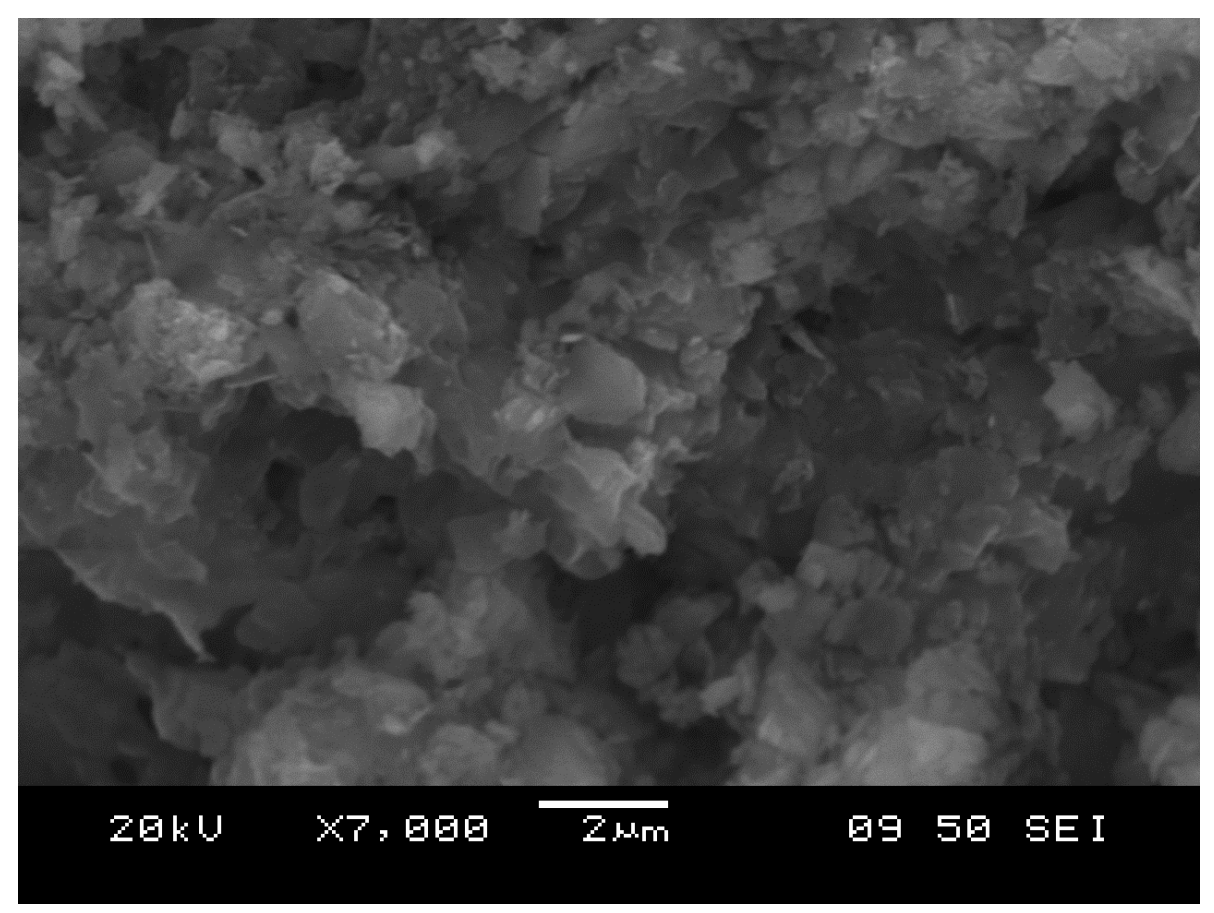

Figure 4-43: SEM micrograph of leached $(1.07 \mathrm{~g} / \mathrm{L})$ Champlain Sea clay treated with $50 \mathrm{~kg} / \mathrm{m}^{3}$ cement and cured for 28 days

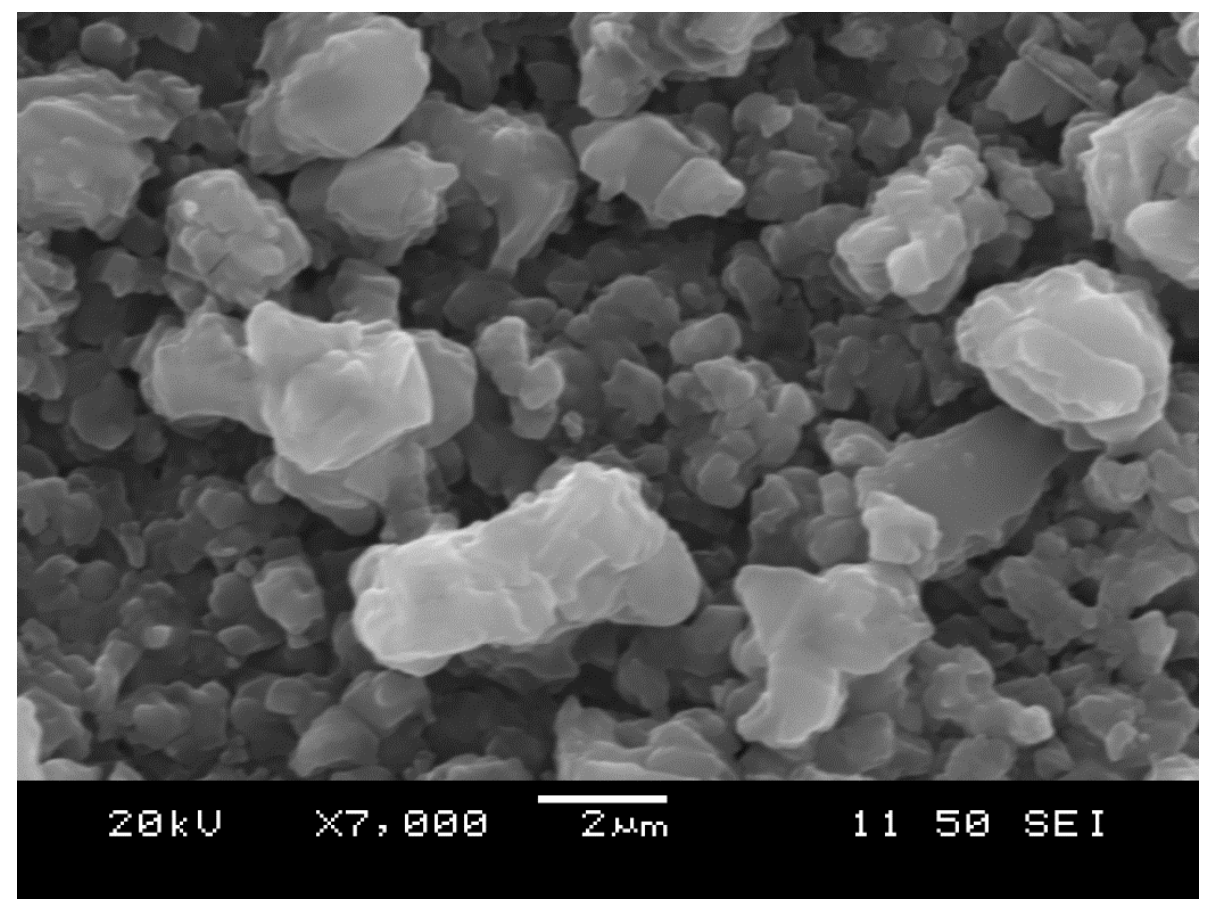

Figure 4-44: SEM micrograph of salinized ( $30.55 \mathrm{~g} / \mathrm{L}$ ) Champlain Sea clay treated with 50 $\mathrm{kg} / \mathrm{m}^{3}$ cement and cured for 28 days 


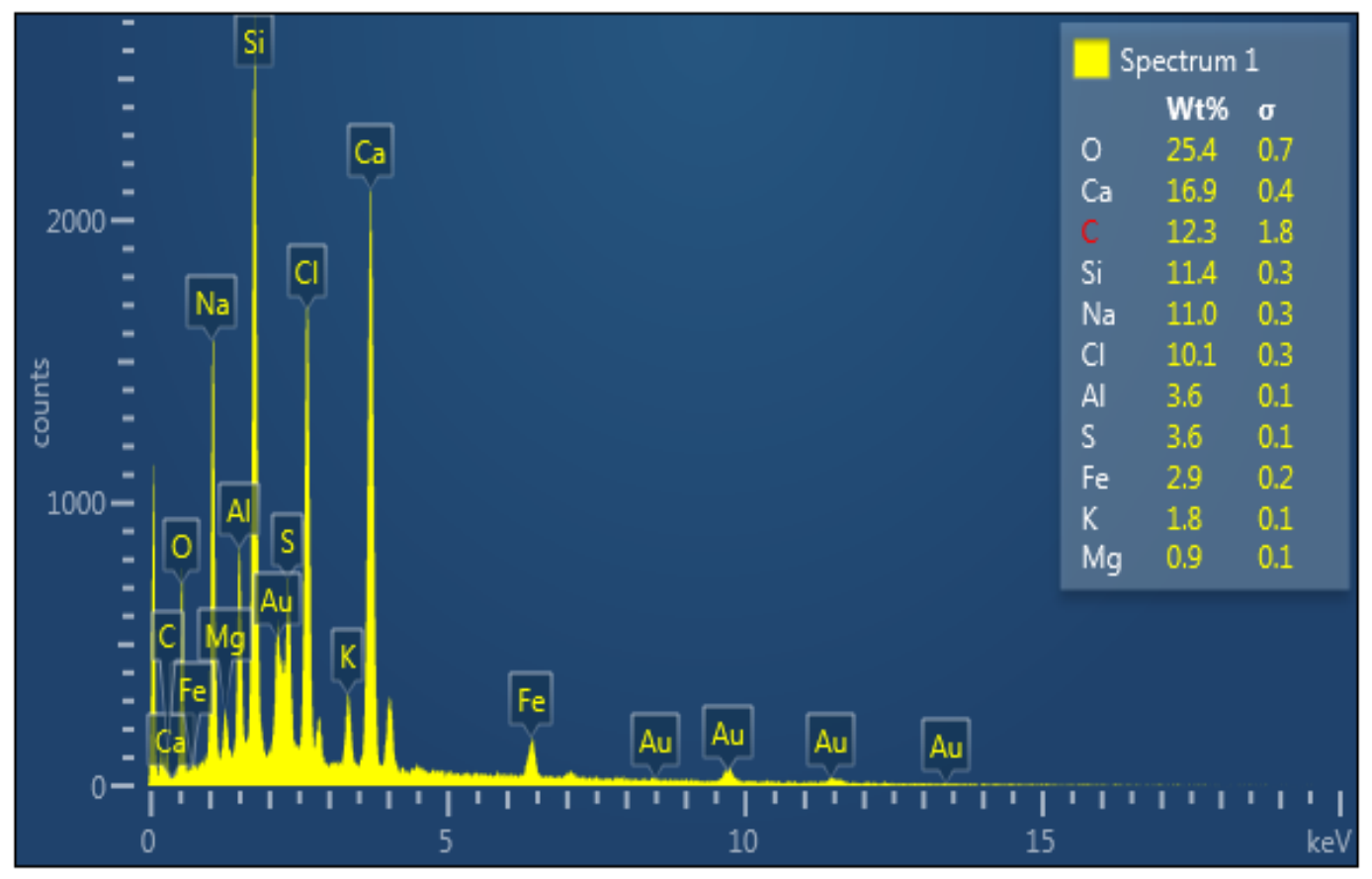

Figure 4-45: Average elemental composition of natural Champlain Sea clay ( $15.53 \mathrm{~g} / \mathrm{L})$ treated with $50 \mathrm{~kg} / \mathrm{m}^{3}$ cement and cured for 28 days

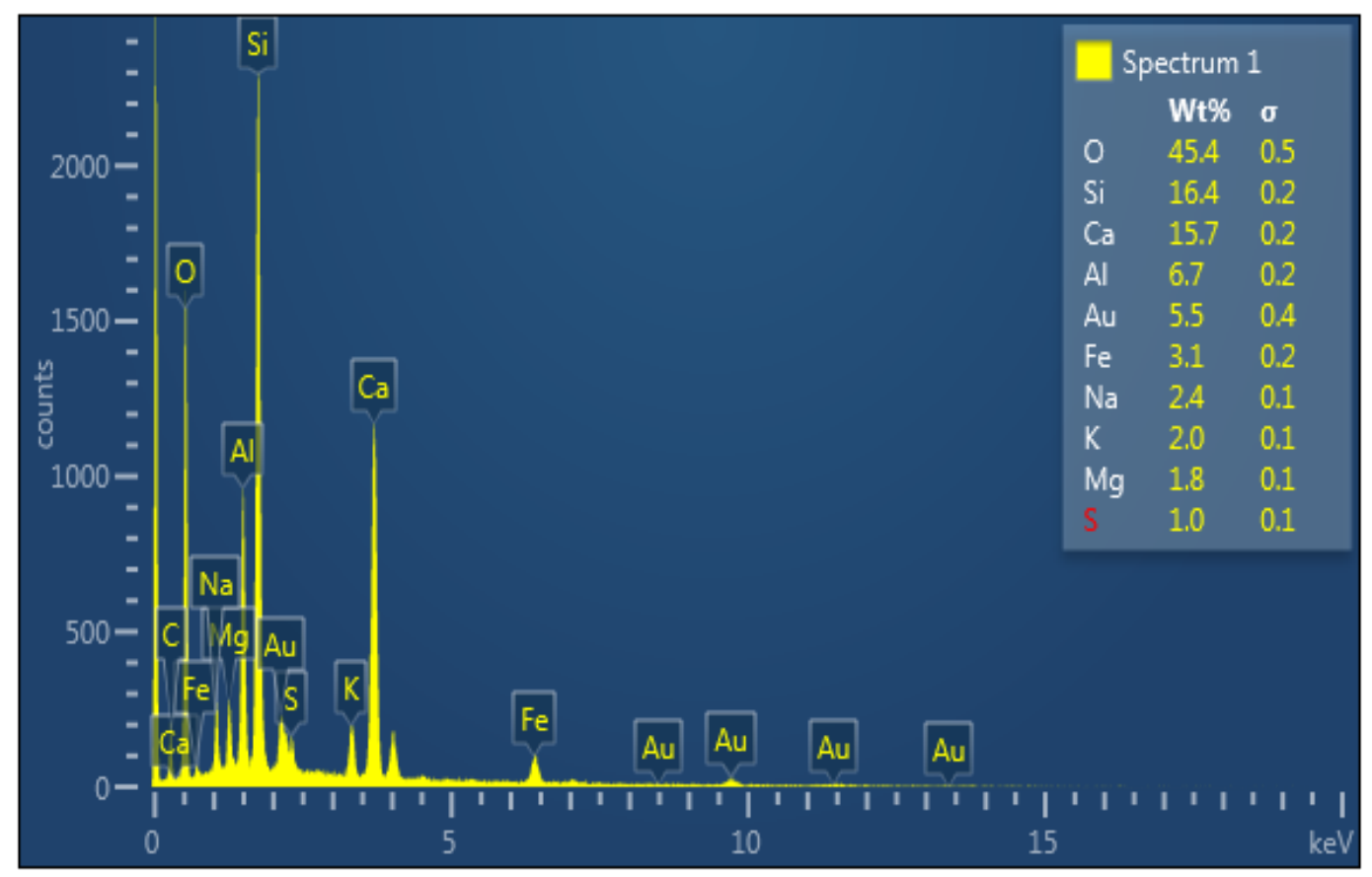

Figure 4-46: Average elemental composition of leached Champlain Sea clay ( $1.33 \mathrm{~g} / \mathrm{L})$ treated with $50 \mathrm{~kg} / \mathrm{m}^{3}$ cement and cured for 28 days 


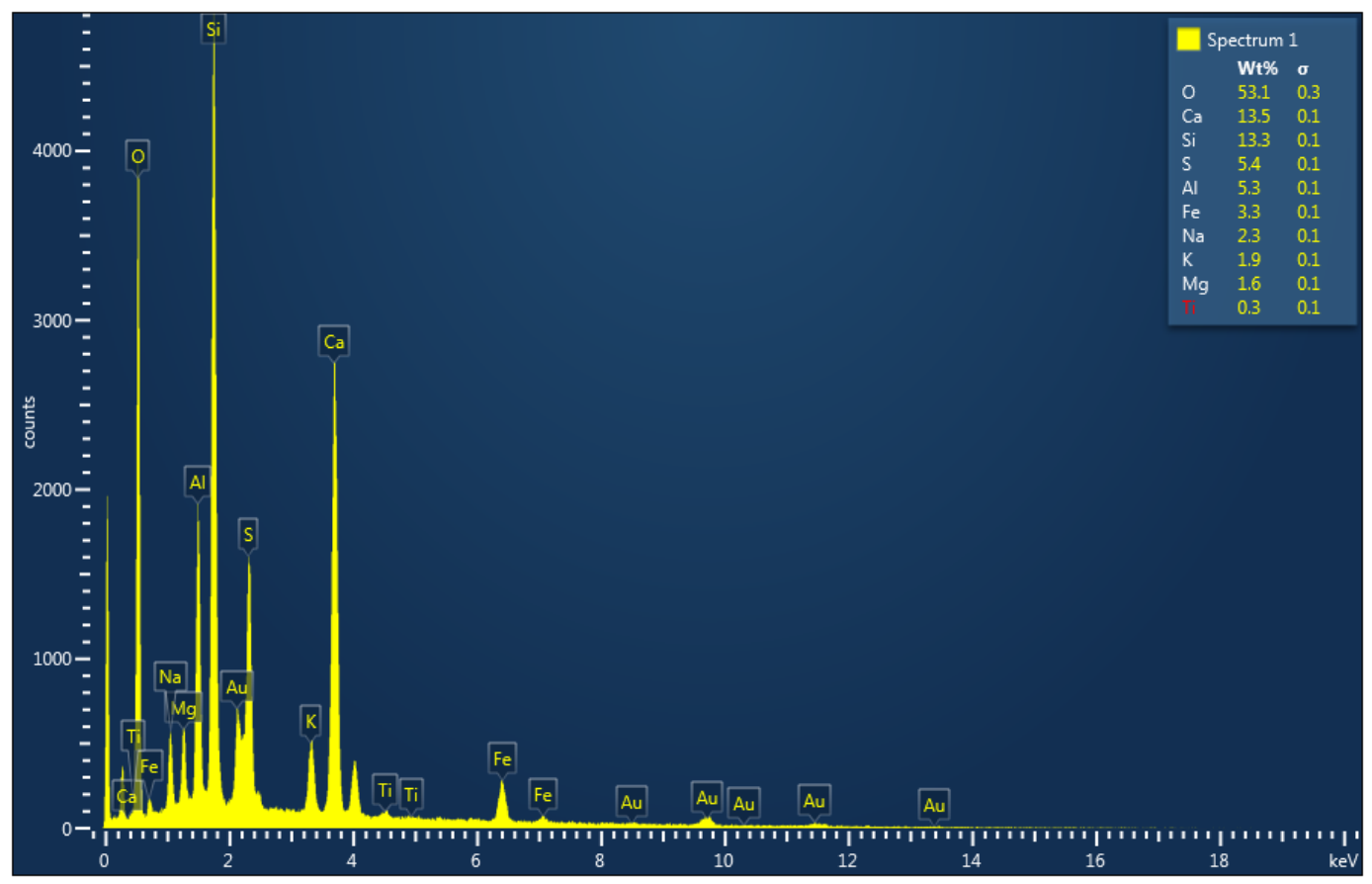

Figure 4-47: Average elemental composition of leached Champlain Sea clay ( $1.07 \mathrm{~g} / \mathrm{L})$ treated with $50 \mathrm{~kg} / \mathrm{m}^{3}$ cement and cured for 28 days

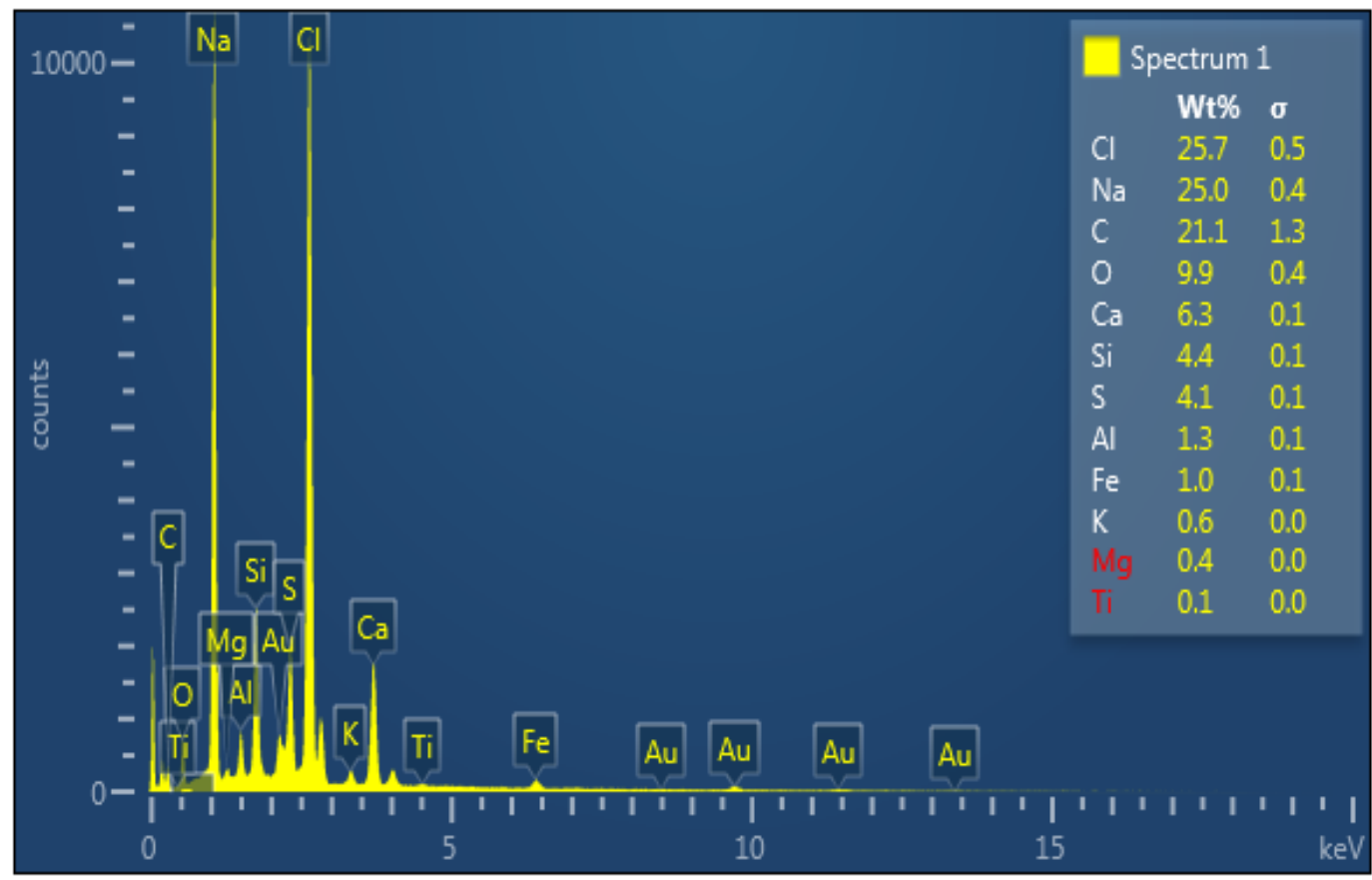

Figure 4-48: Average elemental composition of salinized Champlain Sea clay (30.55 g/L) treated with $50 \mathrm{~kg} / \mathrm{m}^{3}$ cement and cured for 28 days 


\subsubsection{X-Ray diffraction analysis}

The XRD pattern obtained from Champlain Sea clay at its natural pore fluid salinity level of 15.53 $\mathrm{g} / \mathrm{L}$ is shown in Figure 4-49. The major crystalline minerals present in the clay sample are, illite $\left(2 \mathrm{~K}_{2} \mathrm{O} .3 \mathrm{Mg} \mathrm{O} . \mathrm{Al}_{2} \mathrm{O}_{3} .24 \mathrm{Si} \mathrm{O}_{2} .12 \mathrm{H}_{2} \mathrm{O}\right.$ ), kaolinite $\left(\mathrm{Al}_{2} \mathrm{O}_{3} .2 \mathrm{Si} \mathrm{O} 2.2 \mathrm{H}_{2} \mathrm{O}\right.$ ), and quartz $\left(\mathrm{Si} \mathrm{O}_{2}\right)$ from the XRD analysis. Compared to natural clay, a few new peaks of low to moderate intensities are observed in cement-treated clay samples, which were leached or salinized and then treated with the same cement dosage of $50 \mathrm{~kg} / \mathrm{m}^{3}$. These cementitious materials formed in the samples are responsible for the strength increase. Among these, the major hydraulic hydration products are calcium silicate hydrate $\mathrm{CSH}\left(\mathrm{Ca}_{1.5} \mathrm{SiO}_{3.5} . \mathrm{H}_{2} \mathrm{O}\right)$ and calcium tecto-dialumodisilicate tetrahydrate $\mathrm{CA}_{2} \mathrm{~S}_{2} \mathrm{H}_{4}\left(\mathrm{Ca} \mathrm{Al}_{2} \mathrm{Si}_{2} \mathrm{O}_{8}\left(\mathrm{H}_{2} \mathrm{O}\right)_{4}\right)$, as shown in Figure 4-50 to Figure 4-52. Apart from these identified products, there may be several other non-crystalline products which can not be identified using XRD technique.

These new products bind together and form a hardened skeleton matrix. These compounds were observed in all the stabilized soil mixes and hence the improvement in strength properties is achieved. However, the formation of stronger and wider cementitious peaks is observed more clearly in sample with a reduced salinity level of $1.33 \mathrm{~g} / \mathrm{L}$ as noted by the red box in Figure 4-51 . This observation agrees with the strength development and SEM observations mentioned previously.

The peaks of other compounds originally present in the soil (quartz, illite) did not show significant change, which indicate that there was not a significant breakdown of these minerals. This may be because the low cement content $\left(50 \mathrm{~kg} / \mathrm{m}^{3}\right)$, the dissolution of alumina and silica from the cementsoil mixture is negligible. Thus, the pozzolanic reaction at 28 days of curing did not take place to produce more cementitious products. 


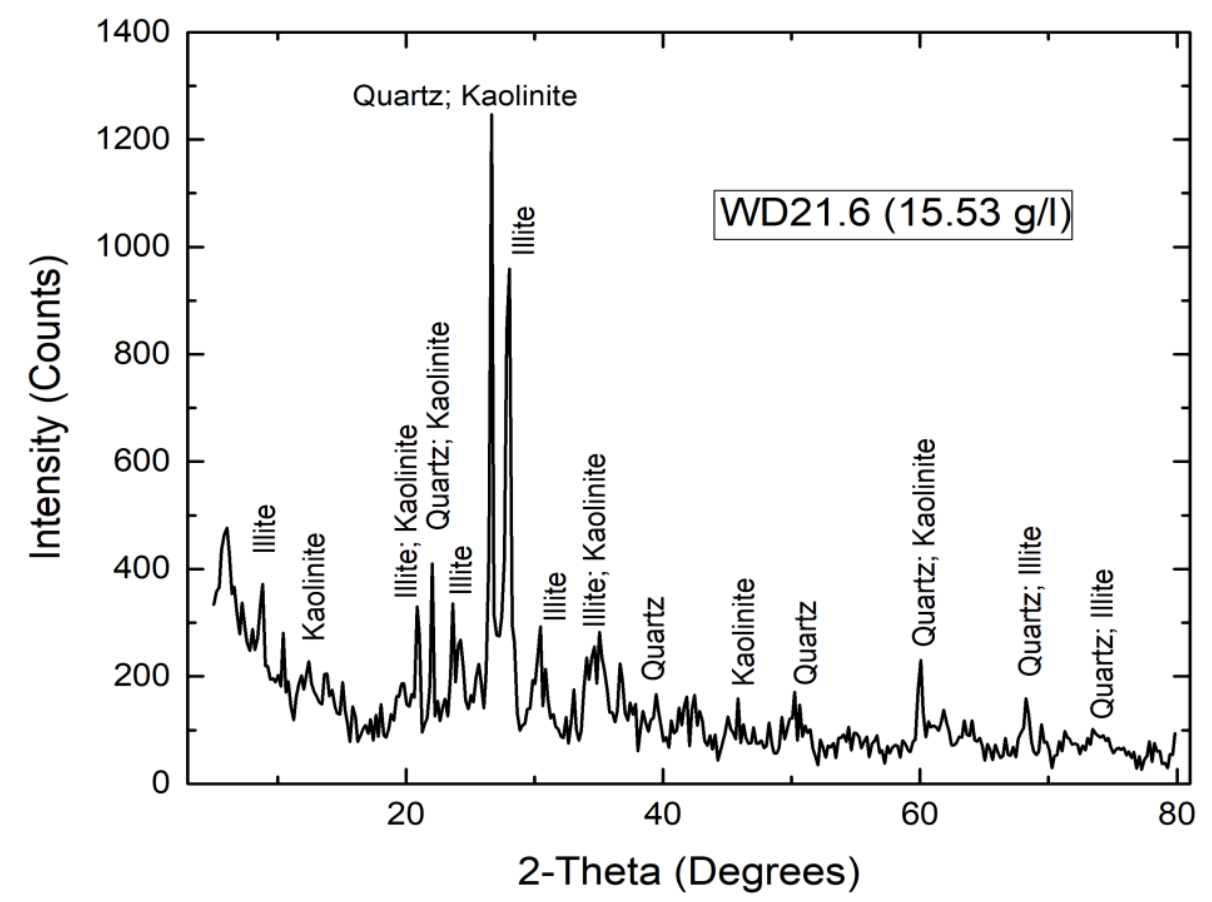

Figure 4-49: X-ray diffraction spectrum of natural clay sample at salt level of $15.53 \mathrm{~g} / \mathrm{L}$

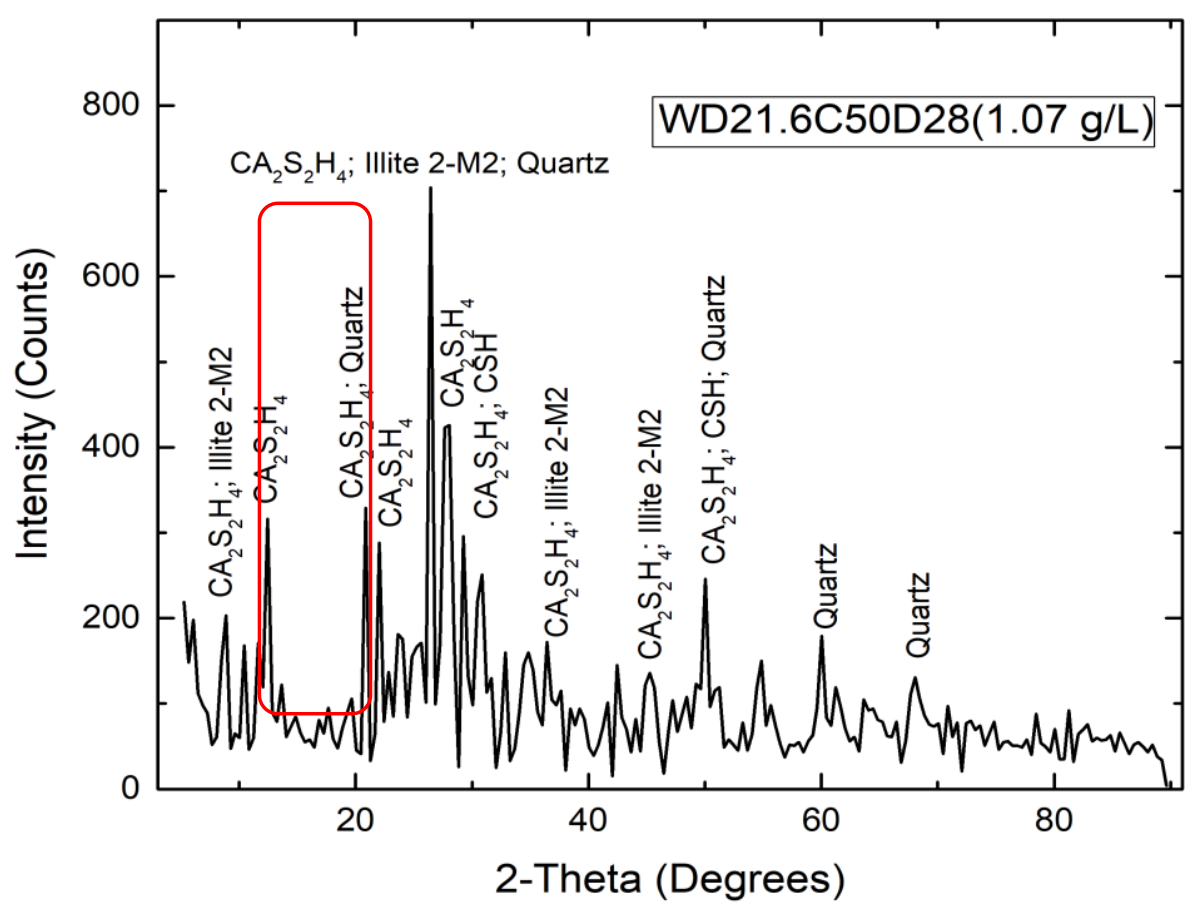

Figure 4-50: X-ray diffraction spectrum of leached clay sample to $1.07 \mathrm{~g} / \mathrm{L}$ treated with $50 \mathrm{~kg} / \mathrm{m}^{3}$ cured for 28 days 


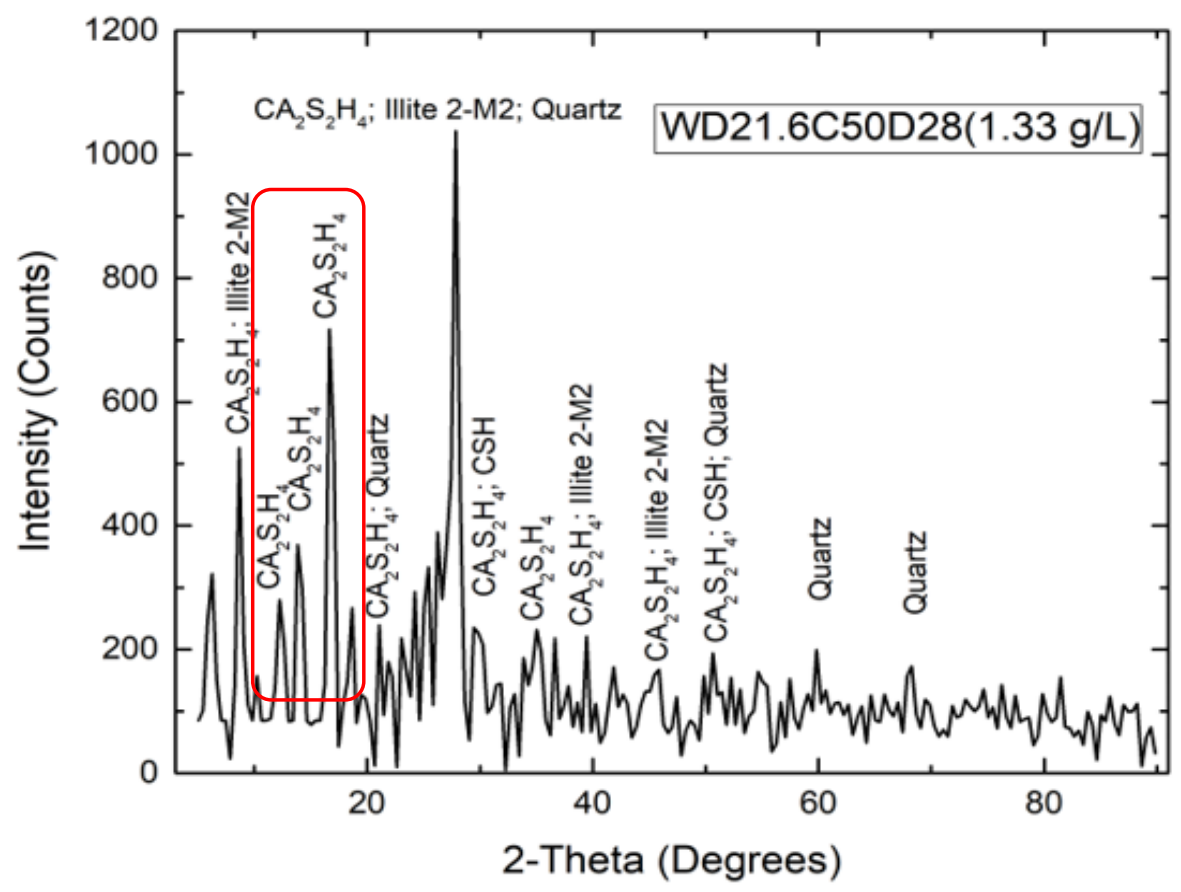

Figure 4-51: X-ray diffraction spectrum for leached clay sample to $1.33 \mathrm{~g} / \mathrm{L}$ treated with 50 $\mathrm{kg} / \mathrm{m}^{3}$ cured for 28 days

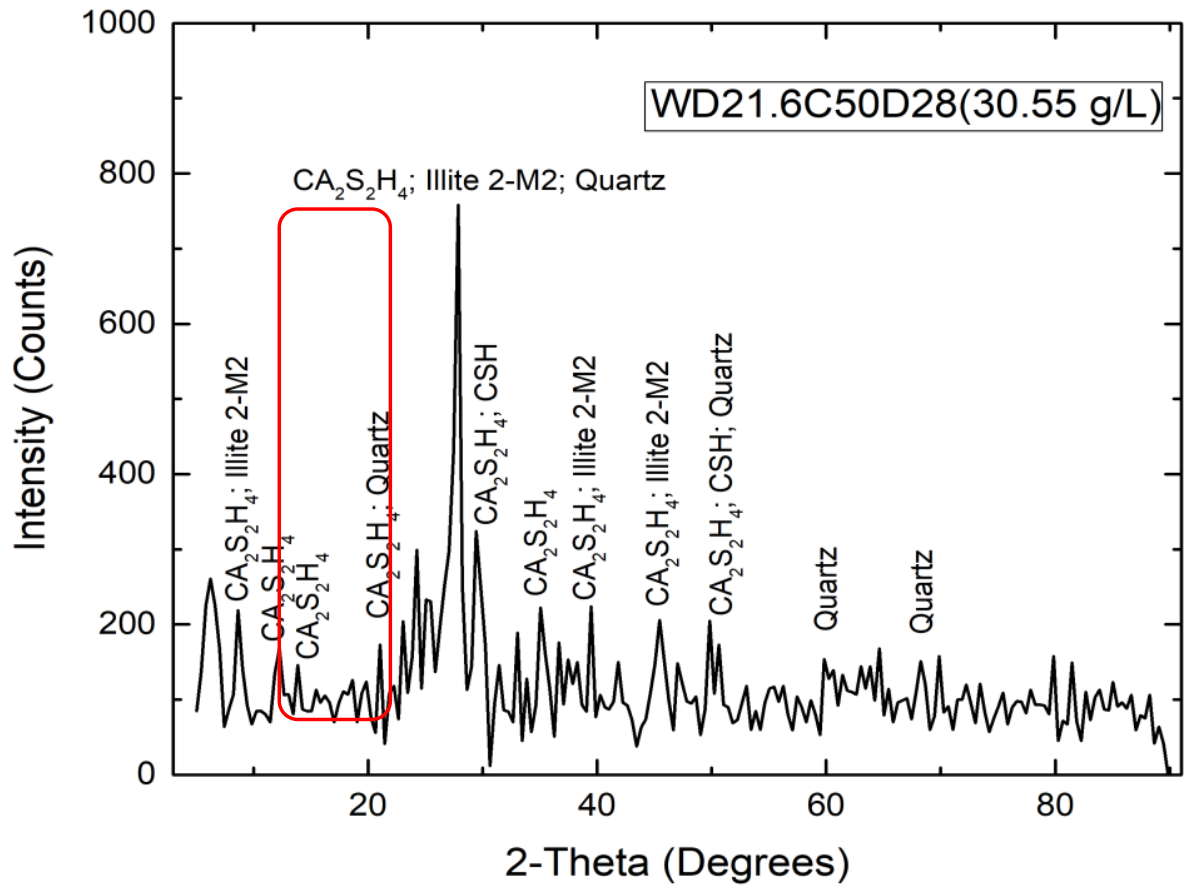

Figure 4-52: X-ray diffraction spectrum for salinized clay sample to $30.55 \mathrm{~g} / \mathrm{L}$ treated with 50 $\mathrm{kg} / \mathrm{m}^{3}$ cured for 28 days 


\subsection{SUMMARY}

This section presented and compared the effect of cement and other binder types when mixed with Champlain Sea clay on the strength development and the microstructural changes. The shear strength of treated samples increases with increasing of cement dosage and curing time. Substantial changes in the microstructure of the clay samples were observed using SEM. Based on UCS and SEM, slag/cement has a higher improvement ratio among other binder. The effect of different pore fluid salinity levels on strength, microstructure and mineralogical changes of Champlain Sea clay mixed with the same cement dosage of $50 \mathrm{~kg} / \mathrm{m}^{3}$ was also presented. XRD results showed that there is an optimum pore fluid salinity level $(1.33 \mathrm{~g} / \mathrm{L})$ where the shear strength reaches the highest. The microstructure of leached samples to a salinity level of $1.33 \mathrm{~g} / \mathrm{L}$ showed the densest microstructure among all other samples. XRD analysis supported the strength results and the SEM observations and confirmed that the hydration products are more significant in samples with salinity level of $1.33 \mathrm{~g} / \mathrm{L}$ than in other samples. 


\section{SUMMARY AND CONCLUSIONS}

\subsection{INTRODUCTION}

In this study, an experimental investigation was conducted to understand the microstructure changes associated with the strength development of Champlain Sea clay stabilizing with cement and other binders. Champlain Sea clay samples used in this study were obtained from an earth dam site in Ottawa region. The effect of five binder types on the strength development and the accompanying microstructural changes were established using the unconfined compressive strength (UCS) tests and the scanning electronic microscopy (SEM) method. A qualitative relationship between the strength development and the microstructural change was established.

The effect of pore fluid salinity level on the cement-treated Champlain Sea clay samples was established by conducting both SEM and X-ray diffraction (XRD) analyses.

\subsection{MAIN CONCLUSIONS}

Based on the test results, the following conclusions can be drawn:

1. In general, deep soil mixing (DSM) is an effective ground improvement technique to significantly improve the shear strength of Champlain Sea clay.

2. Based on SEM observations, undisturbed Champlain Sea clay exhibits an open structure fabric with flocculated particles, which explains the phenomenon related to its low shear strength, large void ratio, and high compressibility.

3. A total of five different binder types were used in this study and the results found that cement/slag is the best binder. Cement-treated samples showed the highest strength development for short-term strength gain up to 28 days of curing. However, as curing time increases to 300 days, samples treated with cement/slag and cement kiln dust gained higher UCS values than those of cement-treated samples due to the addition of cementitious products resulting from the pozzolanic reactions.

4. Links were observed between the microstructural changes due to artificial cementation and the mechanical properties of the specimens. SEM images of the cement-treated clay samples indicated the presence of reticulated matrix within the material. As cement content 
increases, the structure of cement-treated clay gradually transforms from a dispersed structure into a flocculated state. The produced cementitious products are affixed to the particles, coating the particle surfaces, and form matrices that fills the gap between clay aggregates

5. Specimen treated with a high cement dosage displayed a highly flocculated structure and the appearance of needle-like ettringite crystals.

6. Based on XRD analysis, cementitious products such as calcium silicate hydrate $\mathrm{CSH}$ ( $\mathrm{Ca}_{1.5}$ $\left.\mathrm{SiO}_{3.5} . \mathrm{H}_{2} \mathrm{O}\right)$ and calcium tecto-dialumodisilicate tetrahydrate $\mathrm{CASH}\left(\mathrm{Ca} \mathrm{Al}_{2} \mathrm{Si}_{2} \mathrm{O}_{8}\left(\mathrm{H}_{2} \mathrm{O}\right)_{4}\right)$ were formed at 28 days of curing, which explains the strength improvement of Champlain Sea clay due to cement mixing.

7. Leaching has a profound impact on Champlain Sea clay. Leaching reduces the shear strength of Champlain Sea clay specimen. As opposed to the flocculated structure of the natural clay, according to SEM observations, leached Champlain Sea clay exhibits an open dispersed structure resembling that of clays sedimented in fresh water found from other research work.

8. Sodium chloride salt has a negative effect on the strength development of cement-treated Champlain Sea clay. Under the same cement dosage condition, the UCS of cement-treated leached clay samples displayed higher UCS values than those of natural samples.

9. A series of stronger and wider cementitious peaks of CSH and CASH were observed more clearly in sample with salinity level of $1.33 \mathrm{~g} / \mathrm{L}$, which explains a potential optimum salinity level for strength development in cement-treated Champlain Sea clay.

\subsection{FUTURE WORK}

This research achieved its scope by identifying the microstructure changes and their relationships with the strength development of cement-treated Champlain Sea clay. The effect of salinity level on the strength development was also identified. However, a more comprehensive study with different tools will be required to reinforce the findings of this study.

1. In this investigation a qualitative description is investigated on the microstructure of natural and treated Champlain sea clay. Obtaining quantitative information using advanced tools 
such as image processing and mercury intrusion porosimeter (MIP) to determine the porosity will be of help in better quantifying the changes.

2. The influence of the used conventional oven-drying on the observed microstructures requires further investigations. As oven-drying method may affect the microstructural changes.

3. Investigation on the effect of other binder types on the leached Champlain Sea clay at a wide range of salinity level will confirm or negate the existence of an optimum salinity level at which the shear strength increase is the highest due to cement mixing.

4. The average time to obtain a $2 \mathrm{~kg}$ sample of leached sample close to $1.5 \mathrm{~g} / \mathrm{L}$ was about six weeks using the current leaching method through the leaching apparatus. Develop a rapid methodology to obtain leached Champlain Sea clay will accelerate the production of leached samples.

5. A further investigation is needed on the effect of other factors for a comprehensive understanding of the strength development and microstructural changes of cement-treated Champlain Sea clay, such as the chemical composition of the CKD and the pore fluid chemistry and $\mathrm{pH}$. 


\section{APPENDICES}

APPENDIX A: DSM mix design according to FHWA (2103)

\begin{tabular}{|c|c|c|}
\hline \multicolumn{3}{|c|}{ PROJECT INFORMATION } \\
\hline Client & Boring Number & \\
\hline Project Name: MASC Research & Sample Number & $12-19$ \\
\hline Sample Location: Waba Dam & Sample Depth & $21.45-21.75$ \\
\hline Specimen Description: Champlain Sea & Specimen Remarks & \\
\hline \multicolumn{3}{|c|}{ MIX DESIGN (Based on FHWA Guidelines) } \\
\hline Symbol & Long name & \\
\hline \multicolumn{3}{|c|}{ Input } \\
\hline $\mathrm{Nm}$ & Number of molds to be used & 10 \\
\hline $\mathrm{Hm}(\mathrm{m})$ & Height of mold (meter) & 0.1 \\
\hline $\operatorname{Dm}(\mathrm{m})$ & Diameter of mold (meter) & 0.05 \\
\hline$w: b$ & Water to binder ratio & 1 \\
\hline y soil & Total unit weight of soil $(\mathrm{kg} / \mathrm{m} 3)$ & $1,549.00$ \\
\hline$\omega$ & Water content $(/ 100)$ & $79.67 \%$ \\
\hline Gs & Specific gravity of soil & 2.67 \\
\hline $\mathrm{Gb}$ & Specific gravity of binder & 3.15 \\
\hline ain-place & Binder dosage; Factor per total volume of mix $(\mathrm{kg} / \mathrm{m} 3)$ & 200 \\
\hline \multicolumn{3}{|c|}{ Calculations } \\
\hline$\alpha$ & Binder dosage; Factor per volume of wet soil $(\mathrm{kg} / \mathrm{m} 3)$ & 272 \\
\hline$\alpha w(\%)$ & Binder content in percentage of soil solid & $31.50 \%$ \\
\hline $\operatorname{Vmix}(\mathrm{m} 3)$ & (\# of molds) (volume of mold) & 0.00196 \\
\hline yd soil & Dry unit weight of soil $(\mathrm{kg} / \mathrm{m} 3)$ & 862 \\
\hline $\mathrm{S}$ & Soil saturation & 0.998 \\
\hline VR & Volume ratio expressed in terms of binder factor in-place for any $\mathrm{S}$ & 0.358 \\
\hline Vs & Volume of the dry soil (m3) & 0.0004528 \\
\hline Vsoil & Volume of wet soil (m3) & 0.00145 \\
\hline Ws & Weight of soil (wet) (kg) & 2.24 \\
\hline Wsoil & Weight of soil (dry) (kg) & 1.25 \\
\hline $\mathrm{Wb}$ & Weight of the binder $(\mathrm{kg})$ & 0.393 \\
\hline Ww, slurry & Weight of water in the slurry for wet mixing (kg) (water added) (kg) & 0.393 \\
\hline $\mathrm{Vb}$ & Volume of the binder $(\mathrm{m} 3)$ & 0.000125 \\
\hline pd, slurry & Dry unit weight of the slurry (Wb/Vslurry) & 759 \\
\hline Vw,slurry & Volume of water in the slurry for wet mixing $(\mathrm{m} 3)$ & 0.00039 \\
\hline$V_{w, m i x}$ & Volume of water in the mixture & 0.001386 \\
\hline $\mathrm{Vw}, \mathrm{s}$ & Volume of water in the soil (m3) & 0.000993 \\
\hline Ww, mix & Weight of water in the mixture $(\mathrm{m} 3)$ & 1.39 \\
\hline Vslurry & Volume of slurry before mixing $(\mathrm{Vb}+\mathrm{Vw}$,slurry) $(\mathrm{m} 3)$ & 0.000517 \\
\hline Vmix & Volume of the mixture $\left(V_{s}+V b+V w\right.$, mix) $(m 3)$ & 0.00196 \\
\hline Wmix & Weight of the mixture $(W s+W b+W w, m i x)(m 3)$ & 3.0255 \\
\hline \multicolumn{3}{|c|}{ Results } \\
\hline$w: b$ & Water to binder ratio & 1 \\
\hline wT:b & Total water-to-binder ratio of mix (wT:b) & 3.53 \\
\hline VR & Volume ratio expressed in terms of binder factor in-place for any $S$ & 0.36 \\
\hline ain-place & Binder dosage; Factor per total volume of mix $(\mathrm{kg} / \mathrm{m} 3)$ & 200 \\
\hline$\alpha$ & Binder dosage; Factor per volume of wet soil $(\mathrm{kg} / \mathrm{m} 3)$ & 272 \\
\hline$\alpha w(\%)$ & Binder content in percentage of soil solid & $31.50 \%$ \\
\hline Wsoil & Weight of the soil to be used (g) & 2240.06 \\
\hline $\mathrm{Wb}$ & Weight of the binder $(\mathrm{g})$ & 392.70 \\
\hline Ww, slurry & Weight of water in the slurry for wet mixing (g) & 392.70 \\
\hline
\end{tabular}


APPENDIX B: Intact clay sample description (Qualitas, 2016)

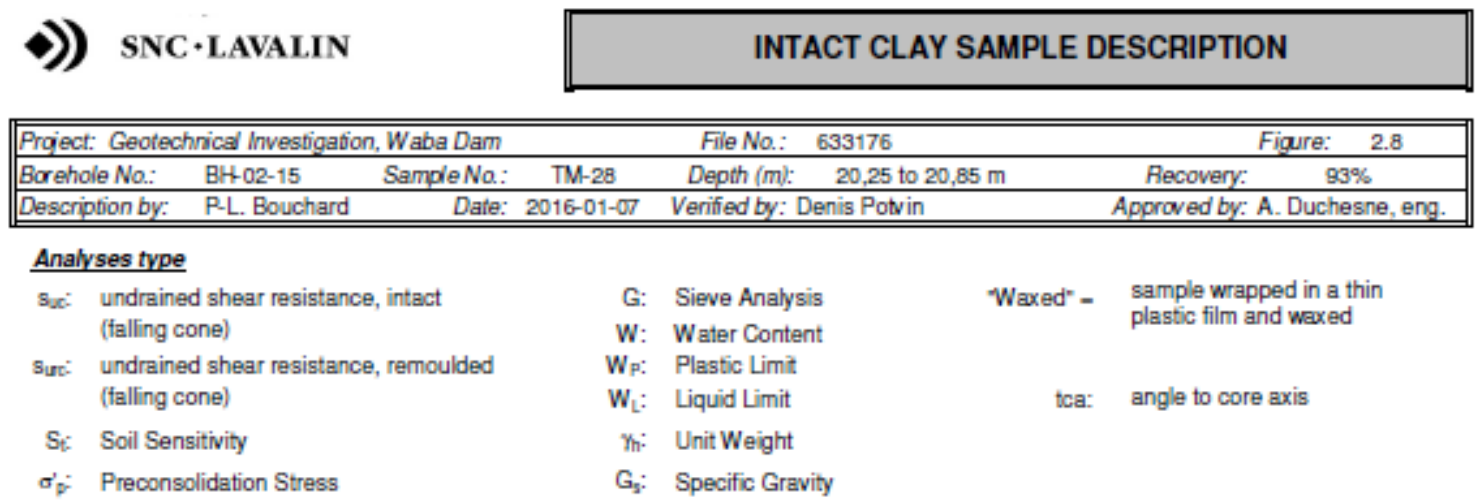

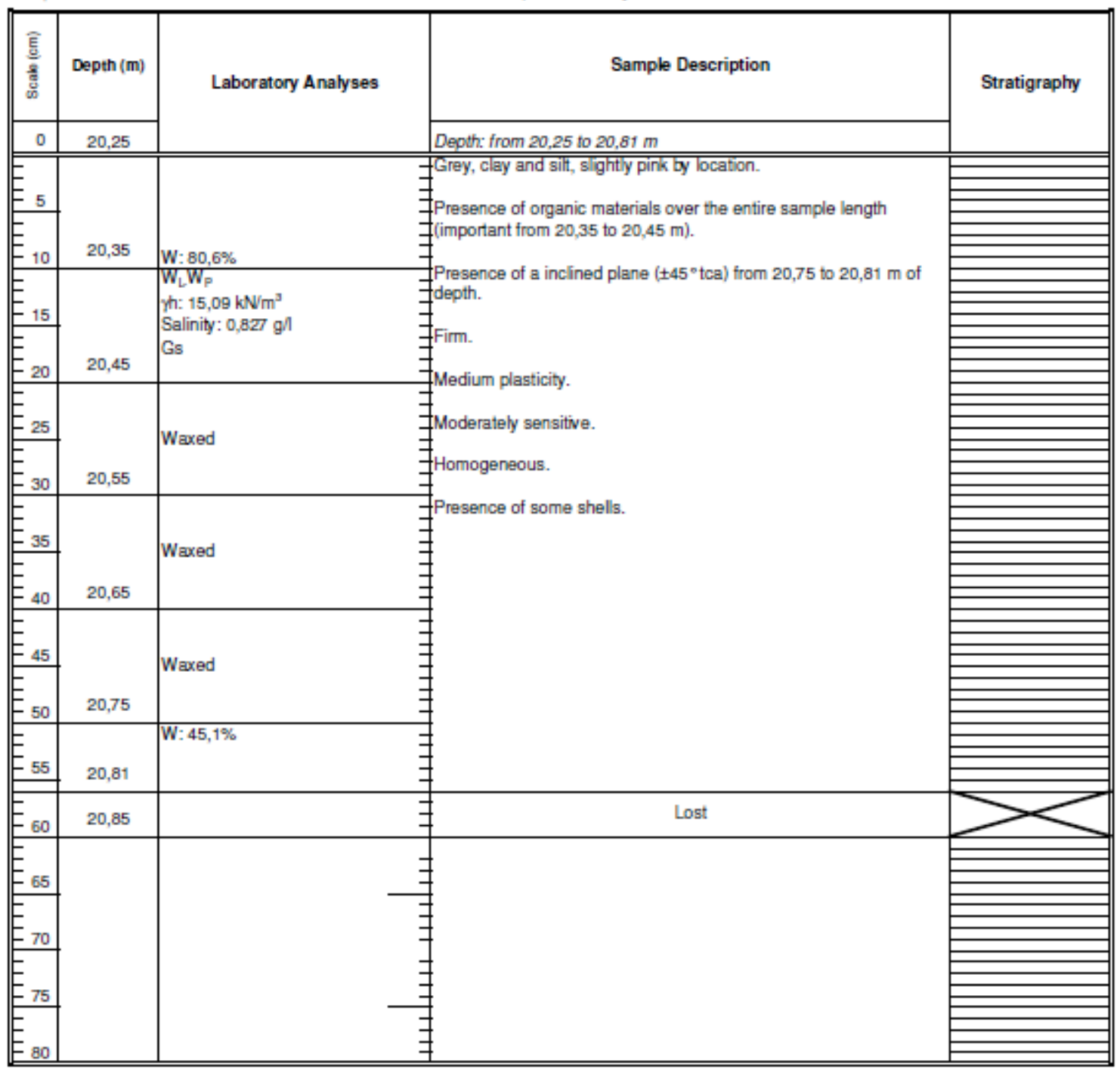


•) SNC+LAVALIN

\section{INTACT CLAY SAMPLE DESCRIPTION}

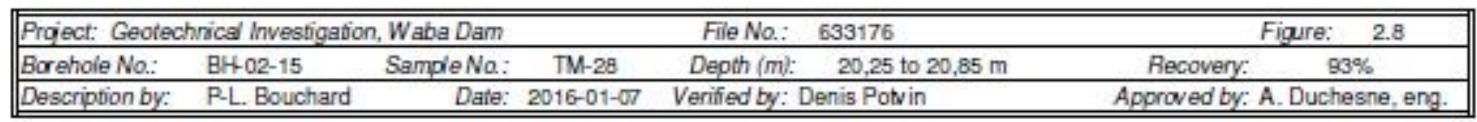

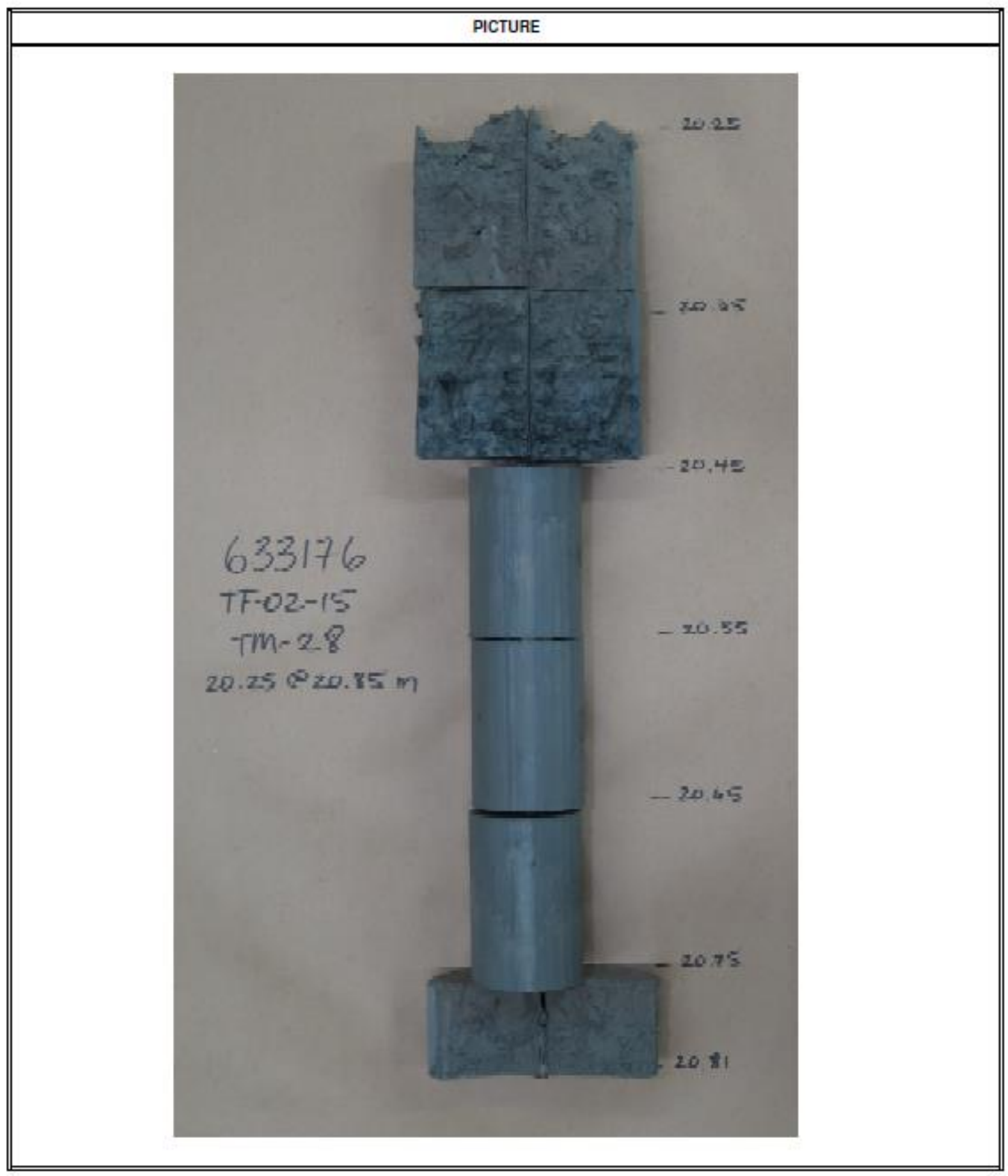




\section{BIBLIOGRAPHY}

Ahnberg, H., Holm, G., Holmqvist, L., \& Ljungkrantz, C. (1994). The use of different additives in deep stabilisation of soft soils. Proceedings of the 13th International Conference on Soil Mechanics and Foundation Engineering. 2, pp. 1191-1194. New Delhi: CRC Press.

Akhtar, K., Khan, S., Khan, S., \& Asiri, A. (2018). Scanning electron microscopy: principle and applications in nanomaterials characterization. In S. Sharma, Handbook of Materials Characterization (pp. 113-145). Cham: Springer.

Bergado, D. T., Anderson, L. R., Miura, N., \& Balasubramaniam, A. S. (1996). Soft ground improvement in lowland and other environments. New York: American Society of Civil Engineers (ASCE) Press.

Bjerrum, L. (1954). Geotechnical properties of Norwegian marine clays. Geotechnique, 49-69.

Bjerrum, L. (1973). Problems of soil mechanics and construction on soft clays and structurally unstable soils (collapsible, expansive and others). 8th Internationl Conference of Soil Mechanics and Foundation Engineering, (pp. 111-159). Moscow.

Brenner, R. P., Nutalaya, P., Chilingarian, G. V., \& Robertson JR, J. O. (1981). Engineering geology of soft clay. In R. P. Brenner, \& E. W. Brand, Soft Clay Engineering (pp. 159231). Amsterdam: Elsevier scientific publishing company.

Bruce,M. E. C.;Berg, R. R.; Collin, J.G.;Filz, G. M.; Terash, M.; Yang, D. S. (2013). Federal Highway Administration Design Manual: Deep mixing for embankment and foundation support. Georgetown Pike : US department of transportation: federal Highway Administration.

Canadian Geotechnical Society. (2006). Canadian Foundation Engineering Manual. Ottawa: Canadian Geotechnical Society. 
Chew, S., Kamruzzaman, A., \& Lee, F. (2004). Physicochemical and engineering behavior of cement treated clays. Journal of Geotechnical and Geoenvironmental Engineering, 130(7), 215-232.

Chittori, B., \& Puppala, A. J. (211). Quantitative estimation of clay mineralogy in fine-grained soils. J. Geotech. Geoenviron. Eng., 137(11), 997-1008.

Choquette, M., Bérubéa, M.-A., \& Locat, J. (1987). Mineralogical and microtextural changes associated with lime stabilization of marine clays from eastern Canada. Applied Clay Science, 2(3), 215-232.

Crawford, C. B., Fannin, R., Deboer, L. J., \& Kern, C. (1991). Experiences with prefabricated vertical (wick) drains at Vernon, B. C. Canadian Geotechnical Journal, 67-79.

Dehghanbanadaki, A., Ahmad, K., Ali, N., Khari, M., Alimohammadi, P., \& Latifi, N. (2013). Stabilization of soft soils with deep mixed soil columns. Electronic Journal of Geotechnical Engineering, 18, 295-306.

Delage, P., \& Lefebvre, G. (1984). Study of the structure of a sensitive Champlain clay and of its evolution during its evolution. Canadian Geotechnical Journal, 21, 21-35.

Diamond, S. (1970). Pore size distribution in clays. Clays and Clay Minerals, 18, 7-23.

Diamond, S., L., W. J., \& L., D. W. (1964). Transformation of clay minerals by calcium hydroxide attack. Proc., 12th National Conference of Clays and Clay Minerals (pp. 359-369). New York: Pergamon Press.

Du, Y., Jiang, N., Liu, S., Jin, F., Singh, D., \& Puppala, A. (2014). Engineering properties and microstructural characteristics of cement-stabilized zinc-contaminated kaolin. Canadian Geotechnical Journal, 289-302.

Duane M., M., \& Robert C., R. (1997). X-Ray diffraction and the identification and analysis of clay minerals. New York: Oxford University. 
EDEN, W. J., FLETCHE, E. B., \& MITCHEL, R. J. (1971). South Nation River landslide, 16 May 1971. Canadian Geotechnical Journal, 446-451.

EuroSoilStab. (2002). Soft soil stabilization: development of design and construction methods to stabilise soft organic soils. UK: BREPress.

Flodin, N., \& Broms, B. (1981). History of civil engineering in soft clay. In E. W. Brand, \& R. P. Brenner, Soft Clay Engineering (pp. 27-133). Amsterdam: Elsevier scentific publishing company.

Frederickson, A. F., \& Reynolds, R. C. (1960). Geochemical method for determining paleosalinity. Clays and Clay Minerals, 203-213.

Gadd, N. R. (1963). Surficial geology of Ottawa map area, Ontario and Quebec. Geological Survey of Canada, 4.

Gadd, N. R. (1986). Lithofacies of Leda clay in the Ottawa basin of the Champlain Sea. Geological Survey of Canada.

Gartner, E. M., Tang, F. J., \& weiss, S. (1985). Saturation factors for calcium hydroxide and calcium sulfates in fresh portland cement pastes. Journal of the American Ceramic Society, 68(12), 667-673.

Genuchten, M. T. (1980). A closed-form equation for predicting the hydraulic conductivity of unsaturated soils. Soil Ssi. Soc. Am. J., 892-898.

Gillot, J. (1970). Fabric of Leda clay invistigated by optical, electron-optical and X-Ray diffreaction methods. Engineering Geology, 133-153.

Gillot, J. (1979). Fabric, composition and properties of sensitive soils from Canada, Alaska and Norway. Engineering Geology, 149-172.

Goldstein, J. I., Michael, J. R., Scott, J. H., Newbury, D. E., Ritchie, N. W., \& Joy, D. C. (2018). Scanning Electron Microscopy and X-Ray Microanalysis. New York: Springer.

Grim, R. E. (1962). Applied Clay Mineralogy. New York: McGraw-Hill Book Company. 
Haofeng, X., Feng, X., \& Feng, Z. (2107). Improvement for the strength of salt-rich soft soil reinforced by cement. Marine Georesources \& Geotechnology, 35(7), 1028-1032.

Haynes, B. W., \& Kramer, G. W. (1982). Characterization of U.S. Cement Kiln Dust. Washignton D.C.: United states. Government Printing Office.

Heller, L., \& Taylor, H. (1956). Crystallographic Data for Calcium Sillicates. London: H.M. Stationary Office.

Herzog, A., \& Mitchell, J. K. (1963). Reactions Accompanying Stabilization of Clay with Cement. Highway Research board. Washington D.C.: National Research Council.

Horpibulsuk, S., Phojan, W., Suddeepong, A., Chinkulkijniwat, A., \& Liu, M. D. (2012). Strength development in blended cement admixed saline clay. Applied Clay Science, 55, 44-52.

Horpibulsuk, S., Rachan, R., Chinkulkijniwat, A., \& Raksachon, Y. (2010). Analysis of strength development in cement-stabilized silty clay from. Construction and Building Materials, 2011-2021.

Kamruzzaman, A., Chew, S., \& Lee, F. (2009). Structuration and destructuration behavior of cement-treated Singapore marine clay. Journal of Geotechnical and Geoenvironmental Engineering, 135(4), 573-589.

Kantro, D., Brunauer, S., \& Weise, C. (1959). the ball-mill hydrtation of tricalcium silicate at room temperature. Journal of Colloid Science, 363-376.

Kawamura, M., \& Diamond, S. (1975). Stabilization of clay soils against erosion. Clays and Clay Minerals, 443-451.

Kazi, A., \& Moum, J. (1973). Effect of leaching on the fabric of normally consolidated marine clays. Proceding Internationl Symposium Soil Structure, (pp. 137-152). Gothenburg.

Keinonen, K. (1963). On the sensitivity of water-laid sediments in Finland and factors inducting sensitivity. The State Inst. for Tech. Research.Publ. , 77.

Kitazume, M., \& Terashi, M. (2013). The Deep Mixing Method. Boca Raton: CRC Press. 
Lambe, T. (1958). The structure of compacted clay. ASCE, 34.

Lambe, T. W. (1953). The structure of inorganic soil. ASCE, 1-49.

Landslides. (2017). Retrieved from Natural Resources Canada: https://www.nrcan.gc.ca/hazards/landslides

Lerman, A. (1966). Boron in clays and estimation of paleosalinities. International Association of Sedimentologists, 267-286.

Li, S., Gurpersaud, N., \& Liu, J. (2016) Experimental investigation of cement mixing to improve Champlin Sea clay. Canadian Geotechnical Society. Vancouver: Canadian Geotechnical Society.

Liu, J., Afroz, M., \& Ahmad, A. (2020) Experimental investigation of the impact of salinity on Champlain Sea clay. Marine Georesources \& Geotechnology DOI: 10.1080/1064119X.2020.1718811

Locat, J., Berube, M.-A., Chagnon, J.-Y., \& Gelinas, P. (1985). The mineralogy of sensitive claysin relation to some engineering geology problems-an overview. Applied Clay Science, 193-205.

Locat, J., Lefebvre, G., \& Ballivy, G. (1984). Mineralogy, chemistry, and physical properties interrelationships of some sensitive clays from eastern Canada. Canadian Geotechnical Journal, 530-540.

Locat, J., Tremblay, H., \& Leroueil, S. (1996). Mechanical and hydraulic behaviour of a soft inorganic clay treated with lime. Canadian Geotechnical Journal, 33(4), 654-669.

MacKay, M., \& Emery, J. (1992). Stabilization/ solidification of contaminated soils and sludges using cementitious systems. Proceedings of the first International symposium, Cement Industry Solutions to Waste Management, Canadian Portland Cement Association, (pp. 135-15). Toronto. 
Mary Ellen C. Bruce, Ryan R. Berg, James G. Collin, George M. Filz,Masaaki Terashi, and David S. Yang. (2013). Fderal Highway Administration Design Manual: Deep Mixing for Embankment and Foundation Support. Georgetown Pike McLean: FHWA.

Mitchell, J. K. (1956). The fabric of natural clays and its relation to engineering properties. Highway Research Board, 693-713.

Mitchell, J. K., \& Soga, K. (2005). Fundamentals of Soil Behavior. New Jersey: John Wiley \& sons.

Mitchell, R. J., \& Markell, A. R. (1974). Flow sliding in sensitive soils. Canadian Geotechnical Journal, 11-31.

Monsif, M., Liu, J., \& Gurpersaud, N. (2019). Fundamentals of cement in stabilizing Champlain Sea clay. Geo St. John's. St. John's.

Morgenstern, N. R., \& Tchalenko, J. S. (1967). The optical determination of preferred orientation in clays and its application to the study of microstructure in consolidated kaolin II. Procedings Royal Society, 235-250.

Okumura, T., \& Terashi, M. (1975). Deep-lime-mixing method of stabilization for marine clays. Proceedings of the 5th Asian Regional Conference on soil Mechanics and Foundation Engineering. 1, pp. 69-75. Bangalore: Indian Institute of Science.

Okumura, T., Terashi, M., Mitsumoto, T., Yoshida, T., \& Watanabe, M. (1974). Deep Lime Method for Soil Stabilization (3rd Report). Tokyo: Report of the Port and Harbour Research Institute.

Osterman, J. (1965). Studies on the Properties and Formation of Quick Clays. Stockholm: Swedish Geotechnical Institute.

Penner, E. (1965). A study of sensitivity in Leda clay. Canadian Journal of Earth Sciences, 425441. 
Quigley, R. M., \& Thompson, C. D. (1966). The fabric of anisotropically consolidated sensitive. Canadian Geotechnical Journal, 3, 61-73.

Quigley, R. M., Gywn, Q. H., White, O. L., Rowe, R. K., Haynes, J. E., \& Bohdanowicz, A. (1983). Leda clay from deep boreholes at Hawkesbury, Ontario. Part I: Geology and geotechnique. Canadian Geotechnical Journal, 288-298.

Quinn, P., Hutchinson, D. J., Diederichs, M. S., Rowe, R. K., \& Alvarez, J. (2008). Susceptibility mapping of landslides in Champlain clay from a digital landslide inventory. 4th Canadian conference on geohazards. Quebec: Geohazards.

Rashid, A. S., Black, J. A., Kueh, A. B., \& Noor, N. M. (2015). Behaviour of weak soils reinforced with soil cement columns formed by the deep mixing method: Rigid and flexible footings. Measurement, 68, 262-279.

Rashid, A. S., Bunawan, A. R., \& Said, K. N. (2017). The deep mixing method: bearing capacity studies. Geotechnical Geological engineering, 35, 1271-1298.

Reed, S. J. (2005). Electron Microprobe Analysis and Scanning Electron Microscopy in Geology. Cambridge: Cambridge University Press.

Rosenqvist, I. (1953). Considerations on the sensitivity of Norwegian quick-clays. Geotechnique, 195-200.

Rosenqvist, I. T. (1962). The influence of physico-chemical factors upon the mechanical properties. Clays Clay Minerals, 12-27.

Rosenqvist, I. T. (1966). Norwegian research into the properties of quick clay- a review. Engineering Geology, 445-450.

Serge, L., François, T., \& Jean-Pierre, L. B. (1983). Propriétés caractéristiques des argiles de l'est du Canada. Canadian Geotechnical Journal, 681-705.

Shi, C. (2002). Characteristics and cementitious properties of ladle slag fines from steel production. Cement and Concrete Research, 32, 459-462. 
Tavenas, F., Changon, J., \& La Rochelle, P. (2011). The Saint-Jean-Vianney landslide: observations and eyewitnesses accounts. Canadian Geotechnical Journal, 463-478.

Terashi, M., Okumura, T., \& Mitsumoto, T. (1977). Fundamental properties of lime-treated soils (in Japanese). Tokyo: Report of the Port and Harbour Research Institute.

Terashi, M., Tanaka, H., Mitsumoto, T., Niidome, Y., \& Honma, S. (1980). Fundamental properties of lime and cement treated soils (2nd Report)(in Japanese). Tokyo: Report of the Port and Harbour Research Institute.

Torrance, J. (1974). A laboratory investigation of the effect of leaching on the compressibility and shear strength of Norwegian marine clays. Geotechnique, 155-173.

U. S. Geological survey. (2020). Coastal and Marine Geology Program. Retrieved from USGS: https://pubs.usgs.gov/of/2001/of01-041/htmldocs/xrpd.htm

Walker, C. T. (1968). Evaluation of boron as a paleosalinity ndicator and its application to offshore prospects. American Association of Petroleum Geologists, 751-766.

Woo, S. M., \& Moh, Z. M. (1977). Effect of leaching on undrained shear strength behaviour of sedimented clay. Geotechnical Engineering and Environmental Control, 452-464. 